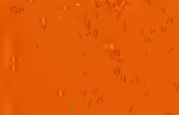




\section{INVESTIGATION OF CONSTRUCTION FAILURE OF REINFORCED CONCRETE COOLING TOWER AT WILLOW ISLAND, WEST VIRGINIA}
by
H. S. Lew
S. G. Fattal
J. R. Shaver
T. A. Reinhold
B. J. Hunt

Center for Building Technology National Engineering Laboratory National Bureau of Standards

Washington, D.C. 20234

November 1979

\section{Sponsored by}

Occupational Safety and Health Administration U.S. Department of Labor

Washington, D.C. 20001

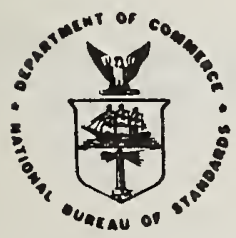

\section{U.S. DEPARTMENT OF COMMERCE}

Luther H. Hodges, Jr., Under Secretary

Jordan J. Baruch, Assistant Secretary for Science and Technology

NATIONAL BUREAU OF STANDARDS, Ernest Ambler, Director 



\section{ABSTRACT}

The collapse of the natural-draft hyperbolic concrete cooling tower unit no. 2 at the Pleasants Power Station at Willow Island, West Virginia was investigated by the National Bureau of Standards. The investigation included onsite inspections, laboratory tests of construction assembly components and concrete specimens, and analytical studies.

Based on the results of these field, laboratory and analytical investigations, it was concluded that the most probable cause of the collapse was due to the imposition of construction loads on the shell before the concrete of lift 28 had gained adequate strength to support these loads. The analysis of the shell indicated that the collapse initiated at the part of the shell in lift 28 where cathead no. 4 was located. It further showed that calculated stress resultants at several points in that part equaled or exceeded the strength of the shell in compression, bending and and shear. The failure of these points in that part of the shell would have propagated to cause the collapse of the entire lift 28.

Key Words: Collapse; concrete; concrete strength; construction; cooling tower; failure; hyperbolic shell; shell. 


\section{PREFACE}

An investigation of the construction failure of the natural-draft concrete cooling tower at Willow Island, West Virginia on April 27, 1978 was carried out by the National Bureau of Standards (NBS) at the request of the Occupational Safety and Health Administration (OSHA), the Department of Labor. This investigation was conducted pursuant to an interagency agreement between OSHA and NBS.

The NBS field investigation team consisted of E. O. Pfrang, J. 0 . Bryson, E. Anderson, S. G. Fatta 1, B. J. Hunt and H. S. Lew. Throughout the course of this investigation, the team received full cooperation from the OSHA regional and area offices. Assistance provided by Mr. David H. Rhone, Regional Administrator and Mr. Stanley Elliot, Area Director, is gratefully acknowledged by the NBS team. 
1. INTRODUCTION .......................

1.1 Background. . . . . . . . . . . . . . . .

1.2 Objective and Scope . . . . . . . . . . . . . .

1.3 Organization of the Report ...............

2. COOLING TOWER CONSTRUCTION . . . . . . . . . . . .

2.1 Introduction . . . . . . . . . . . . . . . .

2.2 Physical Description of Cooling Tower Unit No. 2 at Willow Island ............. 4

2.3 Construction Method ................ 5

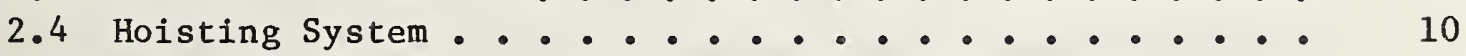

3. SITE INVESTIGATION . . . . . . . . . . . . . . 12

3.1 Introduction .................... 12

3.2 Investigation at the Site ............... 12

3.3 Interview Statements of Workers ........... 17

4. LABORATORY INVESTIGATIONS . . . . . . . . . . . . . 20

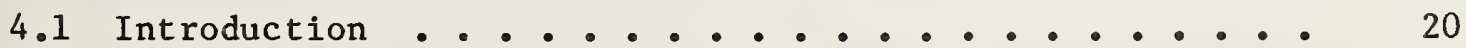

4.2 Concrete Tests ...................... 20

4.2.1 Examination of Constituents of the Concrete ..................

4.2.2 Determination of Strength and Stiffness Concrete . . . . . . . . . . . .

4.3 Anchor Bolt Tests .............. . . 28

4.4 Hoist Cable Tests................. . . 29

4.5 Chain Hoist Test ................... 30

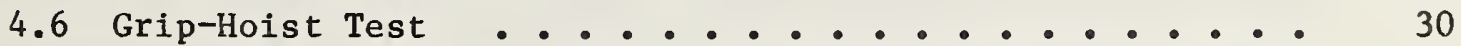

5. EXAMINATION OF CONDITIONS OF CONSTRUCTION ASSEMBLIES AT THE

TIME OF THE COLLAPSE . . . . . . . . . . . . . . .

5.1 Introduction .................. 32

5.2 Examination of Hoisting System . . . . . . . . . 32

5.3 Examination of Scaffolding System . . . . . . . . 37

5.4 Summary ................... . . . . 37 
TABLE OF CONTENTS (Cont.)

Page

6. DEFINITION OF LOADS AND SHELL ANALYSIS . . . . . . . .

6.1 Introduction ................

6.2 Geometry. . . . . . . . . . . . . . . . .

6.3 Mechanism of Load Transfer . . . . . . . . . .

6.4 Weight of Scaffolding - Load Case $2 . . . . . . . . .$.

6.5 Live Loads - Load Case 3. . . . . . . . . . . .

6.6 Weight of Cathead Gantry Assembly - Load Case 4 . . . .

6.7 Hoisting Loads - Load Case 5. . . . . . . . . . .

6.8 Dynamic Effects . . . . . . . . . . . . . .

6.9 Shell Analysis .................

7. INTERPRETATION OF SHELL ANALYSIS . . . . . . . . . .

7.1 Introduction ....................

7.2 Strength of Shel1 Under Combined Axial Load and Bending Moment . . . . . . . . . . . . .

7.3 Strength of She11 Under Shear . . . . . . . . . .

7.4 Probable Modes of Failure . . . . . . . . . .

8. SUMMARY AND CONCLUSIONS . . . . . . . . . . . . . 71

9. ACKNOWLEDGEMENTS ..................... . . 73

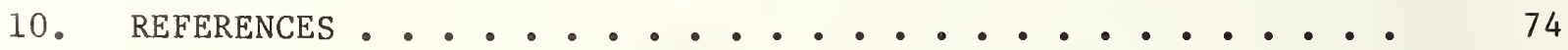

TABLES AND FIGURES . . . . . . . . . . . . . . . . .

A. Patent of Wal1 Construction System . . . . . . .

B. Computer Programs for Shell Analysis . . . . . . .

C. Results of Chemical Analysis of Cement . . . . . .

D. Results of Analysis of Concrete . . . . . . . 


\section{INTRODUCTION}

\subsection{Background}

Two natural-draft hyperbolic concrete cooling towers were being constructed at the Pleasants Power Station which is located on the Ohio River at Willow Island, West Virginia. The shell of the first unit of the two towers was completed in August, 1977. It has a base diameter of $358 \mathrm{ft}(109 \mathrm{~m})$ and stands $430 \mathrm{ft}(131 \mathrm{~m})$ above the ground level. Shortly after $10 \mathrm{a} . \mathrm{m}$. on April 27, 1978, the top portion of the second unit which had reached a height of $166 \mathrm{ft}(51 \mathrm{~m})$ collapsed during construction. Figure 1.1 is a photograph taken after the failure which shows the completed tower unit No. 1 and partially completed tower unit No. 2 in the foreground. A four-level scaffolding system which was anchored to the collapsed portion of the shell fell with it killing all 51 workers who were on the scaffold.

The shell was constructed through the use of a patented lift form technique. Except for the lower and upper portions of the tower, the construction procedure at Willow Island utilized a scheme to place a $5-\mathrm{ft}(1.5-\mathrm{m})$ lift per day. At the time of failure, 28 lifts had been completed with the most recent one having been placed the previous day. The formwork which supported the less than one day old concrete of lift 28 had been raised into place for lift 29. According to eyewitness accounts by workers, lift 28 began to collapse when the third bucket of concrete was being hoisted up to the working platform. It was estimated that about $1.0 \mathrm{yd}^{3}$ $\left(0.8 \mathrm{~m}^{3}\right)$ of concrete had been placed for lift 29 at that time. According to an eyewitness the entire section of lift 28 collapsed into the tower within a few minutes. 
On the day of the collapse, an inspection team from the Occupational Safety and Health Administration (OSHA), Department of Labor, arrived at the site and began an investigation into the collapse. A team from the National Bureau of Standards (NBS) joined the OSHA team two days later.

\subsection{Objective and Scope of the Investigation}

The National Bureau of Standards was requested to assist the field investigation conducted by the Occupational Safety and Health Administration at the site of the collapse and to carry out a detailed study aiming at the determination of the most probable cause of the collapse.

In response to this request, NBS carried out field, laboratory and analytical studies. The NBS investigators also used data obtained from onsite inspections, OSHA case records, the patent for the forming system and drawings showing details of the tower construction.

\subsection{Organization of the Report}

The report is organized in ten chapters:

Chapter 2 presents dimensions of the tower and the material used for construction. It also describes the construction method employed for erection of the tower and the hoisting system used to transport construction materials from the ground level to the top of the tower.

Chapter 3 describes observations made and measurements taken by the NBS investigation team at the Willow Island site. It also describes typical daily construction activities and the chain of events which took place prior to the collapse.

Chapter 4 presents the results of concrete tests which were used to determine the strength and stiffness gaining characteristics of the 
concrete. The test results of anchor bolts, hoist cable, chain hoist and grip-hoist are also presented.

Chapter 5 examines possible component failures of the hoisting and scaffolding systems with the aid of the test results presented in chapter 4 as well as data obtained from the onsite inspection presented in chapter 3.

Chapter 6 describes criteria and rationale for defining the loads which were acting on the shell at the time of the collapse. It also presents analysis of the shell by means of finite element computer programs.

Chapter 7 compares the results of the shell analysis with various strength parameters of the shell and discusses the most probable mode of failure.

Chapter 8 summarizes the findings of the investigation and presents conclusions drawn on the based of field, laboratory and analytical studies. Chapter 9 acknowledges those individuals who made contributions to various phases of the investigation and to the preparation of this report. Chapter 10 lists the references cited in the text. 


\section{COOLING TOWER CONSTRUCTION}

\subsection{Introduction}

This chapter describes dimensions of the tower and the materials used for construction. It also describes the method of construction and the hoisting system. The formwork and scaffolding systems used for construction of the tower were supported only by the previously completed portion of the tower. They moved up as construction progressed with no support other than from the partially completed structure. Because such complex self-lifting formwork and scaffolding systems were used, they are described in some detail.

\subsection{Physical Description of Cooling Tower Unit No. 2 at Willow Island}

Figure 2.1 shows the elevation and plan view of cooling tower unit no. 2. It may be noted that both the diameter and the shell thickness changed along the height of the tower. At the time of failure, the tower elevation had reached 166 feet $(51 \mathrm{~m})$ as indicated by the dotted line on the elevation. The shell portion of the tower was supported by 80 diagonal concrete columns of 34 inches $(0.86 \mathrm{~m})$ in diameter. The shell tapered from the lintel at the base (diameter of $342 \mathrm{ft}, 104.2 \mathrm{~m}$ ) to the throat (diameter of $214 \mathrm{ft}, 85.2 \mathrm{~m}$ ). It then flared out with increasing height. The exterior of the shell was divided by 96 evenly spaced ribs (see figures 1.1 and 3.1). The panel width between two adjacent ribs varied along the height of the tower.

In the wall section, two layers of reinforcement were provided both vertically and horizontally. The size and spacing of steel in both directions varied with the height of the tower. A typical cross section of the wall at lift 28 is shown along with reinforcing and splicing 
details in figure 2.2. The figure shows that, within any one lift height, all of the vertical bars were spliced in every third panel. The horizontal bars were spliced such that no two splices in any one lift occurred in the same vertical plane for bars on the same face. The spacing of splices along the horizontal bars were not specified in the drawings. A11 reinforcing bars were specified to meet ASTM A 615 Grade 60 requirements.

Normal weight concrete was used for the tower. The mix proportions per cubic yard of concrete were: ${ }^{1 /}$

$\begin{aligned} 4701 \mathrm{bs}(214 \mathrm{~kg}) & \begin{array}{c}\text { Type II (moderate heat of hydration) } \\ \text { portland cement }\end{array} \\ 11741 \mathrm{bs}(532 \mathrm{~kg}) & \text { Natural sand } \\ 1900 \text { lbs }(862 \mathrm{~kg}) & \text { Natural gravel } \\ 611 \mathrm{bs}(27 \mathrm{~kg}) & \text { Fly ash } \\ 14.1 \mathrm{oz}(417 \mathrm{~mL}) & \text { Water reducing agent } \\ 5.0 \mathrm{oz}(148 \mathrm{~mL}) & \text { Air entraining agent }\end{aligned}$

Approximately $27.6 \mathrm{gal}(104 \mathrm{~L})$ of water were specified to produce 4.5 in (114 mm) slump.

\subsection{Construction Method}

As mentioned in section 2.1 , both the thickness and the diameter of the she11 changed along its height. To accommodate these changes as well as to provide working surfaces for workers, a complex combination of formwork and scaffolding system was used. A schematic drawing of the formwork-scaffolding system is shown in figure 2.3. It is seen in this figure that the entire system was supported on previously completed portions of the tower. As construction advanced, the system traveled up the tower with no support other than from the partially

I/ See table 4.5(a) and (b). 
completed structure of partially matured concrete. An interior view of a similar tower under construction is shown in figure 2.4. The fourlevel scaffolding system was suspended from the upper part of the tower. A detailed description of the system is illustrated in the U.S. Patent of the system, which is reproduced in appendix A.

The lift form and scaffolding system consisted of four basic functional components. These were:

1) Jumpform beams

2) Jacking frames

3) Stiffback channels and formwork

4) Scaffolding

A cross section through the formwork-scaffolding system is shown in figure 2.5 in which each of the above components is identified. In the text that follows, the function of each of these components is described and illustrated with the aid of photographs taken at Berwick, Pennsylvania where similar hyperbolic cooling towers were under construction using basically the same construction method used at Willow Island.

Figure 2.6 shows the manner in which jumpform beams were attached to the exterior of the shell by hexhead bolts. Typical extruded aluminum jumpform beams which were attached to the interior and exterior of the shell are shown in figure 2.7. Two 10-ft (3-m) long beams were spliced together end to end with clip plates forming a 20-foot (6-m) long section. Figure 2.8 shows the 20-ft long jumpform beams attached to the inside and outside of the shell by means of a number of anchor bolts with internally threaded cone-shaped inserts and the hexhead bolts (also see fig. 6, appendix A). The assembly of the anchor bolt is shown in figure 3.8. It may be noted 
in figure 2.8 that the relative positions of these jumpform beams change in an alternating sequence for each lift of the shell.

The exterior jumpform beam differs from the interior jumpform beam in that the flange of the exterior jumpform beam functions as the rib mold of the shell. The exterior flange of both the interior and exterior jumpform beams has welded lugs to receive the reciprocating and stationa ry pawls for engagement of the jacking mechanism (see fig. 2.7 and figs. 5 and 8 , appendix A).

The second major component of the system was the jacking frame (fig. 2.8). It consisted of two structural channels which rode on both faces of the outer flange of the jumpform beam (see fig. 5, appendix A). A photograph of the jacking frame assembly is shown in figure 2.9. Movement of the jacking frame was restricted to one direction, i.e., para1le1 to the jumpform beam, by means of a set of 12 steel wheels housed in the jacking frame.

The jacking frame also contained a hydraulic ram with a connected reciprocating paw1 and a follower paw1 (item 142 and 124 in figure 5, appendix A). When jacking commenced, the reciprocating pawl was actuated by the hydraulic pressure and engaged with the jumpform beam lugs raising the jacking frame in increments equivalent to the lug spacing. The springloaded follower pawl ratcheted and held the jacking frame until another hydraulic cycle could be repeated.

The third major component in the construction apparatus consisted of the stiffback channels and formwork (fig. 2.8, 2.9 and 2.10). This component held the fresh concrete in place between each rib location. The stiffback was a structural channel vertically supported by the jacking 
frame's lower steel wheel axle (see figures 6, 7 and 8, appendix A). Adjustable joists were bolted to the stiffbacks at the rib locations and were capable of compensating for the shell diameter variation. The plywood form was braced by the joist-stiffback framework. The stiffback and formwork moved integrally with the jacking frame during the entire jacking process. Jacking took place at both the inside and outside jumpform beams simultaneously at all 96 rib locations. Jacking was terminated once the stiffback formwork had cleared the previous lift and had been positioned for placement of concrete for the next lift.

The fourth major component of the lift form-scaffolding system was a four-1eve1 scaffold (fig. 2.5). Working platforms were suspended from both the inside and the outside jacking frames at each of the 96 rib locations. Scaffold planking and guardrails spanned between the rib locations forming the working platform. At the top level construction materials were received via the hoisting system, steel reinforcing was distributed for placement, and concrete was delivered around the tower by Georgia buggies.

Level 2 was used less in the construction process. From this level the stiffback-formwork was accessible for adjustment. Once the formwork was set for a new pour the use of this level became diminished.

The lower levels (levels $3 \& 4$ ) provided access to the bottom half of the jumpform beams. The $10 \mathrm{ft}(3 \mathrm{~m})$ section of the jumpform beam was separated from the upper half and unbolted from the shell and delivered to the top level for new placement. Final shell surface preparation (i.e., patching, removal of threaded insert cones, grouting) was performed from these levels. The entire scaffolding system moved with the jacking frame to the new elevation. 
The sequence of operations for the entire formwork-scaffolding system from lift 27 to lift 29 is illustrated in figures 2.11 through 2.15 . Figure 2.11 depicts the position of the jumpform beams and the scaffolding system prior to concrete placement for lift 27 . It may be noted that the inside jumpform beam was higher than the outside one. Two days after the completion of lift 27 , the formwork and scaffolding systems were raised and simultaneously the lower half of the outside jumpform beam was unbolted and lifted to a new higher position, shown in figure 2.12. Figure 2.13 shows the final position of the entire system prior to concrete placement for lift 28. One day after the completion of lift 28, the formwork and scaffolding systems were again raised and the lower half of the inside jumpform beam was lifted to a new position, as shown in figure 2.14. Figure 2.15 shows the final position of the formwork and scaffolding systems with the inside jumpform beam extending above the outside one.

The daily preparation for concrete placement consisted of five consecutive procedures as follows:

1) Workers removed wedging and loosened stiffbacks and formwork from previously placed concrete. Plywood forms were removed next and cut to new desired size to accommodate changing diameter of the tower. Forms were then placed again in the same place after being cleaned and oiled.

2) Once all forms were replaced, jacking of the entire formwork and scaffolding systems commenced until the next predetermined elevation was reached.

3) The lowest trailing jumpform beam was unbolted and transferred to its new top position on top of the upper half mate of the 
jumpform beam. Therefore, each pair of jumpform beams (inside and outside) at each rib location "leap-frogged" one another throughout the construction process. Figures 2.11 through 2.15 illustrate this process.

4) The formwork was wedged into its new lift position, spacing tolerances checked, reinforcing steel placed, and concrete was then ready for placement.

\subsection{Hoisting System}

At the Willow Island site, up to and including lift 10 , construction materials were handled by moving cranes on the ground and concrete was placed into the formwork by a pumping process. Above this level, the materials and concrete were delivered to the working platform via six cathead gantry cranes (hereafter referred to as catheads) powered by twin-drum hoists.

The six catheads were spaced at equal intervals around the top perimeter. Each cathead was supported from the recently completed shell structure by four legs which were attached to the jacking frame at two adjacent rib locations. The catheads moved up with the lift formscaffolding system as construction advanced.

A static line, which was attached to the slide plate at the interior end of the cathead at one end (fig. 2.16) and secured to an anchor point on the ground level at the other, guided all materials hoisted to the top working level (fig. 2.17). The anchor point location changed from a position near the wall of the tower to the center as construction progressed upward. During hoisting operations, the tautness of the static line was adjusted by means of a grip hoist attached to the ground anchor 
point to keep the material being hoisted from hitting the scaffold at the top of the tower.

Because of the changing she11 curvature, the cathead had to be periodically adjusted to maintain a level configuration. This was done throughout the tower construction by adjusting the pinned telescoping outer legs and by a chain hoist which was an integral part of the counterstatic line (figure 2.16) which also counteracted the pull exerted by the static line.

Three twin-drummed diesel hoists were spaced at equal intervals around the tower base. Each twin-drum hoist had a single operator who served two cathead gantries (fig. 2.18). A hoist line, wound on a drum, passed through two ground-level sheaves and traveled up along the outside face of the tower to the outside sheave of the cathead beam (fig. 2.17). It continued to the inside sheave of the cathead beam and down to the tower center ground location where pickups were made.

The hoist load was guided along the static line by a mechanical pulley device. Figure 2.16 shows a bucket of concrete approaching its maximum elevation at the inside working level. The interlink to the static line through the pulley is also shown.

The hoist system was primarily used for lifting concrete and steel reinforcing bars to the upper working platform on the inside of the tower. As was the case for the cathead, various adjustments to the hoisting system were required from lift to lift due to the changing geometry of the tower. 


\section{SITE INVESTIGATION}

\subsection{Introduction}

During the course of the investigation, the NBS team visited the Willow Island site on five occasions. The first visit was made on April 29, 1978, two days after the incident, while the last visit was on August 10 and 11, 1978. This chapter describes observations made, measurements taken of static and hoist cables, and materials retrieved from the Willow Island site. In addition, a summary of interviews conducted by OSHA personnel with workers is presented. These data were used in the examination of possible component failure of the hoisting and scaffolding systems in chapter 5 and in the establishment of the loading conditions on the tower which existed at the time of collapse in chapter 6 .

\subsection{Investigation at the Site}

Figure 3.1 shows the exterior view of tower unit No. 2. Collapse occurred as concrete was being placed for lift 29. The top $5 \mathrm{ft}(1.5 \mathrm{~m})$ of the she11 (1ift 28) is missing in this photograph since the entire lift had fallen into the center of the tower leaving a jagged edge along the top of lift 27 (fig. 3.2). Evenly spaced ribs on the exterior surface of the shell and 5-ft (1.5-m) lift lines may also be seen in figure 3.1. The exterior scaffolding-type stairs shown in the left part of the photograph were the only means of access to and from the top of the tower by the workers (fig. 3.1).

Figures 3.3 and 3.4 show debris piled upon the floor of the tower around the base perimeter. While the general positions of the debris inside the tower have not been drastically changed, it is known that the debris was lifted and moved to some extent during the rescue operations. 
The debris mainly consists of the cathead gantries, scaffolding and formwork systems, safety nets, and equipment. The concrete of lift 28 apparently pulverized upon impacting the tower floor since no large pieces of broken concrete were found.

As can be seen in figures 3.2 and 3.5 , vertical bars at the top of lift 27 were bent toward the inside of the tower. None of the vertical bars examined at locations around the top perimeter of the tower showed any signs of fracture.

Figure 3.6 shows the exterior view of a portion of the shell between catheads no. 1 and no. 2. Dark patch marks seen in this figure were made by the cement grout used to plug the anchor bolt holes. These marks clearly indicate that two anchor bolts were used in 1 ift 26 and others below. A closeup view of a typical rib in lift 27 (figure 3.7 ) shows that while the top anchor bolt (bolt C in fig. 2.15) was broken away, the bottom anchor bolt (the thread inserts and the crimped rod--bolt D in fig. 2.15) was intact. Careful examination of the jumpform beams on the ground revealed that in many cases the top anchor bolts were still attached to the flange of jumpform beams by hexhead bolts (see fig. 3.8 for the anchor bolt assembly). Further examination also revealed that there were no tears in the flange of jumpform beams at the bolt holes nor any fragments of the hexhead bolt in the bottom anchor bolt in 1ift 27. It was concluded from these observations that at the time of the collapse, while the top anchor bolts were attached to jumpform beams, the bottom hexhead bolts had been removed.

Localized crushing of concrete occurred surrounding the bottom anchor bolt in lift 27 at those ribs where the legs of catheads had been supported (figure 3.9). This indicates substantial overworking on these bolts during 
the previous construction stages as a result of large movements in the cathead legs.

It was observed that the anchor bolts located at the top of lift 27 (bolt $C$ in fig. 2.15) failed in two different modes. In many cases, the anchor bolt together with the concrete surrounding it broke away from the shell (see fig. 3.10). In other cases, the bolt itself fractured into two pieces leaving a clean tapered hole in the shell (see fig. 3.11). It would not be possible to leave such a clean hole in the shell if the cone-shaped inserts had been pulled through the wall. This indicates some bolts fractured. At the time of the field investigations, it was reported by workers at the site that the collapse initiated at the location where cathead no. 4 was positioned. Because of this reason, cathead no. 4 was carefully examined. The overall appearance of a typical cathead gantry is shown in figure 3.12. Although all six cathead gantry assemblies deformed severely, the component parts for each of the cathead gantries were still intact except for the slide plates which were separated from catheads no. 4 and 5 . Figure 3.13 shows the slide plate for cathead no. 4 which was found some distance away from the main assembly. A large bolt to which the slide plate was attached was bent severely. A similar deformation of the bolt was also noted at other gantries (fig. 3.14). The diameter of the sheave which was attached to the slide plate as well as others used for the hoist cable was 12 in ( $305 \mathrm{~mm}$ ).

Figures 3.15 and 3.16 show the inside and outside legs of cathead no. 4 . All four legs remained straight and showed no sign of damage. As is seen in figure 3.16 the cathead beam was severely bent. However, close examination showed no sign of buckling of the beam. It was concluded from this observation that the beam was bent after the collapse had initiated. 
The hoist cable used was $9 / 16$ in $(24 \mathrm{~mm}) 19 \times 7$ non-rotating wire rope. Of the total of six hoist cables, one per cathead gantry, on $1 y$ the cables for catheads no. 4 and no. 5 were broken. The cable for cathead no. 4 was broken at a distance $408.5 \mathrm{ft}(124.5 \mathrm{~m})$ from the axis of the drum hoist, while the cable for cathead no. 5 was broken at the hoist end just above the dead-weight steel ba11. The remaining four hoist lines were draped over the tower following the collapse. At both catheads no. 4 and 5 the hoist cable cut a deep groove in the she11. At cathead no. 4, the cable cut a 4 in $(100 \mathrm{~mm})$ groove ( $\mathrm{fig} .3 .17)$ and at cathead no. 5 a 5 in $(125 \mathrm{~mm})$ groove. The part of the cable from the bucket to the breakage point was still attached to the bucket. Close examination showed that the concrete bucket for cathead no. 4 fell to the ground with concrete in it. Figure 3.18 shows part of the concrete which remained inside the bucket. On the other hand, the concrete bucket for cathead no. 5 was found empty.

The drum hoist which served cathead no. 3 and no. 4 is shown in figure 3.19. Subsequent to the collapse, the hoist cable for cathead no. 4 was played out for visual observation of the condition of the cable. It was noted that the drum hoist was operational. As may be seen from figure 3.19 , the operator of the hoist sat inside the shed which housed the hoist. In addition to audio communication with a worker who was on the top of the tower, the operator normally used paired visual markers on the cable to judge the position of the material being hoisted. When the painted markers on the cable passed over the wooden cross beams located in front of the hoist, the operator reduced the speed of the drum so that 
the final positioning of the material being hoisted could be handled safely. On the hoist cable for cathead no. 4, no such markings were noted.

Based on the measurements and the cable profile, it was determined that the static line was 1/2-in (13-mm) diameter $6 \times 19$ classification wire rope. One end of the line was attached to the slide plate and the other end was anchored at the ground level. As was mentioned in section 2.4, the anchor point was moved as construction progressed. It was moved to the center of the tower on April 17, 1978, on the day lift 25 was placed.

The lengths of the static line and the hoist cable for catheads no. 4 and 5 were measured. The measurements were taken by a professional surveyor for cathead no. 4 and by NBS personnel for cathead no. 5. They were:

Cathead gantry No. 4:

$$
\begin{aligned}
& \text { Static line length }=219.2 \mathrm{ft}(66.8 \mathrm{~m}) \\
& \text { Hoist cable length }=470.4 \mathrm{ft}(143.4 \mathrm{~m})
\end{aligned}
$$

Cathead gantry No. 5:

$$
\begin{aligned}
& \text { Static line length }=221.9 \mathrm{ft}(67.6 \mathrm{~m}) \\
& \text { Hoist cable length }=408.6 \mathrm{ft}(124.5 \mathrm{~m})
\end{aligned}
$$

The above lengths of the hoist cables were taken from the axis of the drum to the top of the dead weight steel ball (fig. 2.16). For the static lines, the lengths were taken from the clevis which was attached to a concrete hopper located near the center of the tower to pivot point $G$ of the clevis which was attached to the slide plate of the cathead gantry (see fig. 6.7). 


\subsection{Interview Statements of Workers}

During the course of the investigation of the collapse, many of the workers at the Willow Island site were interviewed by OSHA personnel. Based on the interviewed statements, the work schedule of a typical day can be described as follows:

(1) At approximately 6:30 a.m., the carpenters arrived at the construction site. Immediate removal of various wedges and loosening of formwork took place around the entire tower perimeter. This operation was executed from the second working platform. The plywood formwork was scraped, trimmed to the new desired dimensions and oiled, and put back into place between the stiffback channels. Simultaneously, laborers removed bolts from the lower jumpform beams. These bolts were readily accessible from the lower working platforms 3 and 4 prior to upward jacking of the scaffolding system.

(2) At approximately 7:30 a.m., the iron workers arrived at the construction site and prepared bundles of reinforcing steel for hoisting. Adjustments were made in the static line and the reinforcing steel was hoisted to the top. The iron workers also distributed and placed the reinforcing steel around the tower perimeter from the top working platform.

(3) The field engineer arrived at the site at approximately 7:30 a.m. and aligned jumpform beams at 16 control locations.

(4) Jacking of the entire scaffolding and formwork system commenced at about 8:30 a.m. Upon completion of jacking the lower jumpform beams were removed from the shell around the entire tower 
perimeter and raised manually to the top level. Formwork was then repositioned and aligned for the new pour.

(5) At approximately 10:00 a.m., the first bucket of concrete was hoisted to the top leve1. During the hoisting of this first bucket of concrete, the static line tension was readjusted. The concreting operation began at catheads no. 4 and 5 and progresses in two directions toward catheads no. 1 and 6 where the operation terminated. While concrete was being placed, tying of reinforcing steel, jumpform beam repositioning, surface preparation at the cold joint and grouting, curing agent application, etc., took place and terminated prior to completion of concrete placement. The remainder of the day, until approximately 2:00 or 3:00 p.m., was used for concrete placement for the entire five-foot lift. Following placement of the concrete all workmen retired and the process was repeated on the following day.

Just prior to the collapse, the following chain of events were described by those who saw the collapse from the center of the tower.

(1) Shortly before the collapse, the first bucket of concrete was delivered to cathead no. 4 and emptied into Georgia buggies.

(2) Cathead no. 5 received its first bucket of concrete which was also emptied into Georgia buggies.

(3) When the workers at the center of the tower heard a loud cracking sound coming from the direction of cathead no. 4, they saw the second bucket of concrete was about two-thirds of the way to the top. The static line went slack. The hoist operator for cathead 
gantry no. 4 also reported the loss of tension in the hoist cable at about the same time. He then applied the brake on the hoist line.

(4) Cathead no. 4 slowly fell toward the inside of the tower together with the scaffolding. The collapse of lift 28 commenced and it appeared to progress toward cathead no. 5. Eventually, lift 28 peeled off with failure radiating circumferentially in two opposite directions. All scaffolding and forms fell toward the inside of the tower.

(5) Those who were at the center of the tower took safety under the concrete truck ramp. All workers who were on the elevated scaffolding were killed in the collapse. 


\section{LABORATORY INVESTIGATIONS}

4.1 Introduction

The laboratory investigations included testing of concrete specimens under simulated field conditions to establish the strength and stiffness values of the concrete of lift 28 at the time of the collapse. The results are also used in determining the elastic moduli of concrete of other lifts which are needed for computer analyses of the shell (presented in chapter 6).

Because it was not possible to determine visually the operating condition of several components of the scaffolding and hoist systems they were examined in the NBS laboratory. They were also tested to determine their ultimate load carrying capacities. The components recovered from the Willow Island site included Williams anchor bolts, two sections of hoist cables, a chain hoist and a grip-hoist. The results of these component tests are used in evaluating any component fallures which might have triggered the collapse. Examination of possible component failures is presented in chapter 5. Laboratory investigations on concrete and testing of each of the components are described below.

\subsection{Concrete Tests}

The purpose of the concrete tests was to establish the compressive, tensile and bond strengths and the stiffness of the concrete of 1 ift 28 at the time of the collapse. Although the results of field-cured standard cylinders, made of the same concrete used for lift 28 and tested at 24 and $25 \mathrm{hr}$, respectively, were known (see table 4.5 a and b), supplementary tests were necessary to establish the rate of stiffness development and rate of gain in bond strength. 
When the collapse occurred, about 18 hours had elapsed since the completion of concrete placement for lift 28. However, because that part of lift 28 where cathead no. 4 was located had been completed earlier, it was estimated that the concrete in that vicinity had been cured about 20 hours prior to the collapse. Therefore, the 24-and 25-hr test results could not be used directly in the analysis of the shell.

In order to duplicate the concrete used for lift 28 in the laboratory, the constituent materials for the concrete were obtained from the concrete. supplier who provided the concrete for tower unit no. 2. The materials included cement,. fine and coarse aggregate, fly ash, water-reducing admixture and air-entraining admixture. These materials will be referred to in the text as the NBS sample. To assure that these materials, which were obtained six weeks after the collapse, were the same as those used for the lift 28 concrete, the individual materials were compared with small quantities of the materials obtained by OSHA personnel from the concrete supplier on May 2, 1978. These materials will be referred to as the OSHA sample. Comparative analyses of the two samples, one obtained by NBS and the other by OSHA, were carried out by NBS and other laboratories.

\subsubsection{Examination of Constituents of the Concrete}

\section{Cement}

Analysis of both the physical and chemical properties of the NBS and OSHA samples were made to examine, first, whether these two samples conformed to the standard requirements given in ASTM C 150 [4.1] ${ }^{2 /}$ and second, whether the two samples had the same properties. The ASTM specified

2/ Numbers in brackets refer to references listed in Chapter 10. 
values, the test results of Law Engineering Testing Co. ${ }^{3}$, and the test results of the Cement and Concrete Reference Laboratory, NBS, are given in table 4.1. Except for the 7-day compressive strength of cement mortar, other physical properties conformed to the ASTM requirements. It is to be noted that while both samples showed a lower 7-day compressive strength than the ASTM specified value, the NBS sample showed 16 percent greater strength than the 7-day value of the OSHA sample. The difference is even greater for the 3-day strength wherein the NBS sample showed 27 percent greater compressive strength than that of the OSHA sample.

The properties of two cement samples were determined by the chemical analysis method given in ASTM C 114 [4.2]. The analysis was carried out by Law Engineering Testing Laboratory. The results of the two cement sample analyses are given in table 4.2 together with the ASTM standard requirements. It is seen that although the cement samples were essentially of similar composition, both NBS and OSHA samples did not conform to the ASTM standard requirements for Type II cement, in that the silicon dioxide content of the samples was less than the ASTM minimum value. Therefore, it may be concluded that, based on both physical and chemical properties, the cement obtained from the concrete supplier would not have met the ASTM standard requirements for Type II cement. In addition, while the chemical properties of the two samples compare we11, a substantially greater compressive strength of the NBS sample than that of the OSHA sample indicates that the strength of concrete made of the NBS sample at early ages would be greater than that of the OSHA sample cement.

3/ See Appendix C for the complete reports. 
$\underline{\text { F1y Ash }}$

Table 4.3 shows the elemental analyses of fly ash of the NBS and OSHA samples. The values listed in the table were obtained by means of atomic emission and absorption spectrometry which was carried out by NBS. The tabulated results suggest that the two fly ash samples were essentially the same. The total contents of alumina, iron oxide and silica in each of the samples were calculated and compared in table 4.4 with the requirement given in ASTM C 618 [4.1]. It is seen that both samples conformed to the ASTM standard.

Fine and Coarse Aggregate

Fine and coarse aggregate consisted of natural river sand and gravel. Those obtained from the concrete supplier were visually compared with the OSHA samples. No difference between the two samples was noted. Water-Reducing Admixture

A water-reducing admixture is a material used for the purpose of reducing the quantity of water required to produce concrete of a given consistency. These admixtures increase the slump of concrete for a given water content. Some admixtures may also retard the setting time of concrete.

The NBS and OSHA samples were compared by means of infrared spectrophotometry which was carried out by NBS. The chemical composition of the two samples as shown by the analysis indicates that the NBS and OSHA samples were essentially the same.

An infrared analysis of concrete constituents from a piece of concrete of lift 28 was made to determine the amount of admixture used in the concrete. This was carried out by the Portland Cement Association. 
The results of the analysis are given in Appendix D. The analysis revealed that the amount of the water-reducing admixture used in the concrete was about the same as the amount specified in the concrete design mix specification, i.e., $3 \mathrm{oz}$ per $100 \mathrm{lb}(89 \mathrm{~mL}$ per $45.4 \mathrm{~kg})$ of cement.

\section{Air-Entraining Admixtures}

Air-entraining admixtures are generally used to improve the durability of concrete exposed to cycles of freezing and thawing. The workability of fresh concrete is also improved, and segregation and bleeding are reduced great1y. The NBS sample of the air-entraining admixture obtained from the concrete supplier was compared with the OSHA sample by means of infrared spectrophotometry. This analysis was carried out by NBS. The results showed no significant difference between the NBS and OSHA samples.

\subsubsection{Determination of Concrete Strengths and Stiffness}

After having determined that, except for possibly the cement, the constituents of the concrete obtained from the concrete supplier by NBS were essentially the same as the ones obtained by the OSHA personnel from the same source shortly after the collapse, a laboratory test program was initiated to determine various strengths and stiffness values of concrete. Included were tests for compressive strength, pullout bond strength and modulus of elasticity.

Test specimens were prepared and cured in an environmentally controlled chamber. Temperature in the chamber was controlled to simulate the temperature conditions at the Willow Island site over the $24 \mathrm{hr}$ period immediately prior to the collapse. The chamber temperature was controlled using the data obtained from the Parkersburg airport which is located about 5 miles $(8 \mathrm{~km})$ from the Willow Island site. It should be noted that the airport 
is situated at an elevation of about $170 \mathrm{ft}$ above the Ohio River on which the tower was situated. The temperature variation prior to the collapse based on the airport data and the temperature variation used for curing of concrete specimens are given in figure 4.1.

The concrete was prepared in several batches using $2 \mathrm{ft}^{3}\left(0.057 \mathrm{~m}^{3}\right)$ and $10 \mathrm{ft}^{3}\left(0.28 \mathrm{~m}^{3}\right)$ capacity mixers. The mix proportions were the same as those reported for the lift 28 concrete (table 4.5 ). The mix proportions specified for one cubic yard of concrete were scaled down to match the size of mixer. Prior to mixing, the components of the concrete were prechilled for at least $18 \mathrm{hr}$ in an environmental chamber at $45^{\circ} \mathrm{F}\left(7.2^{\circ} \mathrm{C}\right)$ to simulate the temperature condition of the components for the lift 28 concrete at the batching plant. To duplicate the mixing condition, hot water was added for mixing. Table 4.6 gives the data on fresh concrete obtained at the time of specimen preparation.

The following tests were performed.

1. Compressive strength test of $6 \times 12$ in ( $150 \times 300 \mathrm{~mm})$ cylindrical specimens.

2. Bond strength tests using $8 \times 8$ in ( $200 \times 200 \mathrm{~mm})$ cylindrical pullout specimens.

While several series of compressive tests were made to examine the strength-gain characteristics, only one series was carried out for the pullout bond tests. For the first 24-hr period after casting, all specimens were subjected to a simulated field temperature condition as described above. Thereafter, the specimens were cured at $55^{\circ} \mathrm{F}\left(12.8^{\circ} \mathrm{C}\right)$. For 28 -day test, a separate set of three companion compression specimens were cured at $73^{\circ} \mathrm{F}\left(22.8^{\circ} \mathrm{C}\right)$. The actual temperature of the concrete was recorded 
periodically by means of a thermocouple inserted in a $6 \times 12$ in ( $150 \times$ $300 \mathrm{~mm}$ ) cylinder. The specimens cured in the chamber were tested at $0.5,1,2,3,5,7,14$ and 28 days.

\section{Compressive Strength}

The compressive tests were performed according to the procedure described in ASTM C 39 [4.1]. Figure 4.2 shows the compressive test setup. Deformation of each specimen was measured during the compressive test with a compressometer such as is described in ASTM C 469 [4.1]. The results of deformation measurements together with strength data were used to determine the modulus of elasticity.

Figure 4.3 shows the results of the compressive strength tests in which the compressive strength is plotted against the maturity of the concrete. The term "maturity" expressed in units of "degree-day" represents a simple function with which the combined effect of temperature and time can be related to the gain in the concrete strength [4.5].

The NBS test data, plotted as squares, are shown in the figure along with the results of compressive tests carried out by the Ohio Valley Testing Laboratory (OVT) and the Pittsburgh Testing Laboratory (PTL), plotted as triangles, and the field test data of $6 \times 12$ in $(150 \times 300 \mathrm{~mm})$ cylinders for the lift 28 concrete, plotted as circles. The test specimens used by the Ohio Valley Testing Laboratory and the Pittsburgh Testing Laboratory were made on May 2, 1978, at the Willow Island site using the concrete delivered by the concrete supplier. These specimens were field cured for the first 24 -hour period and thereafter, in $70^{\circ} \mathrm{F}\left(21.2^{\circ} \mathrm{C}\right)$ lime water. The specimens prepared at the time lift 28 was cast were kept 
at the base of the tower for the first 24-hour period and subsequently, moved to a $70^{\circ} \mathrm{F}\left(21.1^{\circ} \mathrm{C}\right)$ fog room.

It is seen in figure 4.3 that the cylinder strengths of lift 28 agree we11 with the OVT-PTL data. Comparison with the NBS data shows that at early ages, the OVT-PTL data fall below the NBS data, while at later ages, the OVT-PTL data lie above the NBS data. This indicates that the rate of strength gain represented by the two sets of data are different. The results of the cement analysis discussed in section 4.2 .1 suggest that this difference could be attributed to a slower early strength gain exhibited by the cement of the OSHA sample, which was obtained on the same day as the OVT-PTL specimens were prepared. Because the compressive strength data of lift 28 matched closely with the strength gain characteristics of the OVT-PTL data, the OVT-PTL data were used in the analysis of the shell. However, for the relationship between the compressive strength and the modulus of elasticity and the pullout bond strength, the NBS test results were used because they were the only data available. Modulus of Elasticity

From stress-strain curves of the compressive test the values of the secant modulus of elasticity are obtained at the stress level of 40 percent of the maximum compressive stress $\left(0.4 \mathrm{f}_{\mathrm{c}}^{\prime}\right)$. The stress-strain relationship of concrete specimens tested at various ages together with the relationship between the compressive strength and the modulus of elasticity is shown in figure 4.4. In this figure, the secant moduli are plotted against the square root of the compressive strength. A linear regression line is shown together with a line obtained by using the ACI code equation [4.4]. In the analysis 
of the shell, different moduli of elasticity determined by the regression line, for each lift were used.

Pullout Bond Strength

The testing procedure for the pullout bond tests was essentially as described in ASTM C 234 [4.1] except that only the slip of the bar at the free end was measured. Figure 4.5 depicts the test setup. The test specimen consisted of a 48-in (1.2-m) long no. $4(1 / 2 \mathrm{in}, 12.7 \mathrm{~mm})$ deformed reinforcing bar (ASTM 615, Grade 60) cast in an $8 \times 8$ in ( $200 \times 200 \mathrm{~mm}$ ) waxed cardboard cylinder mold. Figure 4.6 shows the pullout specimen and mold. The specimens were made so that the bar was bonded to the concrete for a length of 6 inches $(152 \mathrm{~mm})$.

Figure 4.7 shows the pullout test results in which the maximum test load observed is plotted against the square root of the corresponding compressive strength. The bond strength of the no. 4 bar obtained according to the regression equation was used in the strength evaluation of the shell.

\subsection{Anchor Bolt Tests}

As described in chapter 3, special anchor bolts were used to hold the inside and outside jumpform beams together, separated by a constant distance, prior to casting of concrete. After the concrete had set, although friction existed between the flanges of inside and outside jumpform beams and the shell, the bolts served as the only positive means of transferring all construction loads to the shell. The components of the anchor assembly are shown in figure 4.8. The assembly consisted of two 3/4-in (19-mm) hexhead bolts (ASTM A 494), two rectangular washers, two tapered threaded couplings and a centerpiece threaded crimped rod. By adjusting the amount of insertion 
of the rod into the threaded couplings, the space between the two jumpform beams was adjusted.

Two anchor assemblies after tension testing to failure are shown in figure 4.9. In both cases the fracture took place at the middle where the crimp was present. The average of two anchor assembly tests was 40,350 1b $(179.5 \mathrm{kN})$. Because it was observed in the field that in many cases the rod was fractured in the thread coupling through the net cross section at the first thread, a specimen was tested in tension with the anchor assembly embedded in a $12 \times 12 \times 12$ in ( $305 \times 305 \times 305 \mathrm{~mm}$ ) concrete cube. The purpose of this test was to see whether the failure mode would change if the anchor bolt were tested with concrete encasement. A photograph showing the fractured part is shown in figure 4.10. As can be seen, the male rod fractured through the net cross section at the first thread. The maximum test load was $43,2001 \mathrm{~b}(192.2 \mathrm{kN})$. This latter test load indicated that the strength of an unembedded anchor assembly would give a lower bound capacity.

\subsection{Hoist Cable Tests}

Two 100-ft $(30.4-\mathrm{m})$ hoist cables were obtained from the Willow Island site. One section was cut from the hoist end of the cable, and another from the opposite end of the cable wound on the hoist drum. The hoist cable had a diameter of $9 / 16$ in $(14.3 \mathrm{~mm}$ ) and was made of non-rotating wire rope having two 19 strand layers.

For laboratory tests, ten 6-ft $(1.8-\mathrm{m})$ long specimens were prepared, five from each of the two sections of cable (figure 4.11). Wire rope sockets were attached to the ends of each specimen by means of molten zinc. 
Figure 4.12 shows the test setup for the tension test. Of the ten specimens, eight broke within $2 \mathrm{ft}(0.6 \mathrm{~m})$ of one of the socket ends, while the other two broke close to the middle of the specimen. The results of tension tests of the cables are given in table 4.7 .

The tabulated values show that there is no significant difference between the strength of the cable section which had been subjected to continuous hoisting stress and that of the cable section which had been worked on the hoist drum.

\subsection{Chain Hoist Test}

A 2-ton $(17.8 \mathrm{kN})$ capacity chain hoist was used in cathead no. 4 as part of the counterstatic line. The function of the chain hoist was to adjust the length of the counterstatic line so as to counterbalance the force in the static cable and adjust the position of the cathead gantry. Because any slippage in the chain hoist gear system due to overloading could result in a continuous increase in the chain length and subsequent dynamic instability of the cathead gantry, it was desirable that the maximum strength of the chain hoist be determined.

The test setup shown in figure 4.13 duplicates the field condition using the cable slings and clevises of cathead no. 4. When the test load reached $15,3101 \mathrm{~b}(68.1 \mathrm{kN})$, the internal gear system fractured without the chain slipping. The fracture of the gear system also shattered the cover plate of the housing of the chain hoist (figure 4.14).

\subsection{Grip-Hoist Test}

As shown in figure 4.15 , the static line was anchored to the ground by means of a grip-hoist. By jacking the hand lever on the grip-hoist, the static cable length and tension could be adjusted. Because any slippage 
of the static line through the grip-hoist could cause cathead no. 4 to become unstable the grip-hoist capacity needed to be determined.

Figure 4.16 shows the tension test setup in which the grip-hoist was placed between the head and platen of the testing machine with the static cable attached to the lower end. At a maximum load of $19,1001 \mathrm{~b}(84.96 \mathrm{kN})$, the hook on the lower end broke away from the housing of the grip-hoist (fig. 4.17). Throughout the entire range of test load, no slippage of the static line was observed. 


\section{EXAMINATION OF CONDITIONS OF CONSTRUCTION ASSEMBLIES AT THE TIME OF FAILURE}

\subsection{Introduction}

The construction assemblies which collapsed into the tower may be divided into three groups: the hoisting system, the scaffolding system and the formwork system. Because only $1.0 \mathrm{yd}^{3}\left(0.8 \mathrm{~m}^{3}\right)$ of concrete was delivered to the top of the tower at the time of the collapse, it is reasonable to conclude that no appreciable forces were being exerted on the formwork system, and that any local failure of the formwork system would not have been possible. Therefore, this chapter examines possible failures of those components of the hoisting and scaffolding systems which could have caused cathead no. 4 to become unstable under imbalance of forces. Examination of each critical component is supported by the data collected from site investigations and, where applicable, by test results.

\subsection{Examination of Hoisting System}

Figure 5.1 identifies the main components of the hoisting system as:

1. Hoist cable

2. Static line

3. Counterstatic line

4. Chain hoist

5. Cathead beam

6. Outside legs

7. Inside legs

8. Outside support brackets

9. Inside support brackets 
10. Slide plate assembly

11. Static line anchor - Grip-hoist (not shown in fig. 5.1, see $\mathrm{fig} \cdot 4.15)$

Failure of any of the above items might cause a sudden shift of forces which would create an unstable condition for the cathead. Hoist Cable

Two of the six hoist cables were broken. These were located at cathead no. 4 and cathead no. 5. A comprehensive examination of the fractured area by the Federal Bureau of Investigation reported no kinking, crushing or "bird caging" of the cable and other signs of damage which could have caused distortion in the cable structure.

As mentioned in section 3.2 , both of these cables cut a deep groove in the upper edge of the remaining she11, lift 27 , indicating that they were not broken until after the debris had started plummeting towards the ground. It is believed that a substantial amount of weight must have been hanging on the cable to cut the deep groove and that the break of the cable followed the initiation of the collapse. The laboratory results indicated that the average breaking strength of the cable of ten specimens is $27,2601 \mathrm{~b}(121 \mathrm{kN})$. Even under an impact factor of 2.0 applied to the hoist load, a maximum operating load which would be produced by the concrete bucket and the attachments would be about 4,932 1b ( $22 \mathrm{kN}$ ) (table 6.1). Thus, it is reasonable to conclude that this small magnitude of the hoist load, as compared with the breaking strength, could not have caused the cables to break, and that the falling weight of the cathead together with the scaffolding system must have fractured the cable. 


\section{Static Line}

Examination of all six static cables during the field investigation showed no sign of fracture along their entire length. All of the cables were still attached to the sliding plate at one end and anchored to the ground through a grip-hoist at the other end. Counterstatic Line and Chain Hoist

The counterstatic line consisted of a set of two cable slings interconnected in series by a chain hoist. As presented in chapter 4, the laboratory test revealed that the weakest link in the counterstatic line was the chain hoist which had a maximum test capacity of $15,310 \mathrm{lb}(68.1 \mathrm{kN})$. Because the test also showed the chain hoist would fail in fracture rather than by slippage in the gear system, it can be concluded that no slippage occurred due to the hoist load. This conclusion is also supported by the closeness of the measured length of the counterstatic line in the field (see sect. 3.2) with the computed value based on the reconstruction of the cathead gantry configuration using the actual member sizes measured in the field.

\section{Cathead Beam}

A close examination of the cathead beam of cathead no. 4 revealed that although the two channels ( $C 8 \times 11.5$ )comprising the beam were bent at the midspan (fig. 3.16), they did not exhibit any signs of buckling between the two cathead legs. This also agrees with a simple elastic analysis of the channel section as a compression member. The computed buckling load exceeded by a considerable margin the force produced by the hoisting load with an impact factor of $2.0 ; 23.4$ kip capacity vs. $3.58 \mathrm{kip}$ load (104.1 kN vs. $15.9 \mathrm{kN})$. 
Inside and Outside Cathead Legs

Figures 3.15 and 3.16 show the inside and outside cathead legs, respectively. As discussed in section 3.2, examination of all four individual legs showed no signs of damage or buckling. Support brackets for attachment of the legs to jacking frames were still intact. No welding failure of the square tubular legs to the supporting bracket was noted. Slide Plate Assembly

The slide plate assembly supported the static cable and the inside sheave of the hoist line. It could slide along a track attached to the inside of the two-channel cathead beam. By turning the large bolt above the beam, the position of the slide plate could be adjusted. As can be seen in figure 3.13, the slide plate became detached from the cathead beam. Judging from the bent shape of the bolt, the slide plate first separated from the beam with the bolt still anchored to the clip angle which was attached to the top flanges of the cathead beam. Subsequently, the downward force produced by the falling weight of the concrete bucket as well as the debris weight on the hoist cable could have bent the bolt as well as fractured the bolts which connected the clip angle to the cathead beam. However, the separation of the sliding plate from the cathead beam is not unique to cathead no. 4. A similar condition was also noted at catheads no. 1,5 , and 6 . Because they were buried under debris it was not possible to ascertain the condition of the slide plate for cathead no. 2 and 3 . Based on this observation, no definite conclusion could be reached as to when the slide plate for cathead no. 4 separated from the beam. 
The possibility of the slide plate being hit by the dead weight balls (fig. 5.1), which were attached to the hoist end of the cable, was examined. The measured length of the hoist cable (see sect. 3.2 and 6.2) places the position of the bucket at about $60 \mathrm{ft}(18.3 \mathrm{~m})$ below the cathead beam. This agrees we11 with eyewitness accounts that the bucket was two thirds of its way to the top of the tower when the collapse initiated. Therefore, it can be concluded that the bucket could not have hit the slide plate and caused it to separate from the cathead beam.

\section{Static Line Anchor}

As described in section 3.2, the static line was anchored to the ground through a grip-hoist. This allowed adjustment of tension in the line. Laboratory examination of the grip-hoist which anchored the static line for cathead no. 4 revealed that the two brass shear pins in the ratchet mechanism were still in place. The shear pins limit the amount of torque that could be applied to the grip-hoist to increase the tension in the staticline. It was established from the manufacturer that these brass pins shear off at a torque level that would induce a 3500-1b (15.6-kN) tension in the static line. Conversely, if the tension in the static line is greater than $35001 \mathrm{~b}$, additional tension could not be applied to the line by means of torquing the ratchet mechanism. On the other hand, the gripping mechanism in the grip-hoist had the gripping capacity in excess of $190001 \mathrm{~b}$ $(85 \mathrm{kN})$. Since the maximum tension force produced by the concrete bucket at the critical location is considerably greater than this force ( $47721 \mathrm{~b}$ vs. 3500 1b) (see sec. 6.7), it can be concluded that the tightening of the static line through the ratchet mechanism could not have pulled the cathead gantry inwards to initiate the collapse. 


\subsection{Examination of Scaffolding System}

As described in chapter 2, the platform supports were attached to jacking frames which in turn were supported by jumpform beams. The jumpform beams were anchored to the shell by means of special anchor bolt assemblies (see sec. 3.2). Because the flanges of the inside and outside jumpform beams were interconnected by anchor bolts, the anchor bolts in lift 28 could not be pulled out without either breaking the $3 / 4$ in (19 mm) hexhead bolt, breaking the crimp rod or tearing the flange of the jumpform beams. Close examination of the jumpform beams to which the legs of cathead no. 4 were attached revealed that there were no signs of excessive deformation at the bolt holes. The minimum specified capacity of the hexhead bolt according to ASTM A 449 is 40,100 $1 \mathrm{~b}$ (178 $\mathrm{kN}$ ) and the average tensile strength of the crimped $\operatorname{rod}$ was $40,3501 \mathrm{~b}(179.5 \mathrm{kN})$ (see sec. 4.3). Since the computed tension force produced in the anchor bolt assembly by a combination of the loading conditions including the hoist load with a dynamic amplification factor of 2.0 was only $16,2201 \mathrm{~b}(71.2 \mathrm{kN})$, it was concluded that the bottom anchor bolts in lift 28 could not have failed prior to the collapse.

\subsection{Summary}

In the foregoing sections of this chapter the critical components of the hoisting and scaffolding systems were examined with the support of field laboratory test data. It was shown that each of the components did not fail prior to the initiation of the collapse. Therefore, it may be concluded that the collapse did not initiate due to any component failure of the hoisting and scaffolding systems. In the following chapter, the shell will be analyzed to see whether its capacity was adequate to support the superimposed construction loads. 


\section{DEFINITION OF LOADS AND SHELL ANALYSIS}

\subsection{Introduction and Background Information}

Criteria and rationale for the definition of loads acting at the time of the collapse are developed in sections 6.1 through 6.8 for use in the analytical investigations of the shell presented in section 6.9. A total of five basic sources of loading (load cases) and the manner of their distribution on the shell are identified for this analysis as follows:

1) weight of the tower - continuous

2) weight of the scaffolding - 96 ribs

3) live loads on the scaffolds - 96 ribs

4) weight of cathead assemblies - 12 ribs

5) hoisting loads - 2 ribs

Loads attributed to the weight of the tower are generated internally by the shell analysis programs used in this investigation from the tower geometry and unit weight of concrete prescribed in the input. The procedure for evaluating loads from the other sources cited above is discussed in sections 6.4 through 6.7 . Assumptions made with regard to dynamic loading in the derivation of loads are discussed in section 6.8 . Geometric considerations for the definition of loads and the mechanism for their conversion into forces directly applied to the shell are discussed in section 6.2 and 6.3 , respectively.

The various steps used in the conversion of externally applied loads into equivalent forces acting directly on the shell structure may not be readily obvious to those having no prior familiarity with the construction scheme used. Therefore, some background information for the material contained in subsequent sections is in order. 
The scaled line drawing shown in figure 6.1 is a key sketch that should assist the reader in understanding the construction scheme used at the Willow Island site. It represents a typical sectional profile of the scaffolding, the cathead assembly, the static and hoist lines, and the concrete bucket. The position of the bucket shown at the top is that assumed at the time concrete is unloaded into Georgia buggies (not shown) located on the top deck of the inside scaffold. The sketch of the bucket shown by the dotted lines represents an intermediate position during delivery.

The hoist line rides over two sheaves suspended from the cathead beam as indicated. On the outside, it continues on down to the ground level (fig. 2.17) where it is wound around a hoist drum which controls its movement. The hoisted loads (concrete bucket, bundled bars, construction hardware, etc.) are attached to the inside terminal of the hoist line, and, in addition, by means of a pulley mechanism (point $K$ ), ride on the static line GKB supported at points $G$ and $B$. The static line provides stability against lateral movement during delivery of materials. The hoisting loads exert a transverse pull and thereby induce a tensile force in the static line. As hoisting of materials proceeds up from the ground level, the tension in the static line increases to a maximum somewhere close to but below the halfway mark, gradually diminishes thereafter, and vanishes entirely when the hoist line becomes vertical. At that point the static line is referred to as becoming slack (i.e., tensionless, or stress-free) but without play.

To determine the hoisting loads acting at the time of the collapse, a brief note of explanation is needed about the situation just prior to 
the collapse. All reinforcing bars and various construction-related equipment were delivered to the top. The first bucket of concrete was delivered to cathead no. 4. Worker statements indicated that when the first bucket was delivered to the top, adjustments in the length of the static line were made at the grip-hoist below (point I in fig. 6.2 sec. 6.2) to remove excessive slack, if any, with the assistance of the worker who unloads the bucket at the top. Therefore, if the first delivery of concrete was used as a trial to adjust (tighten) the static line for subsequent runs, the force in that line would be higher during the delivery of the second bucket of concrete to cathead no. 4 . The collapse, in fact, did occur during the second delivery. In the meantime, the first bucket of concrete was delivered to cathead no. 5 and unloaded into Georgia buggies. This bucket had not commenced its descent at the time of the collapse, a situation which was established on the basis of the field data (fig. $6.3-\sec \cdot 6.2$ ). No other hoist lines were in operation at the time of the collapse so that hoisting loads (1oad case 5) occurred only at the two ribs flanking cathead no. 4. In section 6.7 , the hoisting loads at cathead no. 4 are calculated based on the assumption that the static line becomes slack when the bucket reaches its unloading position as shown in figure 6.1 , so that its stressfree length is represented by the solid line GKB. This assumption is further verified by direct measurements of the length of the static line obtained at the site after the collapse, and used in the subsequent investigation of hoisting loads.

Referring to figure 6.1 , it is noted that most of the externally applied loads (load cases 2 to 5) are transmitted to the pair of opposite 
jacking frames present at each of the 96 rib locations (the exceptions are discussed in sec. 6.3). The jacking frames transmit these loads to the jumpform beams which in turn transmit them to the concrete shel1 through a series of interconnecting anchor bolts. The cathead forces, including the weight of the cathead assembly (load case 4), and the forces exerted by the static and hoist lines (load case 5), are transmitted to the shell through the cathead leg support brackets attached to the jacking frames, and through the counterstatic line which bears against a wide flange beam and is attached to the lower diagonal as shown.

Before the analysis of construction loads could be carried out, it was necessary to gather a substantial amount of information about the construction scheme, including sizes, lengths and material compositions of the various components comprising the scaffolding, hoisting and cathead assemblies. All of this information was assembled through numerous site investigations and laboratory testing of components recovered from the wreckage, supplemented and corroborated by information from project drawings and worker statements. The source and nature of this information is cited at the appropriate places in subsequent discussions.

\subsection{Geometry}

To evaluate the hoisting loads on the tower, it is first necessary to define the geometric configuration of the hoisting cables used for the delivery of construction materials to the top of the shell at the cathead locations (fig. 2.18). The cables of particular interest are those serving catheads no. 4 and no. 5 where concrete was being hoisted at the time of the collapse. The required information was developed on the basis of data obtained from the site following the collapse. 
Part of the field survey data is presented in figures 6.1 through 6.3. Figure 6.1 is a sectional profile (through a vertical plane of revolution) of the scaffolding and hoisting systems at a typical cathead location. The scaffolding, jacking frames and jumpform beams occur at each of the 96 ribs while the six catheads, including the static, counterstatic and hoist lines, the skid board and the wide flange beam, occur at equal intervals (every 16 ribs) along the circumference of the shell. Each cathead is located between two adjacent ribs and transmits its loads to these ribs through the counterstatic line (fig. 6.1) and two pairs of inclined legs at the interior and exterior of the she11, respectively. In plan, the hoisting layout for catheads no. 4 and no. 5 is shown in figure 6.2. In elevation, the layout for cathead no. 4 (others are similar) is shown in figure 6.3. These figures are helpful in visualizing the mechanism for the delivery of materials to the top of the partiallycompleted tower shell where the casting operations for lift 29 were being carried out. The lifting of materials at cathead no. 4 is controlled by the hoist drum operator stationed at U. Starting from the drum, the hoist line proceeds toward and around an interior sheave attached to sheave block $\mathrm{T}$ on the ground, toward and around exterior sheave $Q$, up and around the two sheaves suspended from the cathead beam and, before hoisting commences, all the way down to a concrete hopper at B near center A of the tower. A stationary static line is attached to point $G$ on the cathead beam at the top. At the lower end, it passes through a clevis secured to a concrete hopper at B, and terminates at grip hoist I which in turn is secured to the ground. 
The space coordinates of, and distances between, points given in figure 6.2 were established by double triangulation for independent verification of results. Note that the cathead is radially aligned (along $A Q$ ) but the horizontal projection BG (shown dotted) of the chord of the static line is not. Even though this introduces a horizontal force component of the static line acting on the cathead beam in the direction perpendicular to the beam axis, its effect is not significant and has been ignored in subsequent calculations of hoisting loads (sec.6.7). In figure 6.3, dimensions such as those along the cathead beam, the diameter and pivotal distances of the sheaves, the lengths of the cathead legs, the location of their bases relative to the she11, and the height of 1 ift 28 , were obtained by direct measurement in the field and were verified against the drawings. The lengths of the hoist lines for catheads no. 4 and no. 5 shown in figure 6.3 were likewise obtained by measurement in the field. They represent the length from the hoist drum $U$ to the point of attachment of the concrete bucket (point $\mathrm{K}$ in the figure). The cathead leg dimensions shown are the projections of the actual lengths of the cathead legs which are inclined with respect to the plane of the figure. Likewise, line BG in figure 6.3 is the projection of the chord length of the static line which is inclined relative to the plane of the figure (i.e., point B lies outside this radial plane).

The results shown in figure 6.3 were obtained from the foregoing data assuming the cathead beam to be level (see sec. 6.6 for explanation). They define the coordinates of the top support points for the static lines for catheads no. 4 and no. 5 as well as their chord lengths and corresponding horizontal and vertical projections. They also indicate 
the positions of the concrete buckets relative to the respective catheads at the time of the collapse, based on the hoist line lengths measured after the collapse.

\subsection{Mechanism of Load Transfer}

It will be helpful at this stage to review the mechanism of load transfer to the shell. Essentially, most items are connected to the jacking frames at the ribs (fig. 6.4). The loads that are transmitted to these frames are indicated in figure $6.4 \mathrm{a}$ and the points at which they act are keyed to the cross-sectional layout shown in figure $6.4 \mathrm{~b}$ by circled numbers. Forces $F_{1}$ through $F_{6}$ and moment $M$ are reactions induced by the weight of the scaffolds and live loads acting upon them. The connection at point 5 is fixed and therefore capable of developing a a moment $M$. As mentioned previously, these forces occur at a11 of the 96 ribs of the she11. Forces $A_{P}, A_{N}, A_{Z}, B_{P},{ }_{N}$ and $B_{Z}$ are the cathead leg reaction components on the jacking frames (as defined in fig. 6.8 and sec.6.7) and forces $\mathrm{P}_{\mathrm{C}}$ and $\mathrm{Q}_{\mathrm{C}}$ are forces induced by the counterstatic line bearing against the wide flange beam (see also figs. 6.1 and $6.4 \mathrm{~b}$ ). These forces as well as force $F_{c}$ in the counterstatic line (fig.6.8) occur only at the six pairs of adjacent ribs where the six catheads are located (fig. 2.18).

Forces that are not directly transmitted to the jacking frames may be identified by reference to figure $6.4 \mathrm{~b}$. The only force directly applied to the shell is transmitted through the roller at the lower end of the exterior scaffold. The roller at the lower end of the interior scaffold will tend to sway away from the shell so that no bearing force can be expected to develop at that point. On the exterior of the shell, the upper diagonal with the adjustable ratchet transmits, through connection 
$\mathrm{B}_{1}$ at the top, a force which may be resolved into components normal and paralle1 to the she11. The normal component is transmitted to the jumpform beam while the jacking frame receives the parallel component through a pinned extension. Similarly, the lower diagonal to which the counterstatic line is attached exerts a force through its lower connection $\mathrm{F}_{1}$. The normal and parallel components of this force are transmitted respectively to the jumpform beam and the jacking frame. In addition, the connection at this point develops a horizontal pull normal to the plane of the figure due to the inclination of the counterstatic line with respect to that plane. The jumpform beams receive forces through two sets of end rollers and a pawl attached to each jacking frame (see fig. 5, appendix A). The paw1 is mechanically engaged to one of the lugs on the outstanding flange of the jumpform beam. The rollers are free to slide along the flange but are constrained against movement in the normal direction. The forces on the jumpform beam were calculated by treating the jacking frame as a two-span continuous beam on two exterior roller supports and an interior pin support (at the paw1) as indicated in figure $6.4 \mathrm{a}$.

Figure 6.5 identifies forces and couples acting on the outstanding flanges of opposite jumpform beams at a rib. Points A through F (also appearing in fig. 6.4a) define the location of the jacking frame supports relative to the jumpform beams. The two exterior diagonals noted above are connected to points $B_{1}$ and $F_{1}$, Forces $F_{x}, F_{y}, F_{z}$ and circumferential moment $\mathrm{M}_{\mathrm{y}}$ are identified by reference to the local coordinate axes ( $\mathrm{x}$, $y, z)$ as shown. Check marks and zeros shown in tabular form indicate respectively those actions (force component or moment) that can or cannot develop at each point. Actions $F_{z}$ and $M_{y}$ occur in opposite pairs as 
noted in the figure, and develop as a result of the inclination of the cathead legs and counterstatic line relative to the plane of the figure.

The final stage in the conversion of external loads (load cases 2 to 5) into equivalent actions applied directly to the shell leads to the results tabulated in figure 6.6. The points of application of these actions, designated by the letters $\mathrm{I}, \mathrm{J}, \mathrm{K}$ and $\mathrm{L}$ (also appearing in figure 6.5), are located on the middle surface of the shell. Actions occurring at $E$ and $F$ (refer to $f i g \cdot 6.5$ ) are converted into their statically equivalent counterparts and placed at $K$. Actions at $F_{1}$ are converted in a similar manner and placed at L. The resultants of $F_{y}$ forces and $\mathrm{M}_{\mathrm{y}}$ moments acting on the cantilever portion of the jumpform beams (points $A, B, C, D$ and $B_{1}$ ) are distributed equally to the two anchor bolts at $I$ and $J$. The $F_{x}$ forces at $I$ and $J$ induced by the forces acting on the cantilever portion of the jumpform beams are calculated by treating the anchors at these junctions as simple supports.

The preceding steps involve certain assumptions regarding the distribution of forces to the anchor bolts. For instance, the equal distribution of $F_{y}$ forces to anchor bolts at $I$ and $J$ implies that the jumpform beams are axially rigid and no friction can develop at the shell interface. The other extreme situation would occur if the axial rigidity of the jumpform beams were negligible relative to that of the she11, in which case, nearly all of the $F_{y}$ forces from the cantilever portion would be transferred to the top anchor bolt. In reality, the axial stiffness of the shell is many times that of the jumpform beams and therefore, the actual distribution will be somewhere between the two extremes with the greater portion of the force going to anchor bolt I. However, the 
net effect of the two extreme assumptions on the results of the shell analysis is not significant. In fact, after examining the combined effect of all the assumptions made in the conversion of loads from the jumpform beams to the shel1, it was determined that additional refinements will not alter the conclusions of this investigation.

6.4 Weight of Scaffolding - Load Case 2

The scaffolding assembly, including formwork and steel joist supports (fig. 2.5) is axisymmetric so that it transmits equal forces to the 96 peripheral ribs of the shell (fig. 3, appendix A). The procedure for evaluating the forces at a rib due to the weight of a repetitive scaffolding section (see fig. 6.7) is straightforward and involves no major assumptions. The weights of the individual components, evaluated from data on sizes and material composition obtained from the site and the drawings, were placed at their respective centroids and are indicated by vertical arrows in figure 6.7 (arrows with notation are for other load cases). These include planks used for decking and supporting brackets, diagonals and straps, formwork and joists, railings and posts, safety nets, hydraulic actuators, lines and jacks, stiffbacks, jacking frames, jumpform beams and miscellaneous other hardware. In the analysis, the junctions of the lower deck brackets and suspended outer straps (fig. 6.7) were assumed pinned so that with the exception of the diagonally braced bracket at the exterior of the she11 (second deck from the top), the system was rendered statically determinate. This bracket, together with the two diagonals was treated as a pinned truss with one degree of redundancy. The final forces on the shell resulting from case 2 loading are tabulated in figure 6.6 . 


\subsection{Live Loads - Load Case 3}

Live loading consisted of the weight of 51 workers, reinforcing bars, Georgia buggies, electrical and welding equipment, gas cylinders, water drums, tools, grouting materials, fresh concrete, miscellaneous hoses, wires, cables and other hardware. The live loads were applied equally to the top decks of the interior and exterior scaffolds (designated by $\mathrm{P}_{\mathrm{L}}$ in fig. 6.7) and were assumed to be uniformly distributed around the periphery of the shell. After examining all the evidence at hand (field observations at the Willow Island, W. Va. and Berwick, Pa. sites, plus worker statements), it was concluded that live load distributions other than those assumed cannot be reasonably justified so that large concentration of such loading occurring at any one location, including in the vicinity of catheads no. 4 and no. 5, were ruled out. Furthermore, it is noted by reference to figure 6.6 that the contribution of live loads to the total load on the shell is relatively small so that variations in live load distribution will not significantly affect the shell analysis results. The procedure for evaluating shell forces induced by live loads (fig. 6.6) is the same as load case 2 discussed in the foregoing section. 6.6 Weight of Cathead Assembly - Load Case 4

The free-body diagram of a cathead in the radial plane is shown in figure 6.8. Without both the static and counterstatic lines acting (at G and C, respectively), the cathead assembly is rotationally unstable. If, for any reason, the static line were absent, the cathead could still retain its stability provided the resultant overturning moment due to gravity loads about fictitious point 0 (point of intersection of cathead legs a and b) is counterclockwise so that the counterstatic line is in 
tension. Using the values for the gravity load components $W_{1}, W_{2}, W_{3}$ and $W$ and their locations specified in figure 6.8 , it can be readily shown that the corresponding overturning moment is, in fact, counterclockwise if the cathead beam is assumed to be in horizontal alignment. It can also be shown that it does not take much backward tilting from this level position (and this can be manipulated by means of the chain hoist fig. 6.7) to cause a rotational collapse of the cathead in the clockwise direction (outward) in the absence of the static line.

Referring to figure 6.1 , it is noted that, with the cathead beam level, the proximity of the bucket to the top deck of the inner scaffold is sufficient to permit unloading of the concrete into on-deck Georgia buggies by means of a chute pivoted to the bottom of the bucket (see figure 6.9 for chute detail). It should be noted that the position of the bucket relative to the deck can be controlled, in addition to the chain hoist, by the special bolt on the slide plate assembly to which the static line and the inside sheave of the hoist line are attached (fig. 6.7). The position of this plate was established by measurement of dimensions of the component parts found among the wreckage at the site. The assumptions that the cathead beam was level at the time of the collapse is based on the foregoing arguments and is further corroborated by the alignments observed at the Berwick, Pa. site.

The gravity loads which are transmitted to the six pairs of adjacent ribs at the six cathead locations around the shell are designated in figure 6.7 (shown in parentheses) and figure 6.8. They consist of the weights of the cathead legs $W_{1}, W_{2}, W_{3}$, the weight of the cathead beam assembly $\mathrm{W}$, which includes the weights of the sheaves, the weight of the 
hoist line $W_{H}$ but not the hoisting loads, the weight of the steel skidboard ${ }_{\mathrm{SB}}$, the weight of the wide flange beam $\mathrm{P}_{\mathrm{WF}}$, and tension $\mathrm{T}_{\mathrm{o}}$ in the static line due to its own weight. It should be pointed out that tension $\mathrm{T}_{0}$ depends on the stress-free length of the static line assumed. The criterion used in determining this length as well as the corresponding cable forces $T, F_{D}$ and $F_{0}$ due to hoisting loads (load case 5) are discussed in section 6.7 .

Having established the cathead position and component forces of the assembly, the corresponding leg reaction components at supports $A$ and $B$ (fig. 6.8) and the forces $F_{c}, P_{c}$ and $Q_{c}$ (figs. 6.4 and 6.8) transmitted by the counterstatic line were determined by statics. The final forces on the shell corresponding to load case 4 are tabulated in figure 6.6 .

\subsection{Hoisting Loads - Load Case 5}

Once the geometry of the cable profiles are defined (sec. 6.2), cable forces and displacements induced by the hoisting loads can be determined. To minimize the human computational effort involved, a computer program was developed for that purpose. The program is based on the representation of the static line by the simple cable model depicted in figure 6.10.

The model assumes the static and hoist lines to be weightless (the weight of these lines are considered elsewhere - see sec.6.6). The hoist line is very nearly parallel to segment KG of the static line when the bucket is about midway to the top (1ocation for maximum tension in the static line) and the program assumes it to be parallel so that force $F_{D}$ acts in the same direction as KG for all locations of point $K$. The input parameters are as defined in figure 6.10. The fixed input parameters (the values of which are indicated in the figure) are chord length $\mathrm{L}$, 
coordinates $X_{G}$ and $Y_{G}$ of support point $G$ relative to support point $B$, and the cross-sectional area $A$ and modulus of elasticity $E$ of the static line. The variable input parameters are, position $\mathrm{K}$ of the bucket along the static line as defined by chord length segments $L_{1}$ and $L_{2}$, the normal distance of that point from the chord as defined by parameter $D$, and the hoisting load $W_{B}$. Two of the values used for $W_{B}$ were $29001 \mathrm{~b}(1314 \mathrm{~kg})$ and $58001 \mathrm{~b}(2627 \mathrm{~kg})$. They represent, respectively, the weight of the bucket assembly and concrete (calculations shown in fig. 6.9), and twice that weight to assess the effect of a 100 percent dynamic amplification of hoisting loads on cable forces.

Figure 6.11 shows in notation form a partial listing of the equations used for calculating the desired output parameters which are indicated by asterisks. Not shown are the equations for calculating the cathead leg reaction components $A_{P}, B_{P}, A_{Z}, B_{Z}$ and tension $F_{C}$ in the counterstatic line (fig. 6.8), and a refinement introduced in the program to account for changes in the output parameters resulting from the displacement of support point $G$ due to the elastic deformation of the cathead assembly.

Note that $s_{0}$, the stress-free length of the static line, is an output value. The program was used in an iterative fashion by adjusting the input parameter $D$ to produce the value of $s_{0}$ that matched the true stress-free length of the line. The true stress-free length is discussed below.

The cathead leg reactions and the force in the counterstatic line are determined using the free body diagram of the cathead (fig.6.8) under the action of the static line force $T$ and hoist line forces $F_{D}$ and $\mathrm{F}_{\mathrm{o}}$. The cathead sheaves are assumed to be frictionless so that 
$\mathrm{F}_{\mathrm{O}}=\mathrm{F}_{\mathrm{D}}$. By reference to figure 6.3 , note that cathead leg reactions $A_{Z}$ and $B_{Z}$ are normal to the plane of the figure and occur in opposite pairs; reactions $A_{P}$ and ${ }^{B} P$ act along projections $a$ and $b$ of the respective inside and outside cathead legs in the plane of the figure; and reactions $A_{N}$ and $B_{N}$ are zero because no intermediate loads (such as, $W_{1}, W_{2}$ and $W_{3}$ ) are acting in this case (refer to sec. 6.6). Thus, the resultant cathead leg reactions are axia1. Figures 6.12 and 6.13 should further assist in visualization of the spatial configuration of the cathead legs, the counterstatic line, and reaction components (also see fig. 9, appendix A).

For a given location of point K (fig. 6.10), the program outputs two sets of results. The first set corresponds to the assumption that point $G$ is fixed in space. The second set is obtained by an iterative process in which successive trials are based on the adjusted position of $G$ corresponding to the elastic deformation of the cathead assembly under cable forces from the preceding trial.

Figures 6.13 through 6.15 show the analytical formulations for calculating the movement of point $G$ attributed to the elastic deforma tion of the cathead assembly under the action of the static and hoist line forces. The expression for the displacement $\Delta_{c}$ of the counterstatic line under tension $F_{C}$ is derived in figure 6.13. In figure 6.14, small rotational displacement geometry is used to develop the expression for $\left(X_{G}^{\prime}, Y_{G}^{\prime}\right)$, which represent the movement of point $G$, due to the elongation of the counterstatic line. The axial deformations of the cathead legs are smaller than the elongation of the counterstatic line by about one order of magnitude, and therefore, their contribution to the movement of 
point $G$ is negligible. Figure 6.15 shows the formulation for displacements $\left(X_{G}, Y_{G}^{*}\right)$ attributed to the flexural deformation of the cathead beam. As in the case of the legs, the effect of the axial deformation of the beam is neglected so that $\mathrm{X}_{\mathrm{G}}^{\prime \prime}$ is assumed to be zero. The total displacement $\left(\mathrm{X}_{G}, \mathrm{Y}_{G}\right)$ then is obtained by adding the displacements due to the elongation $\Delta_{c}$ of the counterstatic line at the top and flexural deformation of the cathead beam.

In this case, superposition of tension $\mathrm{T}_{0}$ in the static line due to self weight and tension $T$ caused by loads $W_{B}$ gives results that are not appreciably different from the tension in the static line (at support G on the cathead beam) that would be obtained from a solution based on both loads acting simultaneouslý. A more refined analysis was performed for a few cases to verify this fact. The refined analysis considers simultaneously the weight of the cable and the hoisting loads using an approach similar to that advanced by Harrison [6.1]. The reasons for the sma11 difference between the two analyses are obvious. The distributed weight of the static line (100 $1 \mathrm{~b}$ or $45.3 \mathrm{~kg}$ ) is only about 3 percent of the weight of the bucket (2900 1b or $1314 \mathrm{~kg}$ ). In addition, with sufficient slack in the static line (this was the case to enable unloading of concrete at the top of the tower), differences in the results (tension in the static line as well as tension $F_{D}$ in the hoist line - fig. 6.8) from the two alternate procedures tend to disappear.

A glance at the results tabulated in figure 6.6 will indicate that by far the major portion of the forces acting on the shell is produced by the hoisting loads (load case 5 ). In particular, tension $T$ in the static line is the major source of the bending moments in the shell (hoist 
line forces $F_{D}$ and $F_{O}=F_{D}$ remain nearly constant as $T$ varies and balance out so that they contribute mostly to axial loads $F_{y}$ but not to normal forces $F_{x}$ - figs. 6.5 and 6.8). Tension $T$ in turn is quite sensitive to variations in the tautness (or, conversely, in the amount of slack) in the static line. Thus, the criterion for estimating the actual stress-free length of the static line at the time of the collapse would affect significantly the results of the analysis.

As mentioned in section 3.2 , the length of the static line of cathead no. 4 (the line was recovered from the wreckage) was measured on two separate occasions in the field. The measured lengths were within 2 in (51 mm) of each other. The average measured length, after deducting the length of the portion from grip hoist I to clevis B (fig. 6.2), was $219.17 \mathrm{ft}(66.85 \mathrm{~m})$. With the bucket at the unloading position shown in figure 6.1 and the static line assumed tensionless but without play for that position, the stress-free length $s_{o}$ is represented by the solid line GKB as shown. This length can be calculated from the space coordinates of points $B$ and $G$ (figs. 6.2 and 6.3) with the known position of point $K$ (the bucket is hanging vertically down). The computed length is $219.19 \mathrm{ft}(67.46 \mathrm{~m})$, which is almost identical to the length measured in the field.

If a certain amount of play in the static line were allowed when the bucket is at the unloading position, it would permit workers on the top deck to manipulate the bucket or pull it in, if need be, without encountering resistance from the static line. However, even without such resistance, a worker will have to exert a pull of about $4001 \mathrm{~b}$ $(1780 \mathrm{~N})$ to bring the bucket in a distance of $1 \mathrm{ft}(0.31 \mathrm{~m})$. From the 
layout shown in figure 6.1, with the bucket at the unloading position, it is apparent that concrete can be discharged without difficulty into Georgia buggies on the deck by means of the chute projecting inward above the top rail. Thus, there is no reason to believe that such manipulation with the bucket was necessary. Furthermore, if there were any play in the static line at the discharge level, the line would become slack below that level and the possibility of the bucket swaying and impacting the scaffold while being pulled up would increase accordingly. Conversely, with no play at the discharge position, the static line will develop tension at lower levels and will pull the bucket away from the scaffold thus diminishing the likelihood of severe impact.

The foregoing arguments led to the conclusion that the field measured length was the actual length being used at the time of the collapse and, therefore, was adopted as the basis for the stress-free length used in the calculations of hoisting loads (load case 5) and the static line tension due to self weight (load case 4 ).

The analysis of forces induced by hoisting loads leads to the results tabulated in table $6.1 \mathrm{a}$. The results obtained by considering the elastic deformation of the cathead were used to develop the forces for load case 5 tablulated in figure 6.6. For purposes of comparison on $1 y$, table 6.1a also shows computer results obtained by assuming support $G$ to be fixed in space. It should be noted that the forces in this table correspond to the location of the bucket which produces maximum tension in the static line. This is about $123 \mathrm{ft}(37.5 \mathrm{~m})$ below the cathead beam which is at variance with the $60-\mathrm{ft}(18.3 \mathrm{~m})$ position estimated from the field data (fig.6.3). From manufacturer's specification and worker statements the speed at which 
the hoist line was being pulled in was estimated to be about 10 to 12 $\mathrm{ft} / \mathrm{sec}(3.1$ to $3.7 \mathrm{~m} / \mathrm{s})$. Hence, it appears reasonable to assume that failure was initiated when the tension in the static line was approaching or at, its maximum, and during the next several seconds while collapse was in progress, it ended up at the 60-ft $(18.3-\mathrm{m})$ mark below the cathead beam.

Table $6.1 \mathrm{~b}$ tabulates forces produced by twice the weight of the bucket which is equivalent to 100 percent impact on the hoist load (or 100 percent dynamic amplification of the hoist loads). These values are only used to demonstrate that distress conditions would not have occurred in the mechanical system even if there had been reason to believe that 100 percent impact conditions were present (see chap. 5).

\subsection{Other Effects}

The posture adopted in the foregoing derivations was to use lower bound values for loads in situations where they were not known precisely. Hoisting loads, for instance, were treated as though they were stationary because not enough information was available to assess the inherent dynamic effects of the hoisting system used. The reasoning behind this approach was that should such loads lead to structural distress conditions (which turns out to be the case - see sec. 7), the distinct possibility of higher loads having occurred at the time of the collapse will not change the final conclusions of this investigation. The following paragraphs discuss the assumptions made with regard to dynamic loading. 
Dynamic amplification of loads occurs as a result of construction activities on the scaffolds (load case 2) and during hoisting of materials (load case 5). Dynamic amplification of live loads (1oad case 2) is negligible because, for the most part, they are stationary and welldispersed (see sec. 6.5).

Dynamic amplification of hoisting loads occurs principally as a result of the initial acceleration of the holst line to bring the bucket up to speed from at-rest position on the ground, fluctuations in the speed with which the bucket is lifted as the speed of the drum hoist varied, uneven winding of the hoist line on the drum, or any other changes in speed made by the hoist drum operator for whatever reasons during the bucket's journey to the top. An increase in the speed of the bucket will cause a rise in tension in both the static and hoist lines while a drop in speed will have the opposite effect.

The dynamic loading condition induced by start-up acceleration depends on how fast the bucket is brought up to speed and the damping characteristics of the hoisting system. This and the other factors noted above could possibly produce substantial amplification of hoisting loads. However, not enough information is available to make a quantitative assessment of these effects with sufficient accuracy to justify their use as part of the basis for arriving at the conclusion drawn.

It should be pointed out that the path of the bucket is curvilinear and therefore, even when moving at a constant speed, the bucket will exert a transverse dynamic force (outward normal to the path) on the static line. The path will be elliptic with foci at supports B and G (fig. 6.3) 
if the cable is inextensible and nearly so if it is elastic. Placing the bucket at midspan, assuming a speed of $10 \mathrm{ft} / \mathrm{sec}$ or $3.1 \mathrm{~m} / \mathrm{sec}$ (see sec. 6.7) and using the equation of the ellipse yields an incremental tension of about $601 \mathrm{~b}(267 \mathrm{~N})$ in the static line, which is negligible compared with the 4772-1b (21235-N) tension (table 6.1) used in this investigation.

\subsection{Analysis of She11}

An analysis of the cooling tower shell subjected to the construction loads described in the preceding sections was made with SHORE-III [6.2], a finite element program developed for the static and dynamic analysis of axisymmetric shells. The cooling tower shell was discretized by a series of curved ring elements, starting at the top of lift 28 . Modeling was consistent with the shell structure described in Chapter 2 of this report. Details of the SHORE-III analysis and a verification analysis using SAP IV [6.3] are presented in Appendix B. Construction loads were applied to the shell model and the resultant maximum forces in the shell were determined along with their location.

The finite element model used in the cooling tower analysis is shown along with an expanded view of the model for the top 3 lifts, in figure 6.16. The tower structure is discretized by a series of nineteen closed ring elements and one open type element at the bottom which models the column supports. In order to obtain better stress distributions and properly load the tower, the top two lifts (28 and 27) were subdivided into eleven elements. The other element divisions were generally chosen to account for either changes in shell thickness or changes in the modulus of elasticity of the shell material. Points for load application were 
located at the elevations in lifts 28 and 27 where the form system was bolted to the tower. Figure 6.16 shows the elevations, radii, thickness, and elastic moduli used for each element in the model. While the elastic modulus remains constant for an element, the thickness may vary linearly from the top to the bottom of the element as dictated by the shell geometry. Material properties (elastic moduli) used in the analysis were obtained from the test data presented in chapter 4 of this report using the maturity of the concrete in the various lifts on the day of collapse.

The construction loads presented in figure 6.6 are applied to the shel1 model at the load points indicated as distributed line loads by means of a Fourier Series. This distributed line loading technique is depicted in figure 6.17 for the normal, meridional, and tangential forces, $F_{x}, F_{y}$ and $F_{z}$, respectively, and for the meridional moment $M y$. The $x, y, z$ coordinate system shown applies to the construction loads as described in section 6.3 while the corresponding $u, v$, w system is the element coordinate system used in SHORE-III.

The loading function used in the SHORE-III analysis is developed by first distributing the concentrated loads about the centerline of the jumpform beam over 0.358 degree circumferentially (10 in or $254 \mathrm{~mm}$ at lift 28) for load cases 2 and 3 and 1.875 degrees circumferentially ( $4.3 \mathrm{ft}$ or $1.31 \mathrm{~m}$ at 1 ift 28 ) for 1 oad cases 4 and 5 . The 10 in (254 mm) distribution width is the surface contact length between the shell and jumpform beam. This distributed load is then expanded in a Fourier Series which applies the load at the required points around the circumference of the tower for the particular construction load case. The larger distribution angle used in load cases 4 and 5 was chosen because it reduced the number of Fourier series harmonics required to adequately define the loads. 
Ideally, a 0.358 degree distribution angle should have been used for all cases. However, when the 0.358 degree distribution angle was chosen for load cases 4 and 5, 150 harmonics were required to produce a load function with an acceptable shape. Increasing the distribution angle to 0.859 degree made it possible to generate a load function with acceptable shape using only 56 harmonics; thereby, reducing computer time and cost by about two thirds. A comparison analysis using both the 0.358 and 0.859 degree distribution angles showed that the maximum stresses differed by only a few percent and the stress distributions were essentially the same. Consequently, the compromise between distribution angle and computer analysis time is justified. Figure 6.18 illustrates the loading function for a normal force applied to the shell by the jumpform beams at a cathead. This load would then be repeated at all six (6) cathead locations in load case 4 to produce a symmetric loading condition.

The development of a convergent Fourier Series with only a few harmonics was found to be a difficult task for load case 5 which is applied only at cathead no. 4. This is because as the number of application points decreases (two points or ribs for case 5) the number of harmonics required for a convergent series increases rapidly. In addition, the computer time required for solution of a load case is related to the number of harmonics in the series. An investigation of the stress distributions that occurred in load case 4 where the six cathead gantry loads are applied to the shell indicated that the internal shell forces of interest decayed rapidly to a small value at approximately $20^{\circ}$ from the cathead. The SAP IV verification 
analysis also exhibited this stress distribution (see appendix B). Thus, it was concluded that since the catheads are $60^{\circ}$ apart, the loads applied at a cathead have little influence on the internal forces at the catheads on either side. Consequently, the loads for load case 5 were applied at all six cathead locations instead of just at cathead no. 4.

The loading functions were developed for each construction load (cases 2 to 5 ) and a separate analysis was made for each case, including case 1 which was internally generated by the program. Since SHORE-III is a linear elastic finite element program, the principle of superposition applies and the results for each load case may be combined algebraically to find the resultant stresses for any combination of the construction loads. The effect of using a line load with a distribution angle rather than a concentrated load is to predict stress magnitudes which are lower than those that occur in the shell.

Table 6.2 presents the stress resultants in lift 28 at cathead no. 4 for the sum of load cases $1,2,3,4$, and 5 at $\theta=0^{\circ}$ and $2^{\circ}$, respectively. Figure 6.19 shows the sign conventions for the respective stress resultants. Values at $\theta=0^{\circ}$ occur midway between the jumpform beams to which cathead no. 4 is attached while the values at $\theta=1.875^{\circ}$ occur at the meridian along which the jumpform beams are attached to the shell.

Figures 6.20 through 6.23 exhibit the distribution of the meridian stress resultant, $N_{\phi}$, the hoop stress resultant, $N_{\theta}$, and the moments, $M_{\phi}$, $M_{\theta}$, with $\theta$ for selected elevations in lift 28 (refer to fig. 6.17) for the sum of load cases $1,2,3,4$, and 5. Because they are symmetric about the cathead, the distributions are shown for only one side of the cathead. It should be noted that the values of the meridional stress at $\theta=1.875^{\circ}$, figure 6.20 and also table 6.2 , increases significantly at 
elevations of 165.721 and $162.125 \mathrm{ft}$ ( 50.512 and $49.416 \mathrm{~m}$ respect1vely) due to the loads being applied at points I and J (fig. 6.6). The shape of the stress distribution for $\mathrm{N}_{\phi}$ about the circumference of the shell, figure 6.20 , can be understood by considering the way the loads are applied to the shell. The loads prescribed in cases 2 and 3 are applied at each rib and the resulting stress distribution is symetric about each rib and, furthermore, is identical between all ribs. On the other hand, the loads prescribed in cases 4 and 5 are applied only at the cathead locations. The stress distributions illustrated in figure 6.20 reflected the superposition of these cases and the stresses due to load cases 4 and 5 control the shape of the distributions shown. The hoop stress, $\mathrm{N}_{\theta}$, as seen from figure 6.21 is highest at the top of lift 28 and decreases with decreasing elevation. Finally, the maximum values for $\mathrm{N}_{\phi}$ and $\mathrm{N}_{\theta}$ occur near the top bolt in lift 28 at the jumpform beams on either side of cathead 4. A relative maximum for $\mathrm{N}_{\phi}$ occurs near the bottom bolt in lift 28 at the jumpform beams. The maximum moments $M_{\phi}$ and $M_{\theta}$ also occur at the location of the jumpform beams $\left(\theta=1.875^{\circ}\right)$ with $M_{\theta}$ a maximum near the top of lift 28 and $M_{\phi}$ a maximum near the bottom of lift 28 as shown infigs. 6.22 and 6.23 . 


\section{INTERPRETATION OF SHELL ANALYSIS}

\subsection{Introduction}

The overall safety and the reliability of the construction method used at the Willow Island site depend on the integrity of the partially completed shell structure to resist all construction loads. This demands that sufficient strength must be developed in the previously cast shell so that the structural resistance exceeds the construction load effects by a reasonable margin of safety. Obviously, the shell did not have adequate strength to resist the applied load. In order to determine to what extent the applied load effects exceeded the capacity of the shell, the results of the analysis of the shell at a number of critical locations are compared with the resistance values determined by applying existing strength theories. It should be pointed out that no dynamic amplification of the hoist load was included in the shell analysis. Dynamic amplification is known to exist in hoisting systems such as the one used at the Willow Island site, and inclusion of the dynamic effects would have increased the forces in the shell over those determined in this report.

7.2 Strength of the Shell Under Combined Axial Load and Bending Moment

For a given cross section and reinforcement, an interaction diagram such as the one shown in figure 7.1 can be constructed in terms of ultimate axial forces as ordinates and ultimate bending moments as abscissa. For various combinations of axial forces and bending moments, the interaction curve defines a failure envelope in that all points lying on and outside the interaction curve constitute failure. On the other hand, combinations which fall within the area bounded by the interaction curve 
represent a safe condition. In this section a number of cross sections in the critical region of the shell are examined using the interaction diagrams. It was shown previously in the analysis of the shell that maximum forces in lift 28 would occur in the vicinity of the two ribs where the legs of cathead no. 4 were positioned. This critical region includes the section between the two ribs as well as the immediate vicinity along the ribs.

In developing the interaction diagrams for the critical cross sections, a shell section of unit width ( $1 \mathrm{ft}$ ) was treated as a rectangular column. In an actual shell element the forces and moments occur in adjacent cross sections parallel and perpendicular to the meridian. By treating a shell element as a column-like element, the forces and moments in each direction are dealt with separately. Any effect on the compressive strength of concrete due to biaxial compression is small [7.2]. Furthermore, the forces acting normal to the reinforcement have little, if any, effect on the stress that can be developed in the reinforcement. Thus, the treatment of a shell element as an uniaxial element is considered a reasonable and expedient approach.

The cross sectional dimensions of the shell sections used for determining interaction diagrams are shown in figure 7.2. The vertical section has two no. 4 bars and the horizontal section has two bars with an equivalent steel area for a $12-$ inch $(305 \mathrm{~mm})$ wide cross section. The actual shell cross section in lift 28 had $\|^{4}$ vertical bars spaced at 8.7 in on center $(220 \mathrm{~mm}$ ) on each face and 非 4 horizontal bars spaced at 12 in (305 mm) on center on each face (see fig. 2.2). 
Because the strength-gain characteristics of the lift 28 concrete as shown by the results of cylinder tests were significantly different from that of the NBS specimens (fig. 4.3), it was decided to use the lift 28 test data to estimate the concrete strength. The strength of concrete at the time of the collapse, approximately $20 \mathrm{hr}$ after placement of concrete (sec. 4.2), is estimated to be $220 \mathrm{psi}(1.52 \mathrm{MPa}$ ) based on the results of 24 and $25 \mathrm{hr}$ tests, $283 \mathrm{psi}(1.95 \mathrm{MPa}$ ) and $299 \mathrm{psi}(2.06 \mathrm{MPa}$ ), respectively (Table $4.5 \mathrm{a}$ and $\mathrm{b}$ ). The procedure followed to establish the concrete strength is shown in figure 7.3. It is seen that a linear interpolation is made between the time of set $(6 \mathrm{hr})$ and the time when the field cured cylinders were tested. The time of set was established by the experimental results with cement mortar, with consideration given to the inclusion of flyash and water reducing admixture in the lift 28 concrete. Approximately the same value of the compressive strength can be obtained from the strength-maturity plot shown in figure 4.3 with a value of 43 degree Fdays being the maturity at the time of collapse. It should be pointed out that the actual concrete strength at the top of lift 28 could have been lower than 220 psi $(1.52 \mathrm{MPa})$ due to the temperature condition of lift 28 was different than that of the test cylinders which were cured on the ground level and due to the rise of free water to the top of the wall both of which tend to lower the concrete strength. If these factors were taken into consideration, the concrete strength could have been as low as $200 \mathrm{psi}(1.38 \mathrm{MPa})$ rather than $220 \mathrm{psi}(1.52 \mathrm{MPa})$. However, in the evaluation of cross-sectional strengths, 220 psi was used.

The reinforcing steel must be embedded adequately in the concrete to develop its yield strength. The length of embedment required to develop 
yield is proportional to the square root of the strength of concrete. According to ACI $318-77$ [4.4], at a strength level of $220 \mathrm{psi}$ ( $1.52 \mathrm{MPa}$ ) the embedment length for a no. 4 bar in compression is 40.5 in (1029 mm). Because the ACI code requirement incorporates a 25 percent increase in embedment length over that required to develop yield [7.1], the value obtained from the ACI code should be reduced by 25 percent to reflect the actual needed embedment length. Thus, the corrected compression embedment length for a no. 4 bar becomes 32.4 in $(823 \mathrm{~mm})$.

The maximum amount of stress that can be developed in the steel was computed based on available length of embedment. The bars in the circumferential direction, which are in compression, could develop full yield strength of $60 \mathrm{ksi}(414 \mathrm{MPa}$ ) except at lap splices. At the locations where lap splices occur the maximum stress that can be developed in the bar is limited by the length of splice. For the splice length of 22 in ( $559 \mathrm{~mm}$ ), which was provided for no. 4 bars (fig. 2.2), the maximum compression stress in the steel is limited to $60 \mathrm{ksi} \times 22 / 32.4=40.7 \mathrm{ksi}$ (281 $\mathrm{MPa})$. For the bars in the meridian direction the available length of embedment varies depending on the distance from the top edge of lift 28 to cross sections being considered. For a cross section located 32.4 in (823 $\mathrm{mm}$ ) below the top of lift 28 , the steel can develop to yield (60 ksi, $414 \mathrm{MPa}$ ). Under combined bending moments and axial forces, some bars were in tension. For these bars embedment length of 28.8 in (732 mm) was computed using the pullout test results. However, at all locations where the tension embedment length would be a governing factor, the magnitude of these moments and axial forces are relatively low and their combined effects fall we11 within the interaction diagram. 
For the shell cross sections of unit width shown in figure 7.2 and using the limiting concrete and steel stresses described above, interaction diagrams for axial load and bending moment are obtained for critical locations in lift 28 ( $f i g .7 .4$ ). In developing the interaction diagram, it was assumed that the crushing strain of concrete is 0.003 in per in 4 and that the reinforcing steel has an elastic-perfectly plastic stress-strain relationship with a nominal yield strength of $60 \mathrm{ksi}$ ( $414 \mathrm{MPa}$ ).

Figure 7.5 shows an interaction diagram for a cross section resisting meridional forces (hereafter referred to as the horizontal cross section) for all cross sections 32.4 in $(823 \mathrm{~mm})$ below the top of lift 28 . Below this point a sufficient embedment length is available for the vertical bars to develop yield. In lift 28 the meridional force and bending moment are maximum at cross sections along a line through points $B A B$ as shown in figure 7.4. Maximum force and moment combinations for cross sections along this line are plotted in figure 7.5 in which the point corresponding to location $A$ is shown as a square and the point corresponding to location $B$ as a circle. It is to be noted in this figure that at both locations the cross section is controlled predominantly by bending moment. Because the cathead gantry loads are supported at the rib locations, the bending moment is substantially greater at this location than at the center of the panel, exceeding the capacity of the shell cross section. This indicates that a compression failure of concrete would initiate at the inside of the shell

4 In rectangular beam tests, strains 0.003 to 0.004 have been measured near maximum load carrying capacity. Many tests of beams and columns have shown that a satisfactorily accurate prediction of ultimate strength can be made using the crushing strain of 0.003 [4.4]. Limited test data are available for concrete strength of 220 psi (1.52 MPa). However, a more accurate determination of the concrete strain at maximum resistance was not made in this investigation because the effect on the interaction diagram is not large. 
at the rib locations and propagate along the circumference at a distance

$1 \mathrm{ft}(0.3 \mathrm{~m})$ above the bottom of the panel.

The locations of lap splices of the horizontal bars were not known for the cross section resisting hoop forces (hereafter referred to as the vertical cross section). Hence, two interaction diagrams were prepared depending on the maximum stress that can be developed in the steel. If lap splices of the bars are a sufficient distance away from a section being considered, the steel can develop yield (60 ksi, $414 \mathrm{MPa}$ ). For cross sections where lap splices occurred, the maximum stress that can be developed is limited by the length of the splice $(40.7 \mathrm{ks}, 281 \mathrm{MPa})$. The interaction diagrams obtained using these two steel stresses are shown in figure 7.6. These diagrams give the combinations of the hoop force and bending moment for failure of the cross section. In lift 28, the hoop force and associated bending moment are maximum at locations $C^{\prime}$ and $D$. They are plotted on the interaction diagram for these sections in figure 7.6 in which the point corresponding to location $C$ are shown in square and the corresponding to location $D$ in circle. It is seen in this figure that with point D lying considerably outside of the interaction curve a compression failure of concrete at the top of the shell would take place at the rib locations, points D, due to combined effect of high moment and axial force with or without the presence of lap splices. At the center of the panel, the shell section is subjected predominately to axial force.

\subsection{Strength of Shell Under Shear}

In the presence of axial compression the shear capacity of a reinforced concrete section increases. This complex interaction between shear and axial compression is not fully understood. In the absence of a suitable means of determining the shear strength of a shell section, the 
expressions 'in the ACI code [4.4] are used for insight into the strength of the she11 in shear. Those expressions are:

$$
v_{c}=2\left(1+\frac{N_{u}}{2000 A_{g}}\right) \sqrt{f_{c}^{\prime}} b d
$$

and not greater than

$$
v_{c}=3.5 \sqrt{1+\frac{N_{u}}{500 A_{g}}} \sqrt{f_{c}^{\prime}} b d
$$

where

$\mathrm{v}_{\mathrm{c}}=$ nominal shear strength provided by concrete

$\mathrm{N}_{\mathrm{u}}=$ axial normal load to cross section

$A_{g}=$ gross area of section

$\mathrm{f}_{c}^{\prime}=$ compressive strength of concrete in psi

$\mathrm{b}=$ width of section

$d=$ distance from extreme compression fiber to centroid of tension reinforcement.

Radial shear values in the vertical and horizonal cross sections of elements at the top of lift 28 are given in table 7.1 together with corresponding shear capacities computed in accordance with the above formulas. It may be seen in the table that the radial shears in the vertical and horizontal sections $\left(Q_{\theta}\right.$ and $\left.Q_{\phi}\right)$ are very high at the top of lift 28 along two ribs, while the radial shears at the center of the panel are either zero or very small. The radial shear in both the vertical and horizontal sections in the region near the top of lift 28 along the ribs, points $D$ in figure 7.4, exceed those values computed by the formulas. Although the calculated shear values may be influenced by the distribution of concentrated loads along a line, as discussed in section 6.5 , this clearly indicates that relatively high radial shear forces were present in this region of the shell. 


\subsection{Probable Mode of Failure}

It was shown in the previous sections that maximum stresses occur in the region of the panel bounded by the two ribs where cathead gantry no. 4 was located. The analysis showed that a compression fallure of concrete would have initiated in lift 28 along the circumference of the shell at a distance $1.0 \mathrm{ft}(0.3 \mathrm{~m})$ above the bottom of lift 28, the line through points BAB in figure 7.4. In addition, because both the large hoop forces and moments along the ribs, a band of the compression failure would also have spread along the rib of the panel. The presence of high radial shear in the panel could have further weakened the shell where combination of high axial loads and moments occurred and could have initiated the failure before the capacity in axial forces and moments was reached. Therefore, it may be concluded that the failure of lift 28 resulted from inadequate strength of the shell section where cathead no. 4 was located to resist the applied construction loads. The failure was brought about by compressive crushing of the concrete due to combinations of axial forces and moments, and/or cracking due to the high radial shear. 


\section{SUMMARY AND CONCLUSIONS}

As a result of the cooling tower construction collapse at Willow Island, West Virginia, the National Bureau of Standards (NBS) was requested by the Occupational Safety and Health Administration (OSHA) to carry out a detailed study aiming at the determination of the most probable cause of the collapse. In response to this request, NBS has undertaken a comprehensive field investigation, laboratory tests of construction assembly components and concrete specimens, and chemical analyses of concrete. In addition, mathematical models of the tower were prepared and analyzed by computer using shell analysis program. The findings presented in this report are based on the results of these field, laboratory and analytical studies with other information such as structural drawings of the tower and OSHA case records.

1. At the time of failure the concrete bucket was in transit from the base of the tower to cathead no. 4. The measured length of the hoist cable indicated that the bucket was about $60 \mathrm{ft}(16.4 \mathrm{~m})$ below the cathead beam. This also agrees with eyewitness accounts. Therefore, it is believed that the concrete bucket did not hit the cathead to cause it to fail.

2. Although the hoist cables for catheads no. 4 and 5 were broken, field observations and the laboratory test indicate that the breakage of the cables occurred after the onset of collapse of lift 28. Thus, the breakage of the cables did not trigger the failure. 
3. Field and laboratory investigations revealed that the major components of the hoisting, scaffolding and formwork systems did not fail prior to the collapse. Thus, the collapse did not initiate due to any component failure of these systems.

4. Based on the results of field cured cylinder tests, the compressive strength of concrete of that part of lift 28 where cathead no. 4 was located was estimated to be about 220 psi (1.52 $\mathrm{MPa}$ ) at the time of the collapse.

5. The analysis of the shell as well as eyewitness accounts indicated that the collapse initiated in lift 28 at the area where cathead no. 4 was located. The analysis showed that calculated stress resultants at several points in this area equaled or exceeded the strength of the shell in compression, bending and shear. Failure at any of these points would have propagated causing the collapse of lift 28 .

6. These results of the analysis indicate that the most probable cause of the collapse was due to the imposition of construction loads on the shell before the concrete of lift 28 had gained adequate strength to support these loads. 


\section{ACKNOWLEDGMENTS}

The authors acknowledge the contributions made by the following persons:

Dr. E. 0. Pfrang provided technical guidance and constructive criticism.

Dr. E. V. Leyendecker, Mr. J. R. Harris and Dr. B. Ellingwood critically reviewed the report.

Mr. R. Williams coordinated the laboratory tests and Messrs. F. Rankin, J. Owens and T. Ruschell performed the tests.

Mr. C. Mullen coordinated graphic work and prepared figures.

Mrs. A. Salazar typed the several drafts of this report manuscript.

Mr. Ray Mele and Mr. John Day carried out the graphic work. 


\section{REFERENCES}

[4.1] 1978 Annual Book of ASTM Standards, Part 14, American Society of Testing and Materials, Philadelphia, PA 19103.

[4.2] 1978 Annual Book of ASTM Standards, Part 13, American Society of Testing and Materials, Philadelphia, PA 19103.

[4.3] Lew, H. S. and Reichard, T. M., "Mechanical Properties of Concrete at Early Ages," Journal of the American Concrete Institute, Vol 75, American Concrete Institute, Detroit, Michigan, October 1978.

[4.4] ACI 318-77, "Building Code Requirements for Reinforced Concrete," American Concrete Institute, Detroit, Michigan, 1977.

[6.1] Harrison, H. B., "Iterative Nonlinear Structural Analysis," Journal of Structural Division, American Society of Civil Engineers, New York, NY, July 1976.

[6.2] Basu, P. K. and Gould, P. L., "SHORE-III - Shell of Revolution Finite Element Program Users' Manual," Research Report No. 49, Structural Division, Washington University, St. Louis, September 1977.

[6.3] Bathe, K. J., Wilson, E. L., and Peterson, F. E., "SAP IV Structural Analysis Program for Static and Dynamic Response of Linear Systems," Earthquake Engineering Research Center Report No. EERC 73-11, College of Engineering, University of California, Berkeley, April 1974.

[6.4] Winter, George, Urquhart, L. C., 0'Rourke,"C. E., and Nilson, Arthur H., "Design of Concrete Structures", McGraw-Hill Company, New York, Y.Y., 1973. 
[7.1] Orangun, C. O., Jirsa, J. O. and Breen, J. E., "A Reevaluation of Test Data on Development Length and Splices," Journal of the American Concrete Institute, Vo1. 74, American Concrete Institute, Detroit, Michigan, March 1977.

[7.2] Kupfer, H., Hilsdorf, H. K., and Rusch, H., "Behavior of Concrete Under Biaxial Stress," Journal of the American Concrete Institute, Vol. 66, American Concrete Institute, Detroit, Michigan, August 1969.

[8.1] Department of Labor, Bureau of Labor Standards, "Safety and Health Regulations for Construction," (29 CFR part 1926), Washington, D.C. 
TABLES AND FIGURES 


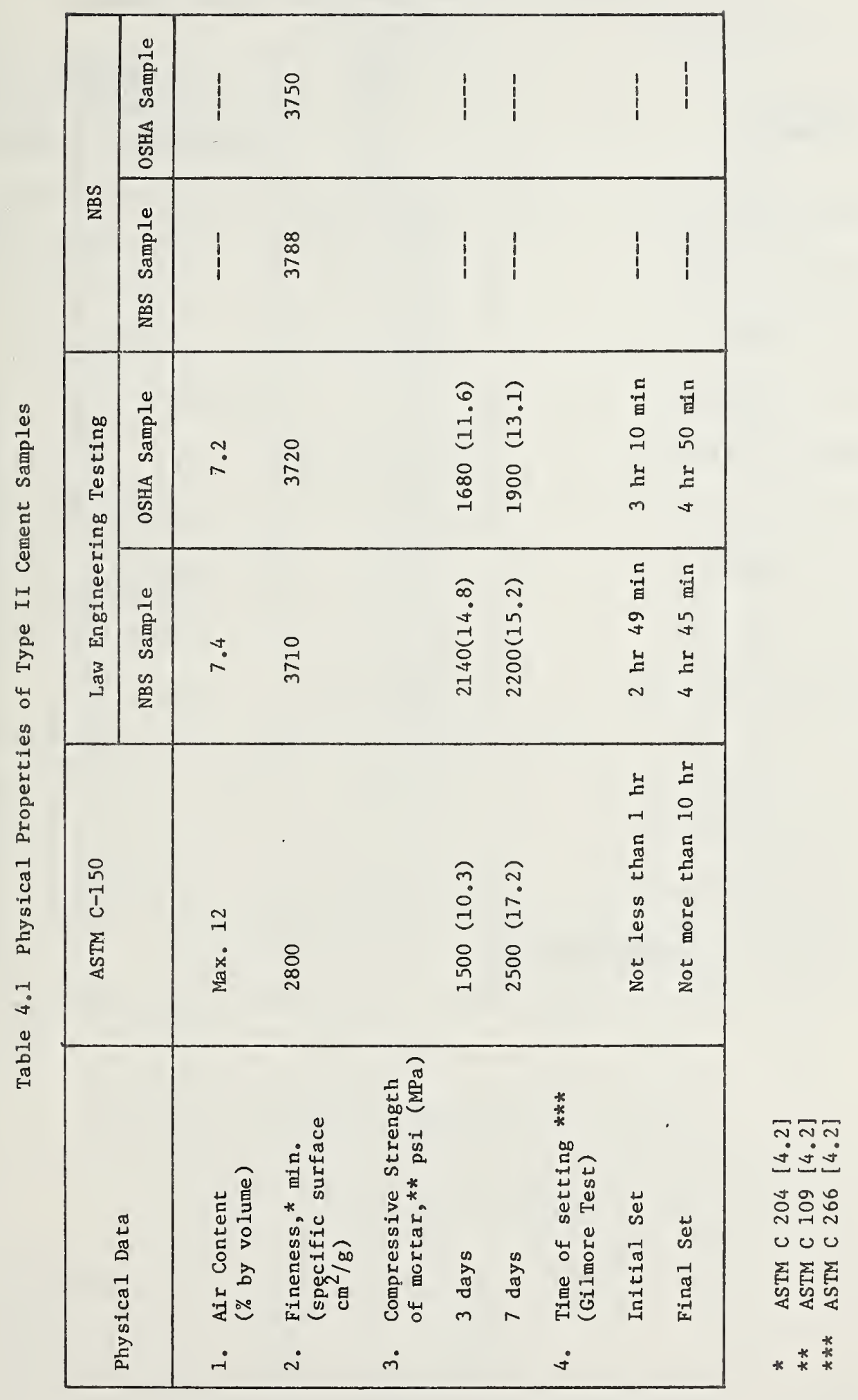


Tabie 4,2 Chemical Properties of Type II Cement

\begin{tabular}{|c|c|c|c|}
\hline \multirow{2}{*}{$\begin{array}{l}\text { Chemical } \\
\text { Elements }\end{array}$} & \multirow{2}{*}{$\begin{array}{c}\text { ASTM } \\
\text { C } 150 \\
\%\end{array}$} & \multicolumn{2}{|c|}{ Wet Chemical Analysis } \\
\hline & & $\underset{\%}{\text { NBS Sample }}$ & $\begin{array}{c}\text { OSHA Sample } \\
\%\end{array}$ \\
\hline Silicon Dioxide & Min. 21.0 & 20.6 & 20.0 \\
\hline Aluminum Oxide & $\operatorname{Max} .6 .0$ & 5.3 & 5.2 \\
\hline Ferric Oxide & $\operatorname{Max} \cdot 6.0$ & 3.0 & 3.9 \\
\hline Calcium Oxide & -- & 64.1 & 63.5 \\
\hline Magnesium Oxide & $\operatorname{Max} \cdot 6.0$ & 2.4 & 2.1 \\
\hline Sulfur Trioxide & $\operatorname{Max} .3 .0$ & 2.1 & 2.0 \\
\hline Total Alkalies & -- & 0.38 & 0.44 \\
\hline Loss on Ignition & $\operatorname{Max} .3 .0$ & 1.2 & 1.6 \\
\hline Insoluble Residue & $\operatorname{Max} \cdot 0.75$ & 0.22 & 0.25 \\
\hline Tricalcium Silicate & -- & 60 & 60 \\
\hline Dicalcium Silicate & -- & 14 & 12 \\
\hline Tricalcium Aluminate & $\operatorname{Max} .8 .0$ & 7.1 & 7.1 \\
\hline Tetracalcium Alumioferrite & -- & 9 & 12 \\
\hline
\end{tabular}


Table 4.3 Element Analysis of Flyash

\begin{tabular}{|lcc|}
\hline Element & $\begin{array}{c}\text { NBS Sample } \\
(\text { in } \%)\end{array}$ & $\begin{array}{c}\text { OSHA Sample } \\
\text { (in \%) }\end{array}$ \\
\hline Aluminum & 12.8 & 11.3 \\
Boron & 0.05 & 0.05 \\
Barium & 0.15 & 0.20 \\
Carbon & 0.50 & 1.30 \\
Calcium & 2.00 & 3.00 \\
Chromium & 0.01 & 0.01 \\
Copper & 0.01 & 0.01 \\
Iron & 9.8 & 10.5 \\
Potassium & 2.00 & 2.00 \\
Lithium & 0.15 & 0.12 \\
Magnesium & 2.00 & 2.00 \\
Manganese & 0.05 & 0.05 \\
Sodium & 0.30 & 0.30 \\
Nickel & 0.01 & 0.01 \\
Rubidium & 0.01 & 0.01 \\
Silicon & 20.9 & 20.7 \\
Strontium & 0.07 & 0.10 \\
Titanium & 0.50 & 0.50 \\
\hline
\end{tabular}

Table 4.4 Chemical Composition of Fly Ash

\begin{tabular}{|l|c|c|c|}
\hline & NBS Sample & OSHA Sample & ASTM C 618 \\
\hline Aluminum Oxide & 24.1 & 21.3 & -- \\
Iron Oxide & 14.0 & 14.9 & -- \\
Silicon Dioxide & 44.6 & 44.2 & - \\
\hline Sum & 82.8 & 80.5 & 70.0 \\
\hline
\end{tabular}



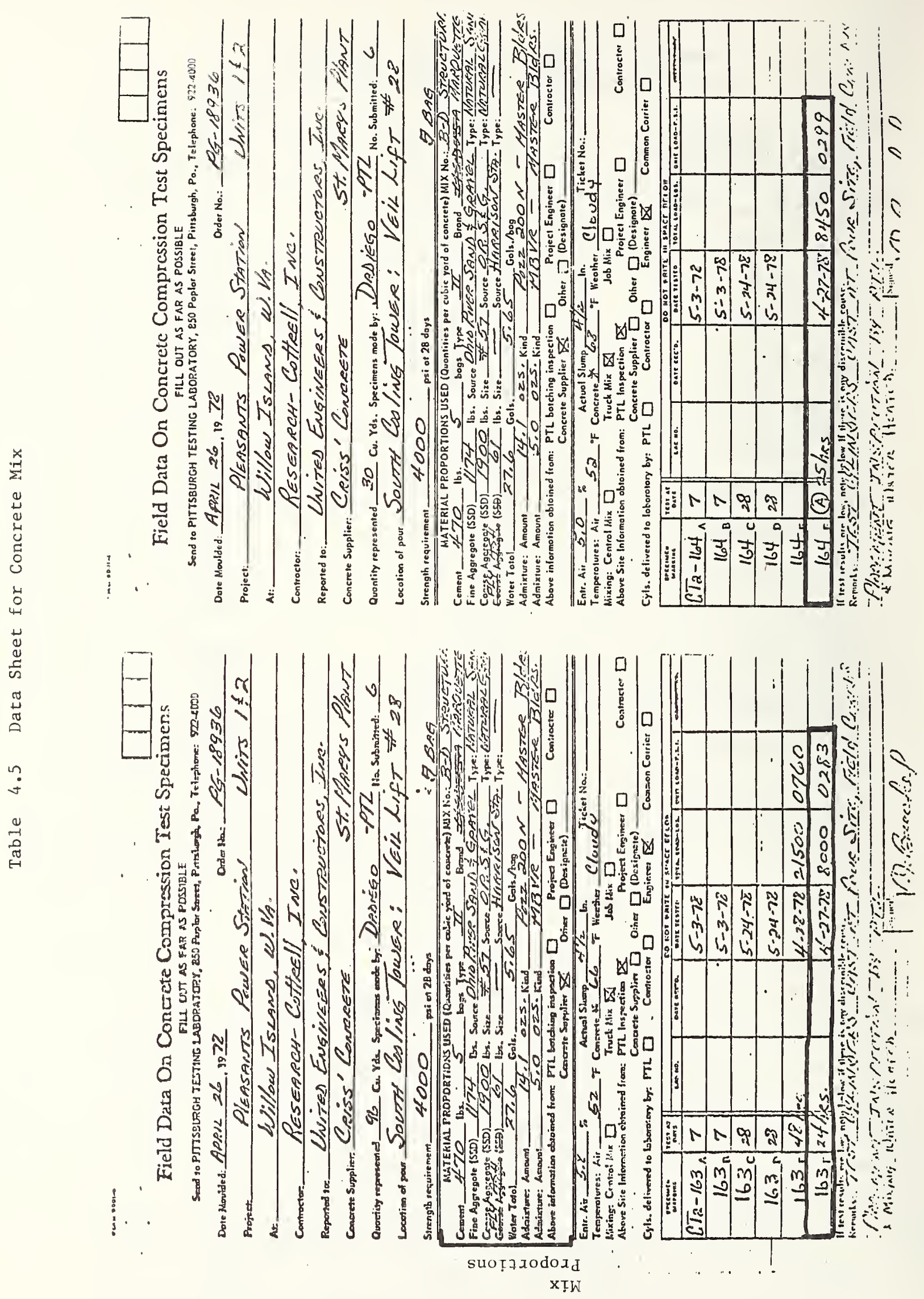
Table 4.6 Data on Fresh Concrete

\begin{tabular}{|c|c|c|c|}
\hline & & Range & Average \\
\hline & $\begin{array}{l}\text { Unit weight of Concrete } \\
1 \mathrm{~b} / \mathrm{ft}^{3}\left(\mathrm{~kg} / \mathrm{m}^{3}\right)\end{array}$ & $\begin{array}{l}140.5-144.4 \\
(2251-2313)\end{array}$ & $\begin{array}{r}143.1 \\
(2292)\end{array}$ \\
\hline & $\begin{array}{l}\text { Slump } \\
\text { in }(\mathrm{mm})\end{array}$ & $\begin{aligned} 6 & -9 \\
(152 & -229)\end{aligned}$ & $\begin{array}{c}7.4 \\
(188)\end{array}$ \\
\hline & $\underset{\%}{\text { Air }}$ Content & $4.5-5.9$ & 5.1 \\
\hline 4. & $\begin{array}{l}\text { Temperature of Concrete } \\
\text { at the Time of Pour } \\
{ }^{\circ} \mathrm{F}\left({ }^{\circ} \mathrm{C}\right)\end{array}$ & $\begin{array}{c}66.3-66.9 \\
(17.2-20.6)\end{array}$ & $\begin{array}{c}66.4 \\
(19.1)\end{array}$ \\
\hline
\end{tabular}

Table 4.7 Results of Tension Tests of Cables

\begin{tabular}{|c|cc|cc|}
\hline & \multicolumn{2}{|c|}{ Hoist End Section } & \multicolumn{2}{|c|}{ Drum End Section } \\
\hline 1 & $28.53 \mathrm{kip}(126.91 \mathrm{kN})$ & $26.55 \mathrm{kip}(118.10 \mathrm{kN})$ \\
2 & 26.82 & $(119.30)$ & 27.00 & $(120.01)$ \\
3 & 27.20 & $(120.99)$ & 26.20 & $(116.54)$ \\
4 & 27.75 & $(123.44)$ & 27.45 & $(122.10)$ \\
5 & 27.40 & $(121.88)$ & 27.78 & $(123.57)$ \\
\hline \multirow{2}{*}{ Ave rage } & $27.54 \mathrm{kip}(122.50 \mathrm{kN})$ & $27.00 \mathrm{kip}(120.01 \mathrm{kN})$ \\
\hline
\end{tabular}


Table 6.1 Forces and Reactions Induced by Hoisting Loads (for load case 5)

\begin{tabular}{|c|c|c|c|c|}
\hline & \multicolumn{2}{|c|}{ (a) } & \multicolumn{2}{|c|}{ (b) } \\
\hline Impact Factor & \multicolumn{2}{|c|}{$0 \%$} & \multicolumn{2}{|c|}{$100 \%$} \\
\hline $1 b^{W_{B}}(\mathrm{~kg})$ & \multicolumn{2}{|c|}{$\begin{array}{c}2900 \\
(1315)\end{array}$} & \multicolumn{2}{|c|}{$\begin{array}{c}5800 \\
(2630)\end{array}$} \\
\hline $\mathrm{ft}{ }^{\mathrm{s}}$ ?m) & \multicolumn{2}{|c|}{$\begin{array}{l}219.17 \\
(66.80)\end{array}$} & \multicolumn{2}{|c|}{$\begin{array}{l}219.17 \\
(66.80)\end{array}$} \\
\hline $\begin{array}{l}\text { Condition of } \\
\text { Support G }\end{array}$ & Fixed & Elastic & Fixed & Elastic \\
\hline$F_{D} b_{(N)}$ & $\begin{array}{c}2460.14 \\
(10943.24)\end{array}$ & $\begin{array}{c}2451.69 \\
(10905.66)\end{array}$ & $\begin{array}{c}4928.35^{\prime} \\
(21922.31)\end{array}$ & $\begin{array}{c}4931.73 \\
(21937.42)\end{array}$ \\
\hline $\begin{aligned} \mathrm{T} & \\
1 \mathrm{~b} & (\mathrm{~N})\end{aligned}$ & $\begin{array}{c}5378.64 \\
(23925.37)\end{array}$ & $\begin{array}{c}4772.26 \\
(21228.06)\end{array}$ & $\begin{array}{c}8860.59 \\
(39413.85)\end{array}$ & $\begin{array}{c}7670.59 \\
(34120.47)\end{array}$ \\
\hline $1 b^{F}(N)$ & $\begin{array}{c}11311.67 \\
(50316.80)\end{array}$ & $\begin{array}{c}10131.61 \\
(45067.63)\end{array}$ & $\begin{array}{c}18760.19 \\
(83449.45)\end{array}$ & $\begin{array}{c}16339.25 \\
(72680.58)\end{array}$ \\
\hline${ }_{1 b}^{A_{P}}(N)$ & $\begin{array}{c}18630.78 \\
(82873.81)\end{array}$ & $\begin{array}{c}16913.27 \\
(75233.95)\end{array}$ & $\begin{array}{c}31858.23 \\
(141712.41)\end{array}$ & $\begin{array}{r}28461.90 \\
(126604.79\end{array}$ \\
\hline${ }_{1 b}^{B} P(N)$ & $\begin{array}{c}296.91 \\
(1320.72)\end{array}$ & $\begin{array}{c}496.14 \\
(2206.94)\end{array}$ & $\begin{array}{c}1213.33 \\
(5397.15)\end{array}$ & $\begin{array}{c}1602.59 \\
(7128.67)\end{array}$ \\
\hline $1 \mathrm{~b}_{\mathrm{Z}}(\mathrm{N})$ & $\begin{array}{c}3453.00 \\
(15359.70)\end{array}$ & $\begin{array}{c}3134.69 \\
(13943.79)\end{array}$ & $\begin{array}{c}5904.57 \\
(26264.83)\end{array}$ & $\begin{array}{c}5275.10 \\
(23464.81)\end{array}$ \\
\hline $1 b^{B}(N)$ & $\begin{array}{c}57.71 \\
(256.71)\end{array}$ & $\begin{array}{c}96.44 \\
(428.99)\end{array}$ & $\begin{array}{c}235.84 \\
(1049.07)\end{array}$ & $\begin{array}{c}311.51 \\
(1385.67)\end{array}$ \\
\hline $\mathrm{ft}^{\mathrm{L}} \mathrm{l}(\mathrm{m})$ & $\begin{array}{c}95.0 \\
(29.0)\end{array}$ & $\begin{array}{l}100 \\
(30.5)\end{array}$ & $\begin{array}{c}95.0 \\
(29.0)\end{array}$ & $\begin{array}{l}100 \\
(30.5)\end{array}$ \\
\hline $\mathrm{ft}^{\mathrm{L}_{2}}(\mathrm{~m})$ & $\begin{array}{l}123.56 \\
(37.66)\end{array}$ & $\begin{array}{l}118.56 \\
(40.41)\end{array}$ & $\begin{array}{l}123.56 \\
(37.66)\end{array}$ & $\begin{array}{l}118.56 \\
(40.41)\end{array}$ \\
\hline
\end{tabular}


Table 6.2a Stress Resultants in Lift 28 for Sum of Load Cases at Angles of 0 and 1.875 Degrees

Sum of Load Cases: $12,3,4,5$ $\underline{\theta}=0^{\circ}$

\begin{tabular}{|c|c|c|c|c|c|c|c|c|c|c|}
\hline $\begin{array}{l}\text { Point of } \\
\text { Load } \\
\text { Application }\end{array}$ & Location & $\begin{array}{c}\text { Top } \\
\text { of } \\
\text { Element }\end{array}$ & Node & $\begin{array}{c}N_{\phi} \\
k / f t\end{array}$ & $\begin{array}{c}N_{\theta} \\
k / f t\end{array}$ & $\begin{array}{r}N_{\theta \phi} \\
k / f t\end{array}$ & $\begin{array}{c}M_{\phi} \\
1 n-k / f t\end{array}$ & $\begin{array}{c}M_{\theta} \\
\text { In-k/ft }\end{array}$ & $\begin{array}{c}Q_{\phi} \\
k / f t\end{array}$ & $\begin{array}{c}Q_{\theta} \\
k / f t\end{array}$ \\
\hline $\begin{array}{l}\mathrm{I} \\
\mathrm{K} \\
\mathrm{L} \\
\mathrm{J}\end{array}$ & $\begin{array}{l}\text { TL } 28 \\
\text { TL } 27\end{array}$ & $\begin{array}{l}1 \\
2 \\
3 \\
4 \\
5 \\
6 \\
7 \\
8\end{array}$ & $\begin{array}{l}1 \\
2 \\
3 \\
4 \\
5 \\
6 \\
7 \\
8\end{array}$ & $\begin{array}{r}0.000 \\
0.034 \\
-0.047 \\
-0.114 \\
-0.127 \\
-0.099 \\
0.023 \\
0.102\end{array}$ & $\begin{array}{l}-27.11 \\
-25.81 \\
-22.95 \\
-18.64 \\
-14.94 \\
-11.72 \\
-9.46 \\
-13.18\end{array}$ & $\begin{array}{l}0.0 \\
0.0 \\
0.0 \\
0.0 \\
0.0 \\
0.0 \\
0.0 \\
0.0\end{array}$ & $\begin{array}{r}0.000 \\
1.912 \\
8.804 \\
23.532 \\
36.840 \\
47.892 \\
54.312 \\
60.768\end{array}$ & $\begin{array}{r}-2.449 \\
-1.255 \\
-3.632 \\
-7.699 \\
-10.286 \\
-11.707 \\
-11.344 \\
-24.696\end{array}$ & $\begin{array}{l}0.0000 \\
0.0295 \\
0.7103 \\
0.9382 \\
0.9345 \\
0.8683 \\
0.9559 \\
0.4627\end{array}$ & $\begin{array}{l}0.0 \\
0.0 \\
0.0 \\
0.0 \\
0.0 \\
0.0 \\
0.0 \\
0.0\end{array}$ \\
\hline
\end{tabular}

Sum of Load Cases: $1,2,3,4,5$ $\theta=1.875^{\circ}$

\begin{tabular}{|c|c|c|c|c|c|c|c|c|c|c|}
\hline $\begin{array}{l}\text { Point of } \\
\text { Load } \\
\text { Application }\end{array}$ & Location & $\begin{array}{c}\text { Top } \\
\text { of } \\
\text { Element }\end{array}$ & Node & $\begin{array}{c}N_{\phi} \\
k / f t\end{array}$ & $\begin{array}{c}\mathrm{N}_{\theta} \\
\mathrm{k} / \mathrm{ft}\end{array}$ & $\begin{array}{l}N_{\theta \phi} \\
k / f t\end{array}$ & $\begin{array}{c}M_{\phi} \\
1 n-k / f t\end{array}$ & $\begin{array}{c}M_{\theta} \\
1 n-k / f t\end{array}$ & $\begin{array}{c}Q_{\phi} \\
k / f t\end{array}$ & $\begin{array}{c}Q_{\theta} \\
k / f t\end{array}$ \\
\hline $\begin{array}{l}\mathrm{I} \\
\mathrm{K}\end{array}$ & $\begin{array}{l}\text { TL } 28 \\
\text { TL } 27\end{array}$ & $\begin{array}{l}1 \\
2 \\
3 \\
4 \\
5 \\
6 \\
7 \\
8\end{array}$ & $\begin{array}{l}1 \\
2 \\
3 \\
4 \\
5 \\
6 \\
7 \\
8\end{array}$ & $\begin{array}{r}-0.001 \\
-5.341 \\
-3.644 \\
-1.869 \\
-0.814 \\
0.374 \\
-3.811 \\
-2.012\end{array}$ & $\begin{array}{l}-31.91 \\
-28.28 \\
-22.59 \\
-17.64 \\
-13.97 \\
-10.94 \\
-9.06 \\
-12.28\end{array}$ & $\begin{array}{r}0.000 \\
-1.122 \\
-1.276 \\
-1.362 \\
-1.671 \\
-1.343 \\
-0.792 \\
-1.387\end{array}$ & $\begin{array}{r}0.000 \\
-8.732 \\
18.492 \\
35.400 \\
49.908 \\
70.644 \\
89.520 \\
62.556\end{array}$ & $\begin{array}{r}-76.416 \\
-81.792 \\
-62.628 \\
-34.080 \\
-13.788 \\
3.307 \\
13.704 \\
5.300\end{array}$ & $\begin{array}{r}0.000 \\
8.594 \\
4.707 \\
3.234 \\
3.074 \\
2.322 \\
-3.506 \\
-1.526\end{array}$ & $\begin{array}{r}4.3880 \\
1.4400 \\
-0.5434 \\
0.2385 \\
0.1788 \\
-1.5720 \\
-0.5855 \\
1.6810\end{array}$ \\
\hline
\end{tabular}


Table 6.2 b Stress Resultants in Lift 28 for Sum of Load Cases at Angles of 0 and 1.875 Degrees

Sum of Load Cases: $1,2,3,4,5$ $\theta=0^{\circ}$

\begin{tabular}{|c|c|c|c|c|c|c|c|c|c|c|}
\hline $\begin{array}{l}\text { Point of } \\
\text { Load } \\
\text { Application }\end{array}$ & Location & $\begin{array}{l}\text { Top } \\
\text { of } \\
\text { Element }\end{array}$ & Node & $\begin{array}{c}\mathrm{N}_{\phi} \\
\mathrm{KN} / \mathrm{m}\end{array}$ & $\begin{array}{c}\mathrm{N}_{\theta} \\
\mathrm{KN} / \mathrm{m}\end{array}$ & $\begin{array}{l}\mathrm{N}_{\theta \phi} \\
\mathrm{KN} / \mathrm{m}\end{array}$ & $\begin{array}{c}\mathrm{M}_{\phi} \\
\mathrm{KN}-\mathrm{m} / \mathrm{m}\end{array}$ & $\begin{array}{c}\mathrm{M}_{\theta} \\
\mathrm{KN}-\mathrm{m} / \mathrm{m}\end{array}$ & $\begin{array}{c}\mathrm{Q}_{\phi} \\
\mathrm{KN} / \mathrm{m}\end{array}$ & $\begin{array}{c}\mathrm{Q}_{\theta} \\
\mathrm{KN} / \mathrm{m}\end{array}$ \\
\hline $\begin{array}{l}\mathrm{I} \\
\mathrm{K}\end{array}$ & $\begin{array}{l}\text { TL } 28 \\
\text { TL } 27\end{array}$ & $\begin{array}{l}1 \\
2 \\
3 \\
4 \\
5 \\
6 \\
7 \\
8\end{array}$ & $\begin{array}{l}1 \\
2 \\
3 \\
4 \\
5 \\
6 \\
7 \\
8\end{array}$ & $\begin{array}{r}0.002 \\
0.493 \\
-0.679 \\
-1.667 \\
-1.858 \\
-1.438 \\
0.342 \\
1.486\end{array}$ & $\begin{array}{l}-395.7 \\
-376.7 \\
-335.0 \\
-272.1 \\
-218.1 \\
-171.1 \\
-138.1 \\
-192.4\end{array}$ & $\begin{array}{l}0.00 \\
0.00 \\
0.00 \\
0.00 \\
0.00 \\
0.00 \\
0.00 \\
0.00\end{array}$ & $\begin{array}{r}0.000 \\
0.708 \\
3.263 \\
8.721 \\
13.653 \\
17.749 \\
20.128 \\
22.521\end{array}$ & $\begin{array}{l}-0.908 \\
-0.465 \\
-1.346 \\
-2.853 \\
-3.811 \\
-4.339 \\
-4.204 \\
-9.152\end{array}$ & $\begin{array}{r}0.000 \\
0.431 \\
10.368 \\
13.694 \\
13.640 \\
12.674 \\
13.952 \\
6.754\end{array}$ & $\begin{array}{l}0.00 \\
0.00 \\
0.00 \\
0.00 \\
0.00 \\
0.00 \\
0.00 \\
0.00\end{array}$ \\
\hline
\end{tabular}

Sum of Load Cases: 1, 2, 3, 4, 5 $\theta=1.875^{\circ}$

\begin{tabular}{|c|c|c|c|c|c|c|c|c|c|c|}
\hline $\begin{array}{l}\text { Point of } \\
\text { Load } \\
\text { Application }\end{array}$ & Location & $\begin{array}{c}\text { Top } \\
\text { of } \\
\text { Element }\end{array}$ & Node & $\begin{array}{l}\mathrm{N}_{\phi} \\
\mathrm{KN} / \mathrm{m}\end{array}$ & $\begin{array}{c}\mathrm{N}_{\theta} \\
\mathrm{KN} / \mathrm{m}\end{array}$ & $\begin{array}{l}\mathrm{N}_{\theta \phi} \\
\mathrm{KN} / \mathrm{m}\end{array}$ & $\begin{array}{c}\mathrm{M}_{\phi} \\
\mathrm{KN}-\mathrm{m} / \mathrm{m}\end{array}$ & $\begin{array}{c}\mathrm{M}_{\theta} \\
\mathrm{KN}-\mathrm{m} / \mathrm{m}\end{array}$ & $\begin{array}{c}\mathrm{Q}_{\phi} \\
\mathrm{KN} / \mathrm{m}\end{array}$ & $\begin{array}{c}\mathrm{Q}_{\theta} \\
\mathrm{KN} / \mathrm{m}\end{array}$ \\
\hline $\begin{array}{l}\mathrm{I} \\
\mathrm{K} \\
\\
\mathrm{L} \\
\mathrm{J}\end{array}$ & $\begin{array}{l}\text { TL } 28 \\
\text { TL } 27\end{array}$ & $\begin{array}{l}1 \\
2 \\
3 \\
4 \\
5 \\
6 \\
7 \\
8\end{array}$ & $\begin{array}{l}1 \\
2 \\
3 \\
4 \\
5 \\
6 \\
7 \\
8\end{array}$ & $\begin{array}{r}-0.01 \\
-77.95 \\
-53.19 \\
-27.28 \\
-11.88 \\
5.47 \\
-55.63 \\
-29.37\end{array}$ & $\begin{array}{l}-465.8 \\
-412.8 \\
-329.7 \\
-257.5 \\
-203.9 \\
-159.7 \\
-132.3 \\
-179.2\end{array}$ & $\begin{array}{r}0.00 \\
-16.38 \\
-18.62 \\
-19.88 \\
-24.39 \\
-19.60 \\
-11.56 \\
-20.25\end{array}$ & $\begin{array}{r}0.00 \\
-3.24 \\
6.85 \\
13.12 \\
18.50 \\
26.18 \\
33.18 \\
23.18\end{array}$ & $\begin{array}{r}-32.03 \\
-30.31 \\
-23.21 \\
-12.63 \\
-\quad 5.11 \\
1.23 \\
5.08 \\
1.96\end{array}$ & $\begin{array}{r}-0.00 \\
125.40 \\
68.70 \\
47.20 \\
44.67 \\
33.89 \\
-51.17 \\
-22.27\end{array}$ & $\begin{array}{r}64.05 \\
21.02 \\
-7.93 \\
3.48 \\
2.61 \\
-22.95 \\
-8.55 \\
24.54\end{array}$ \\
\hline
\end{tabular}


Table 7.1 Shear Forces in Lift 28

\begin{tabular}{|l|cc|cc|}
\hline $\begin{array}{l}\text { Loading Cond. } \\
1,2,3,4,5\end{array}$ & $Q_{\theta}$ & $\begin{array}{c}\text { Shear } \\
\text { Strength } \\
\text { (in pounds) }\end{array}$ & $Q_{\phi}$ & $\begin{array}{c}\text { Shear } \\
\text { Strength } \\
\text { (in pounds) }\end{array}$ \\
\hline At Center & 0 & 2539 & 30 & 2225 \\
\hline At Rib & 4388 & $2594^{*}$ & 8594 & $2286^{*}$ \\
\hline
\end{tabular}

* Capacity of the section is less than shear force.

$Q_{\theta}=$ Radial shear in the vertical cross section

$Q_{\phi}=$ Radial shear in the horizontal cross section

$1.0 \mathrm{lbf}=4.44822 \mathrm{~N}$ 


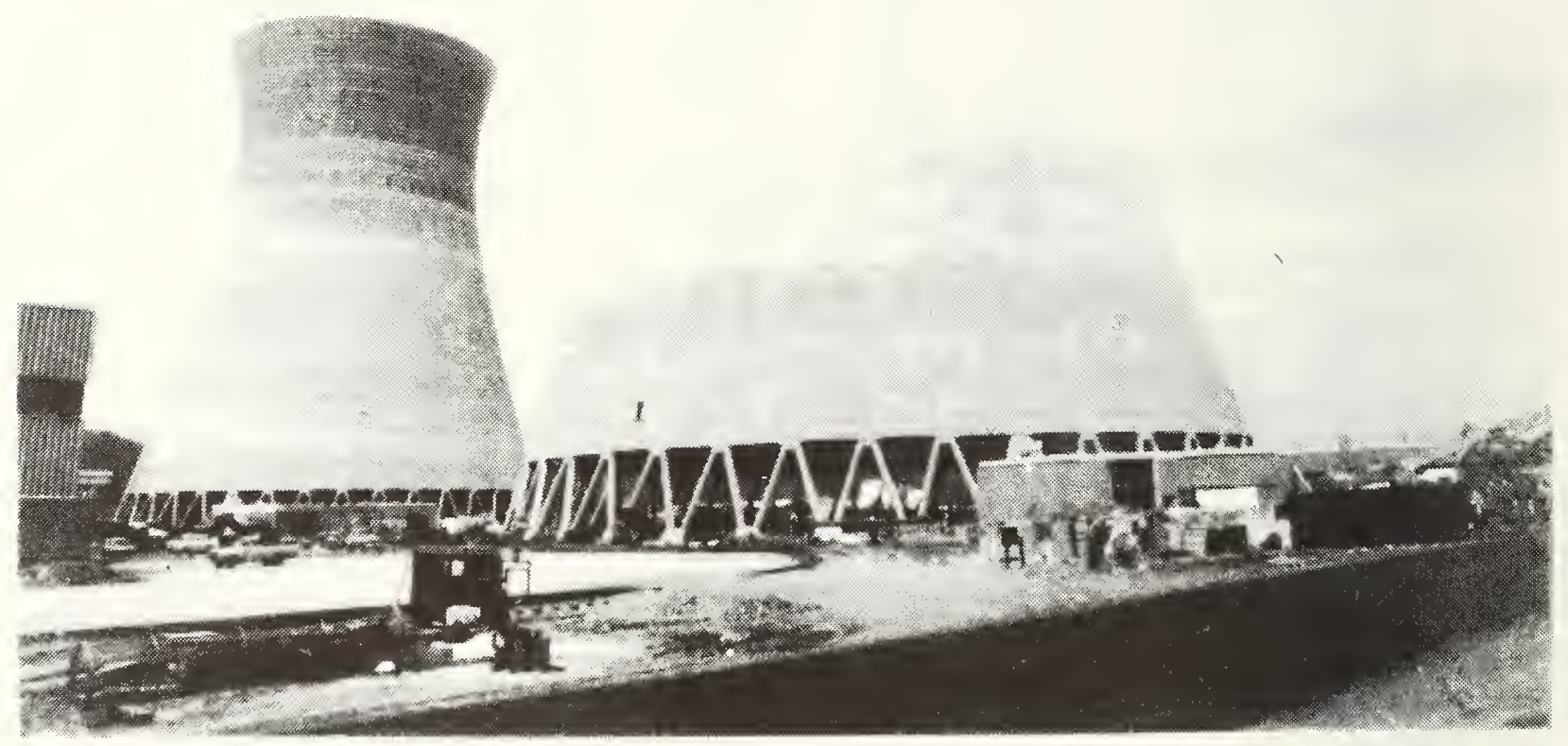

Figure 1.1 A General View Showing Completed Tower Unit No. 1 and Unit No. 2 

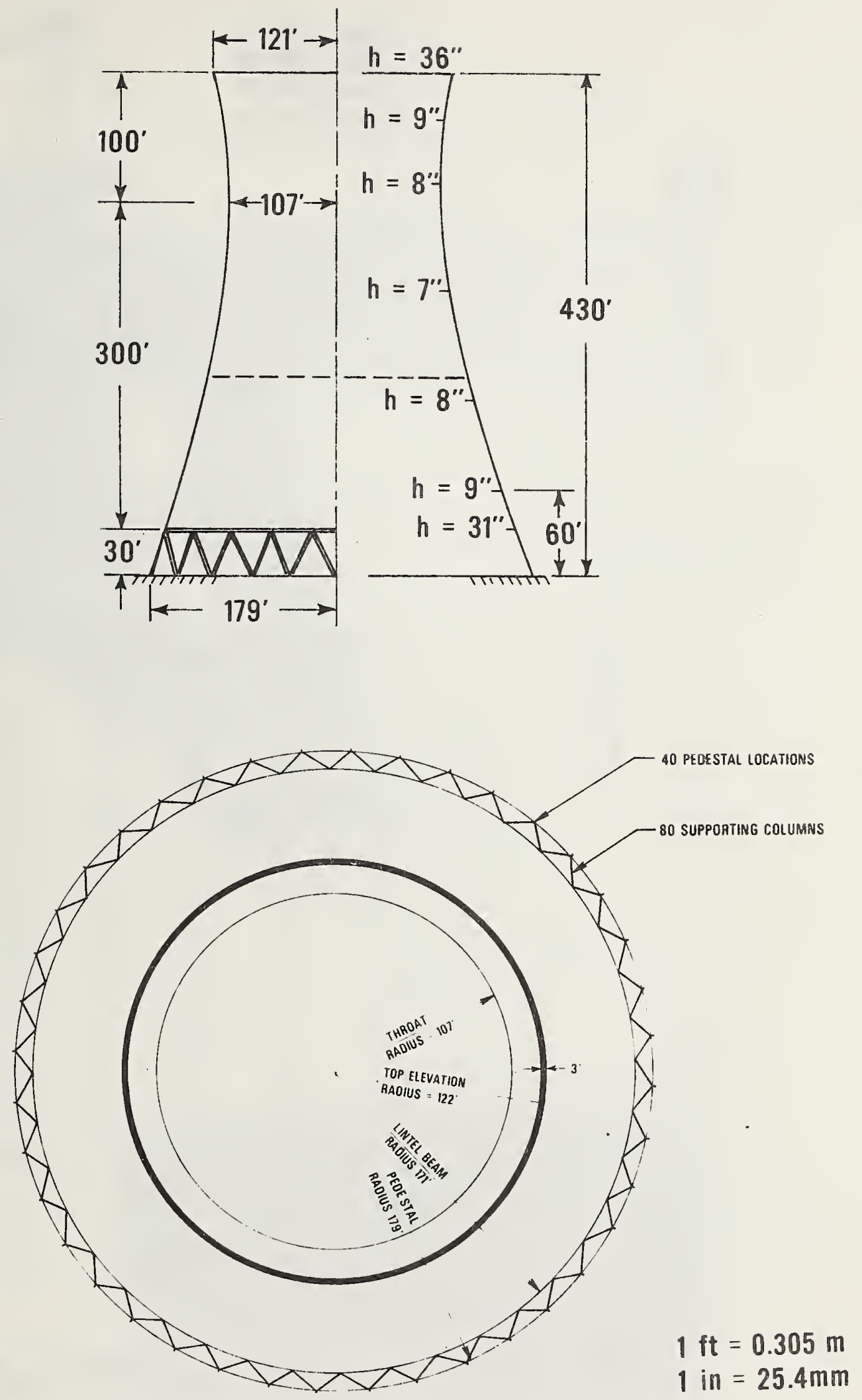

Figure 2.1 Elevation and Plan View of Cooling Tower Unit No. 2 
$4^{\prime}-7$ " MIN LAP FOR \#8

2'-9" MIN LAP FOR \#6

$2^{\prime}-3^{\prime \prime}$ MIN LAP FOR \#5

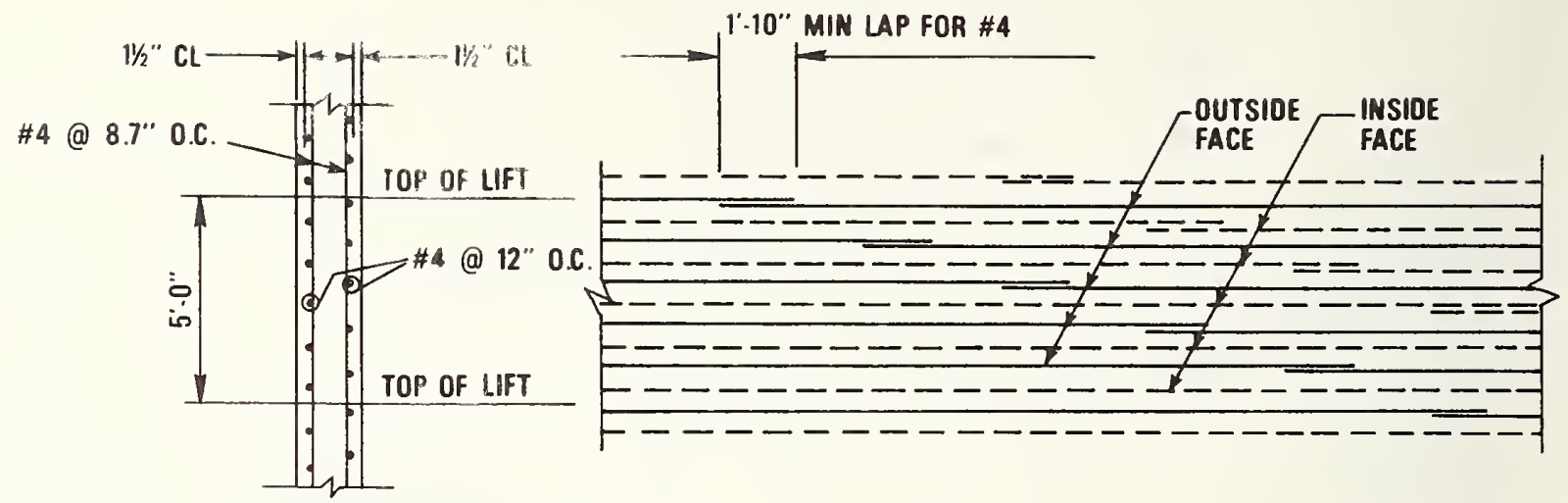

(a) Bar Sizes and Spacing for lift 28

(b) Splice Detall for Horizontal Bars
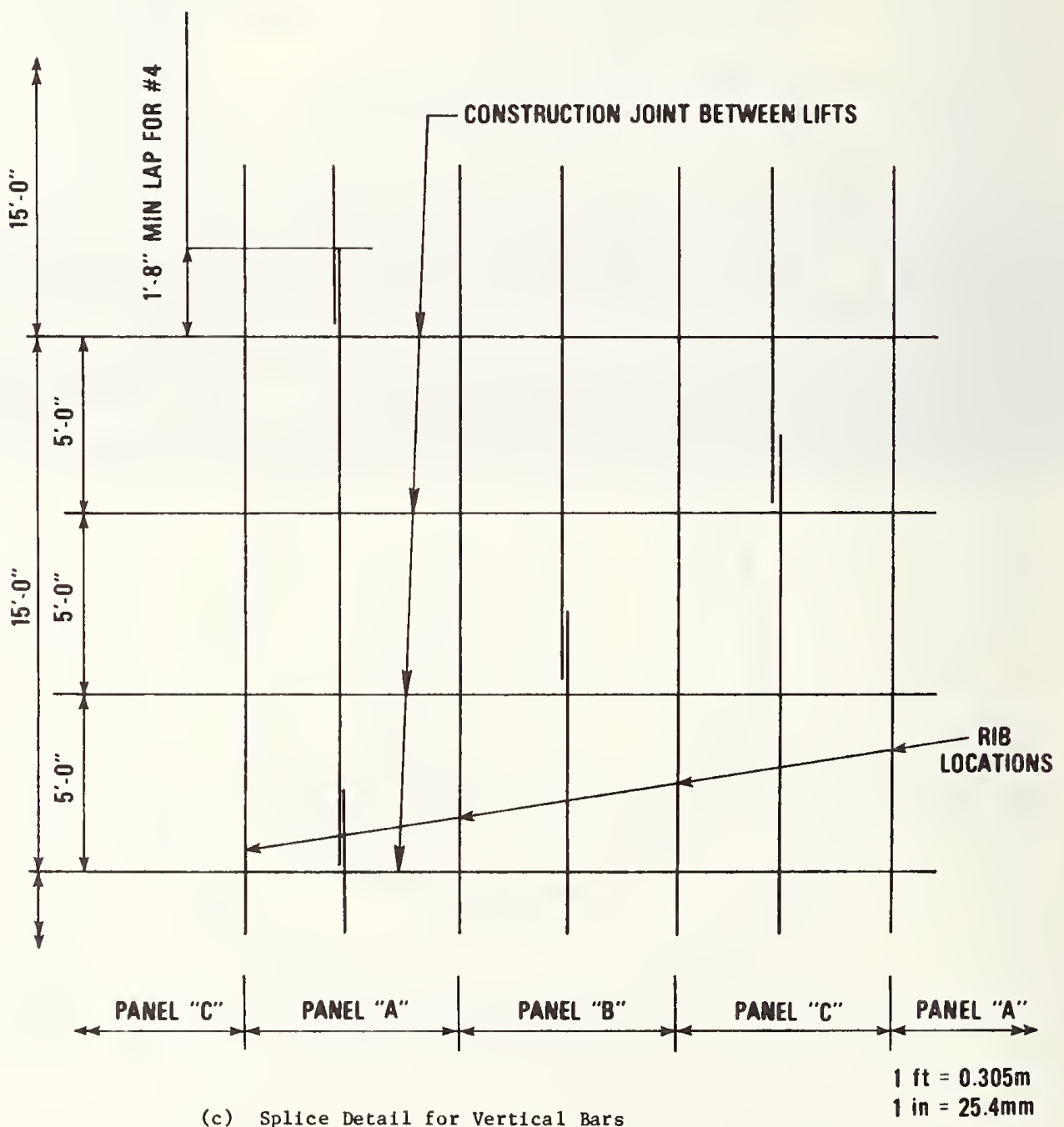


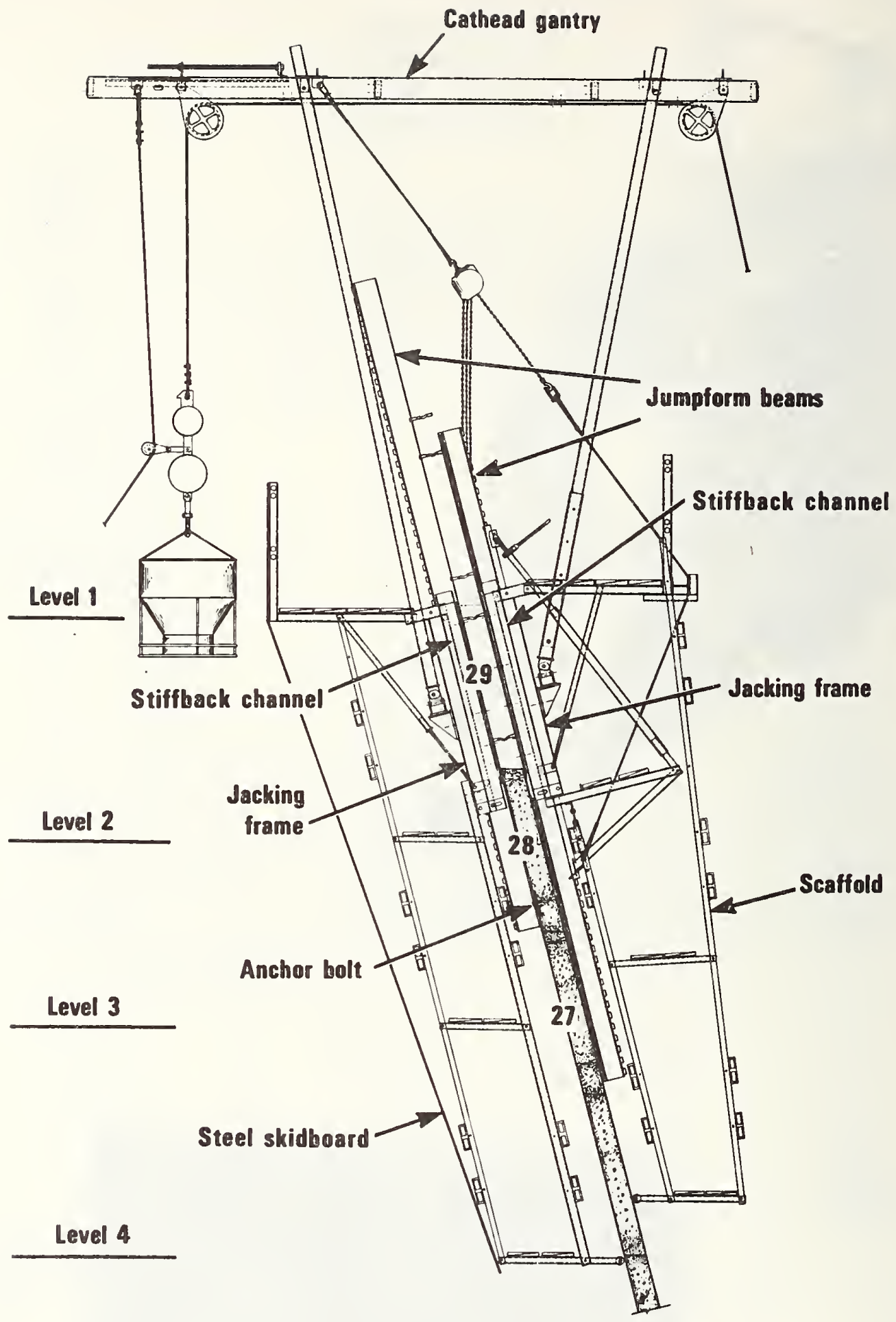

Figure 2.5 A Cross Section through the Formwork and Scaffolding Systems 


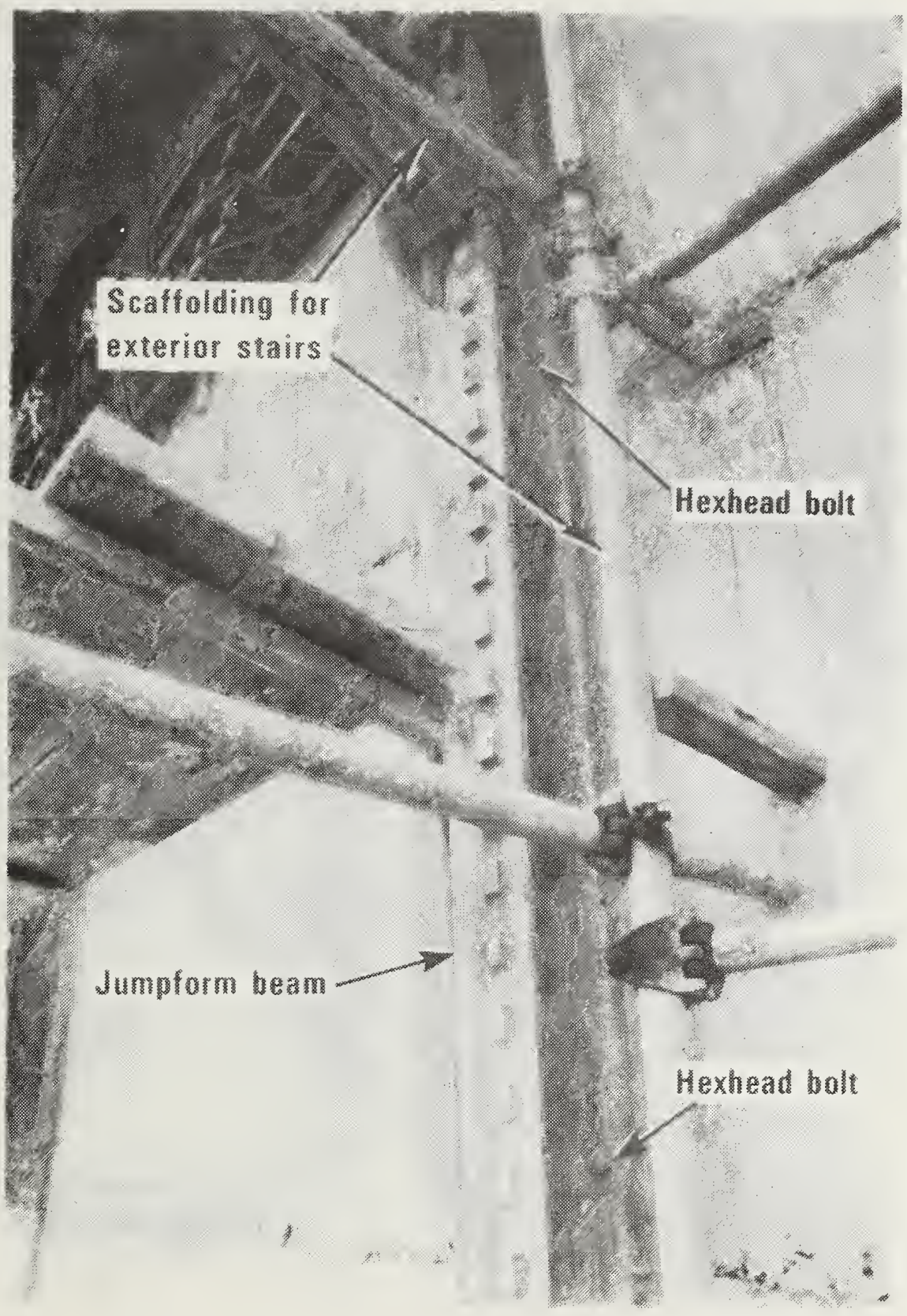

Figure 2.6 Attachment of Jumpform Beam to the Exterior of She11 


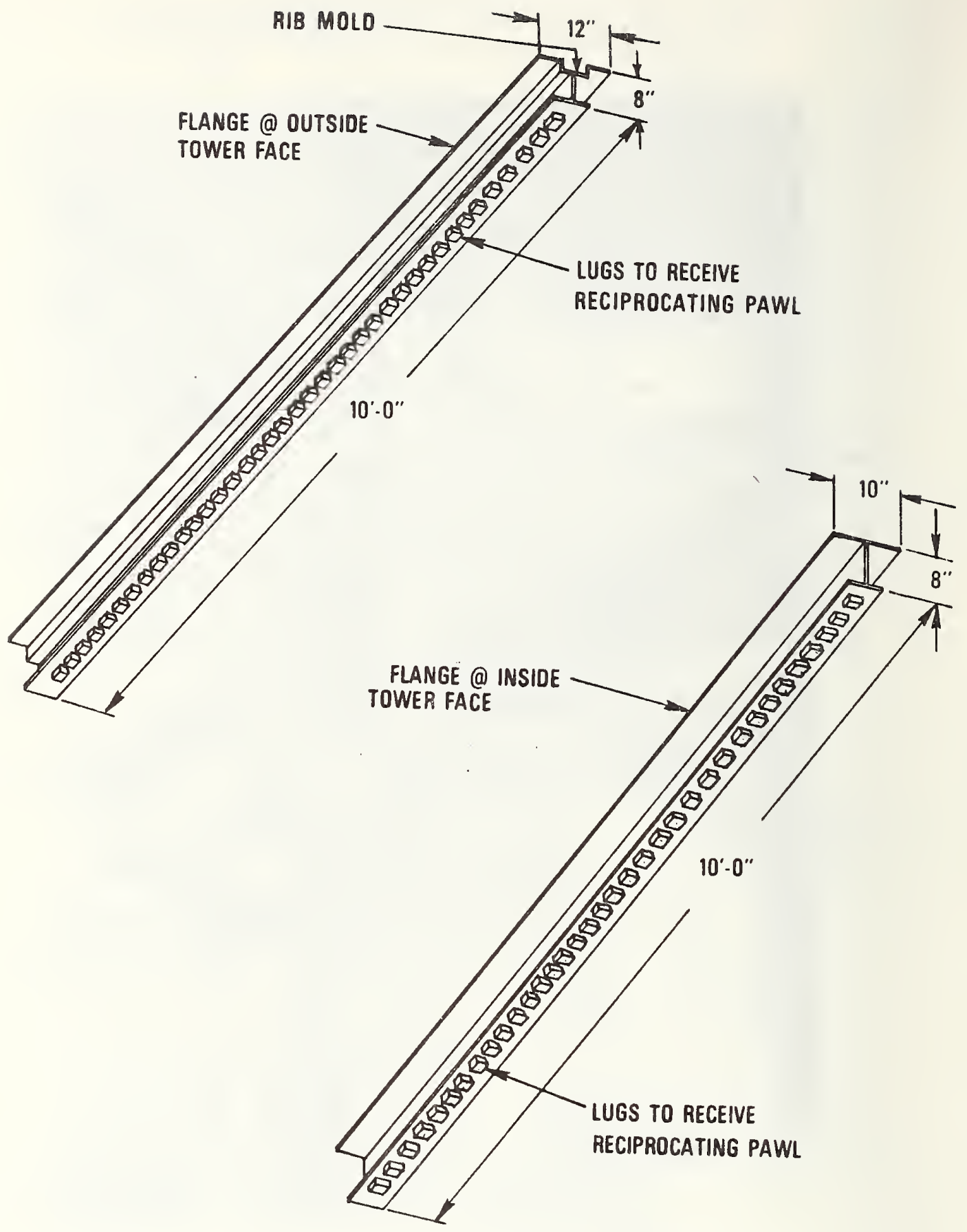

Figure 2.7 Jumpform Beam Detail 


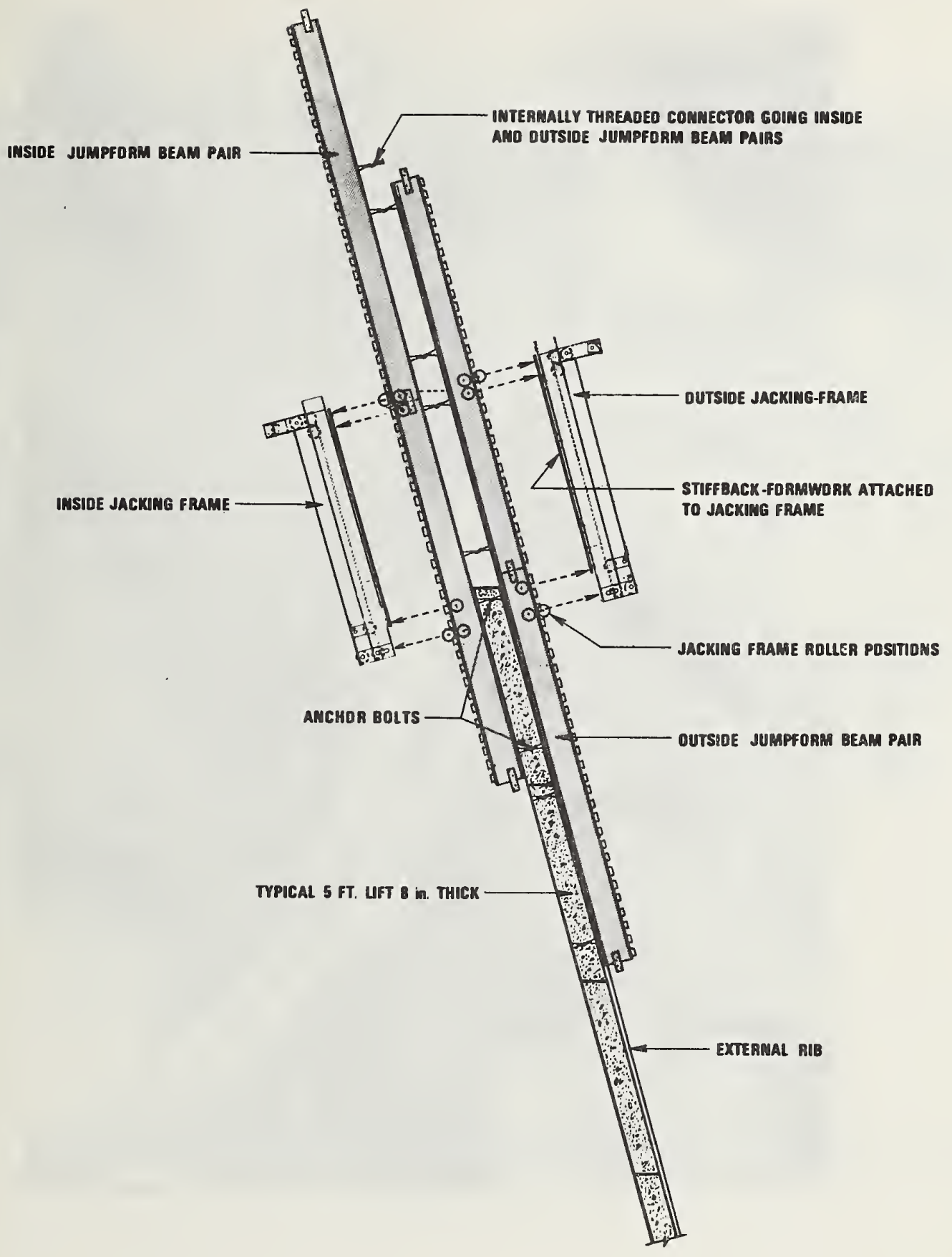

Figure 2.8 Attachment Deta11 of Jumpform Beams and Jack1ng Frames 


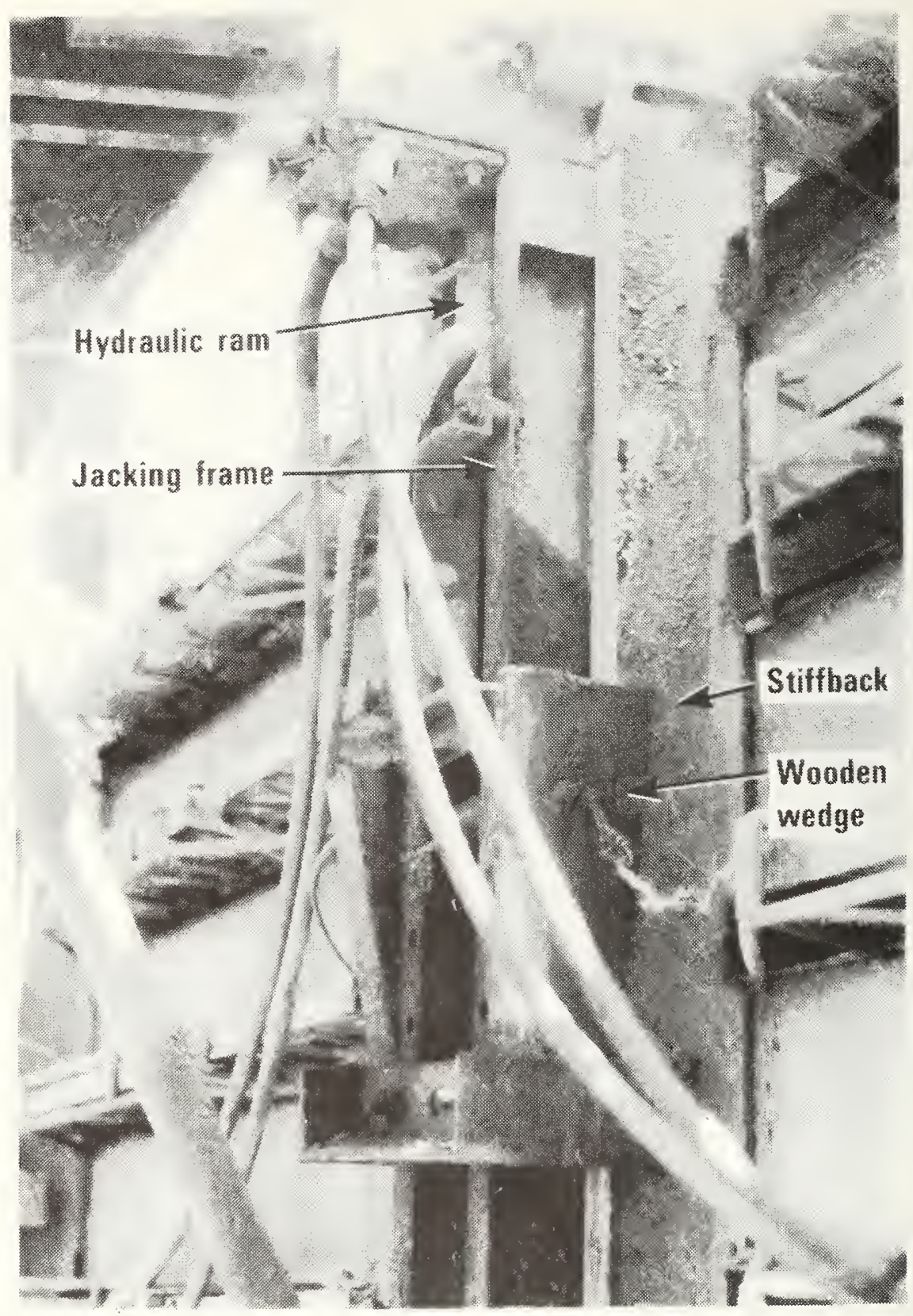

Figure 2.9 Jacking Frame Assembly 


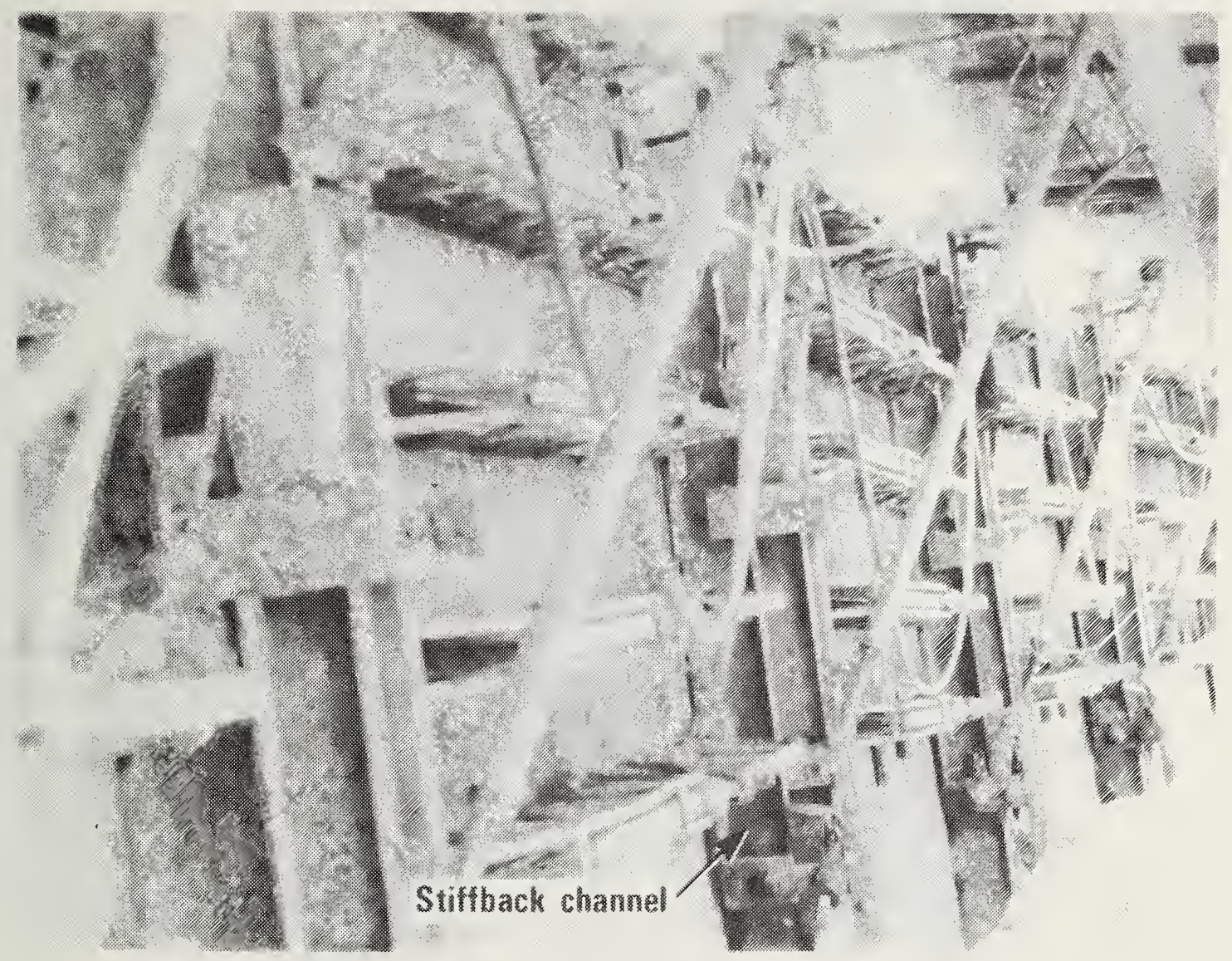

Figure 2.10 Formwork Support System

(Note five levels of adjustable joists are used per lift.) 


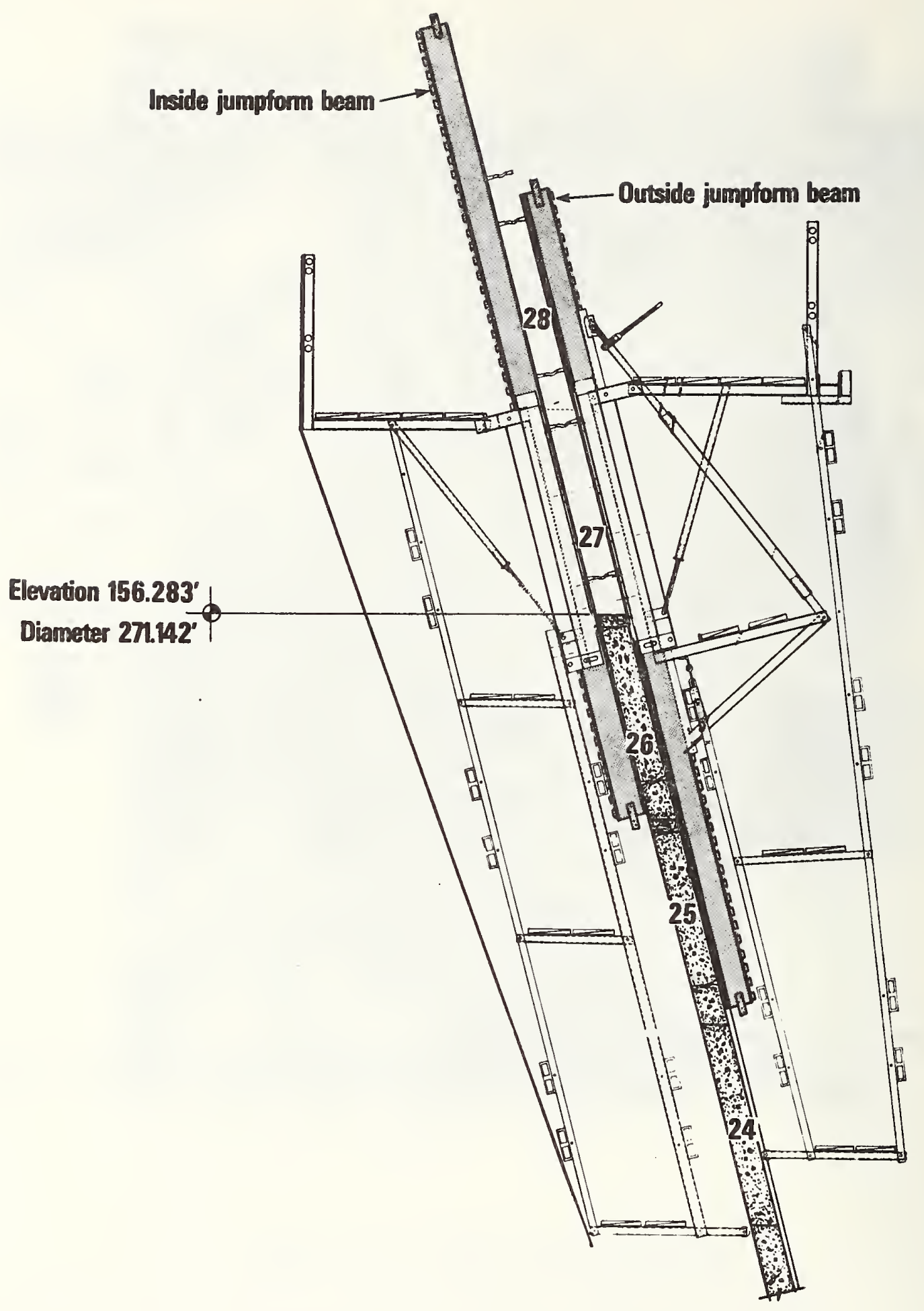

F1gure 2.11 Position of Jumpform Beams prior to Concrete Placement for Lift 27 


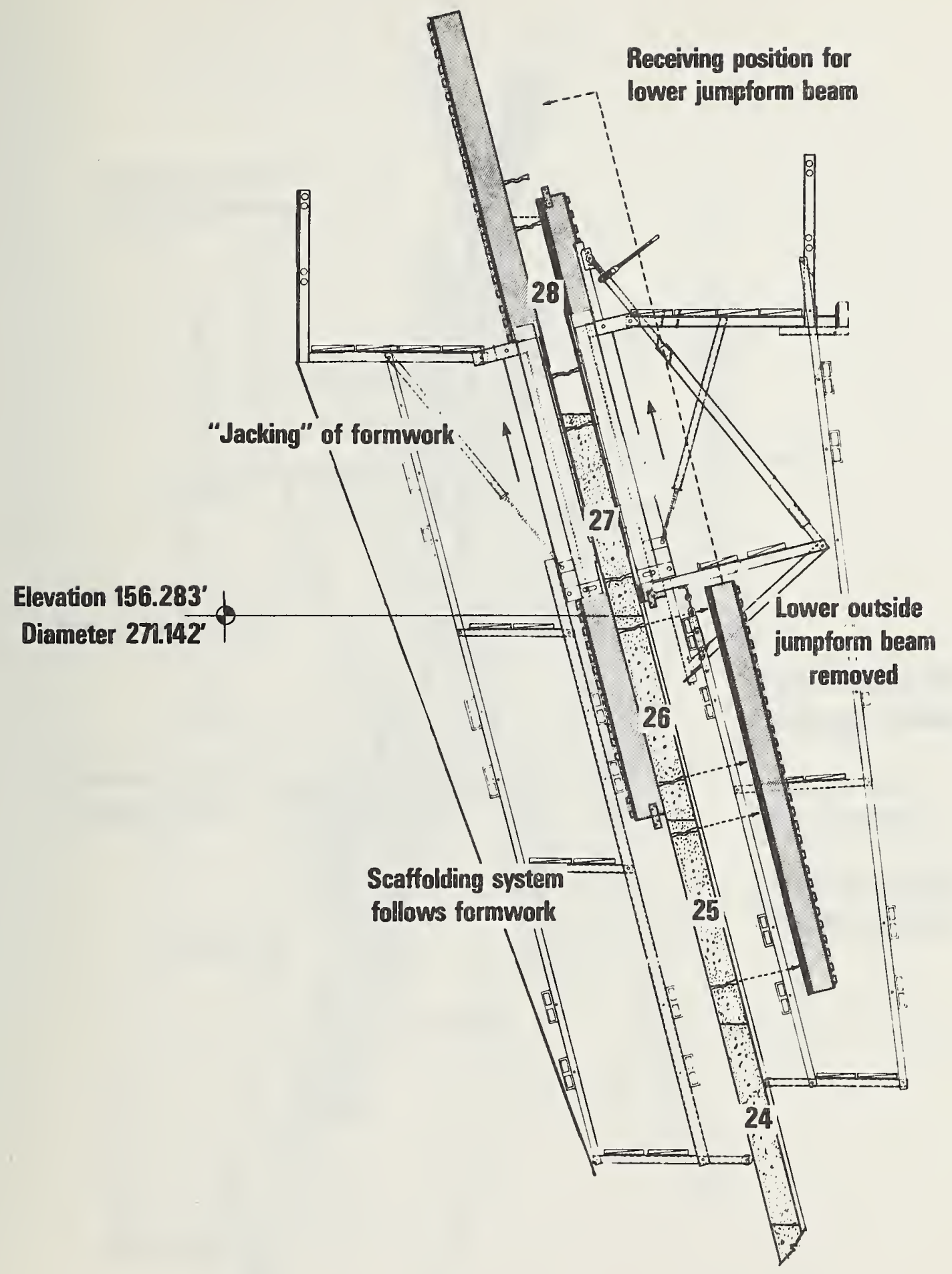

Figure 2.12 Raising of Formwork and Relocation of Jumpform Beam after Casting of Lift 27 


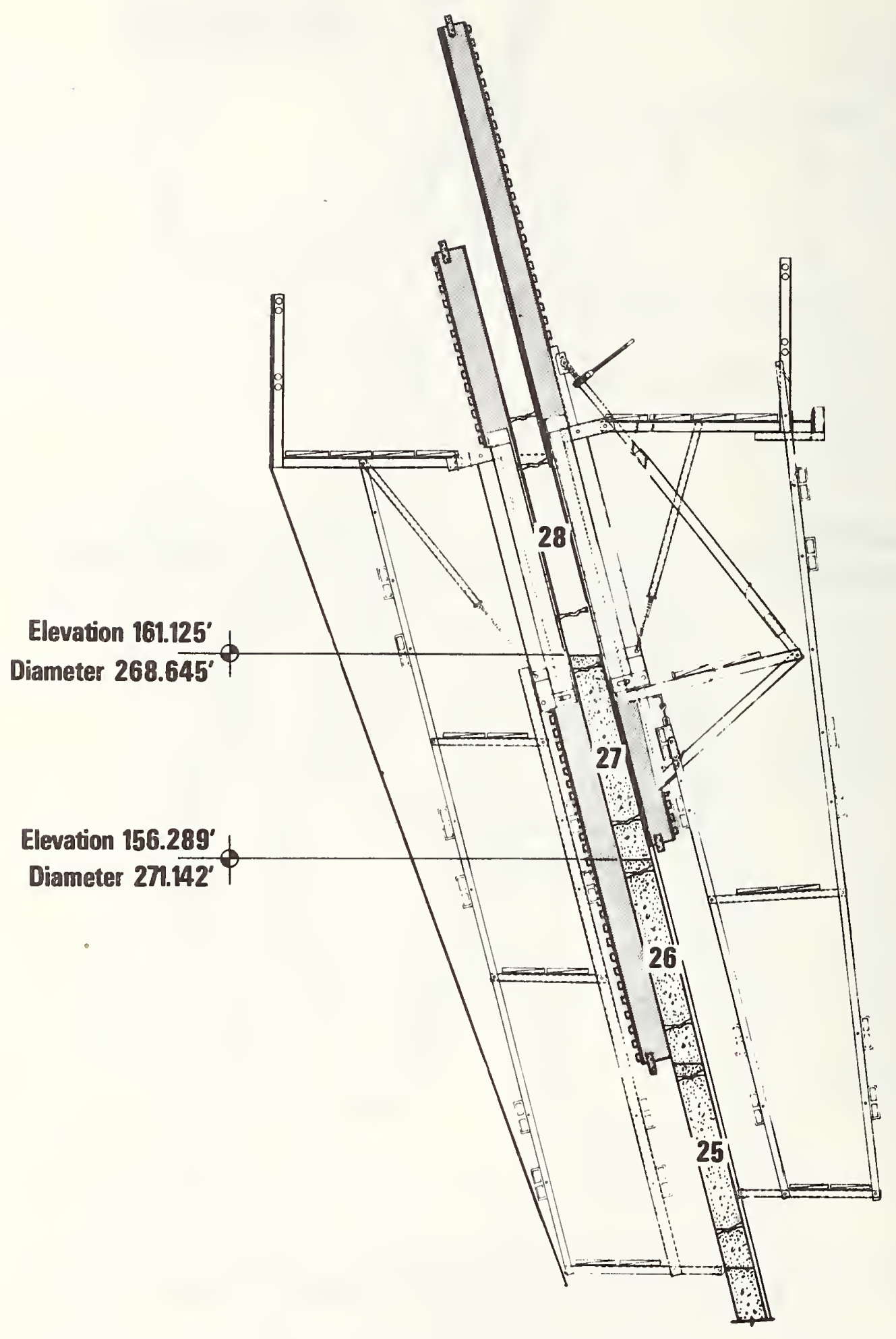

Figure 2.13 Position of Jumpform Beams Prior to Concrete Placement for Lift 28 


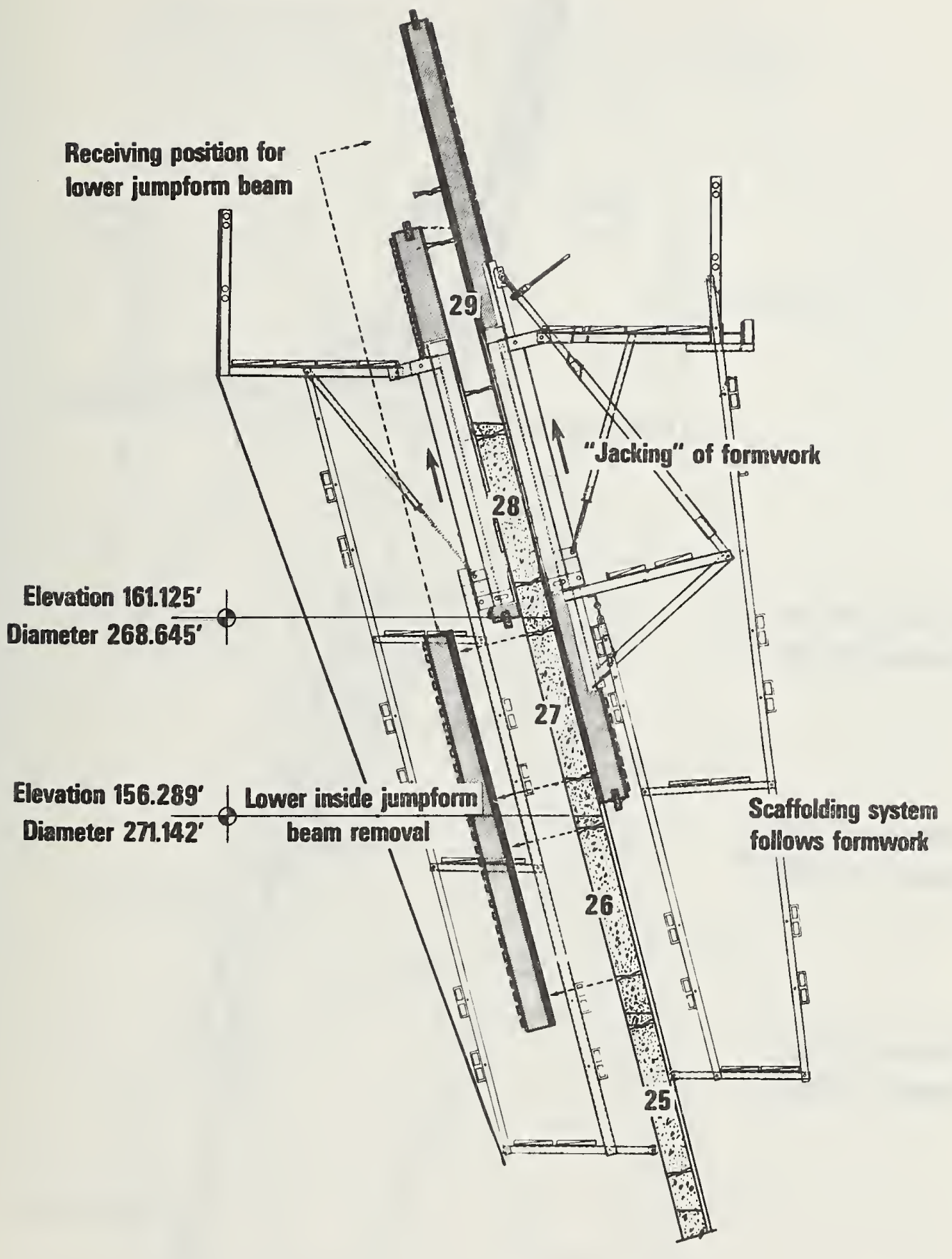

Figure 2.14 Raising of Formwork and Relocation of Jumpform Beam after Casting of Lift 28 


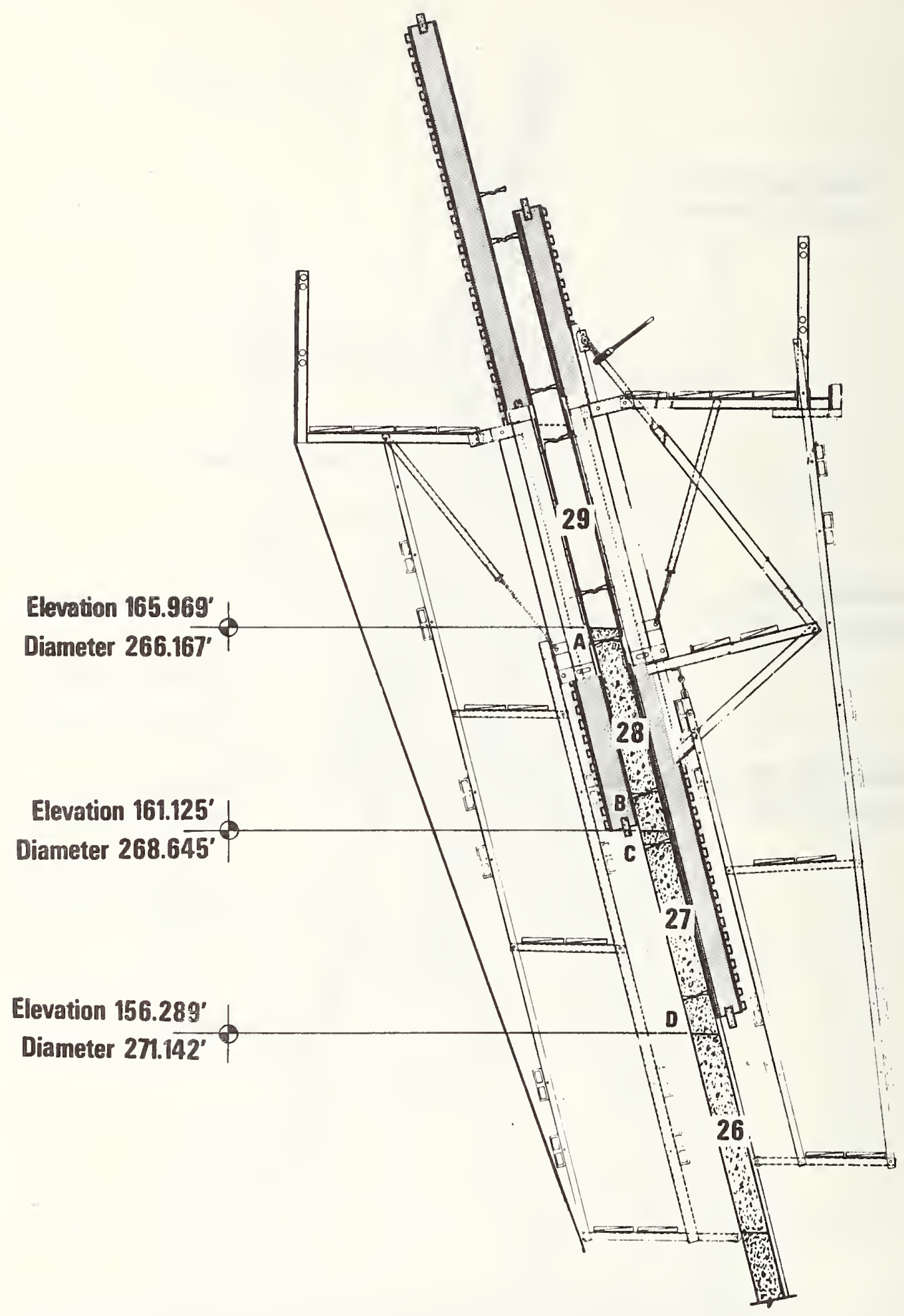

Figure 2.15 Position of Jumpform Beams Prior to Concrete Placement for Lift 29 


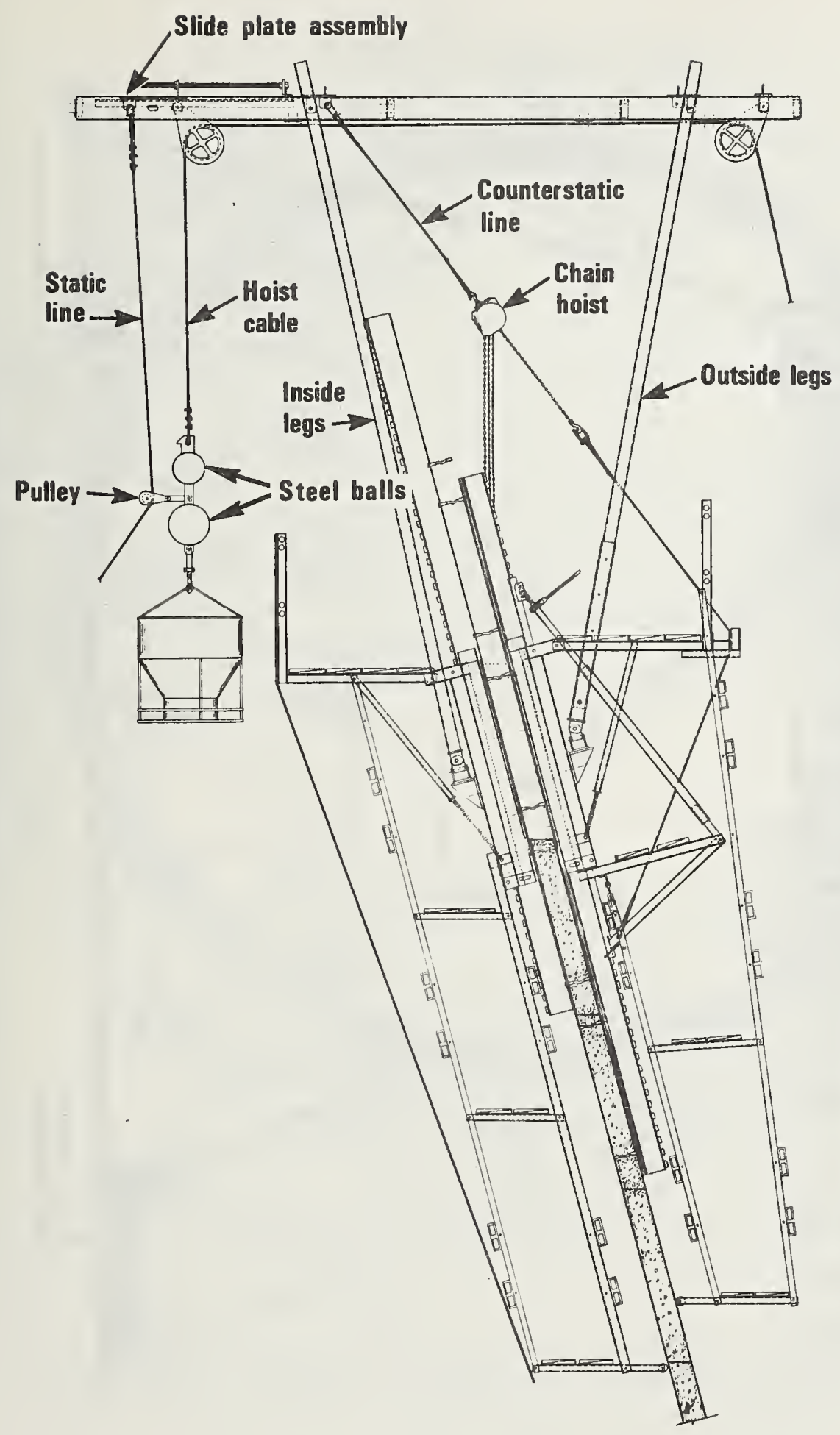

Figure 2.16 Cathead Gantry Assembly 


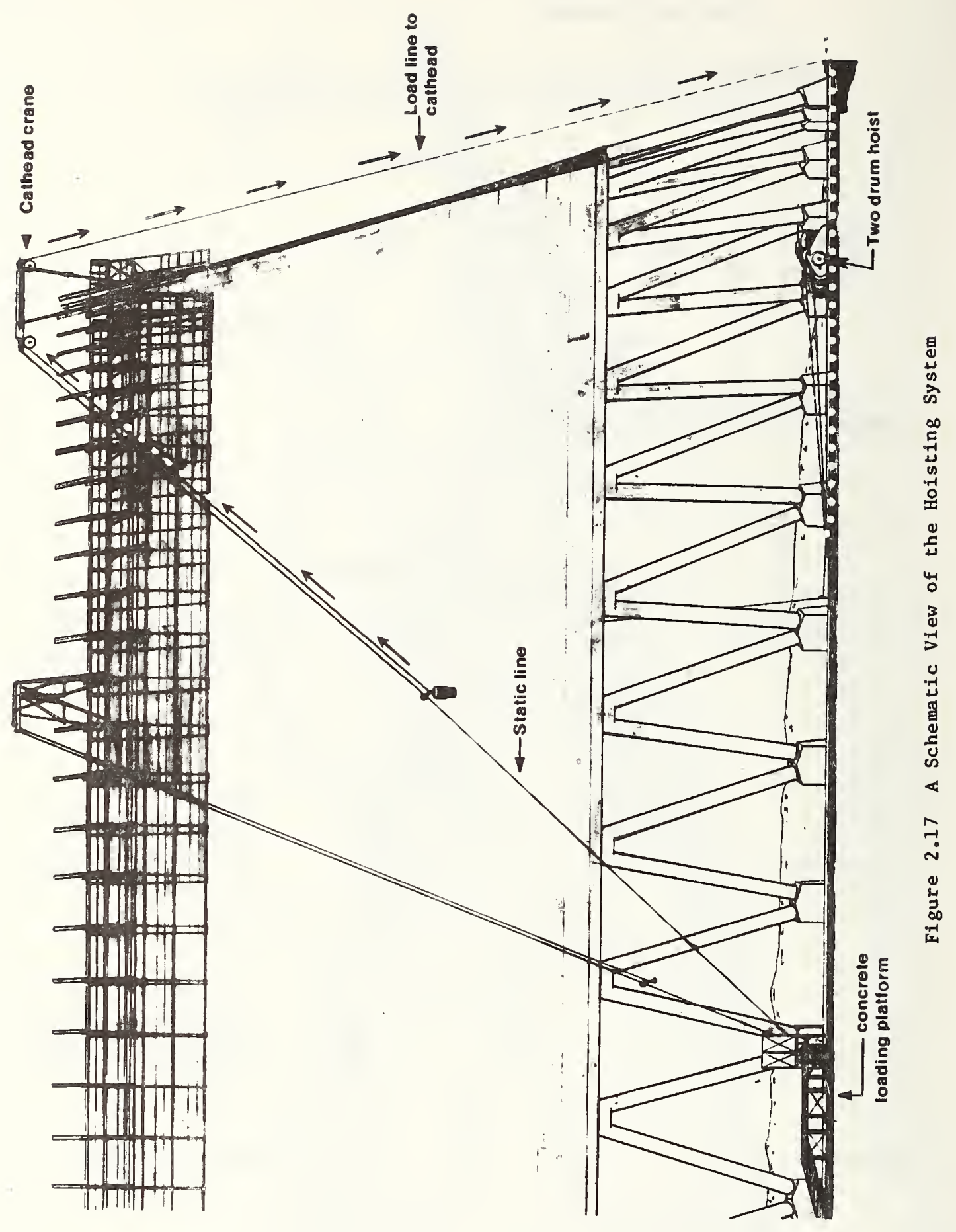




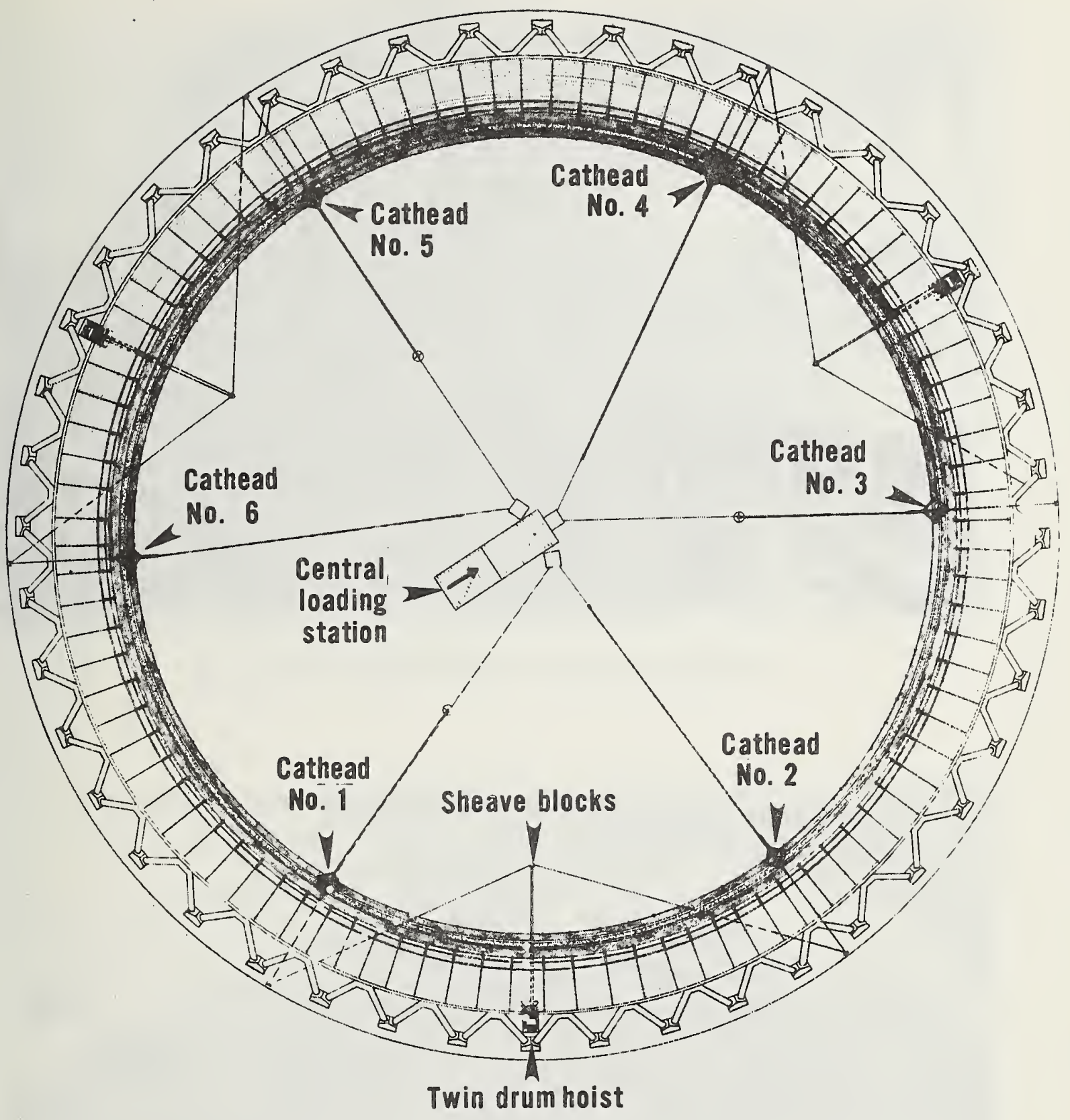

Figure 2.18 Location of Drum Hoist Relative to Cathead Gantries 


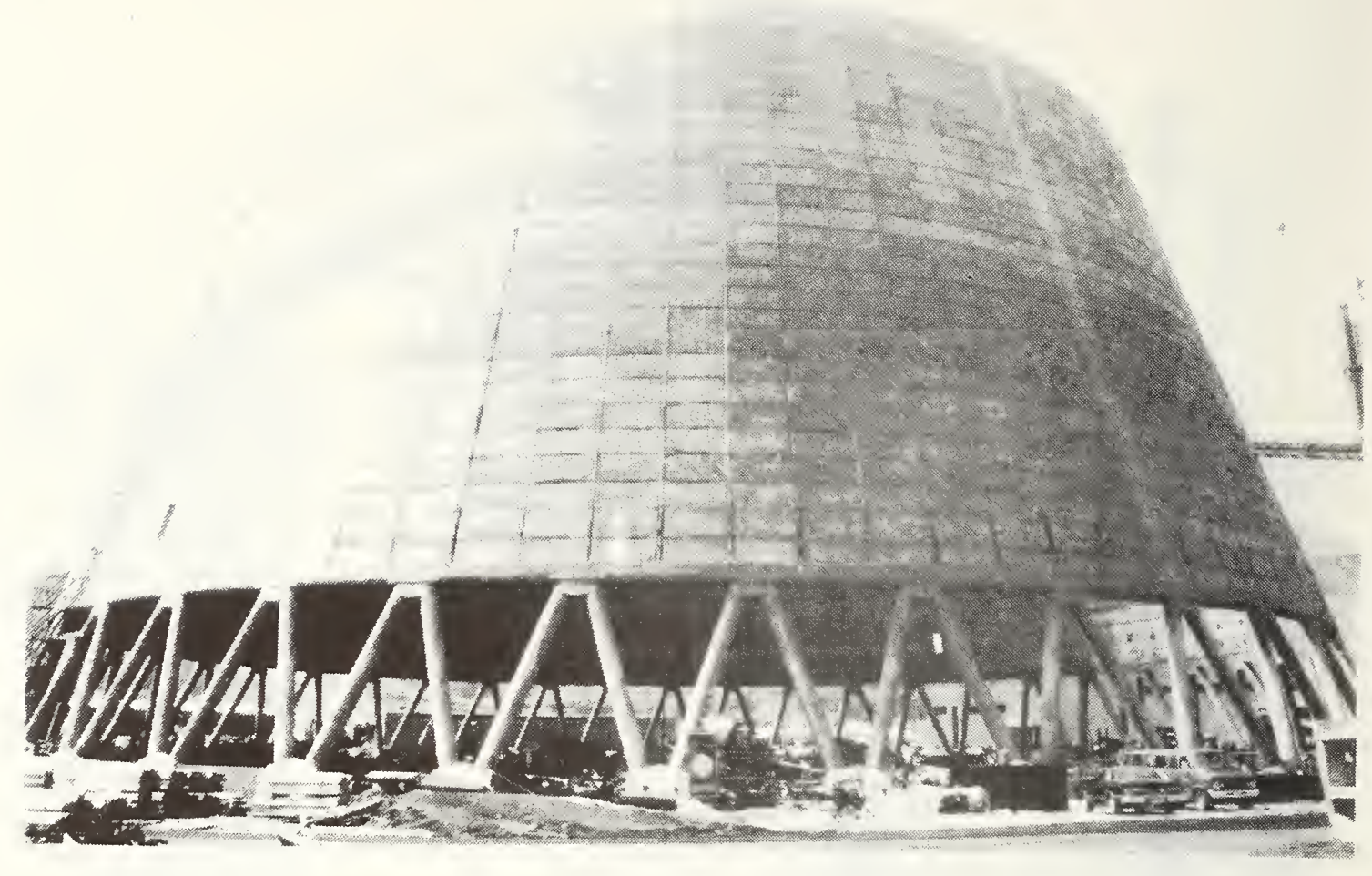

Figure 3.1 Exterior View of Tower Unit No. 2

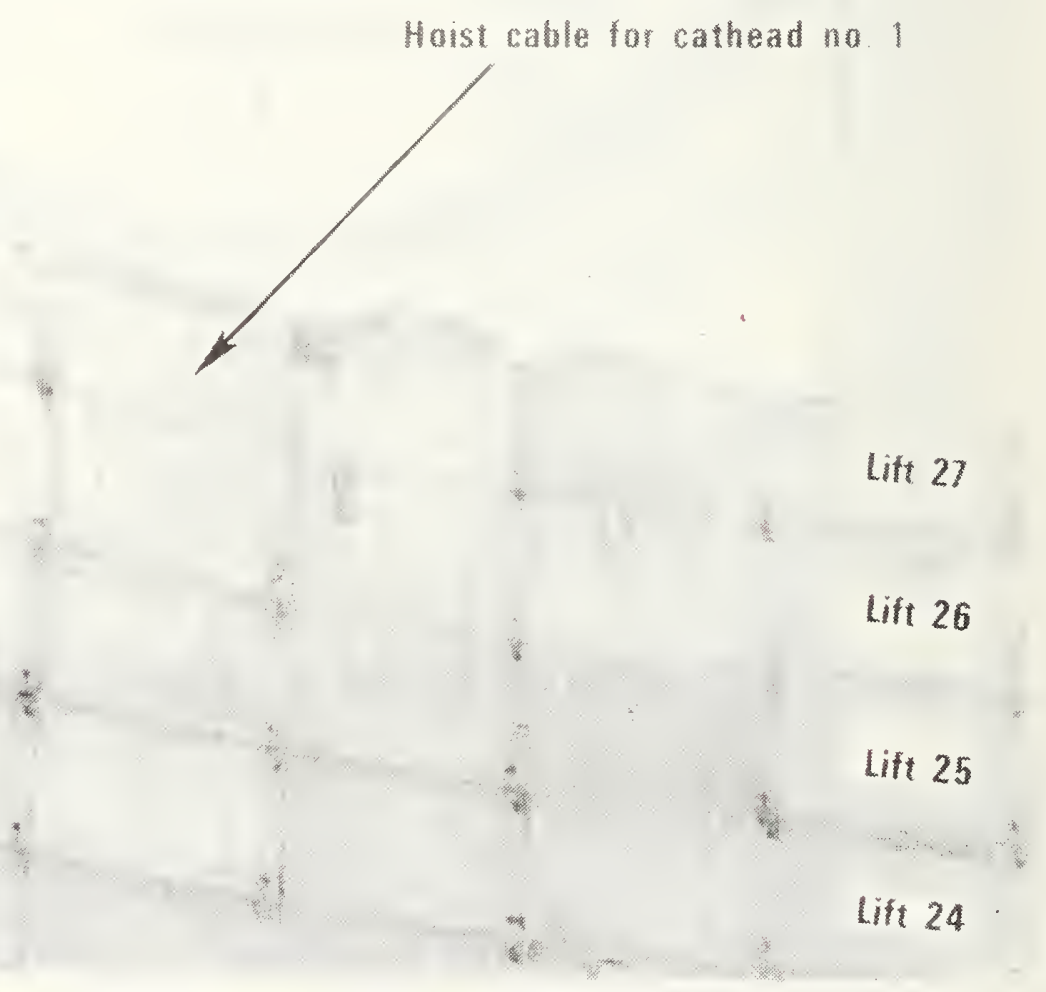

Figure 3.2 Top of Lift 27 Showing Jagged Edge 


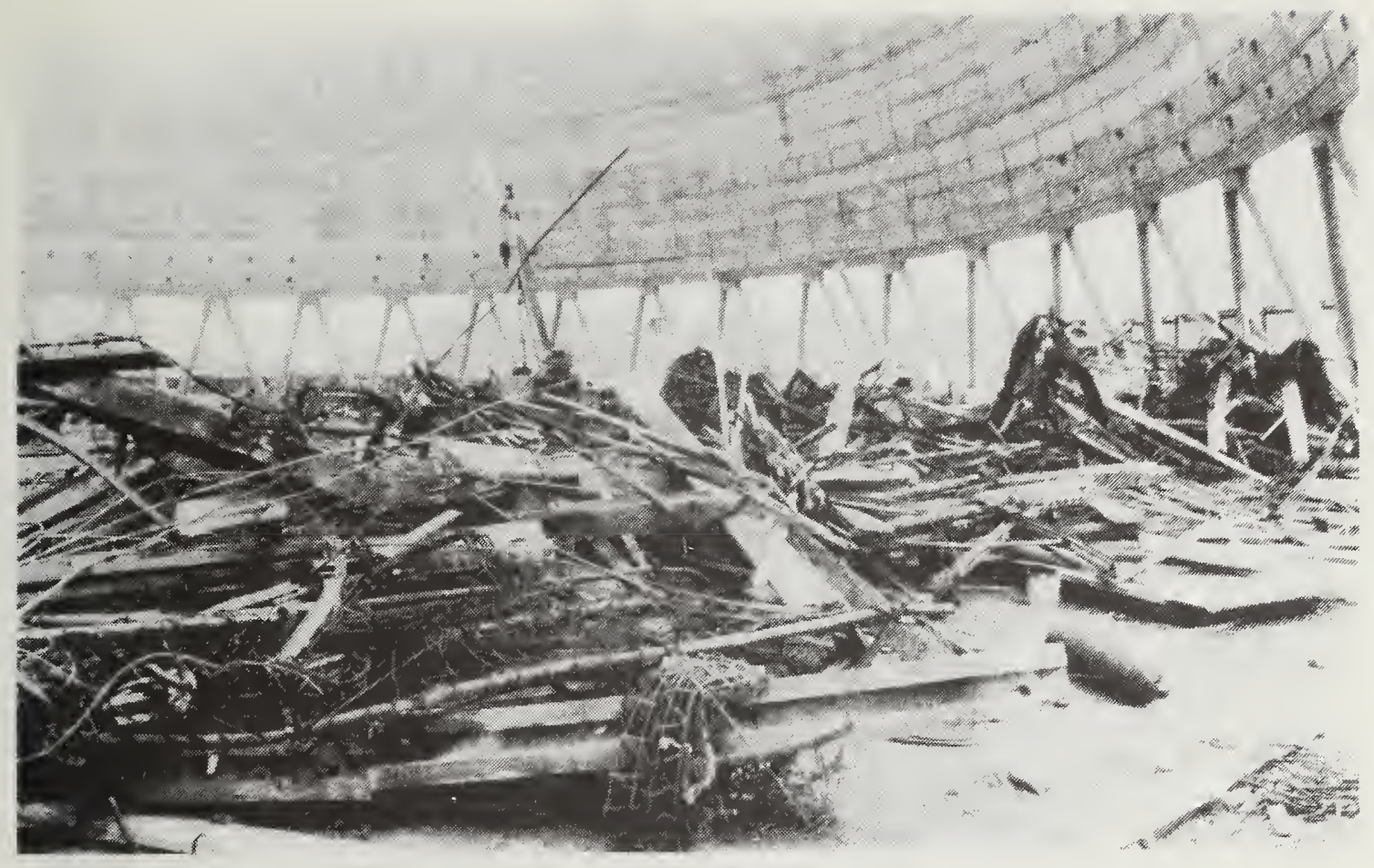

Figure 3.3 Debris Piled up Inside the Tower

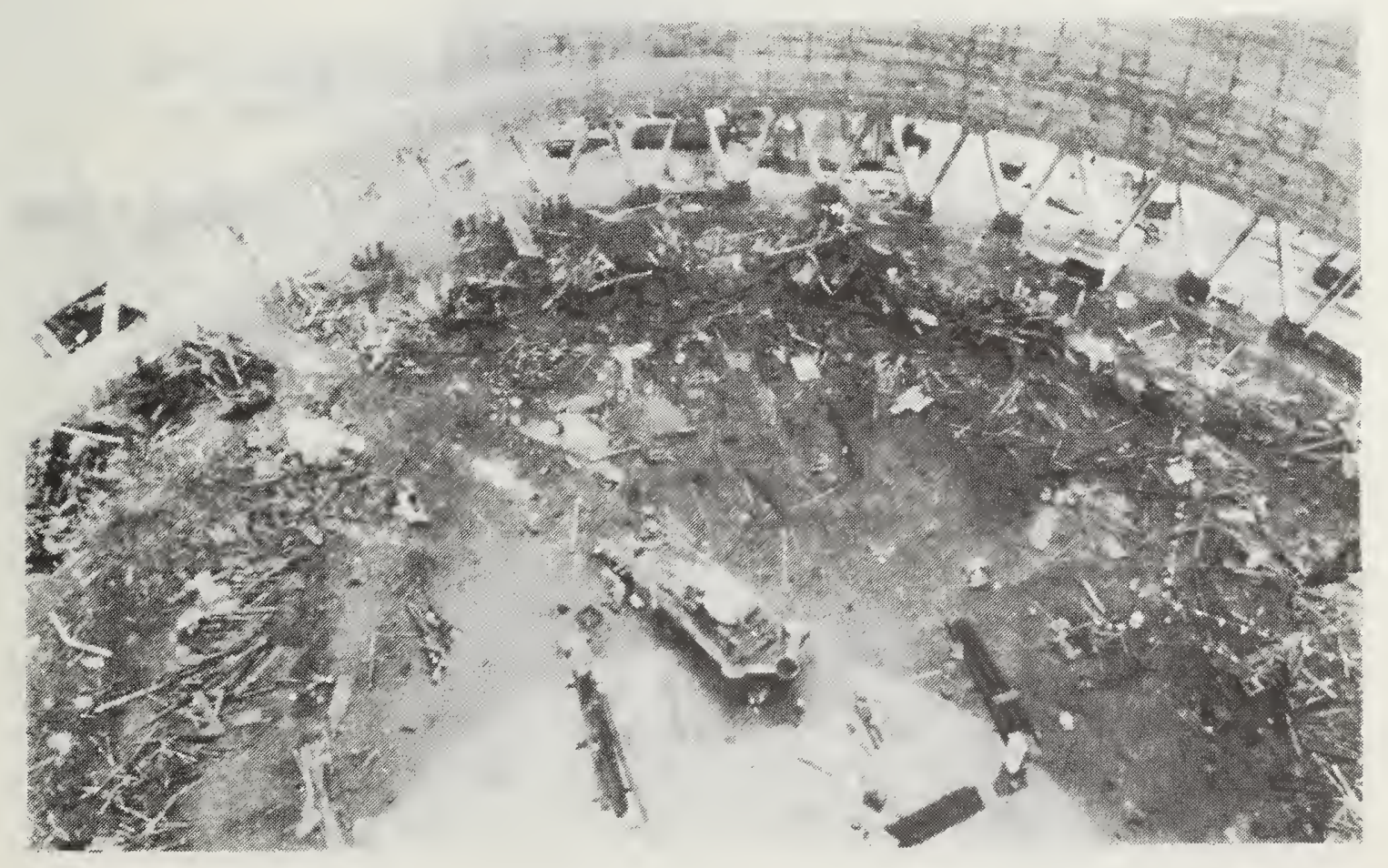

Figure 3.4 Distribution of Debris Around the Base of the Tower 


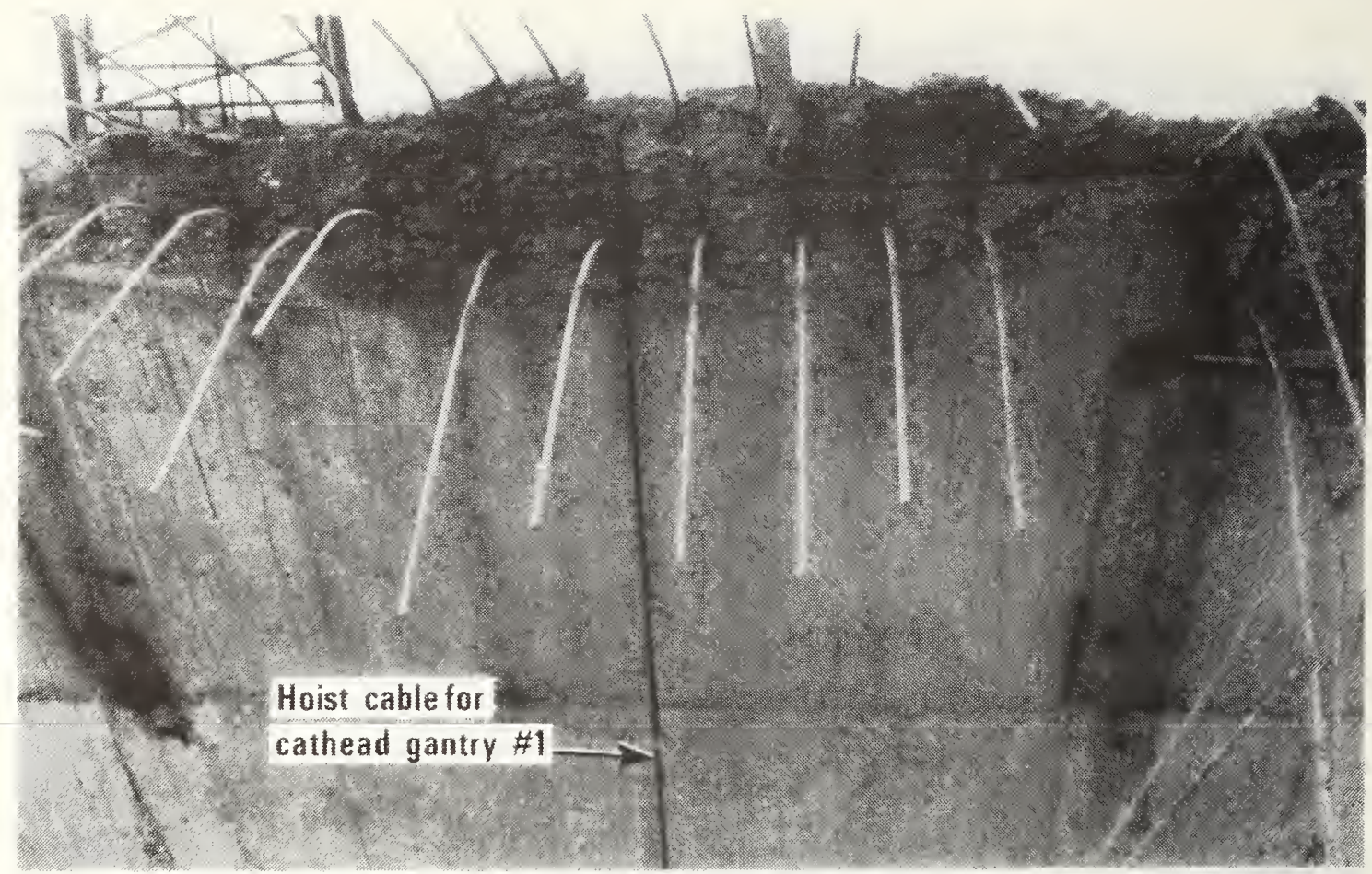

Figure 3.5 Top of Lift 27 at Cathead Gantry No. 1

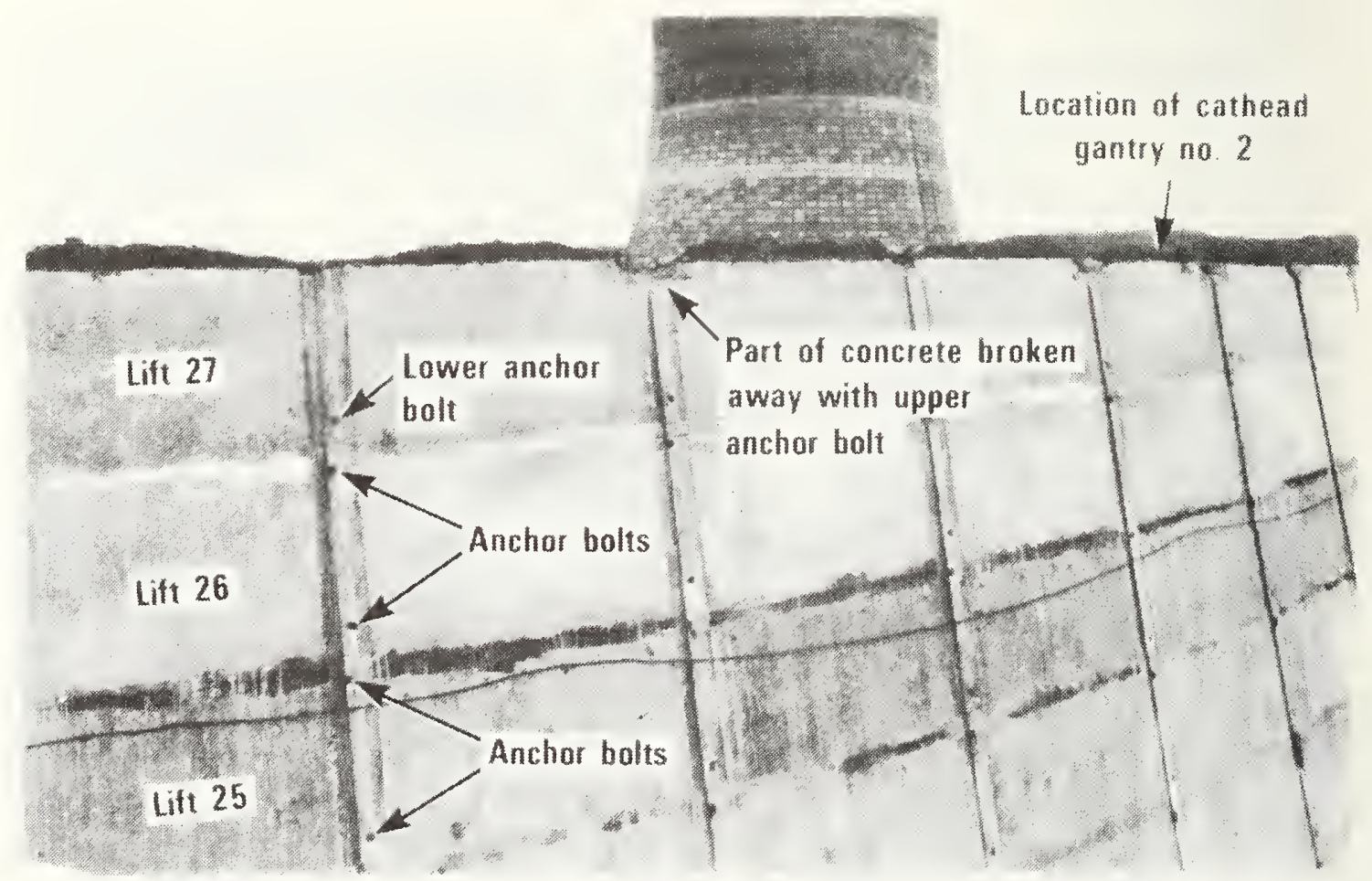

Figure 3.6 Exterior View of Top Portion of the Shell Between Cathead Gantry No. 1 and No. 2 


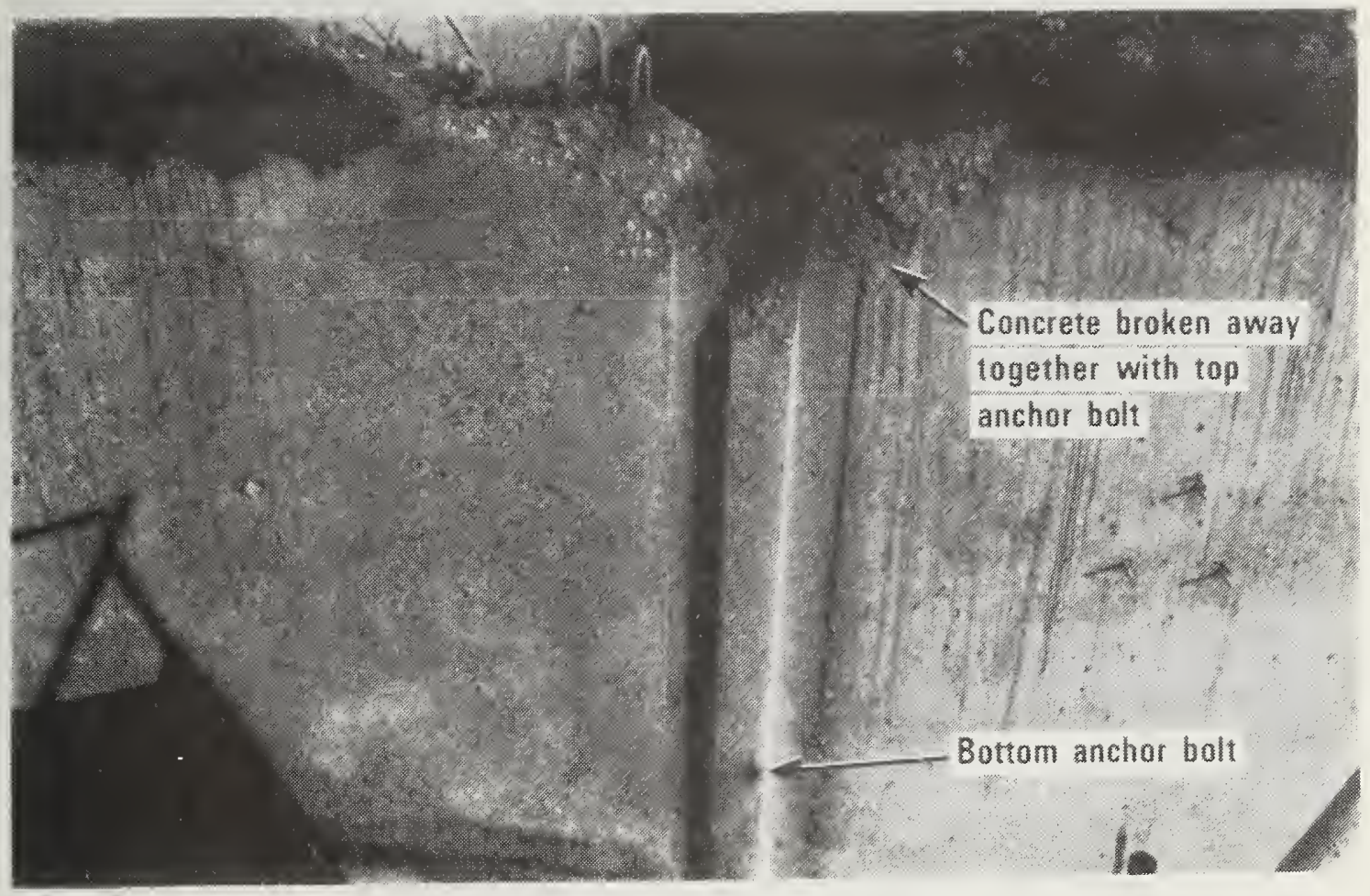

Figure 3.7 Typical Rib in Lift 27

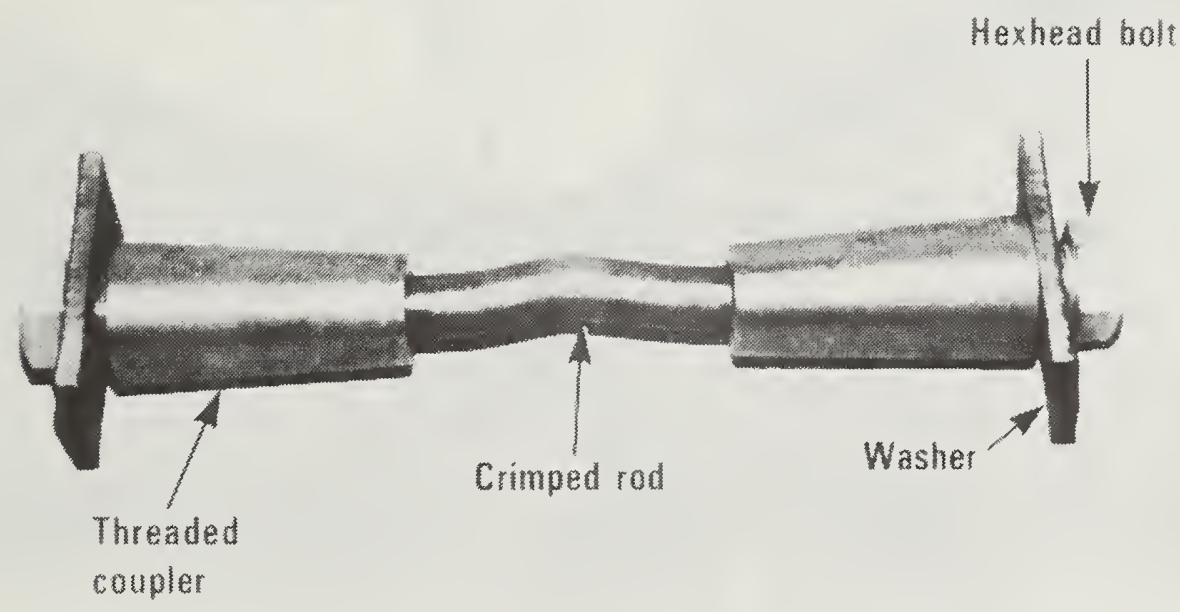

Figure 3.8 Anchor Bolt Assembly 


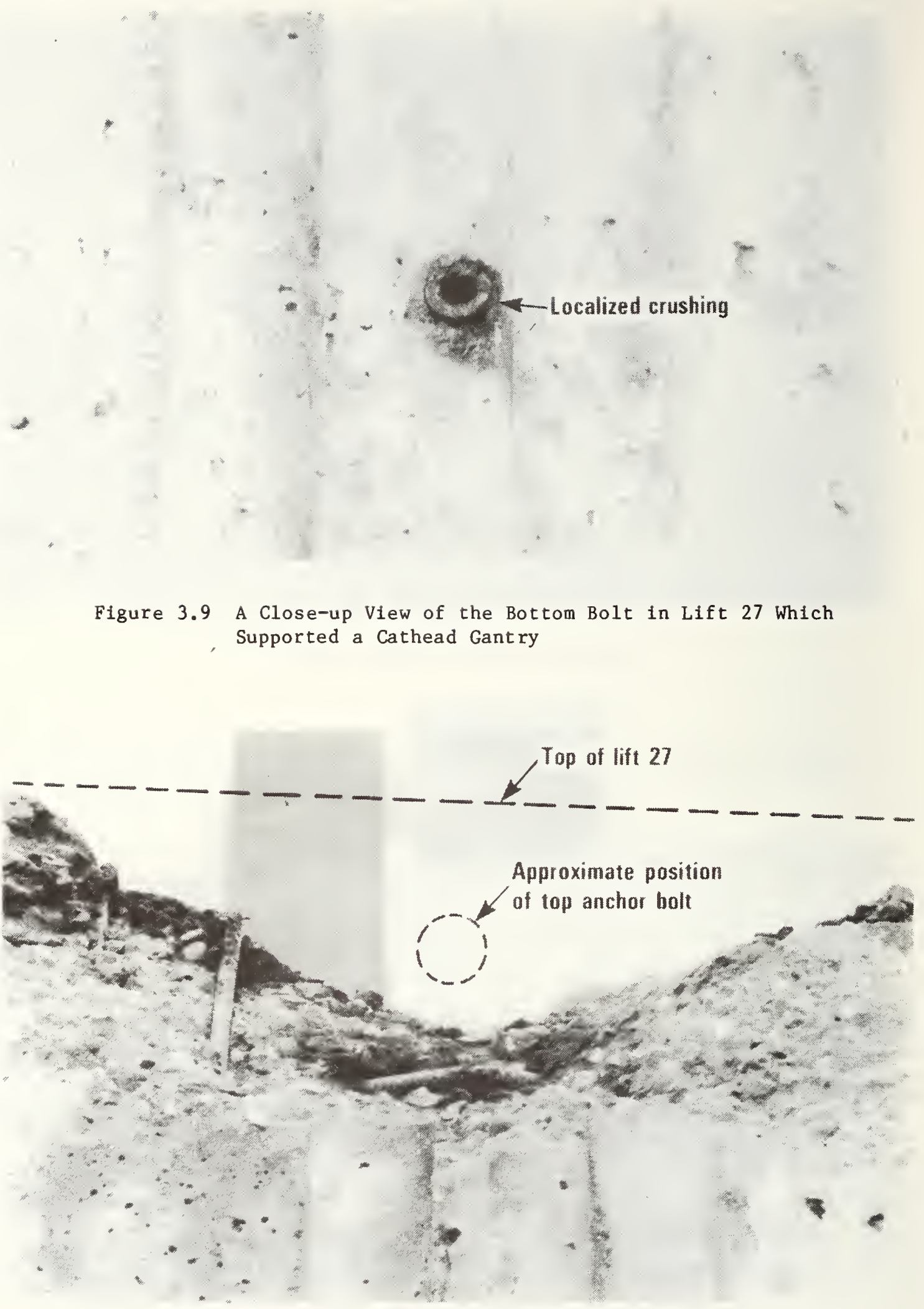

Figure 3.10 Close-up View of Top of Lift 27 at a Rib Location 


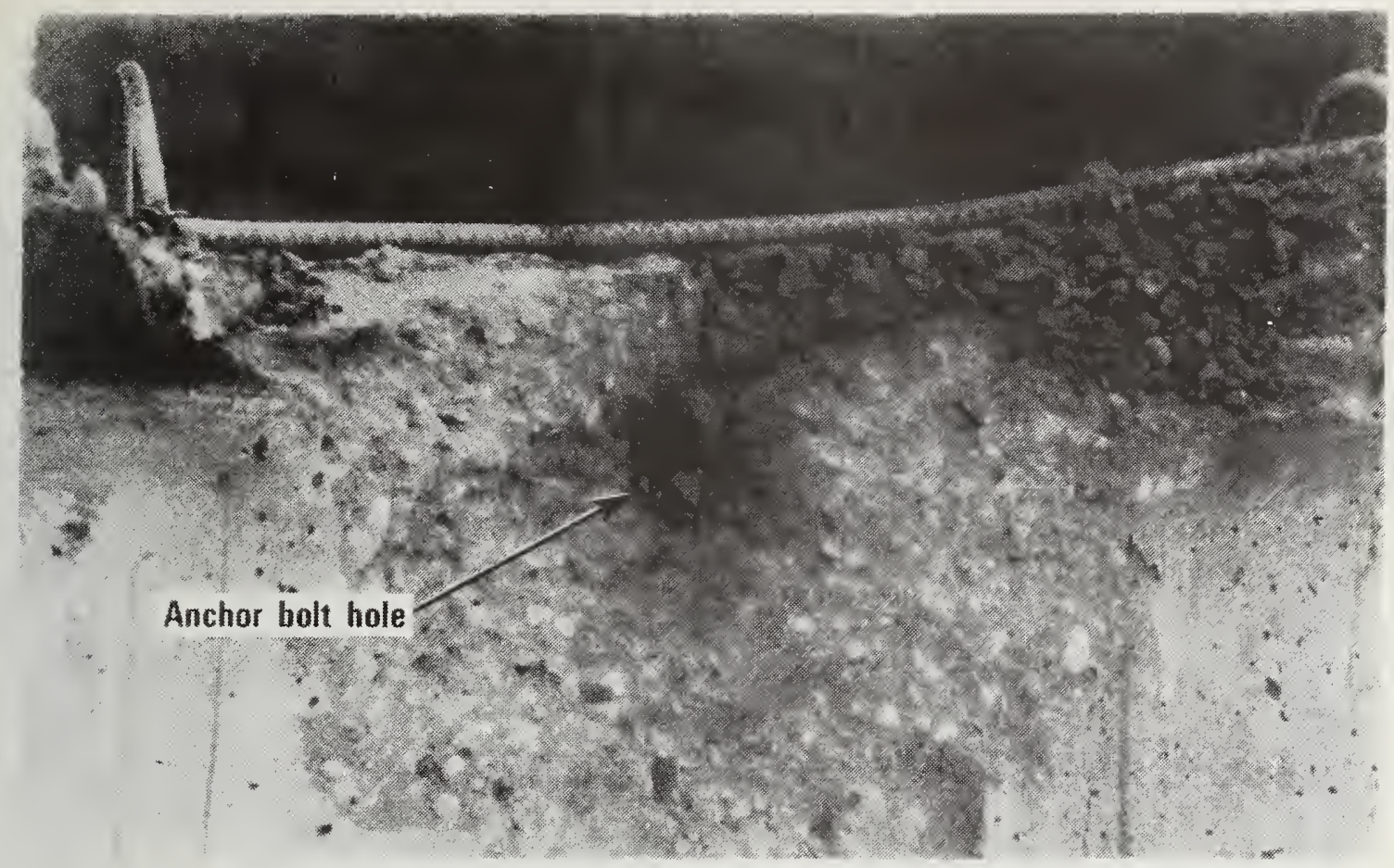

Figure 3.11 Close-up View of Top of Lift 27 Showing an Anchor Bolt Hole in Concrete

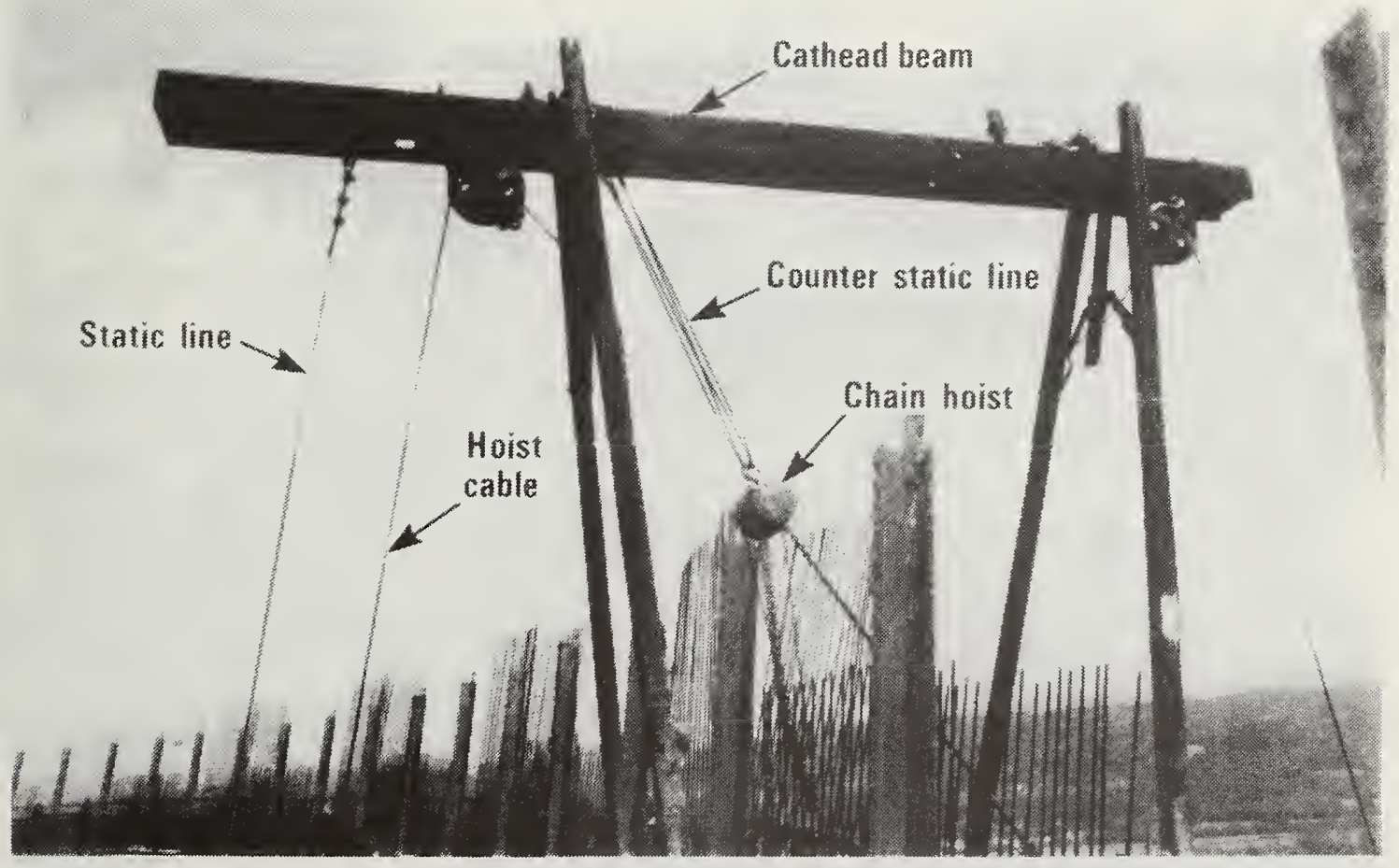

Figure 3.12 An Overall View of Cathead Gantry 


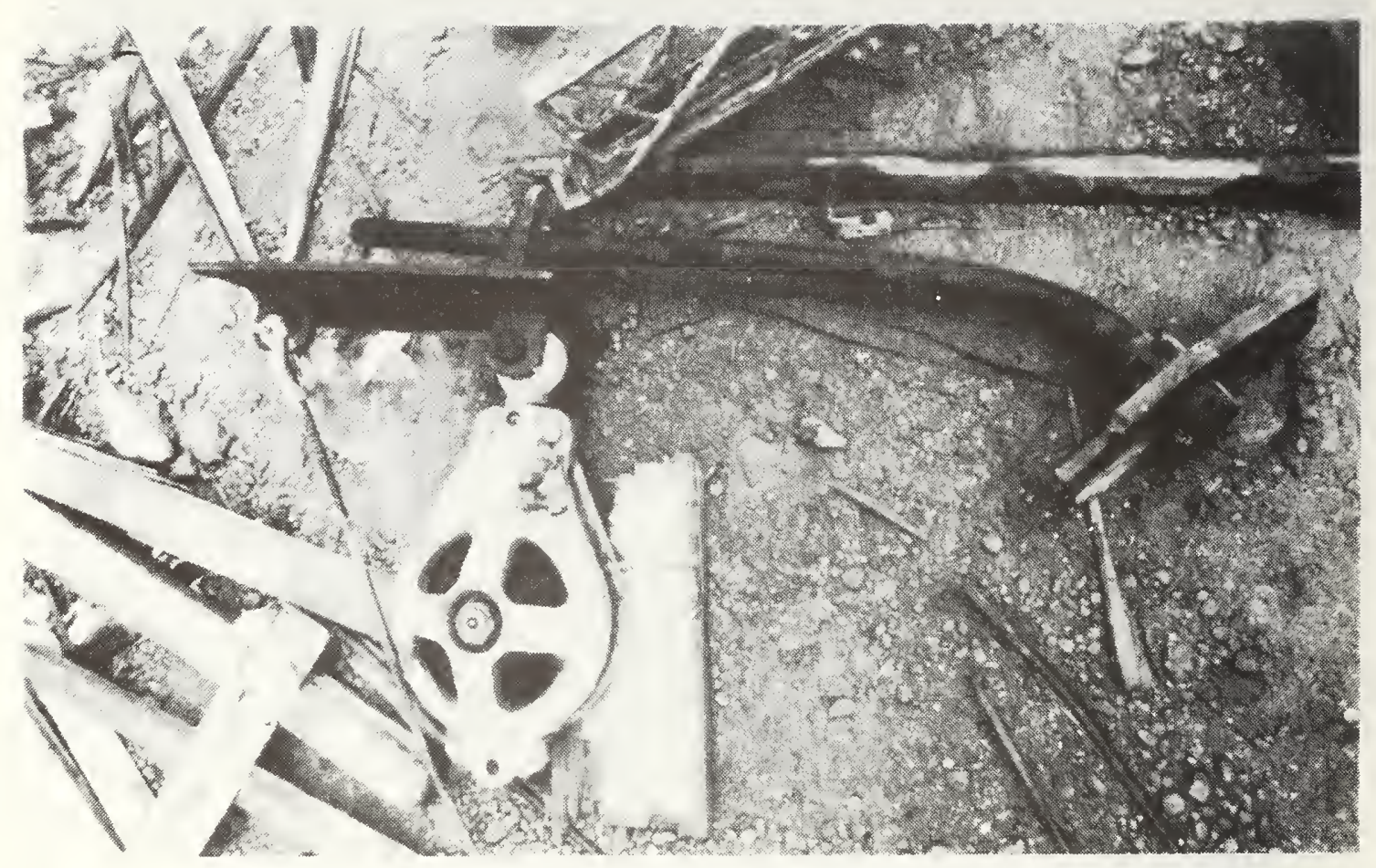

Figure 3.13 Slide Plate for Cathead Gantry No. 4

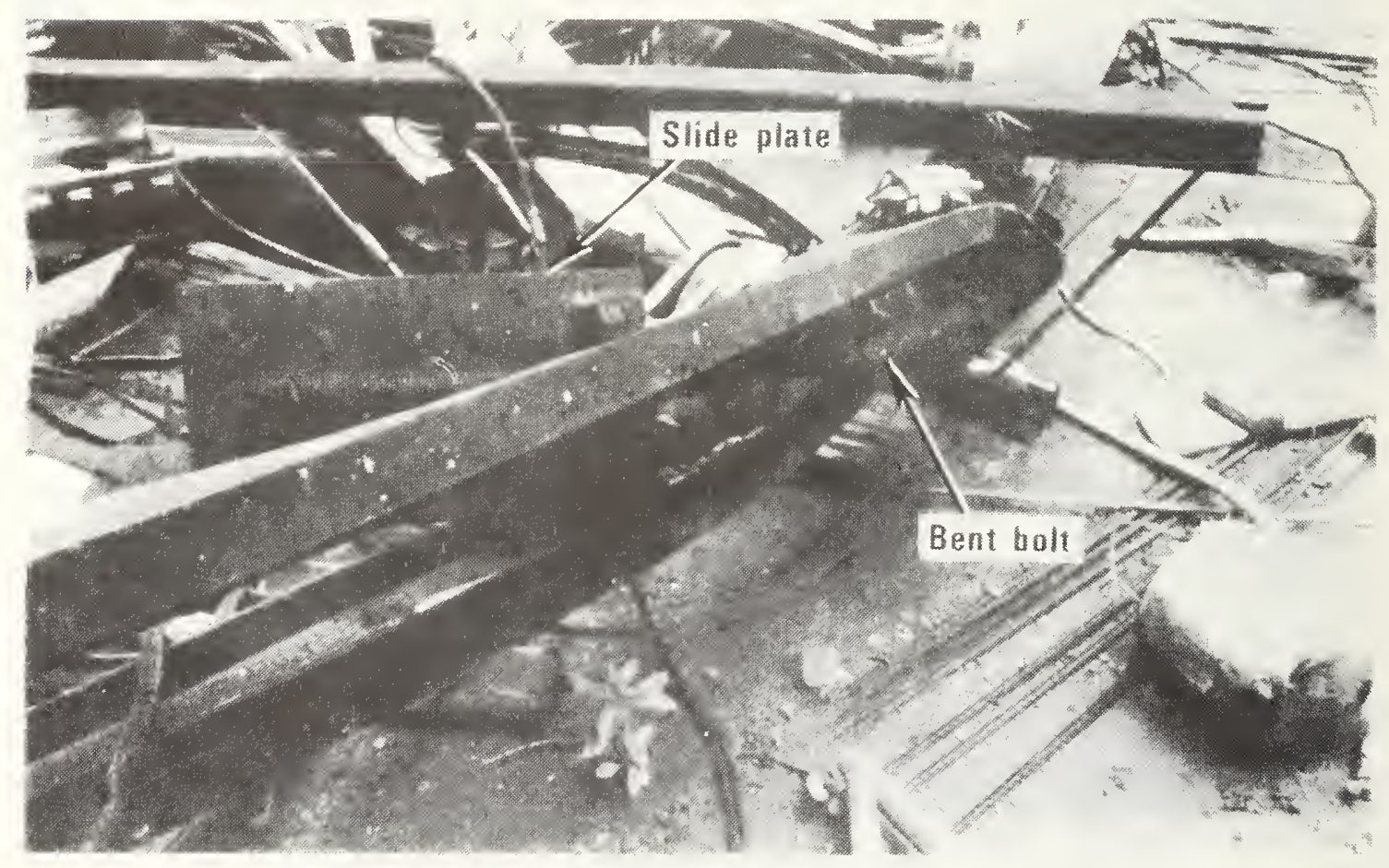

Figure 3.14 Displaced Slide Plate of Cathead Gantry No. 6 


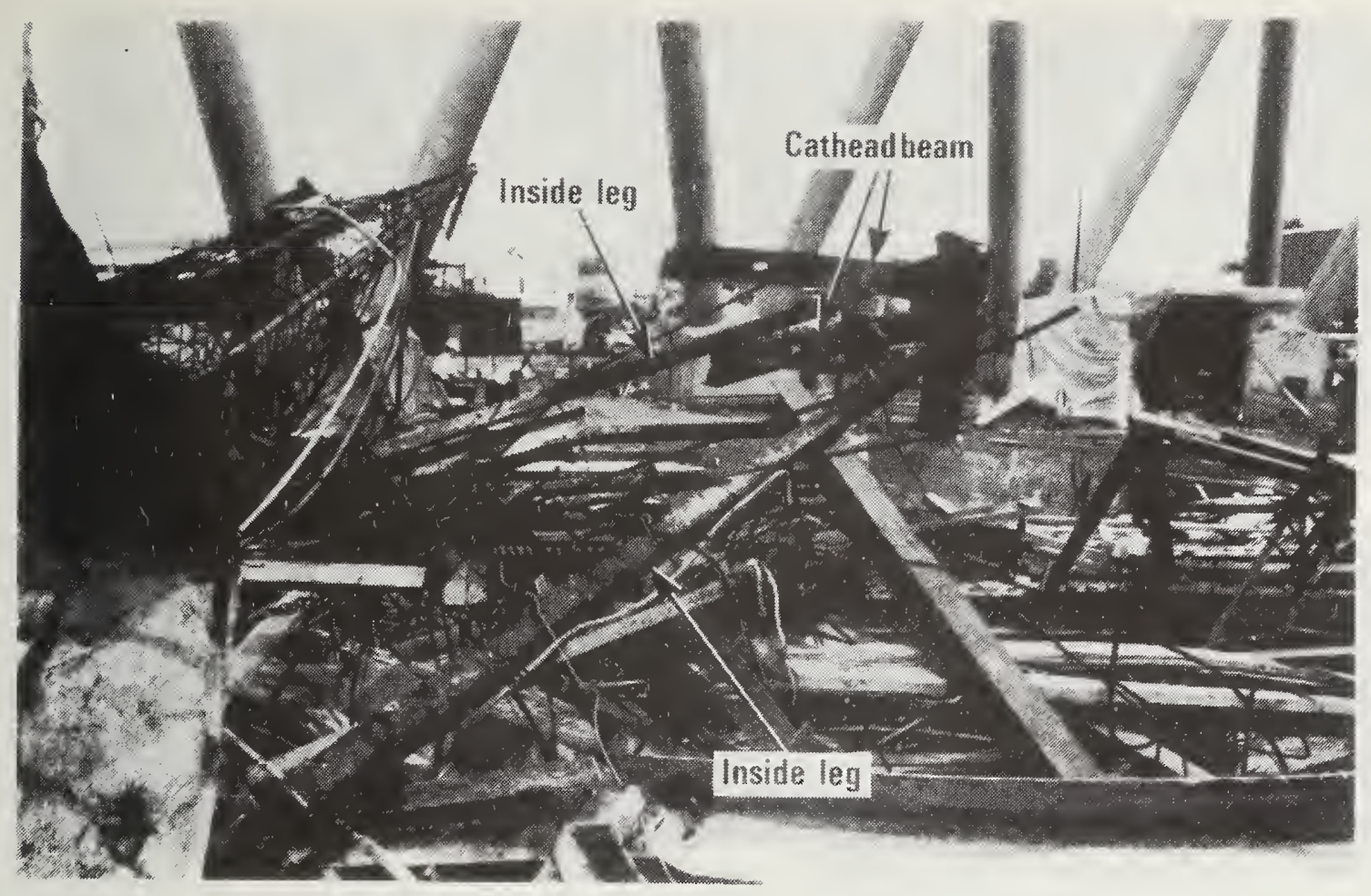

Figure 3.15 Inside Legs of Cathead Gantry No. 4

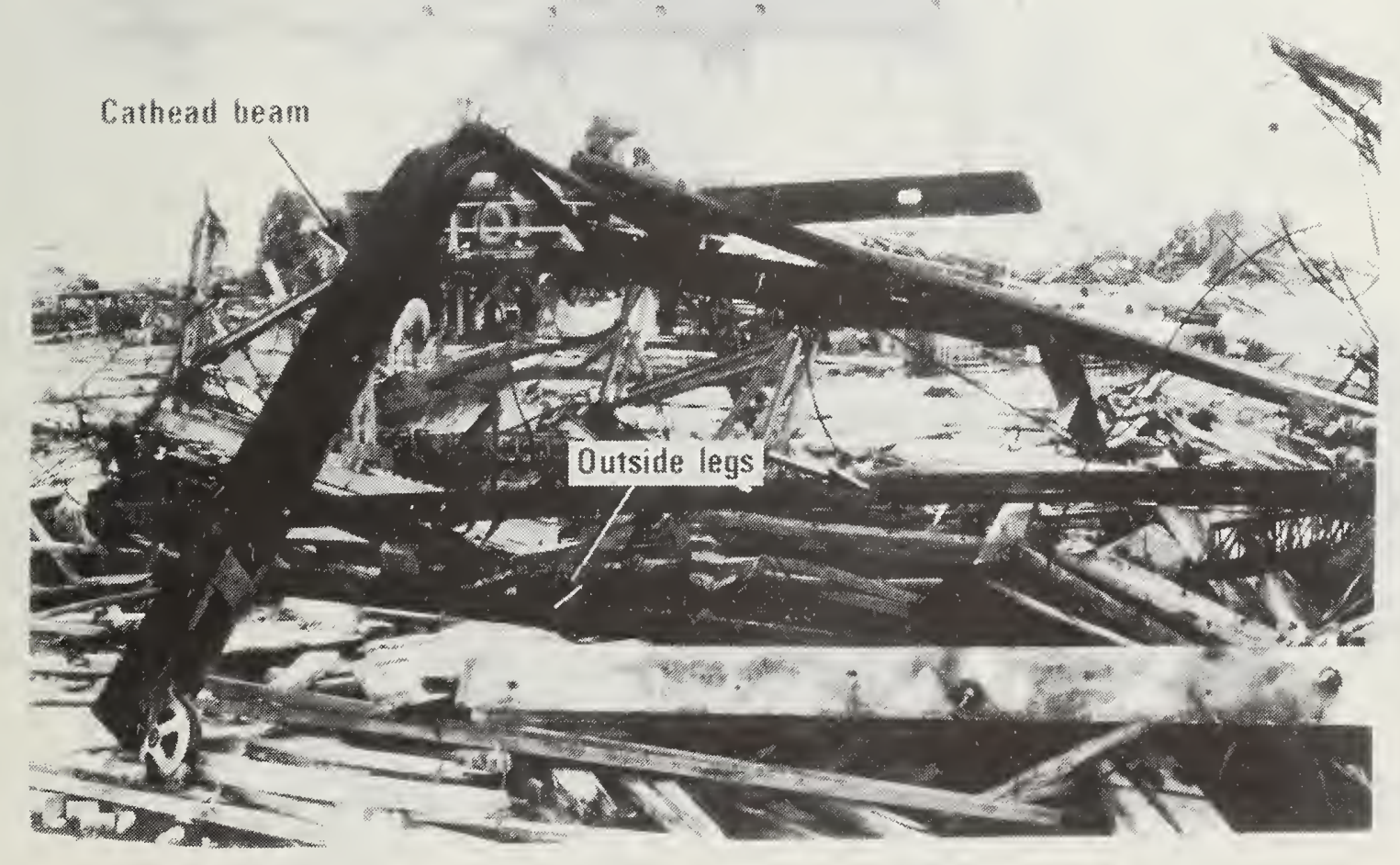

Figure 3.16 Outside Legs of Cathead Gantry No. 4 


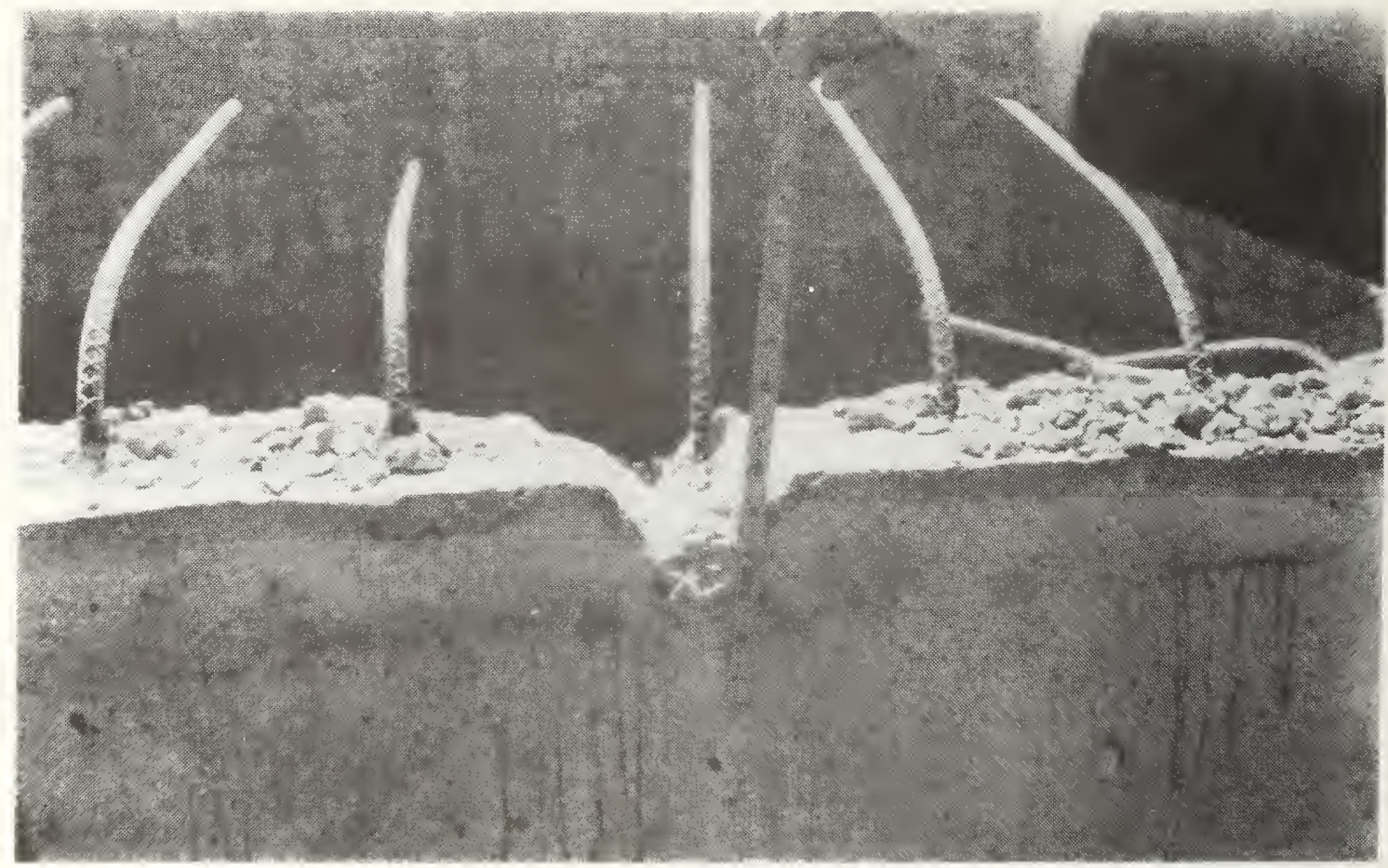

Figure 3.17 A Groove in the Shell Cut by the Hoist Line at Cathead Gantry No. 4

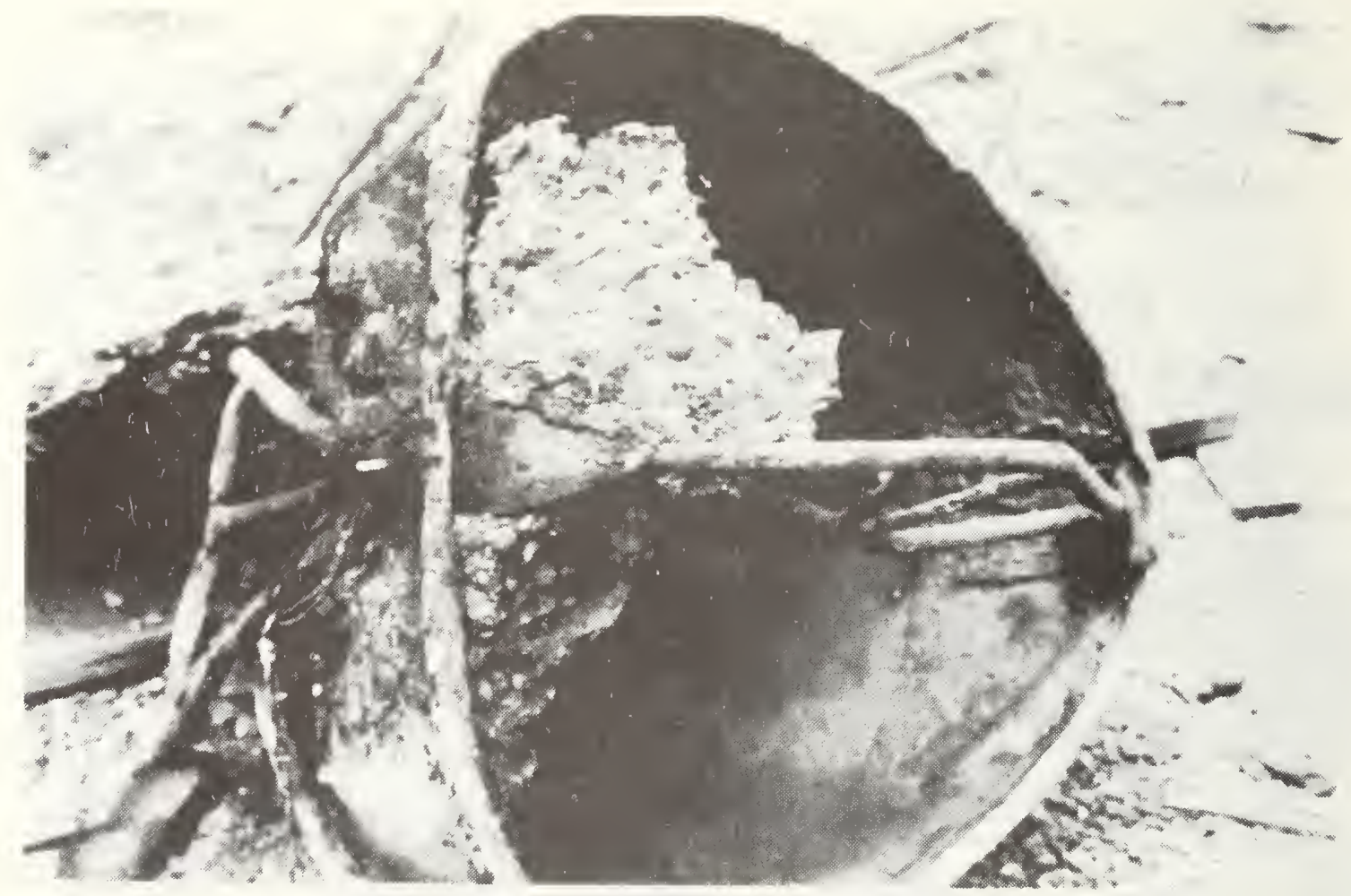

Figure 3.18 Concrete Basket Used for Cathead Gantry No. 4 Which Was Recovered from Wreckage 


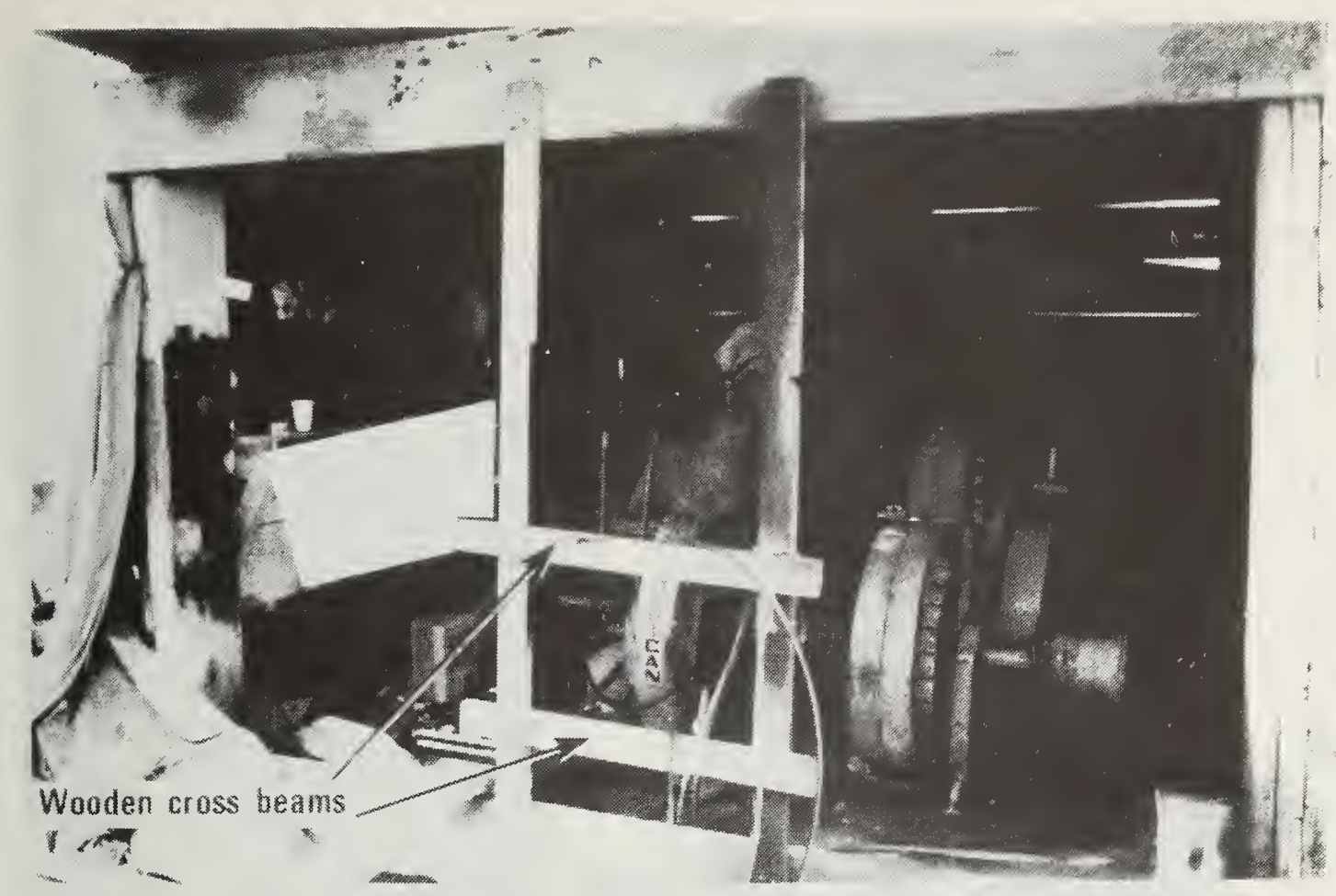

Figure 3.19 Drum Hoist for Cathead Gantry No. 3 and 4

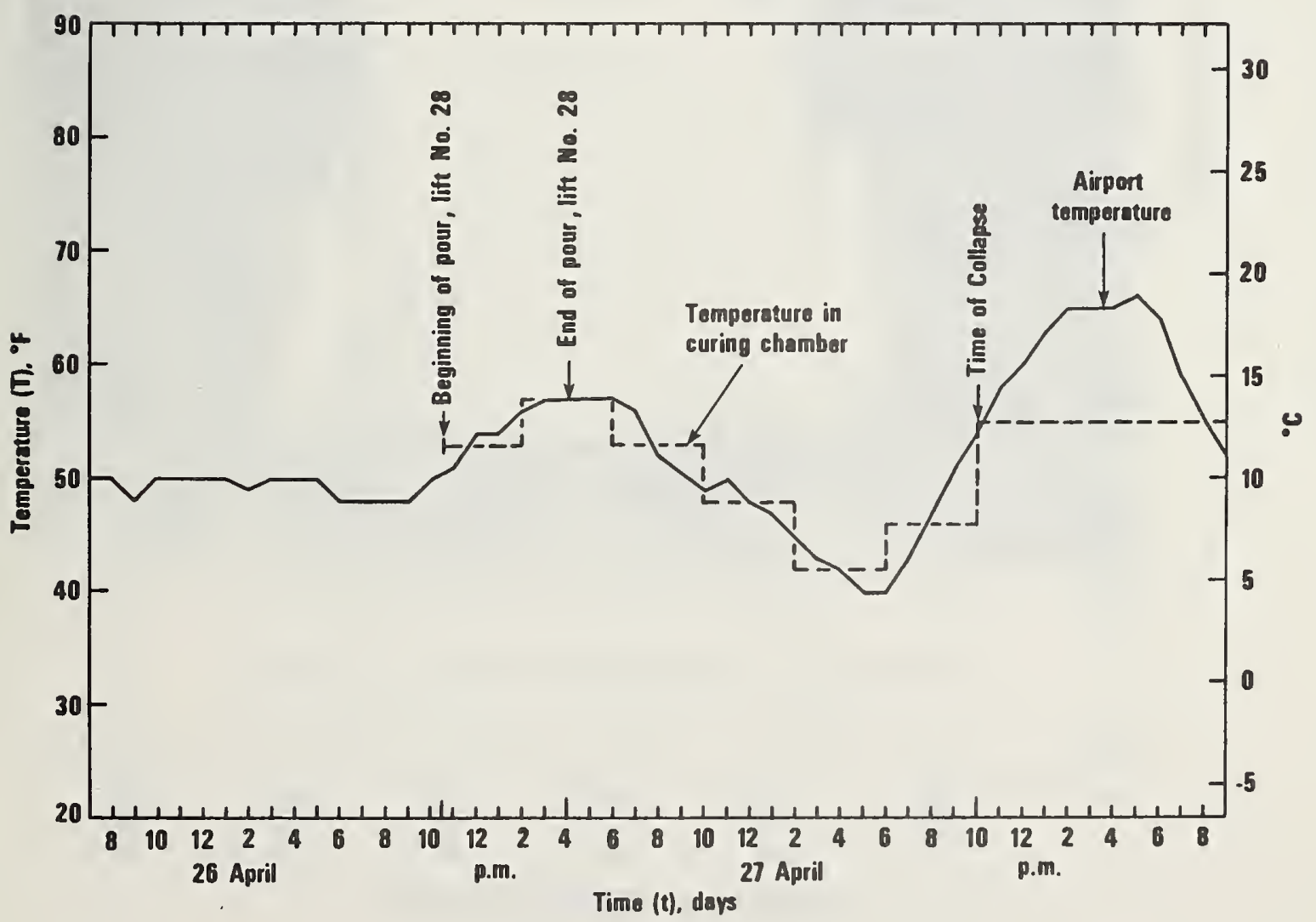

Figure 4.1 Temperature Variation Used to Cure Test Specimens 


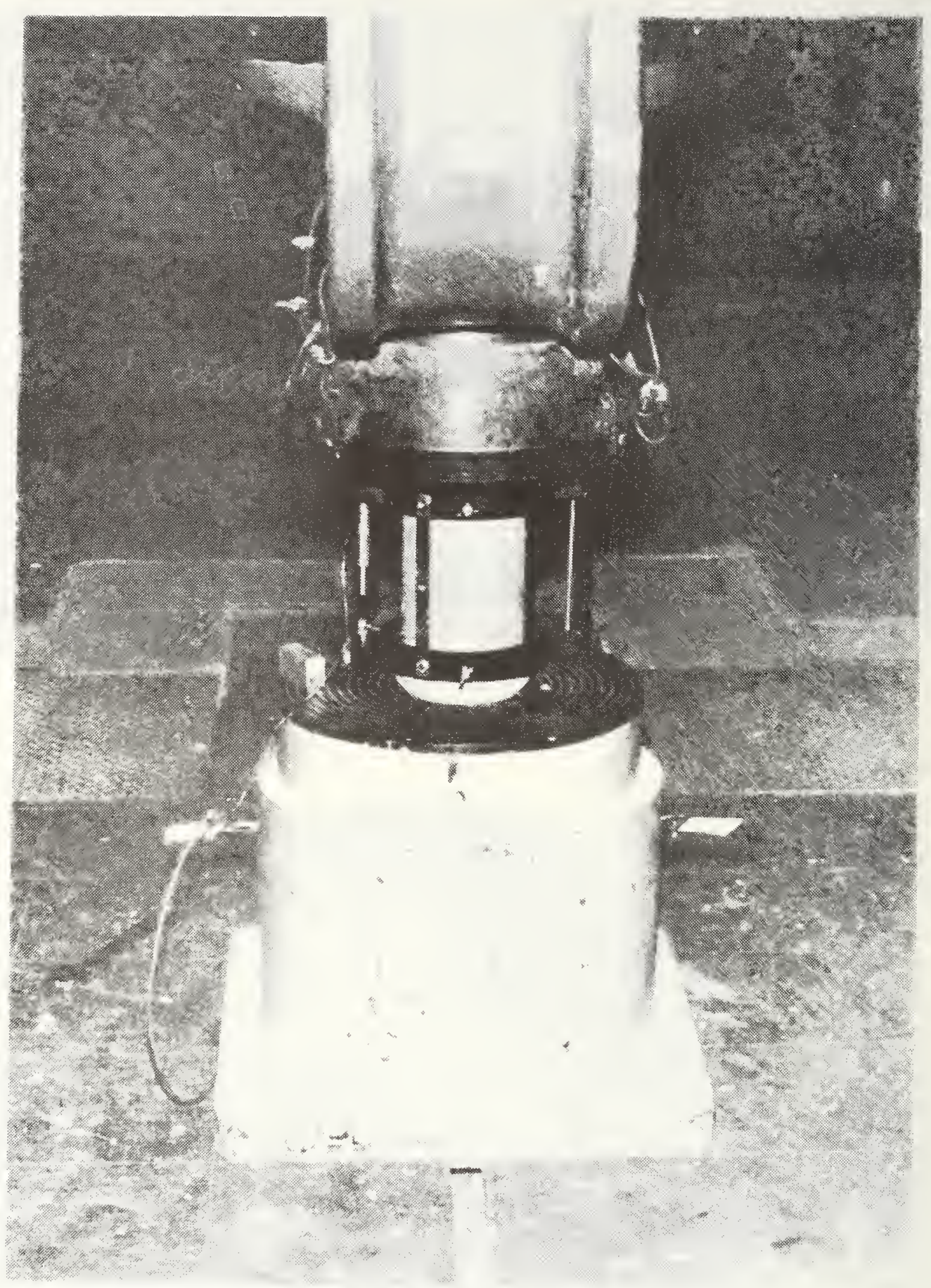

Figure 4.2 Compressive Test of Cylinder 


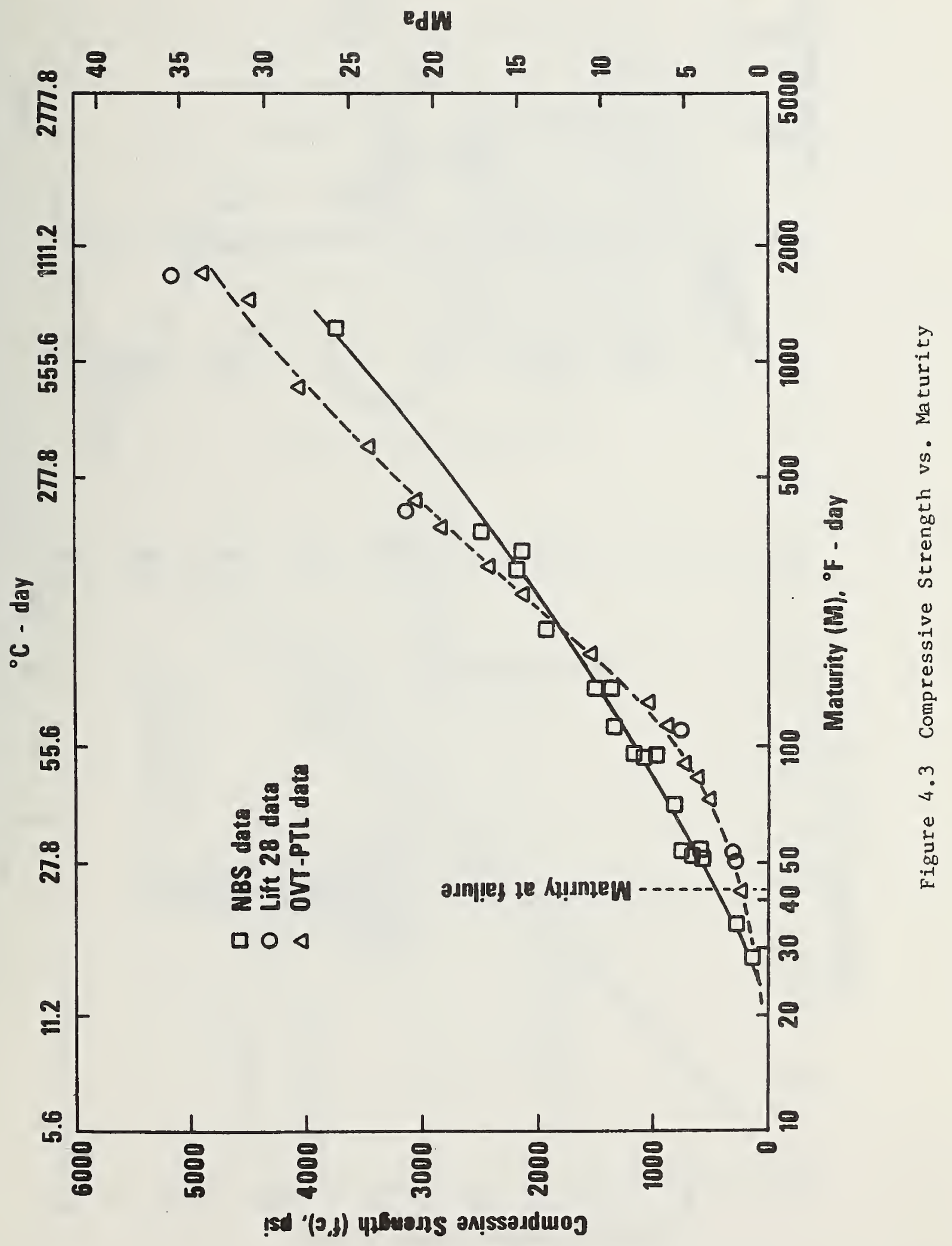



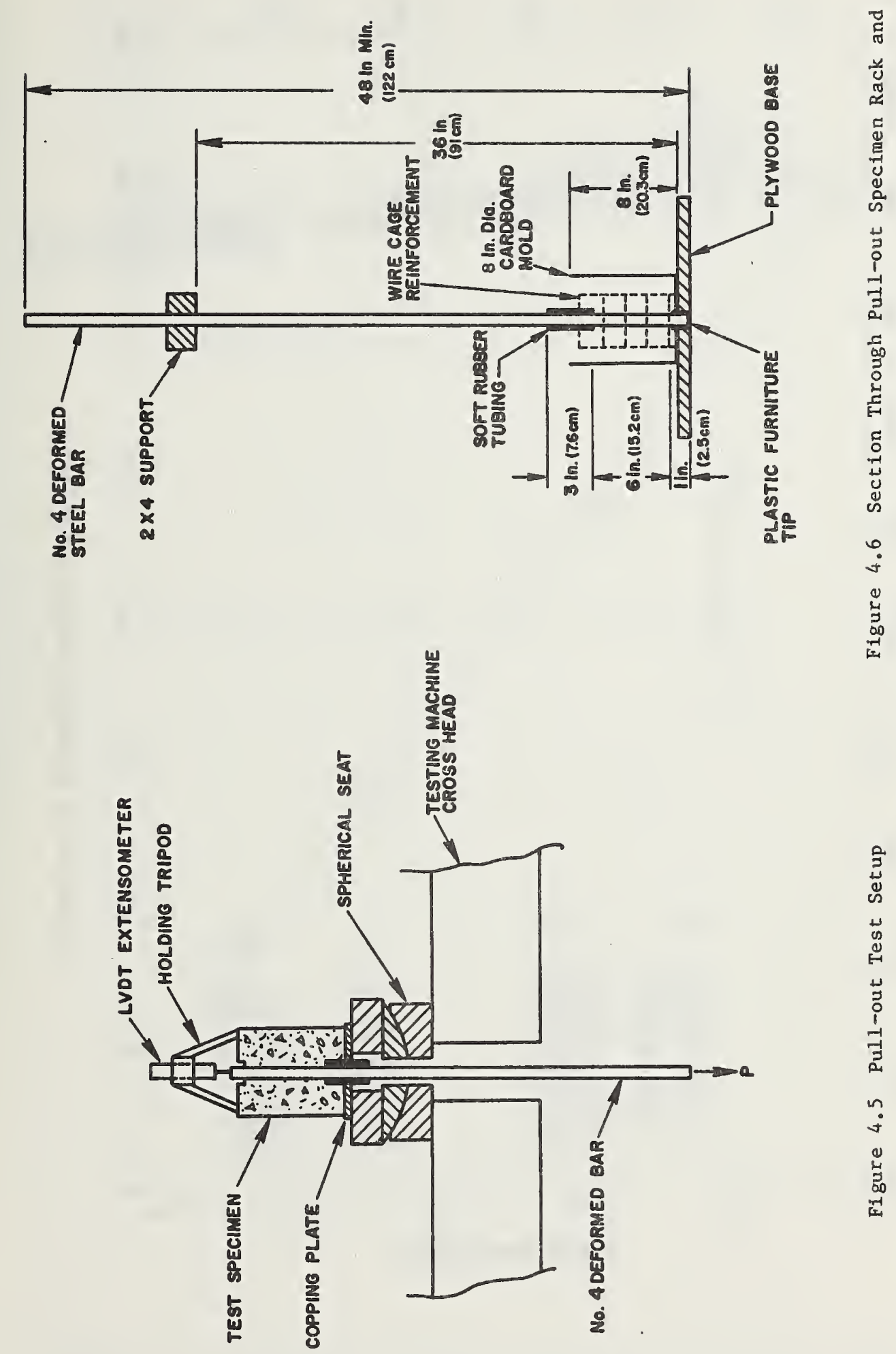

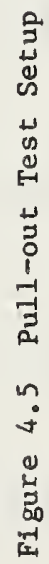




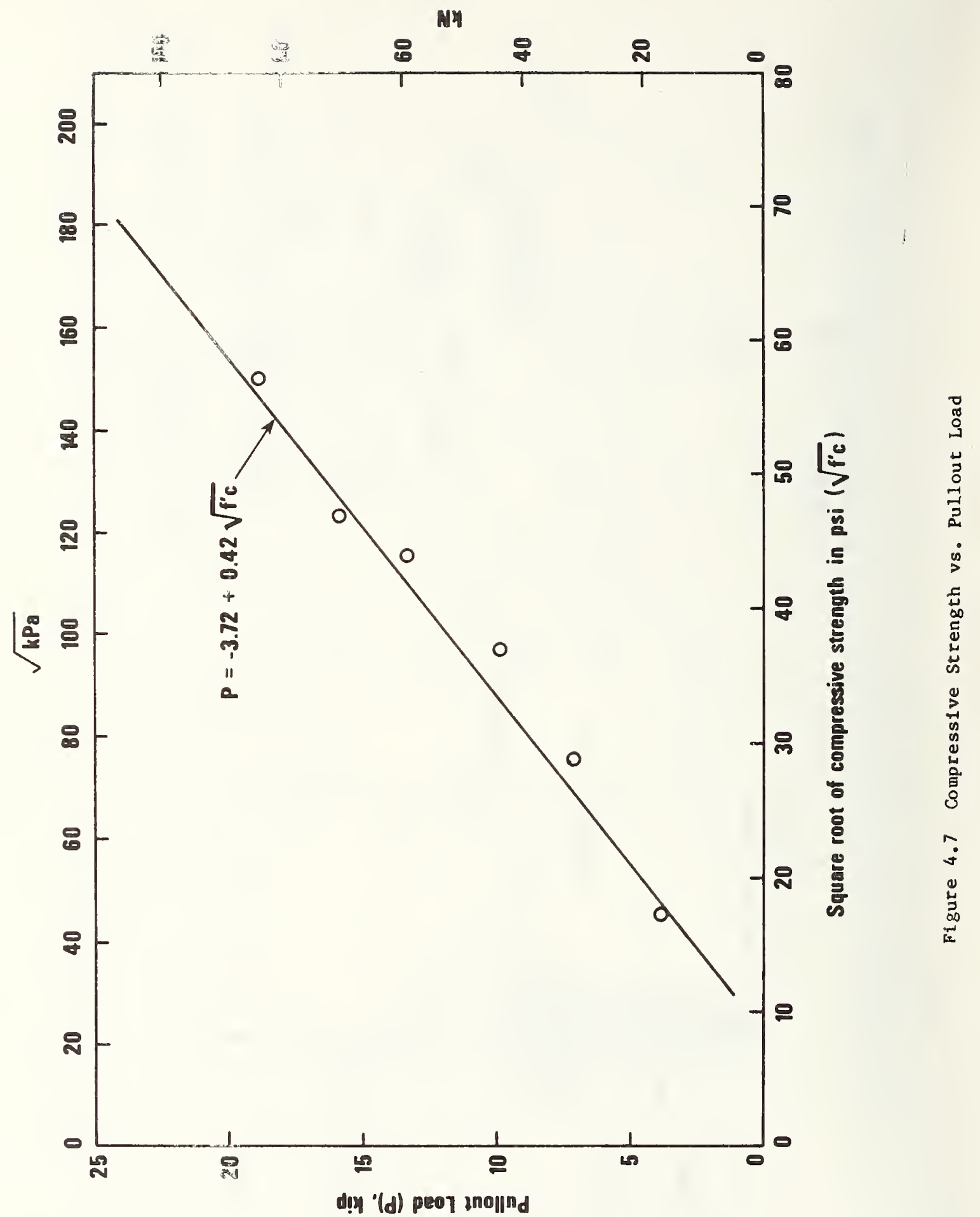



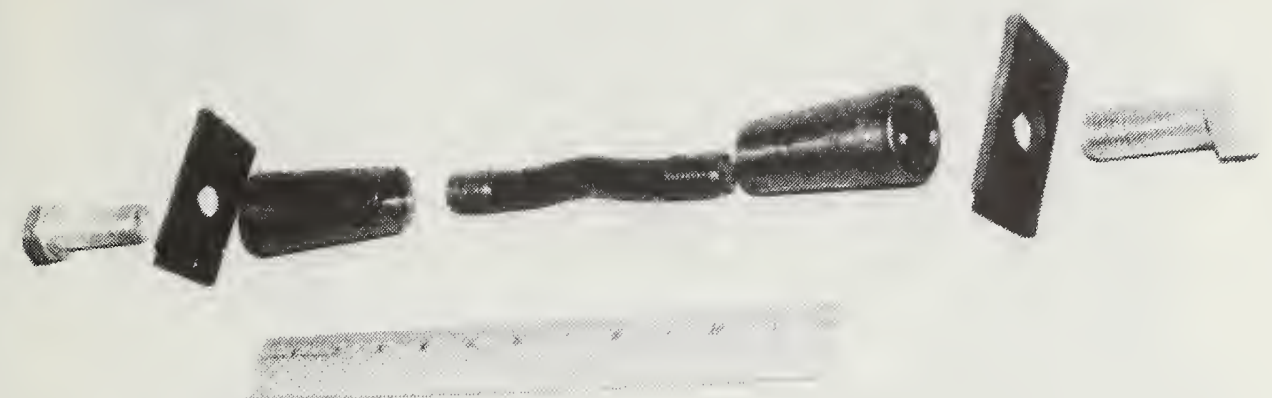

Figure 4.8 Williams Anchor Bolt Assembly
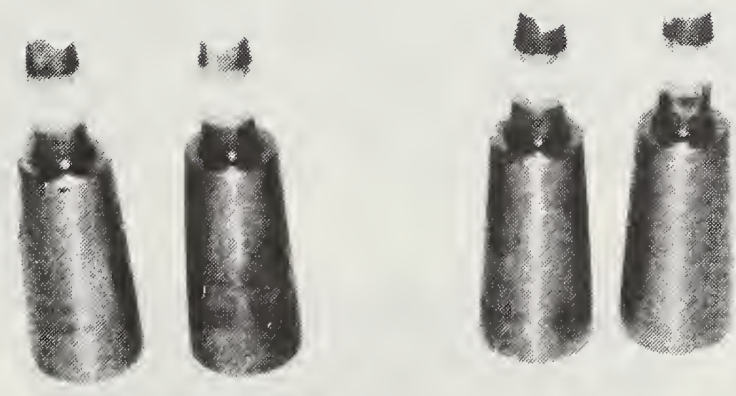

Figure 4.9 Appearance of Williams Anchor Bolts After Tension Test 


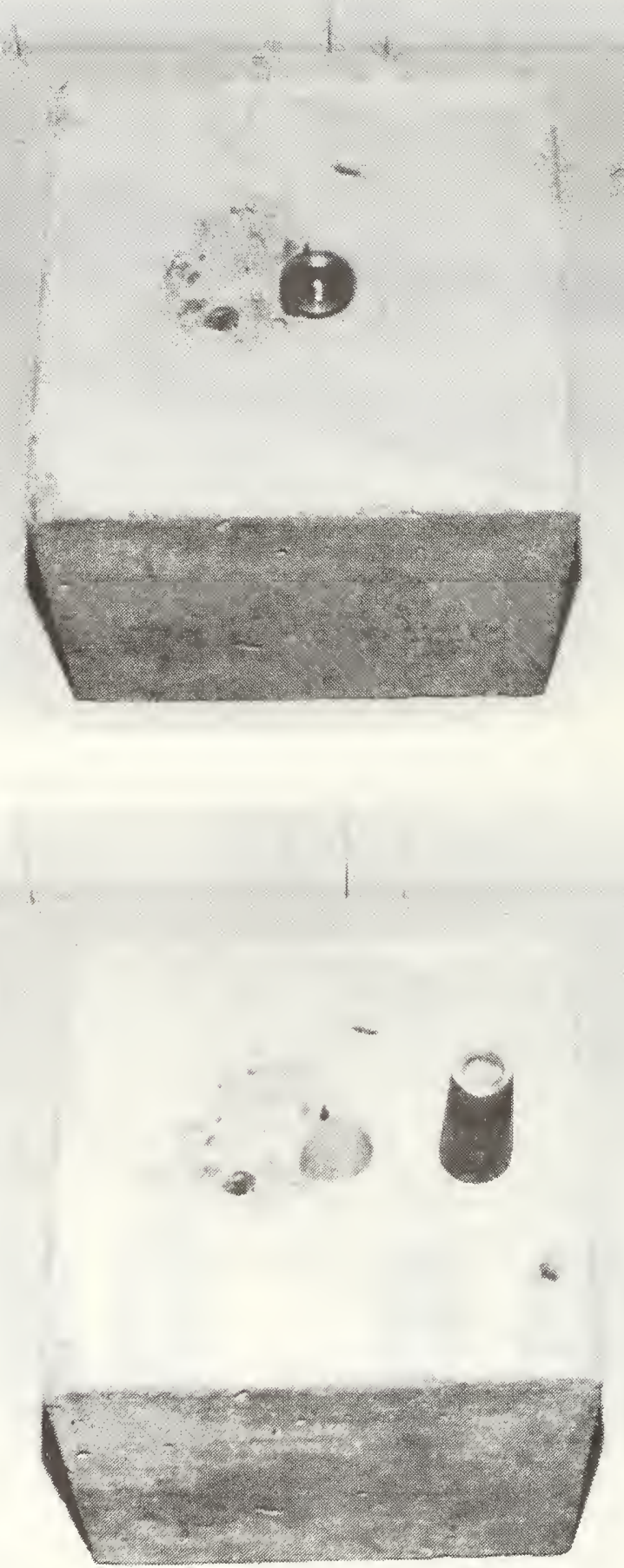

Figure 4.10 Fractured Williams Anchor Bolt Embedded in a Concrete Block 


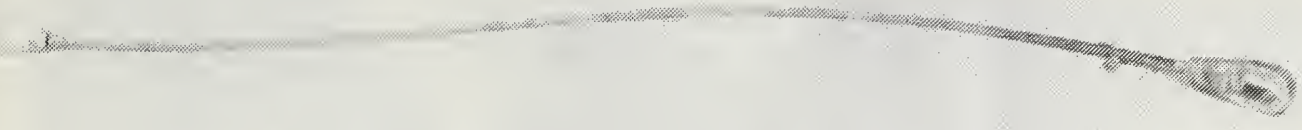

Figure 4.11 Typical Wire Rope Test Specimen

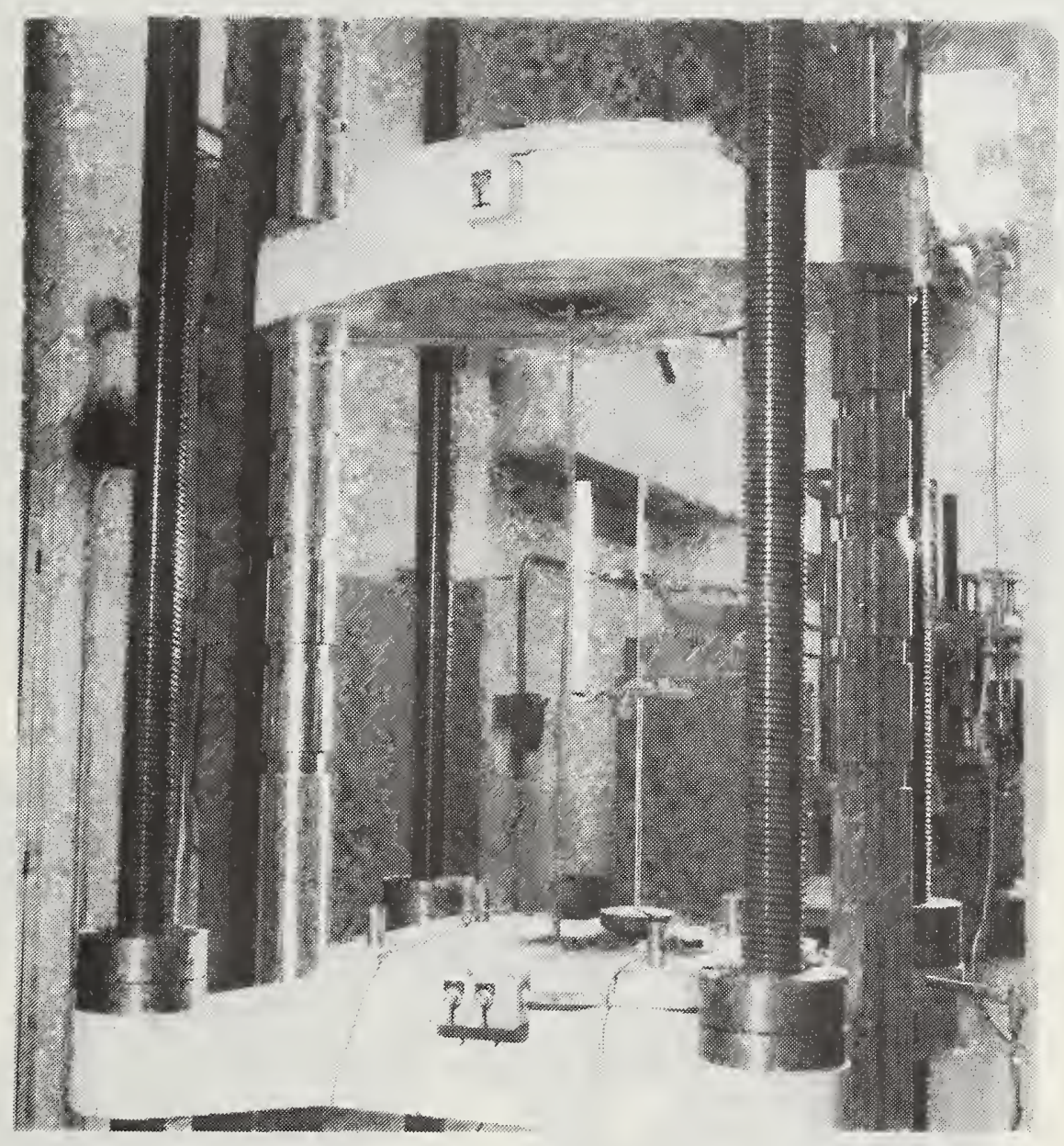

Figure 4.i2 Tension Test Setup for Wire Rope 


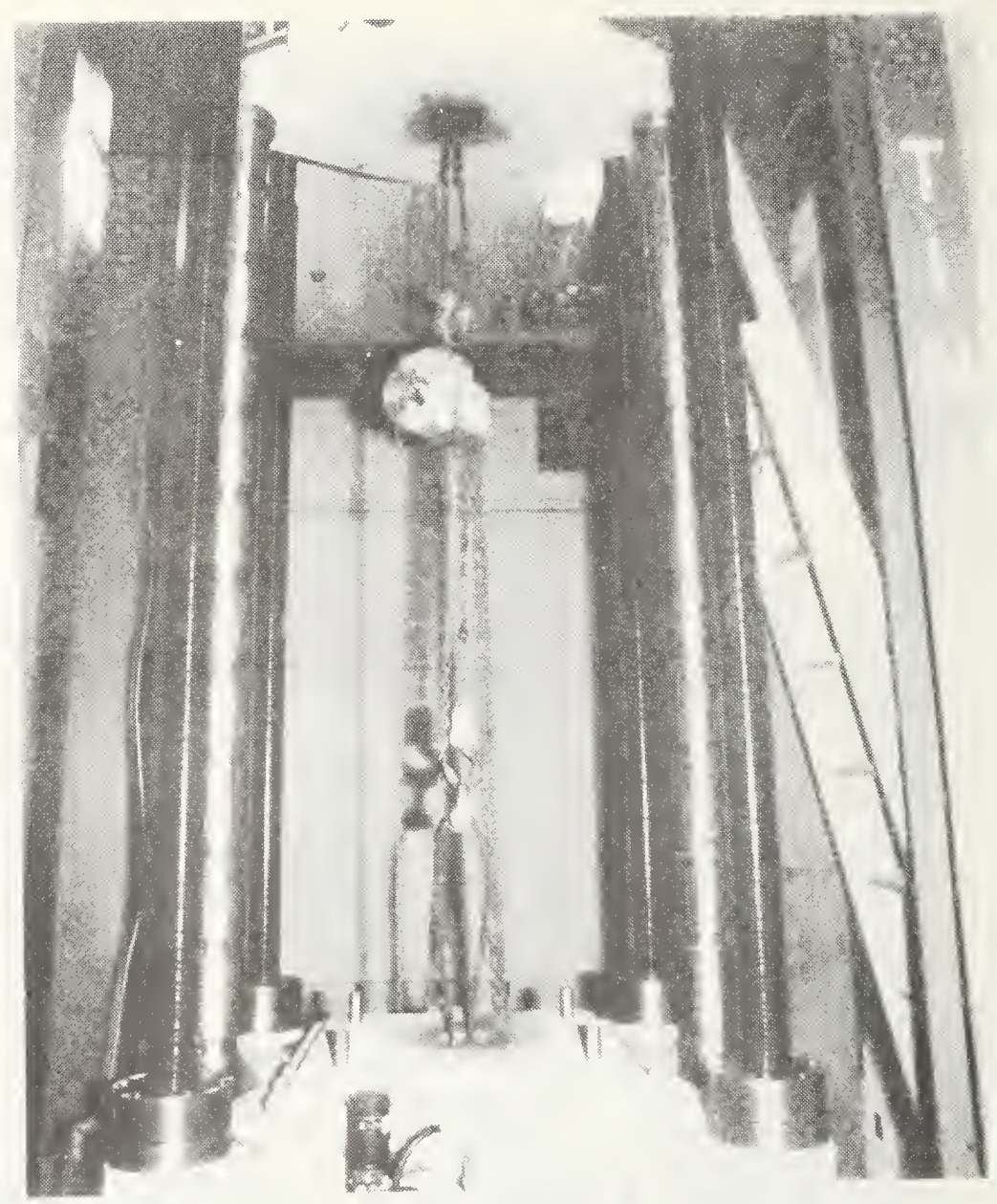

Figure 4.13 Test Setup for Chain Hoist

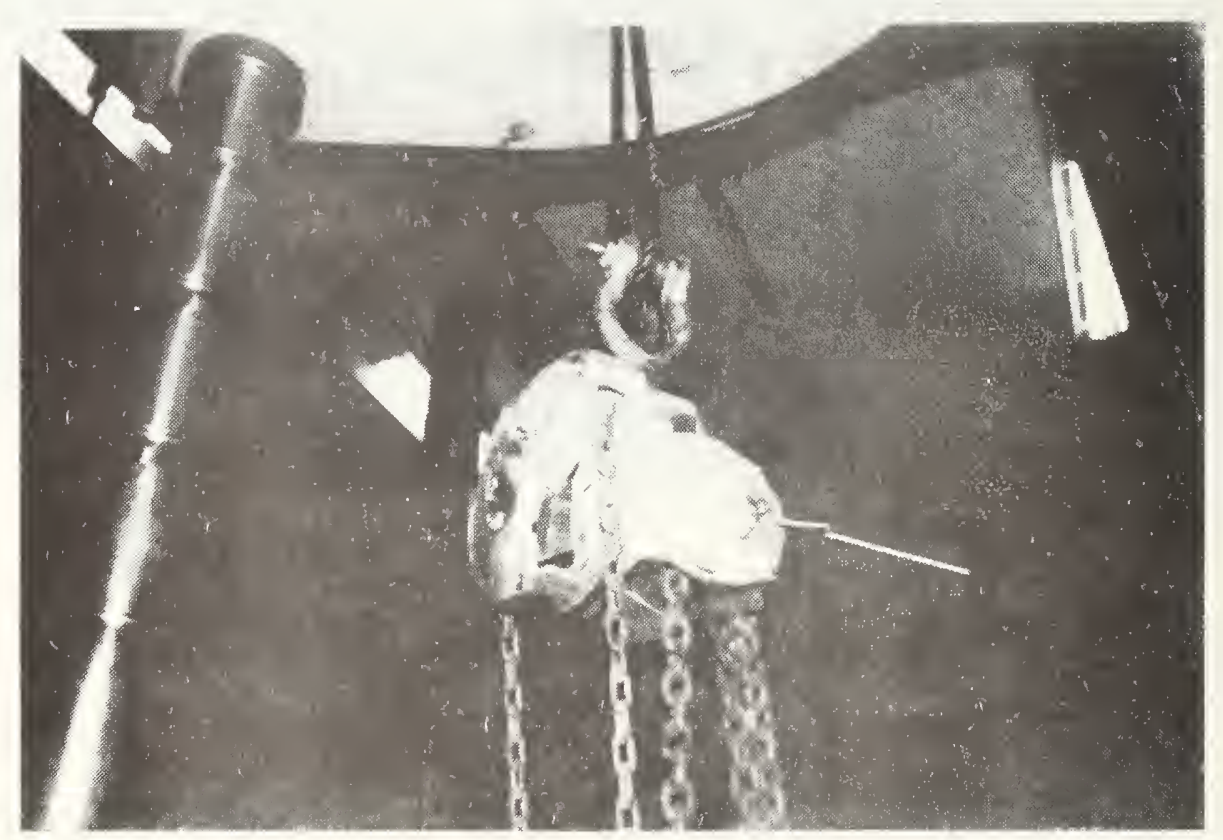

Figure 4.14 Fractured Cover Plate for Gear Box 


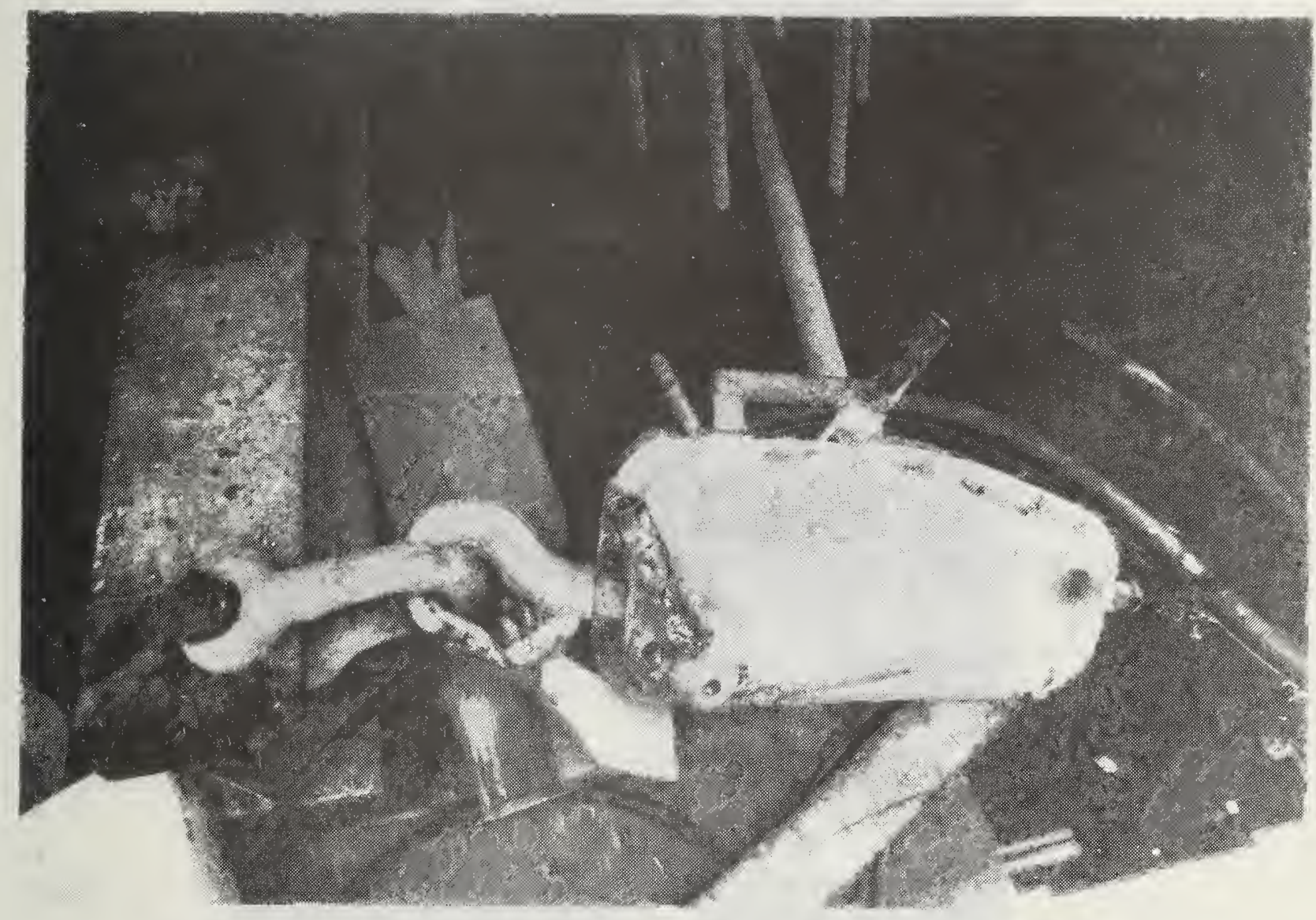

Figure 4.15 Anchorage of Static Line to Ground Through Grip-Hoist 


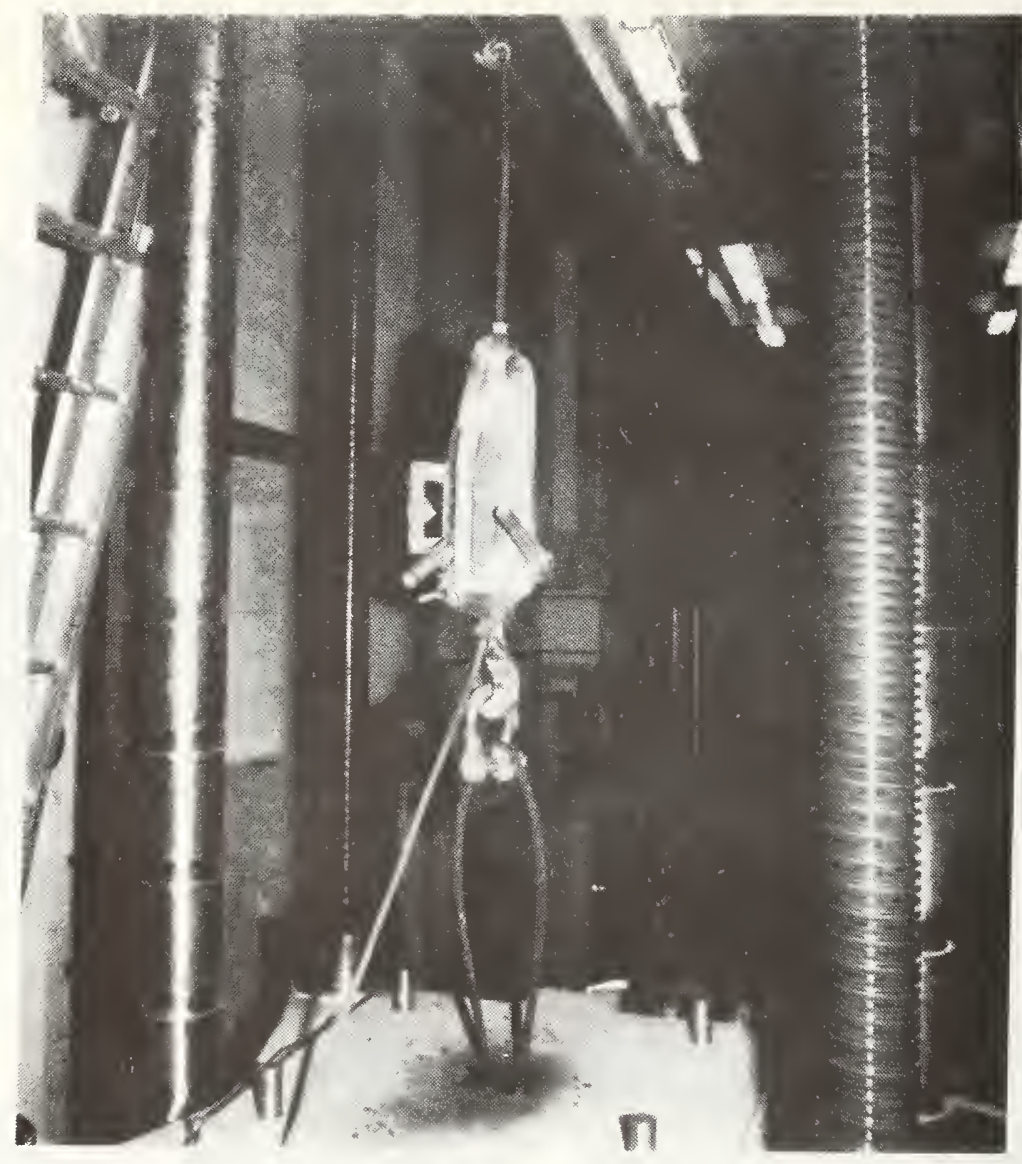

Figure 4.16 Test Setup for Grip-Hoist

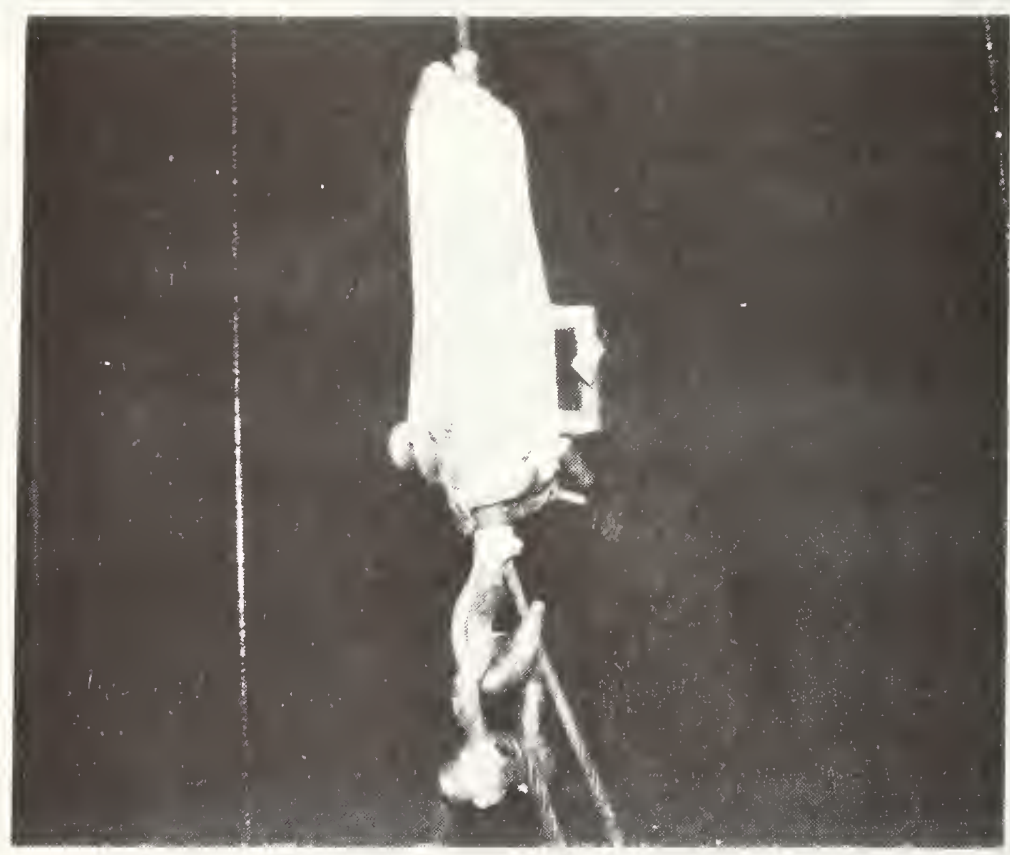

Figure 4.17 A Close-up View of Grip-Hoist After Tension Test. The Hook Pulled Away from the Housing. 


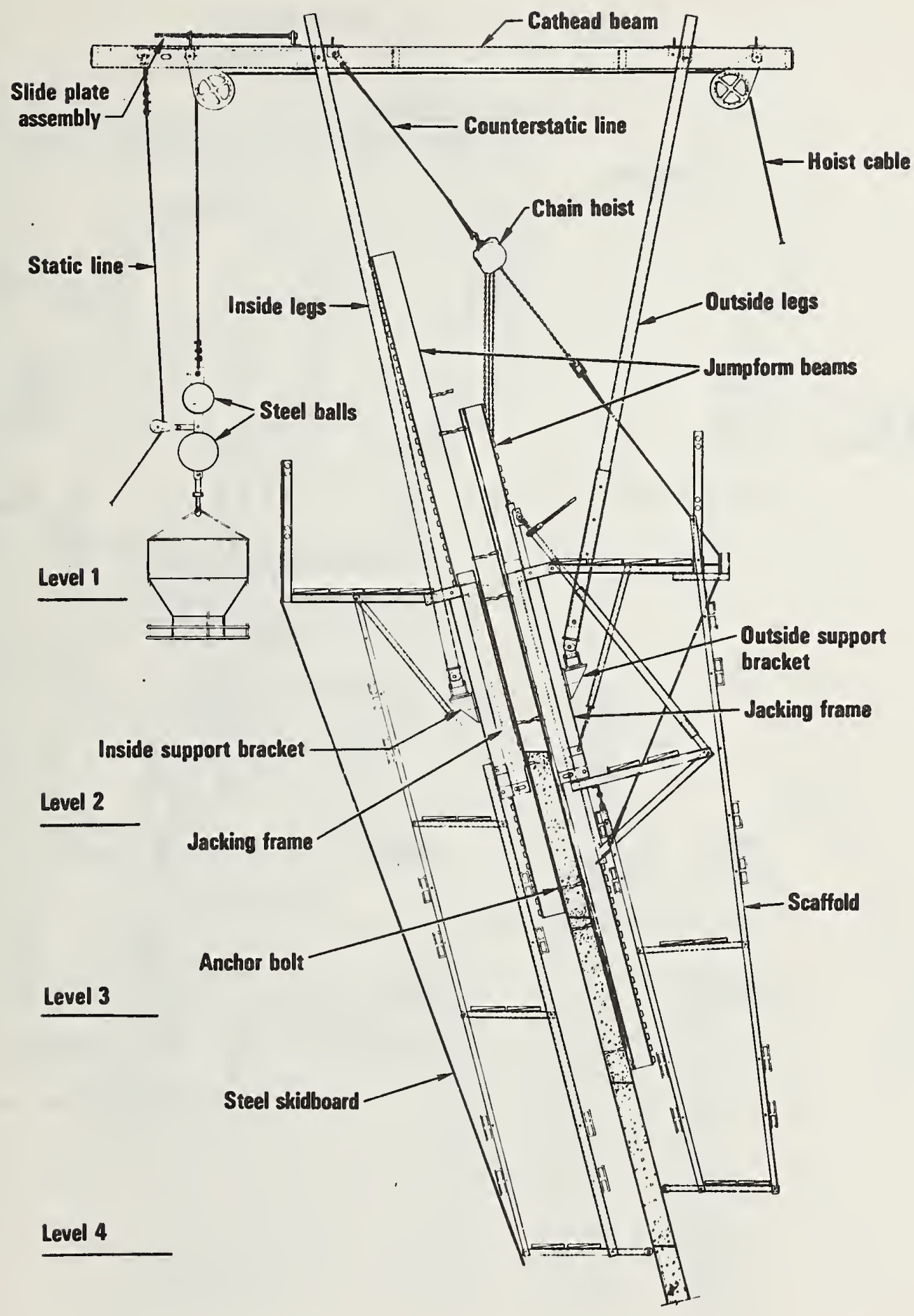

Figure 5.1 Cathead Gantry Assembly 


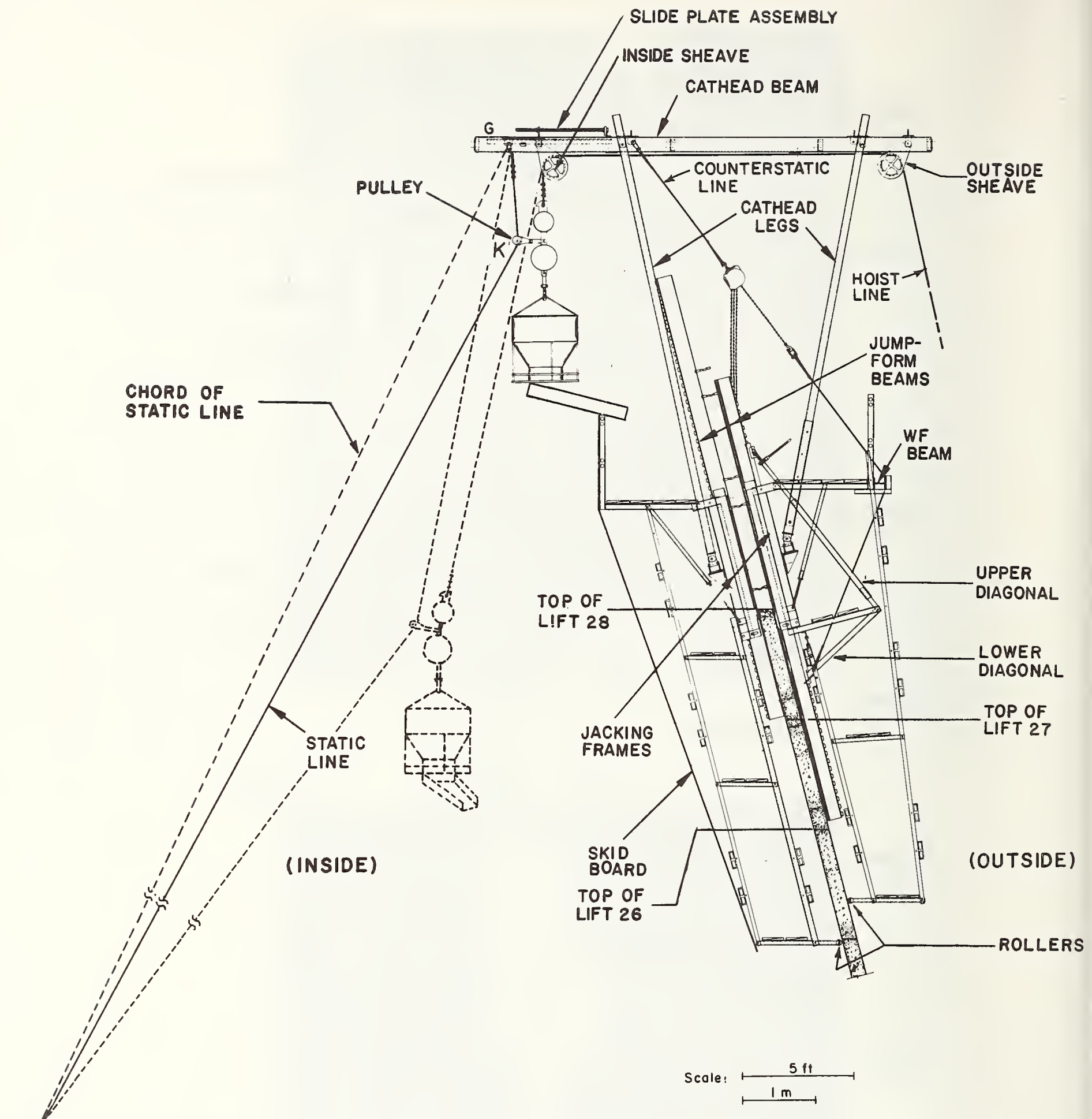

Figure 6.1 General Sectional Configuration of Construction Scheme 


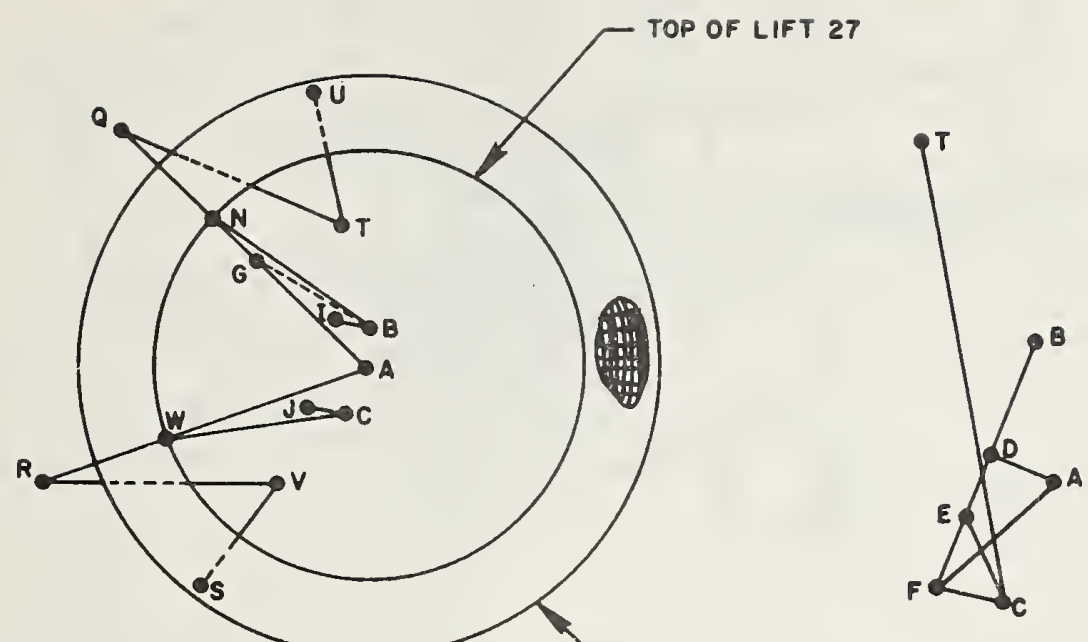

BASE OF CONCRETE SHELL

\section{FIELD SURVEY DATA}

C: cathead no. 5 static line clevis at concrete hopper Elevation of $C=105.37 \mathrm{ft}(32.13 \mathrm{~m})$

$\mathrm{BD} / / \mathrm{DE} \| \mathrm{EF} \perp \mathrm{AD}$

\begin{tabular}{|c|c|c|c|}
\hline$\overline{B D}$ & $D E$ & $A D$ & $\overline{E F}$ \\
\hline $\begin{array}{c}8.4583 \\
(2.5798)\end{array}$ & $\begin{array}{c}6.5417 \\
(1.9952)\end{array}$ & $\begin{array}{c}1.0625 \\
(0.3241)\end{array}$ & $\begin{array}{c}2.0 \\
(0.61)\end{array}$ \\
\hline CE & CF & CT & $\mathrm{AF}$ \\
\hline $\begin{array}{c}2.7708 \\
(0.8451)\end{array}$ & $\begin{array}{c}1.5417 \\
(0.4702)\end{array}$ & $\begin{array}{c}92.5625 \\
(28.2316)\end{array}$ & $\begin{array}{c}8.6075 \\
(2.6253)\end{array}$ \\
\hline
\end{tabular}

Coordinates, it (m)

\begin{tabular}{|c|c|c|c|c|}
\hline & \multirow{2}{*}{$\begin{array}{l}\text { Location and } \\
\text { Description of Point }\end{array}$} & \multicolumn{3}{|c|}{ Space Coordinates } \\
\hline & & Notth & South & Elevation \\
\hline & Center Marker & $\begin{array}{c}919.44 \\
(280.43)\end{array}$ & $\begin{array}{l}1023.39 \\
(312.13)\end{array}$ & $\begin{array}{c}97.81 \\
(29.83)\end{array}$ \\
\hline B: & $\begin{array}{l}\text { Cathead } 4 \text { Static } \\
\text { Line Clevis at Hopper }\end{array}$ & $\begin{array}{c}927.94 \\
(283.02)\end{array}$ & $\begin{array}{l}1022.66 \\
(311.91)\end{array}$ & $\begin{array}{l}104.92 \\
(32.00)\end{array}$ \\
\hline I: & $\begin{array}{l}\text { Sheave Block for Holet } \\
\text { Lines of Catheads } 3 \text { and } 4\end{array}$ & $\begin{array}{l}1000.00 \\
(305.00)\end{array}$ & $\begin{array}{l}1000.00 \\
(305.00)\end{array}$ & $\begin{array}{c}98.45 \\
(30.03)\end{array}$ \\
\hline N: & $\begin{array}{l}\text { Cold Joint Top of } \\
\text { Lift } 27 \text { at Cathead } 4\end{array}$ & $\begin{array}{l}1009.23 \\
(307.82)\end{array}$ & $\begin{array}{c}923.50 \\
(281.67)\end{array}$ & $\begin{array}{l}264.69 \\
(80.73)\end{array}$ \\
\hline U: & $\begin{array}{l}\text { Holet Drum for } \\
\text { Catheads } 3 \text { and } 4\end{array}$ & $\begin{array}{l}1079.80 \\
(329.34)\end{array}$ & $\begin{array}{c}976.84 \\
(297.94)\end{array}$ & $\begin{array}{c}99.53 \\
(30.36)\end{array}$ \\
\hline Q: & $\begin{array}{l}\text { Ground Sheave for Holst } \\
\text { Line of Cathead } 4\end{array}$ & $\begin{array}{l}1040.92 \\
(317.48)\end{array}$ & $\begin{array}{c}887.84 \\
(270.79)\end{array}$ & $\begin{array}{c}98.61 \\
(30.08) \\
\end{array}$ \\
\hline V: & $\begin{array}{l}\text { Sheave Block for Holst } \\
\text { Lines of Catheads } 5 \text { and } 6\end{array}$ & $\begin{array}{c}852.22 \\
(259.93)\end{array}$ & $\begin{array}{l}973.94 \\
(297.05)\end{array}$ & $\begin{array}{c}98.49 \\
(30.04)\end{array}$ \\
\hline $\bar{W}:$ & $\begin{array}{l}\text { Cold Jolnt Top of } \\
\text { Lift } 27 \text { at Cathead } 5\end{array}$ & $\begin{array}{c}869.48 \\
(264.58)\end{array}$ & $\begin{array}{c}898.75 \\
(274.12)\end{array}$ & $\begin{array}{l}265.54 \\
(80.99)\end{array}$ \\
\hline $\mathrm{R}:$ & $\begin{array}{l}\text { Ground Sheave for Holst } \\
\text { Line of Cathead } 5\end{array}$ & $\begin{array}{l}851.94 \\
(259.84)\end{array}$ & $\begin{array}{l}854.35 \\
(260.58)\end{array}$ & $\begin{array}{l}98.90 \\
(30.16)\end{array}$ \\
\hline S: & $\begin{array}{l}\text { Holst Drum for } \\
\text { Catheads } 5 \text { and } 6\end{array}$ & $\begin{array}{l}784.79 \\
(239.36)\end{array}$ & $\begin{array}{c}924.36 \\
(281.93)\end{array}$ & $\begin{array}{l}99.36 \\
(30.30)\end{array}$ \\
\hline
\end{tabular}

Figure 6.2 Field Survey Data for Location of Hoisting Cables 


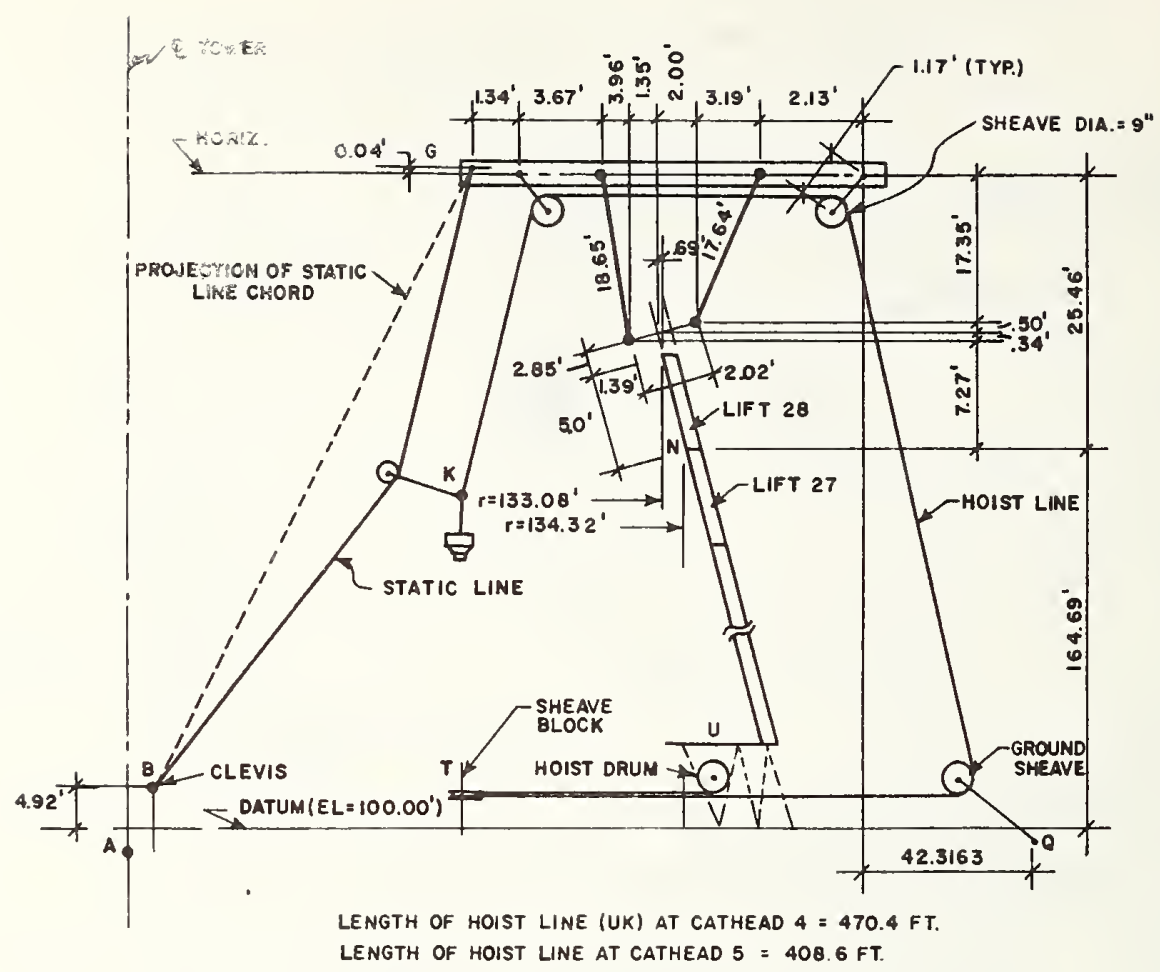

COMPUTED RESULTS

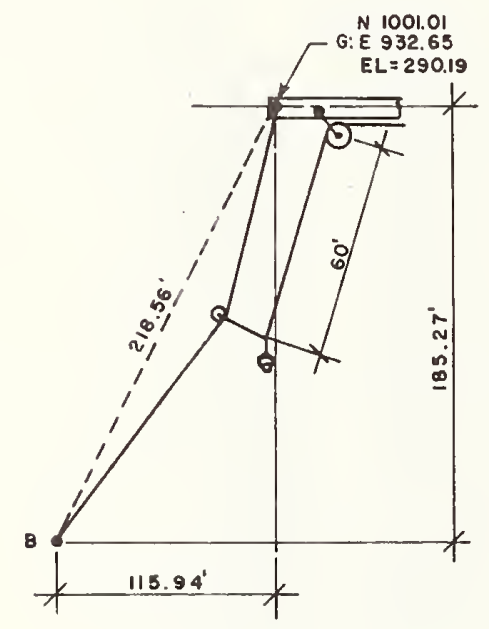

AT CATHEAD 4

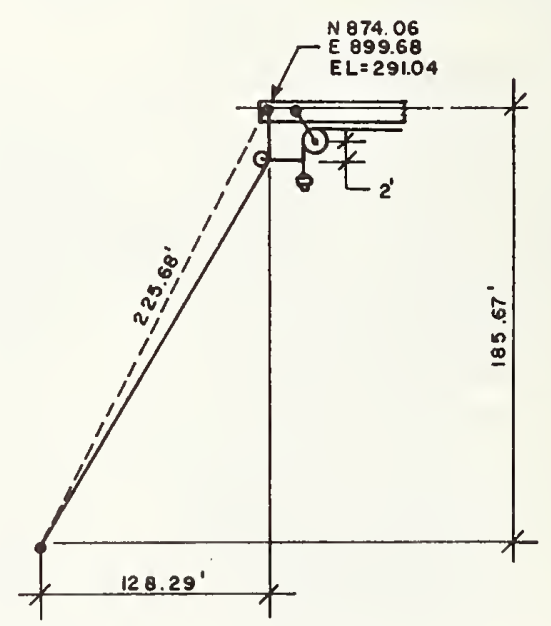

AT CATHEAD 5

$1 \mathrm{fl}=0.305 \mathrm{~m}$ 

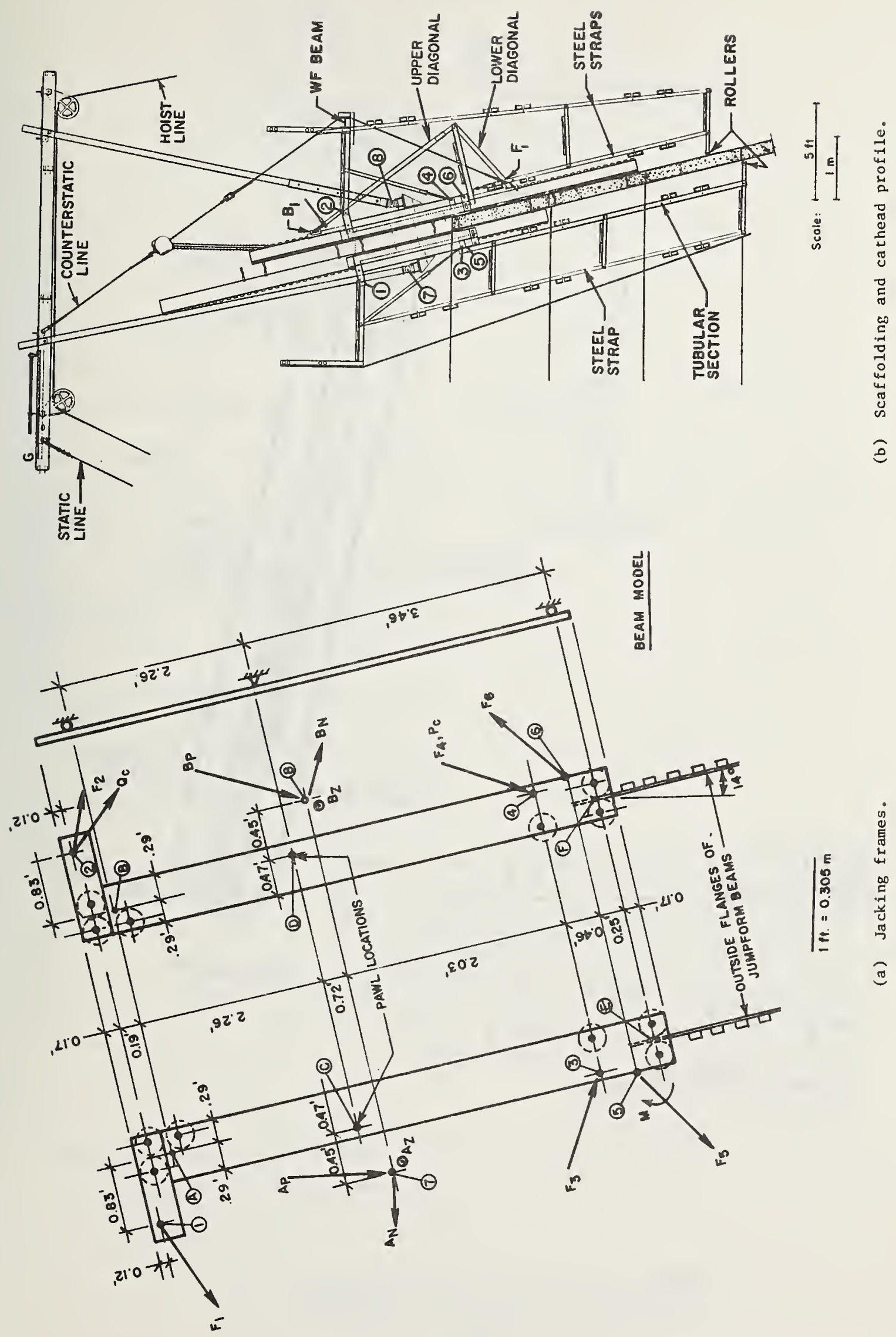


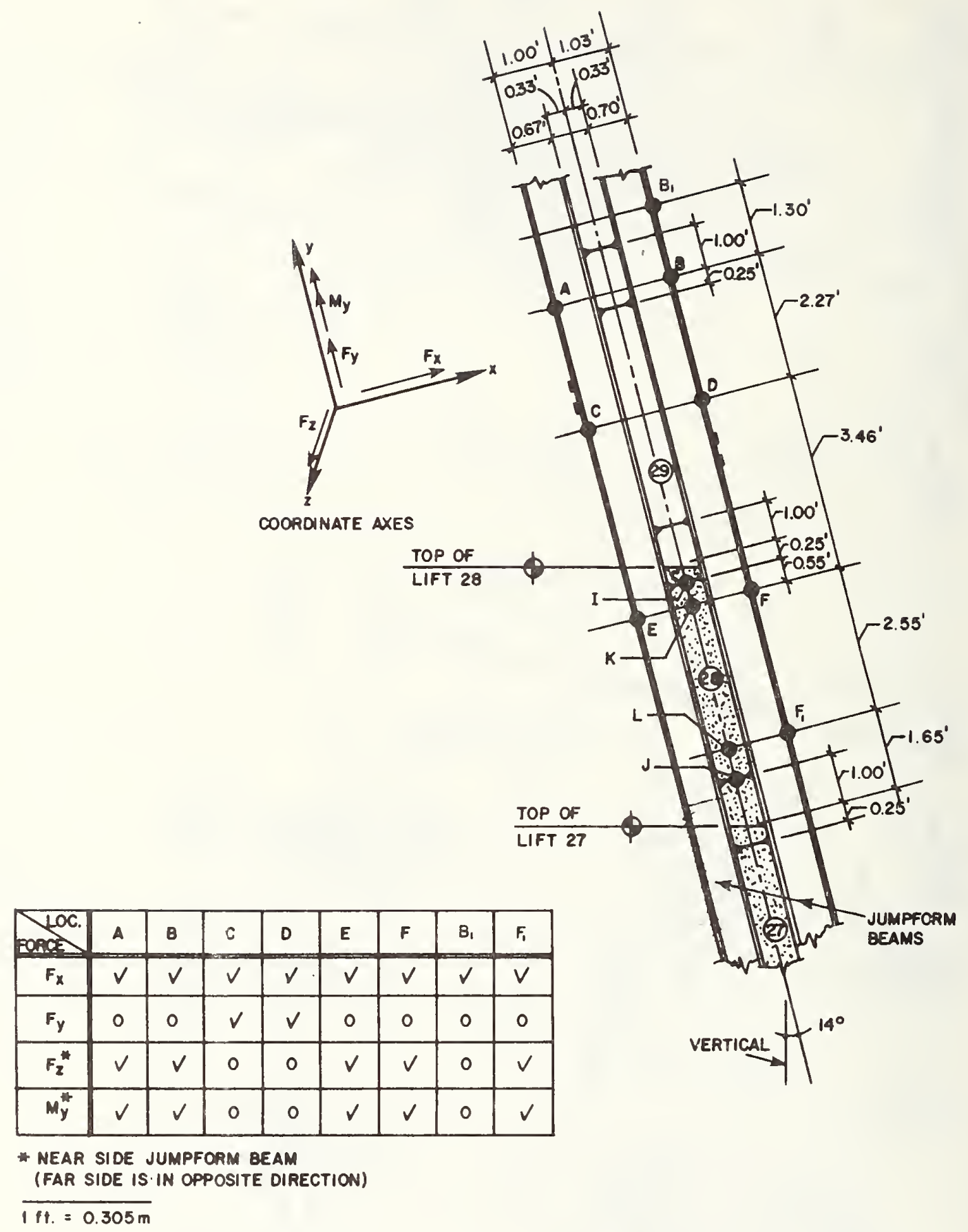

Figure 6.5 Forces on the Jumpform Beams 


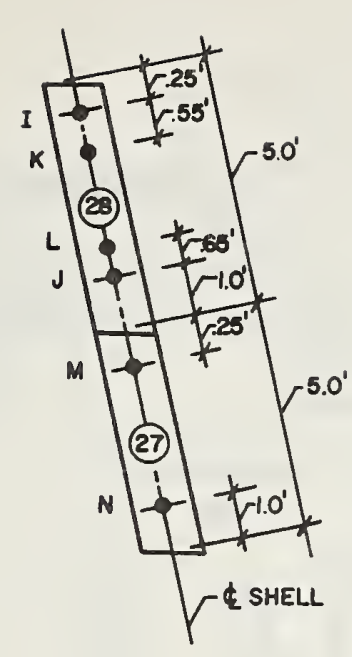

Load Case(2) - Weight of Scaffolding

\begin{tabular}{|c|c|c|c|c|}
\hline Loc & $I$ & $J$ & $K$ & $L$ \\
\hline$F_{x}$ & -674 & 366 & 91 & -226 \\
$F_{y}$ & -2426 & -2426 & 0 & 0 \\
$F_{z}$ & 0 & 0 & 0 & 0 \\
$M_{y}$ & 0 & 0 & 0 & 0 \\
\hline
\end{tabular}

Load Case (4) -Weight of Cathead

\begin{tabular}{|c|c|c|c|c|}
\hline Forces & $\mathrm{I}$ & $\mathrm{J}$ & $\mathrm{K}$ & $\mathrm{L}$ \\
\hline $\mathrm{F}_{\mathrm{x}}$ & -1293 & 784 & -55 & 232 \\
$\mathrm{~F}_{\mathrm{y}}$ & -928 & -928 & 0 & 0 \\
${ }^{*} \mathrm{~F}_{\mathrm{z}}$ & 213 & -123 & 71 & -66 \\
${ }_{\mathrm{M}} \mathrm{y}$ & 67 & 66 & 101 & 91 \\
\hline
\end{tabular}

$y$ (parallel to shell)

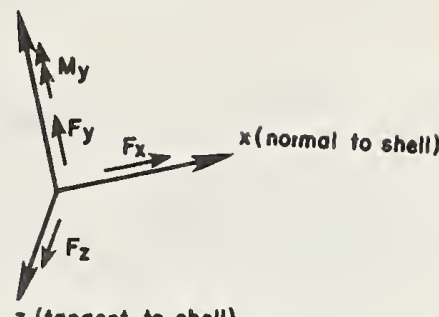

2 (tangent to shell)

\begin{tabular}{|c|r|r|r|r|}
\hline Loc & $\mathrm{I}$ & $\mathrm{J}$ & $\mathrm{K}$ & $\mathrm{L}$ \\
\hline $\mathrm{F}_{\mathrm{x}}$ & 337 & -212 & 32 & 0 \\
$\mathrm{~F}_{\mathrm{y}}$ & -970 & -970 & 0 & 0 \\
F $_{\mathrm{z}}$ & 0 & 0 & 0 & 0 \\
${ }_{\mathrm{M}} \mathrm{y}$ & 0 & 0 & 0 & 0 \\
\hline
\end{tabular}

Load Case (5) - Hoisting Loads

\begin{tabular}{|r|r|r|r|r|}
\hline Forces & I & $\mathrm{J}$ & $\mathrm{K}$ & $\mathrm{L}$ \\
\hline $\mathrm{F}_{\mathrm{x}}$ & -19025 & 12296 & 426 & 2964 \\
$\mathrm{~F}_{\mathrm{y}}$ & -1996 & -1996 & 0 & 0 \\
$\mathrm{~F}_{\mathrm{z}}$ & 2151 & -2151 & 707 & -1544 \\
M M $_{\mathrm{y}}$ & 798 & 798 & 1243 & 2115 \\
\hline
\end{tabular}

* Near side jumpform beam (force on far side beam equal and opposite)

Units: Moment in $\mathrm{ft}-1 \mathrm{~b}(1.00 \mathrm{ft}-1 \mathrm{~b}=1.36 \mathrm{~N}-\mathrm{m})$

Force in $1 \mathrm{~b}(1.001 \mathrm{~b}=4.45 \mathrm{~N})$

Figure 6.6 Summary of Loads Applied to the Shell 


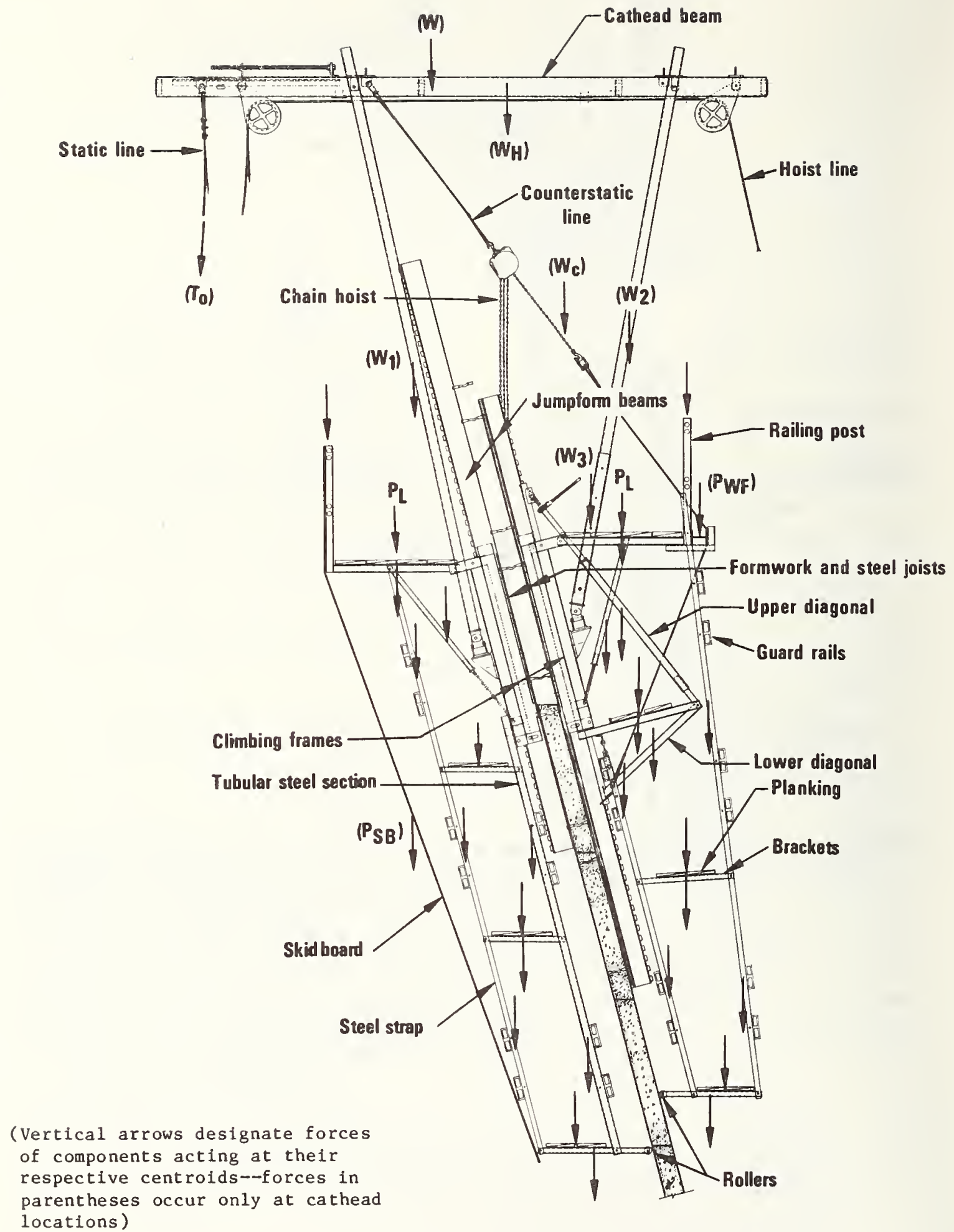

Figure 6.7 Definition of Gravity Loads 


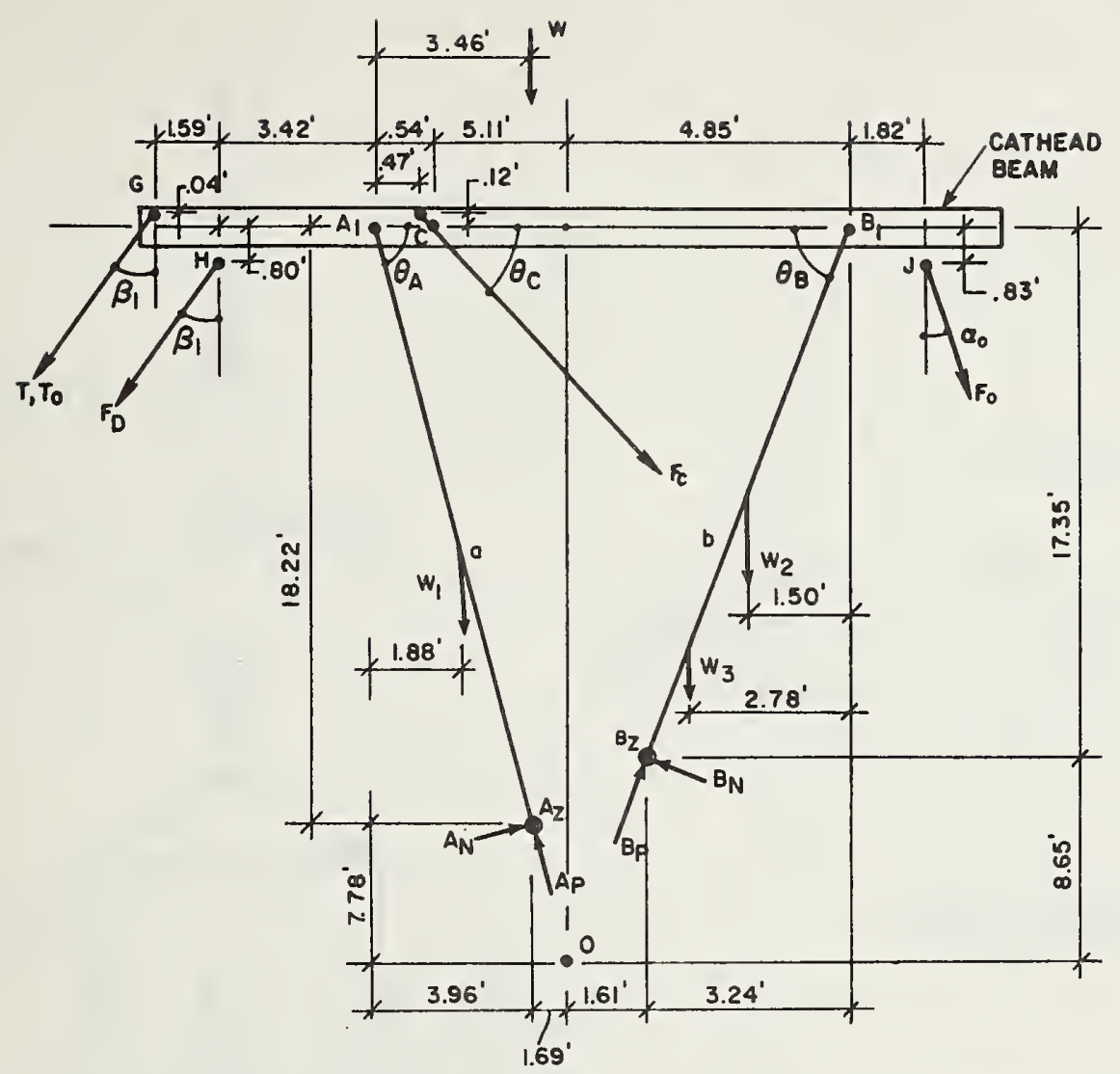

A, $B=$ supports of Inside and outside cathead legs, respectively.

$A_{N}, B_{N}=$ cathead leg reaction components in plane of figure and normal to $A A_{1}$ and $B_{1}$, respectively.

$A_{P}, B_{P}=$ cathead leg reaction components in plane of figure and parallel to $\mathrm{AA}_{1}$ and $\mathrm{BB}_{1}$, respectively.

$\mathrm{A}_{\mathrm{Z}}, \mathrm{B}_{\mathrm{Z}}=$ horizontal cathead leg reaction components of $\mathrm{A}$ and $\mathrm{B}$, respectively, normal to plane of figure.

$\mathrm{W} \quad=$ resultant weight of cathead beam assembly

$T, T_{0}=$ tension in static line due to hoisting loads and self weight

$F_{D}, F_{0}=$ tension in hoist line $\left(F_{D}=F_{0}\right)$

$F_{c}=$ tension in counterstatic line

$$
\begin{aligned}
& \mathrm{a}=\overline{\mathrm{AA}}_{1}=18.65 \mathrm{ft} \\
& \mathrm{b}=\overline{\mathrm{BB}}_{1}=17.64 \mathrm{ft} \\
& \mathrm{w}=10711 \mathrm{~b} \\
& \mathrm{w}_{1}=5001 \mathrm{~b} \\
& \mathrm{w}_{2}=4491 \mathrm{~b}
\end{aligned}
$$$$
\mathrm{w}_{3}=239 \mathrm{Ib}
$$$$
{ }^{\theta} \mathrm{A}=77.740^{\circ}
$$$$
\theta_{B}=79.434^{\circ}
$$$$
{ }^{\theta} \mathrm{C}=53.031^{\circ}
$$$$
\alpha_{0}=12.4^{\circ}
$$ 

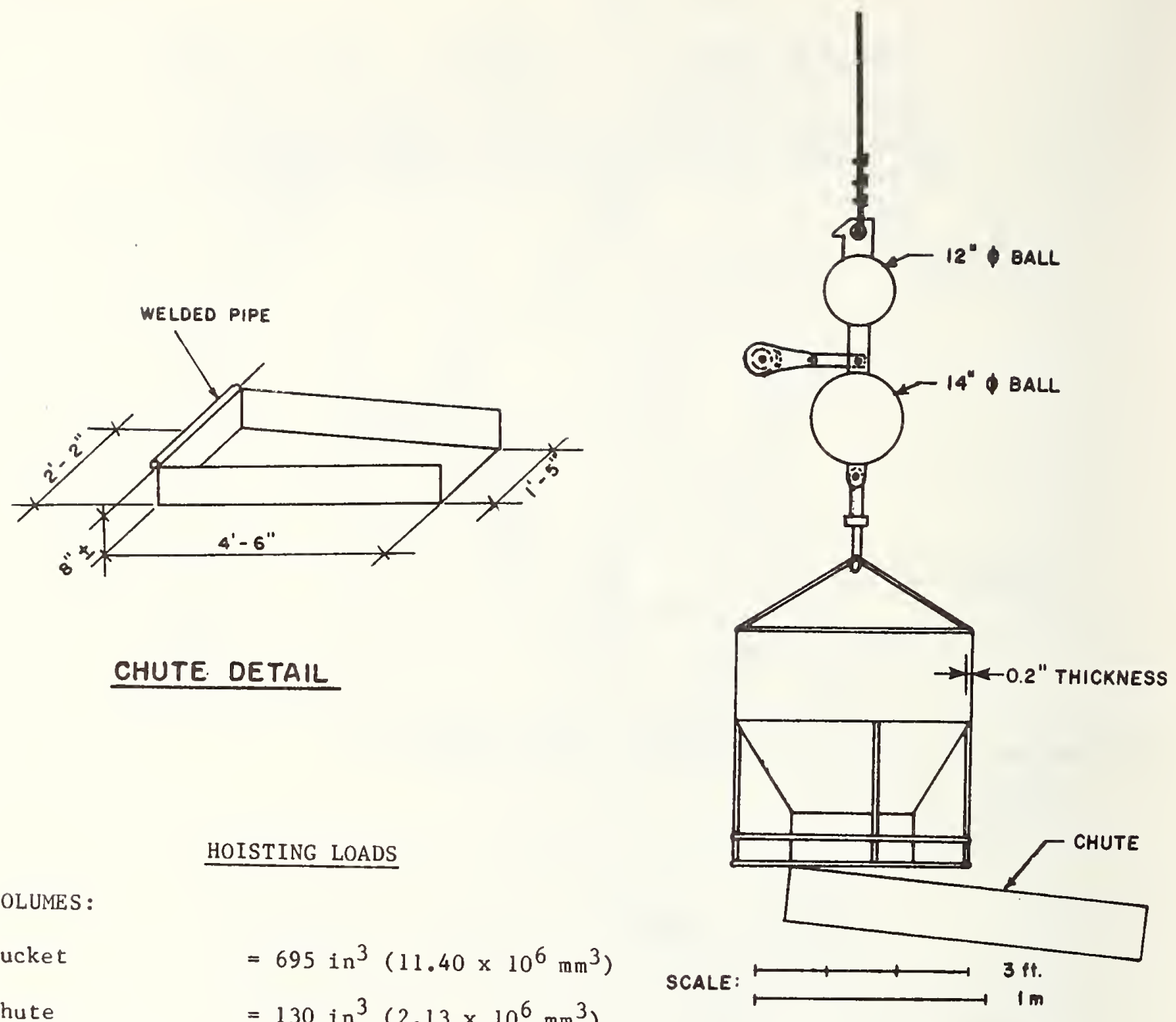

VOLUMES :

HOISTING LOADS

$$
\begin{array}{ll}
\text { Bucket } & =695 \mathrm{in}^{3}\left(11.40 \times 10^{6} \mathrm{~mm}^{3}\right) \\
\text { Chute } & =130 \mathrm{in}^{3}\left(2.13 \times 10^{6} \mathrm{~mm}^{3}\right) \\
1 / 2 \mathrm{yd} . \text { Concrete } & =13.5 \mathrm{ft}^{3}\left(0.378 \mathrm{~m}^{3}\right)
\end{array}
$$

WE IGHTS :

$$
\begin{aligned}
& \text { Bucket } \quad=(.283 \times 695)=1971 \mathrm{~b}(89.2 \mathrm{~kg}) \\
& \text { Chute } \quad=(.283 \times 130)=371 \mathrm{~b}(16.8 \mathrm{~kg}) \\
& \text { Concrete } \quad=(150 \times 13.5)=2,0251 \mathrm{~b}(917.3 \mathrm{~kg}) \\
& \text { Stee } 1 \text { Balls ( } t \text { wo })=5801 \mathrm{~b}(263 \mathrm{~kg} \text { ) } \\
& \text { Misc: Hardware } \quad=\text { TOTAL }=\frac{65 \mathrm{lb}(29 \mathrm{~kg})}{2,904 \mathrm{lb}(1316 \mathrm{~kg})} \\
& \text { Use } W_{B} \quad=2,9001 \mathrm{~b}(1314 \mathrm{~kg})
\end{aligned}
$$

Figure 6.9 Concrete Bucket Dimensions and Weights 


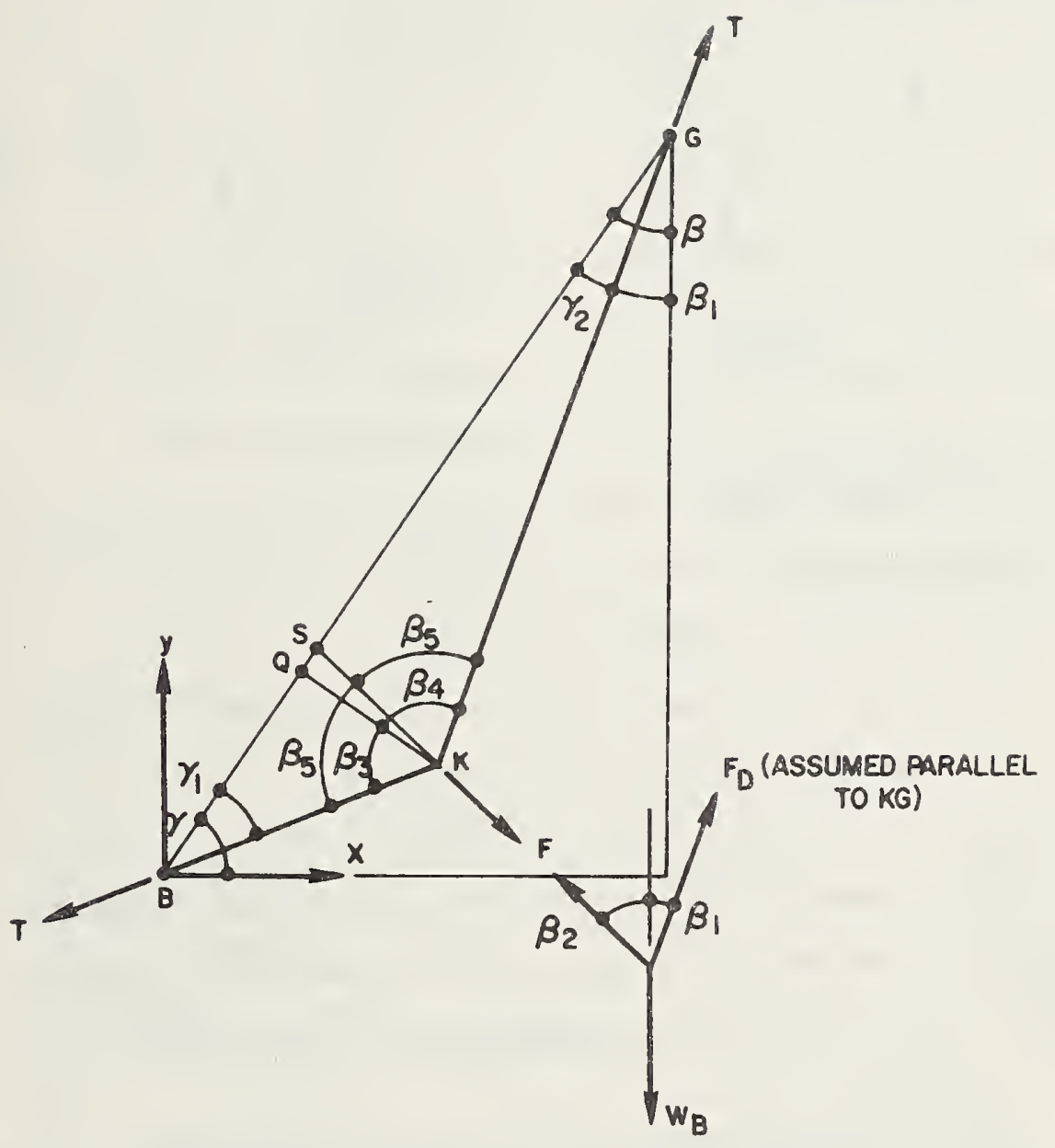

\section{CONSTANT INPUT PARAMETERS}

$L=B G=218.56 \mathrm{ft}(66.66 \mathrm{~m})$

$A=0.098 \mathrm{in}^{2}\left(63.21 \mathrm{~mm}^{2}\right)$

$\mathrm{E}=13 \times 10^{6} \mathrm{psi}\left(89.7 \times 10^{6} \mathrm{kN} / \mathrm{m}^{2}\right)$

$X_{G}=115.94 \mathrm{ft}(35.36 \mathrm{~m})$

$Y_{G}=185.27 \mathrm{ft}(56.51 \mathrm{~m})$

\section{VARIABLE INPUT PARAMETERS}

$$
\mathrm{L}_{1}=\mathrm{BQ}
$$$$
\mathrm{L}_{2}=\mathrm{GQ}
$$$$
\mathrm{D}=\mathrm{KQ}
$$

$\mathrm{W}_{\mathrm{B}}=$ Bucket Weight 


$$
\begin{aligned}
& r_{1}=\tan ^{-1}\left(D / L_{1}\right) \\
& r_{2}=\tan ^{-1}\left(D / L_{2}\right) \\
& \beta_{3}=\frac{\pi}{2}-r_{1} \\
& \begin{array}{l}
B_{4}=\frac{\pi}{2}-\gamma_{2} \\
B_{5}=\left(B_{3}+\beta_{4}\right) / 2
\end{array} \\
& B_{1}=B-\gamma_{2} \\
& B_{2}=B_{5}-B_{1} \\
& \text { * } F=W_{B} \sin B_{1} / \sin \left(B_{1}+B_{2}\right)=\text { force on static line } \\
& \text { * } F_{D}=W_{B} \sin B_{2} / \sin \left(B_{1}+B_{2}\right)=\text { tension of hoist line } \\
& \text { * } T=F /\left(2 \cos B_{5}\right)=\text { tension in static 1ine } \\
& D_{1}=L_{1} / \sin B_{3}=\text { length BK, fig. } 6.10 \\
& \mathrm{D}_{2}=\mathrm{L}_{2} / \mathrm{sin} \mathrm{B}_{4}=\text { length GK, fig. } 6.10 \\
& \text { * } s=D_{1}+D_{2}=\text { stressed length of static line under tension } \mathrm{T} \\
& \text { * } \delta=\mathrm{Ts} /(\mathrm{AE}+\mathrm{T})=\text { static line elongation } \\
& \text { * } s_{0}=s-\delta=\text { stress-free length of static line } \\
& \text { * } \mathrm{x}_{\mathrm{G}}=\mathrm{x} \text { coordinate of } \mathrm{G} \text { after elastic deformation of cathead } \\
& { }^{*} y_{G}=y \text { coordinate of } G \text { after elastic deformation of cathead } \\
& \text { * } \mathrm{F}_{\mathrm{c}}=\text { force in counterstatic line due to hoisting loads }
\end{aligned}
$$

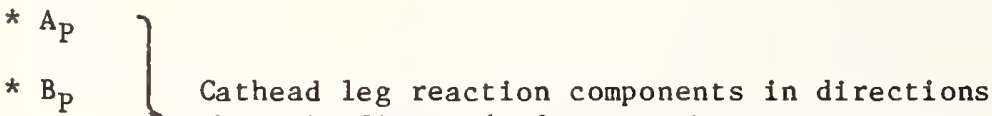

$$
\begin{aligned}
& \text { * } \mathrm{A}_{\mathrm{Z}} \int \text { shown in figure } 6.12 \text { due to hoisting loads } \\
& \left.* \mathrm{~B}_{\mathrm{Z}} \quad\right\} \\
& \text { * Designates results printed out by computer }
\end{aligned}
$$




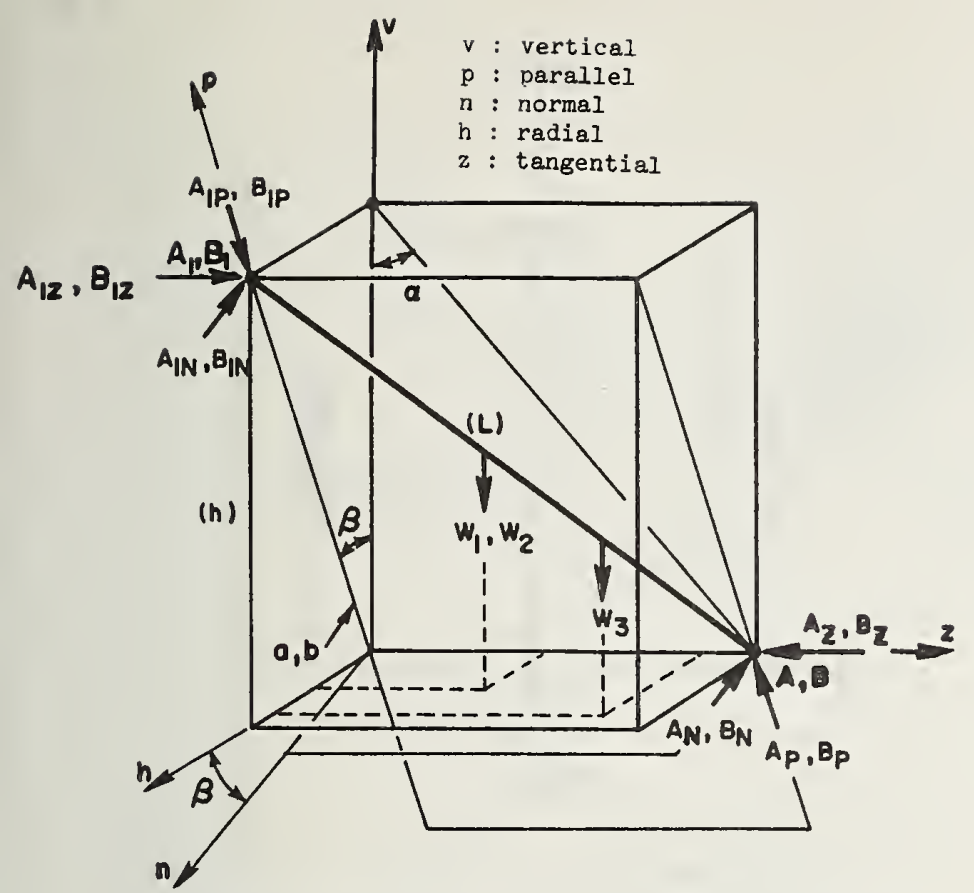

(a) Space configuration of a cathead leg.

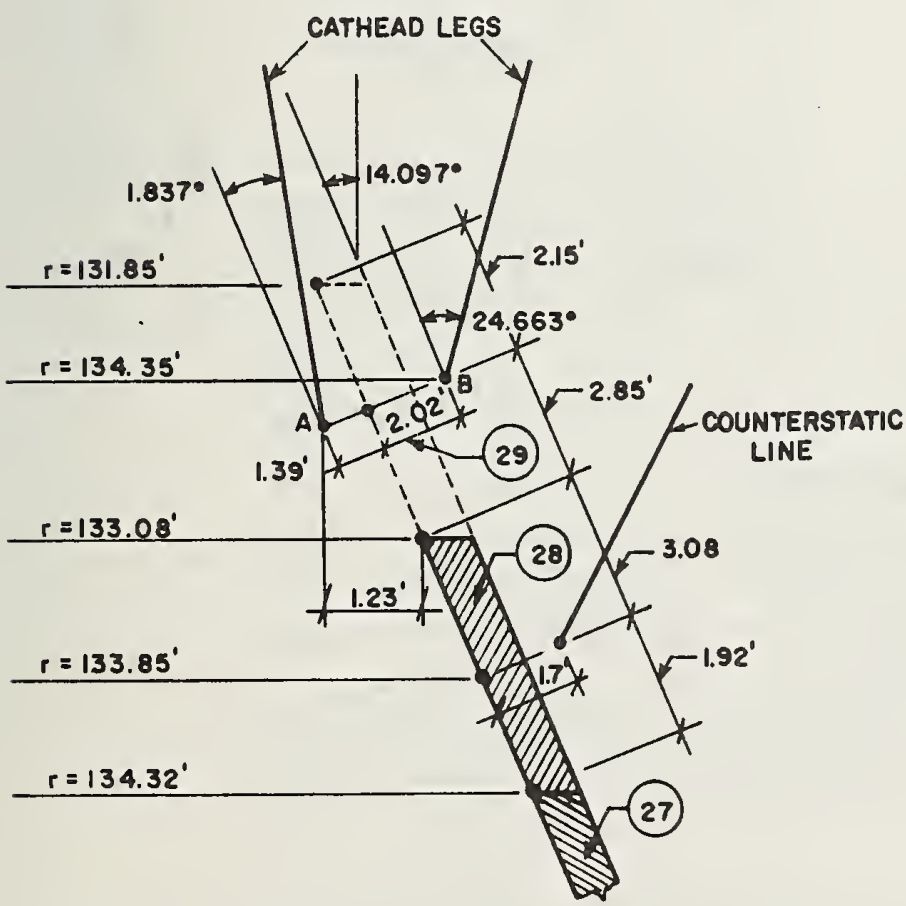

(c) Partial shell prof 11 e.

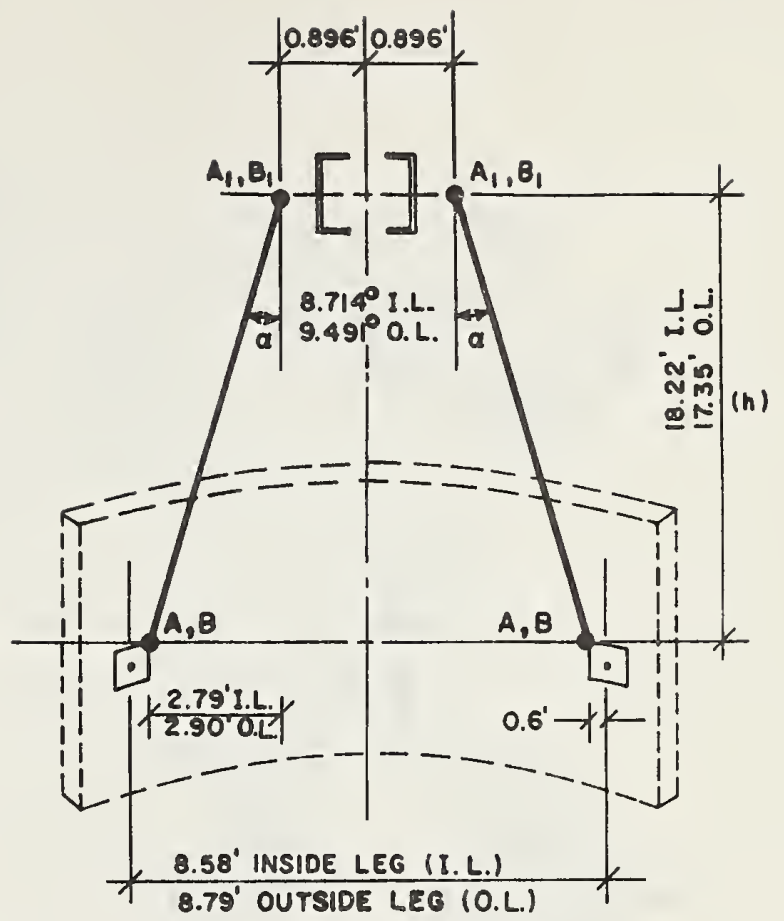

(b) View of cathead legs

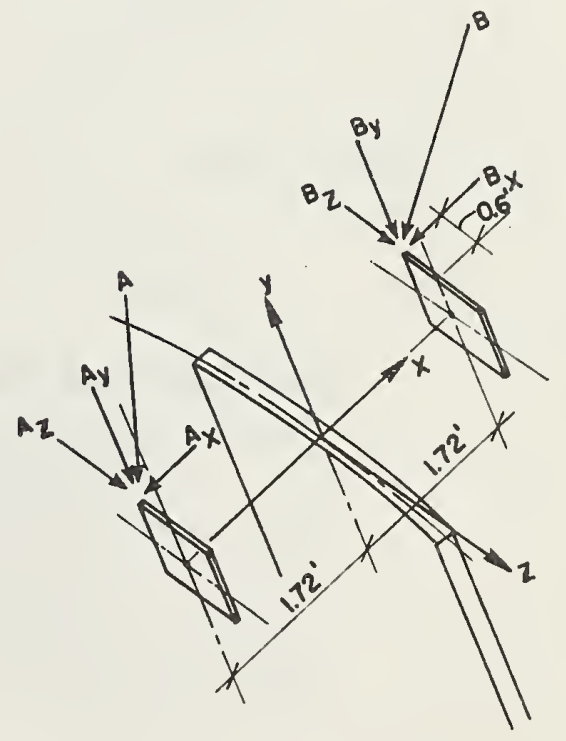

(d) Conf iguration of cathead leg reactions relative to shell. 


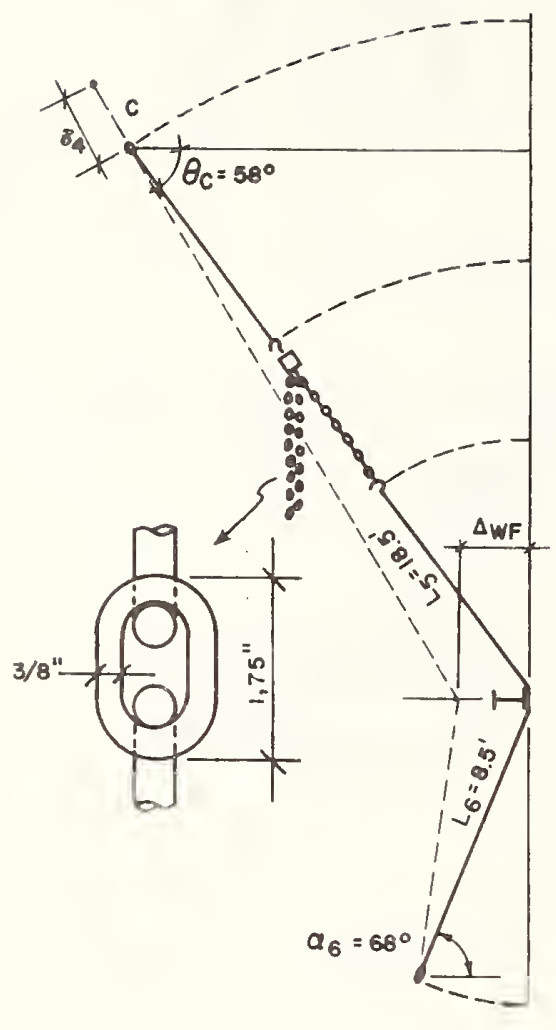

PROFILE

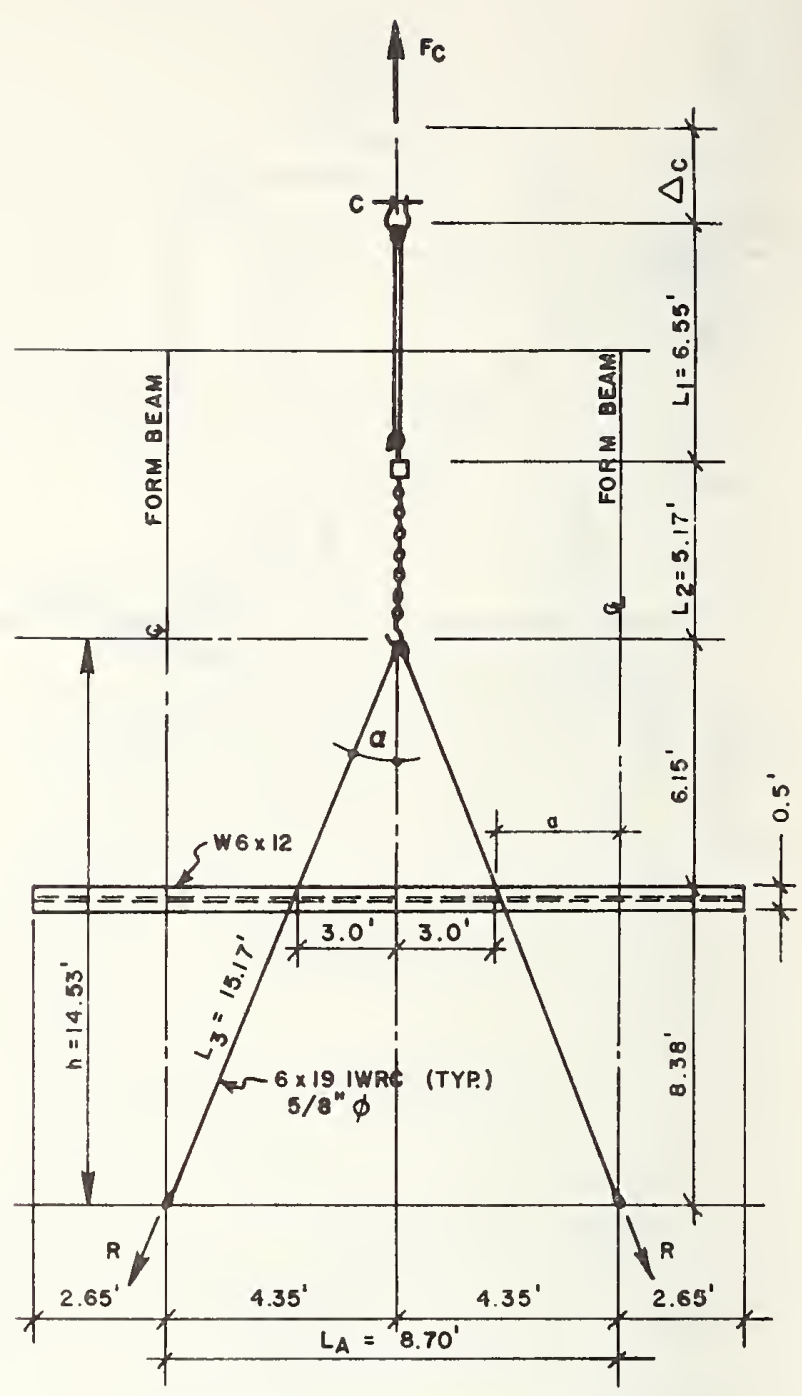

DEVELOPED LENGTH

FORMULATION OF LOAD-DISPLACEMENT EQUATIONS

$$
\begin{aligned}
& \text { Cable: } A=0.154 \mathrm{fn}^{2}\left(99.33 \mathrm{~mm}^{2}\right) \\
& E=13000 \mathrm{ksI}\left(89.7 \times 10^{6} \mathrm{kN} / \mathrm{m}^{2}\right) \quad \delta_{2}=F_{c} L_{2} / 2(A E)_{2} \\
& \text { Chafn: } A=0.110 \mathrm{fn}^{2}\left(70.95 \mathrm{~mm}^{2}\right) \\
& E=29000 \mathrm{ksI}\left(200 \times 10^{6} \mathrm{kN} / \mathrm{m}^{2}\right) \\
& (\mathrm{AE})_{1}=(\mathrm{AE})_{3}=2 \times 10^{6} 1 \mathrm{~b}\left(8.9 \times 10^{6} \mathrm{~N}\right) \\
& (\mathrm{AE})_{2}=3.2 \times 10^{6} \mathrm{lb}\left(14.2 \times 10^{6} \mathrm{~N}\right) \\
& \mathrm{R} \quad=0.522 \mathrm{~F}_{\mathrm{C}} \\
& \delta_{1}=\mathrm{F}_{\mathrm{c}} \mathrm{L}_{1} / 2(\mathrm{AE})_{1} \\
& \delta_{3}=\mathrm{RL}_{3} \text { sec } a /(\mathrm{AE})_{1} \\
& \Delta_{W F}=F_{c}\left(3 L_{4}-4 a\right) / 12 E I \\
& \delta_{4}^{*}=f\left(\Delta_{W F}, L_{5}, L_{6},{ }_{C}, a_{6}\right) \\
& \Delta_{c}=\delta_{1}+\delta_{2}+\delta_{3}+\delta_{4} \\
& \Delta_{c}=K F_{c}(K=\text { const. })
\end{aligned}
$$

$1 \mathrm{ft}=0.305 \mathrm{~m}$

* $\delta_{4}=$ displacement of point $C$ due to lateral deflection $\Delta_{W F}$ of WF beam

Figure 6.13 Geometric, Material and Load-displacement Characteristics of Counterstatic Line 


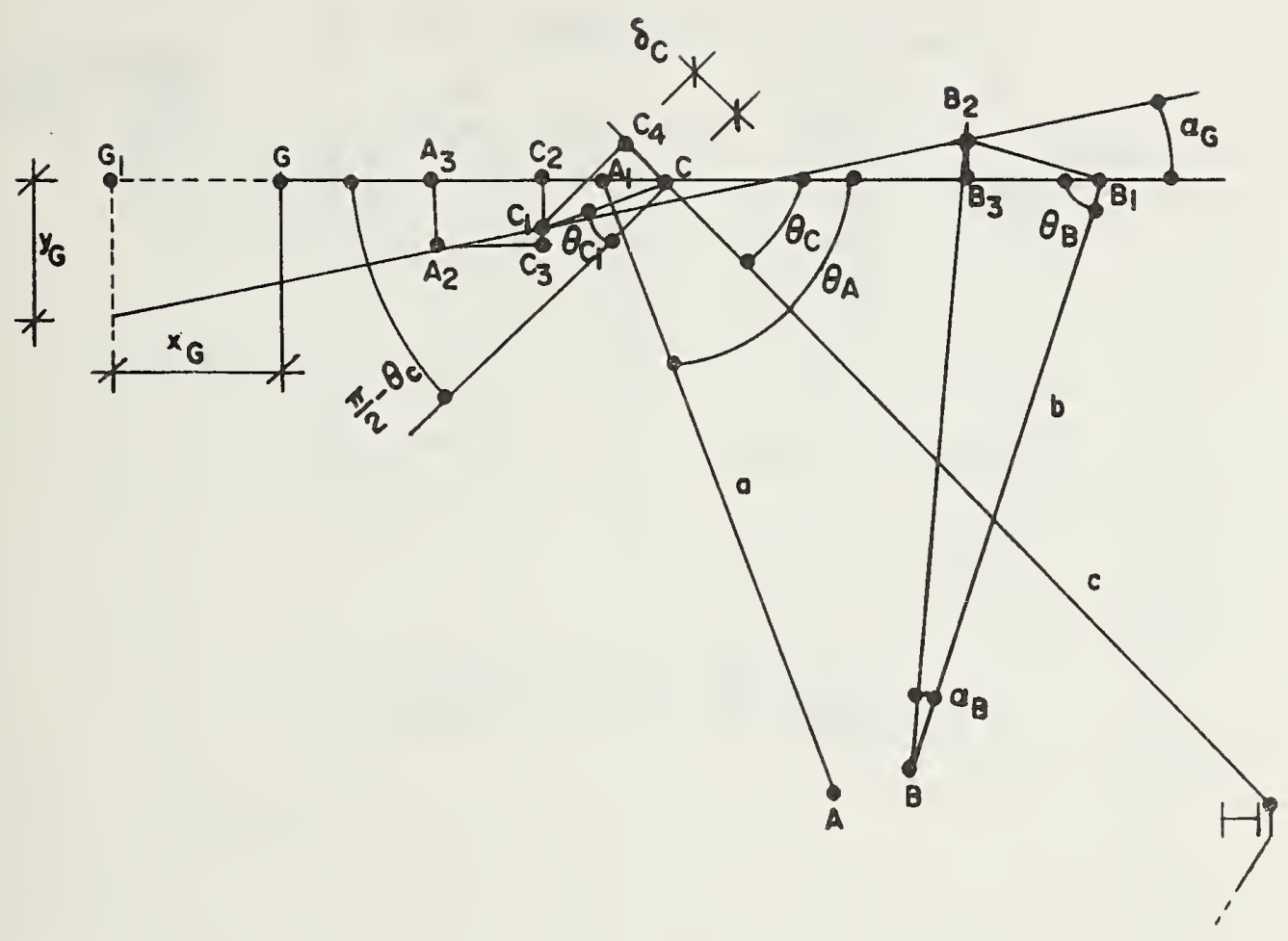

SMALL DISPLACEMENT GEOMETRY:

$$
\begin{aligned}
& B_{1} B_{2}=b a_{b}^{*} \perp B_{1}, \quad B_{1} B_{3}=A_{1} A_{3}=G G_{1}=C C_{2}=B_{1} B_{2} \cos \left(\frac{\pi}{2}-\theta_{B}\right) \\
& B_{2} B_{3}=B_{1} B_{2} \sin \left(\frac{\pi}{2}-\theta_{B}\right), A_{2} A_{3}=A_{1} A_{3} \tan \left(\frac{\pi}{2}-\theta_{A}\right) \\
& \alpha_{G}=\tan ^{-1}\left[\left(A_{2} A_{3}+B_{2} B_{3}\right) / A_{1} B_{1}\right], A_{3} G_{1}=A_{1} G \\
& G_{1} G_{2}=A_{3} G_{1} \text { tan } \alpha_{G}+A_{2} A_{3}, x_{G}=B_{1} B_{3}, y_{G}=G_{1} G_{2} \\
& C_{1} C_{2}=A_{2} A_{3}-A_{1} C \tan \alpha_{G}, C_{2} \widehat{C C}_{1}=\tan ^{-1}\left(C_{1} C_{2} / C_{2}\right) \\
& { }^{\theta} \mathrm{C} 1=\frac{\pi}{2}-{ }^{\theta} \mathrm{C}-\widehat{\mathrm{C}_{2} \widehat{C C}_{1}}, \mathrm{C}_{1} \mathrm{C}=\left(\overline{\mathrm{CC}}_{2}^{2}+{\overline{\mathrm{C}_{1} \mathrm{C}_{2}}}^{2}\right)^{1 / 2} \\
& \delta_{\mathrm{c}}=\mathrm{C}_{1} \mathrm{C} \sin \theta_{\mathrm{C} 1}, \Delta_{\mathrm{C}}=\mathrm{KF}_{\mathrm{C}} \text { (from figure 6.13) } \\
& \mathrm{X}_{G}^{\prime}=\left(\Delta_{C} / \delta_{C}\right) x_{G}, Y_{G}^{\prime}=\left(\Delta_{C} / \delta_{C}\right) y_{G}^{* *}
\end{aligned}
$$

* $a_{b}=$ rotation of $\mathrm{BB}_{1}$ about point $\mathrm{B}$

** $X_{G}^{\prime}, Y_{G}^{\prime}=$ displacement of $G$ due to $F_{C}$

$$
\begin{aligned}
& \text { Figure } 6.14 \text { Displacement of Point } G \text { due to Axial } \\
& \text { Elongation } \Delta_{c} \text { of Counterstatic Line }
\end{aligned}
$$



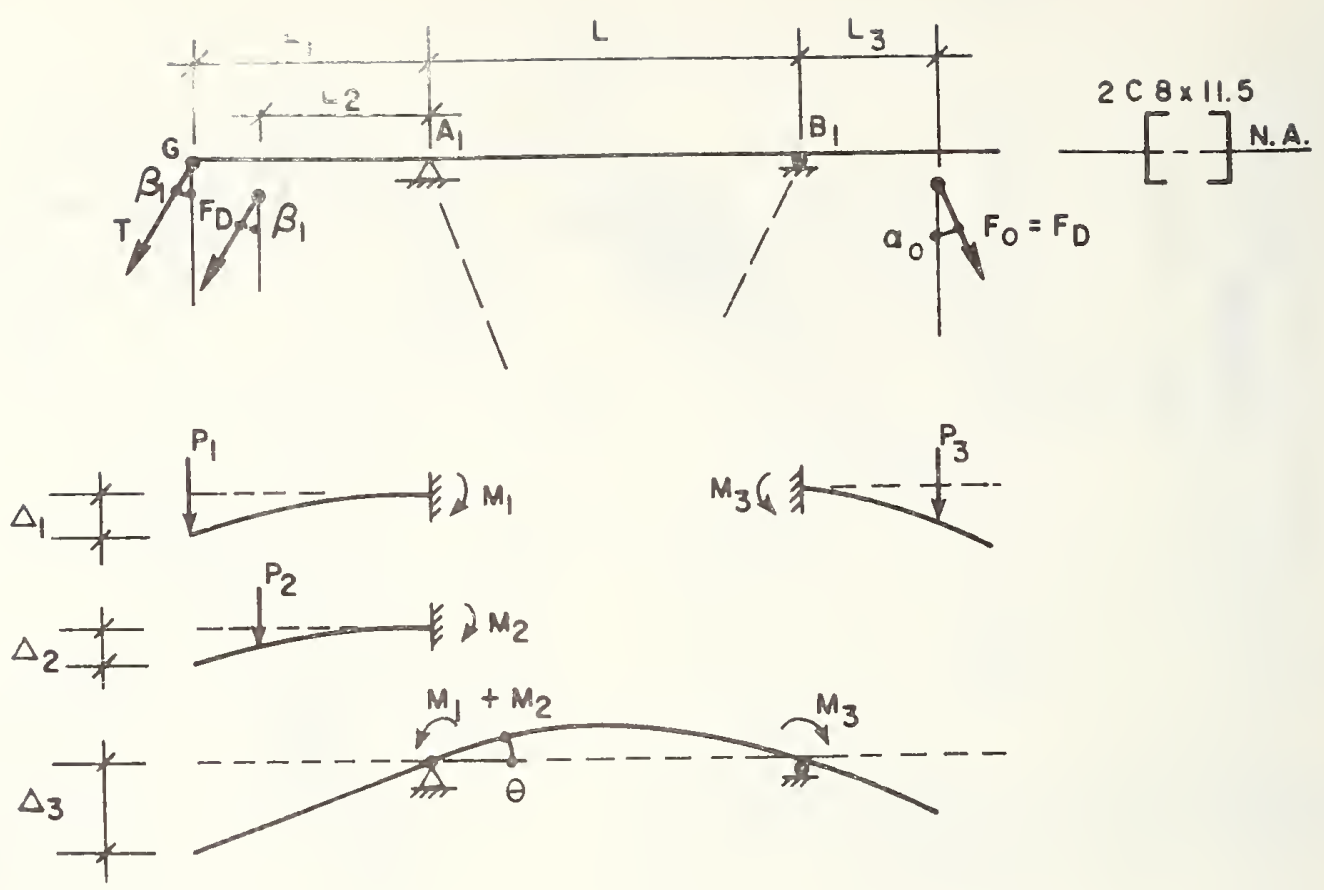

Known:

$$
\begin{aligned}
& \mathrm{T}, \mathrm{F}_{\mathrm{D}}, \mathrm{F}_{\mathrm{O}}=\mathrm{F}_{\mathrm{D}}, \mathrm{B}_{1}, \alpha_{\mathrm{O}}=12.4^{\circ} \\
& \mathrm{E}=29 \mathrm{x} 10^{6} \mathrm{psi}\left(200 \times 10^{6} \mathrm{kN} / \mathrm{m}^{2}\right), I=65.2 \mathrm{in}^{4}\left(27.1 \times 10^{6} \mathrm{~mm}^{4}\right) \\
& \mathrm{L}_{1}=5.3 \mathrm{ft}(1.6 \mathrm{~m}), \mathrm{L}_{2}=3.7 \mathrm{ft}(1.1 \mathrm{~m}) \\
& \mathrm{L}_{3}=1.8 \mathrm{ft}(0.55 \mathrm{~m}), \mathrm{L}_{4}=10.5 \mathrm{ft}(3.20 \mathrm{~m})
\end{aligned}
$$

Computed :

$$
\begin{aligned}
& \Delta_{1}=\mathrm{P}_{1} \mathrm{~L}_{1}^{3} / 3 \mathrm{EI}, \Delta_{2}=\left(3 \mathrm{~L}_{1}-\mathrm{L}_{2}\right) \mathrm{P}_{2} \mathrm{~L}_{2}^{2} / 6 \mathrm{EI} \\
& \mathrm{M}_{1}=\mathrm{P}_{1} \mathrm{~L}_{1}, \mathrm{M}_{2}=\mathrm{P}_{2} \mathrm{~L}_{2}, \mathrm{M}_{3}=\mathrm{P}_{3} \mathrm{~L}_{3} \\
& \theta=\left(2 \mathrm{M}_{1}+2 \mathrm{M}_{2}+\mathrm{M}_{3}\right) \mathrm{L} / 6 \mathrm{EI}, \Delta_{3}=\mathrm{L}_{1} \theta \\
& \mathrm{Y}_{\mathrm{G}}^{\prime \prime}=\Delta_{1}+\Delta_{2}+\Delta_{3} \\
& \mathrm{X}_{\mathrm{G}}^{\prime \prime}=0 * \\
& \mathrm{X}_{\mathrm{G}}=\mathrm{X}_{\mathrm{G}}^{\prime}+\mathrm{X}_{\mathrm{G}}^{\prime \prime}=\mathrm{X}_{\mathrm{G}}^{\prime} \quad \text { (seefig. 6.14) } \\
& \mathrm{Y}_{\mathrm{G}}=\mathrm{Y}_{\mathrm{G}}^{\prime}+\mathrm{Y}_{\mathrm{G}}^{\prime \prime} * * \quad \quad \text { (see fig. 6.14) }
\end{aligned}
$$

* $\left(\mathrm{X}_{\mathrm{G}}^{\prime \prime}, \mathrm{Y}_{\mathrm{G}}^{\prime \prime}\right)=$ displacement of $\mathrm{G}$ due to cathead beam deflection ** $\left(\mathrm{X}_{\mathrm{G}}, \mathrm{Y}_{\mathrm{G}}\right)=$ displacement of $\mathrm{G}$ due to elastic deformation of cathead 
EXPANDED VIEW OF TOP 3 LIFTS, F.E. MDOEL

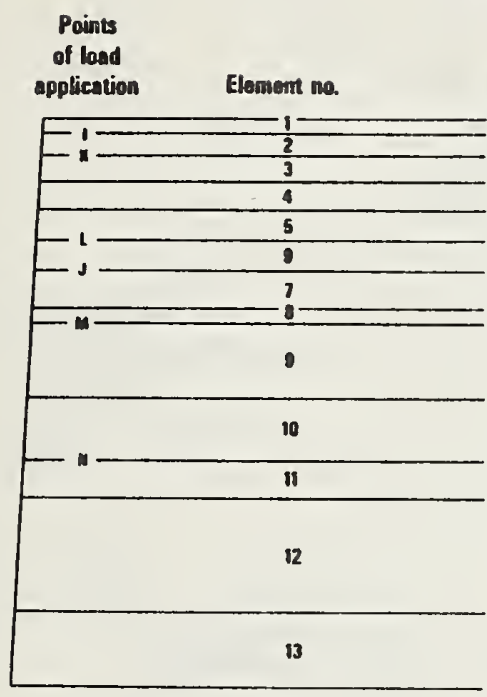

- Batt hole location
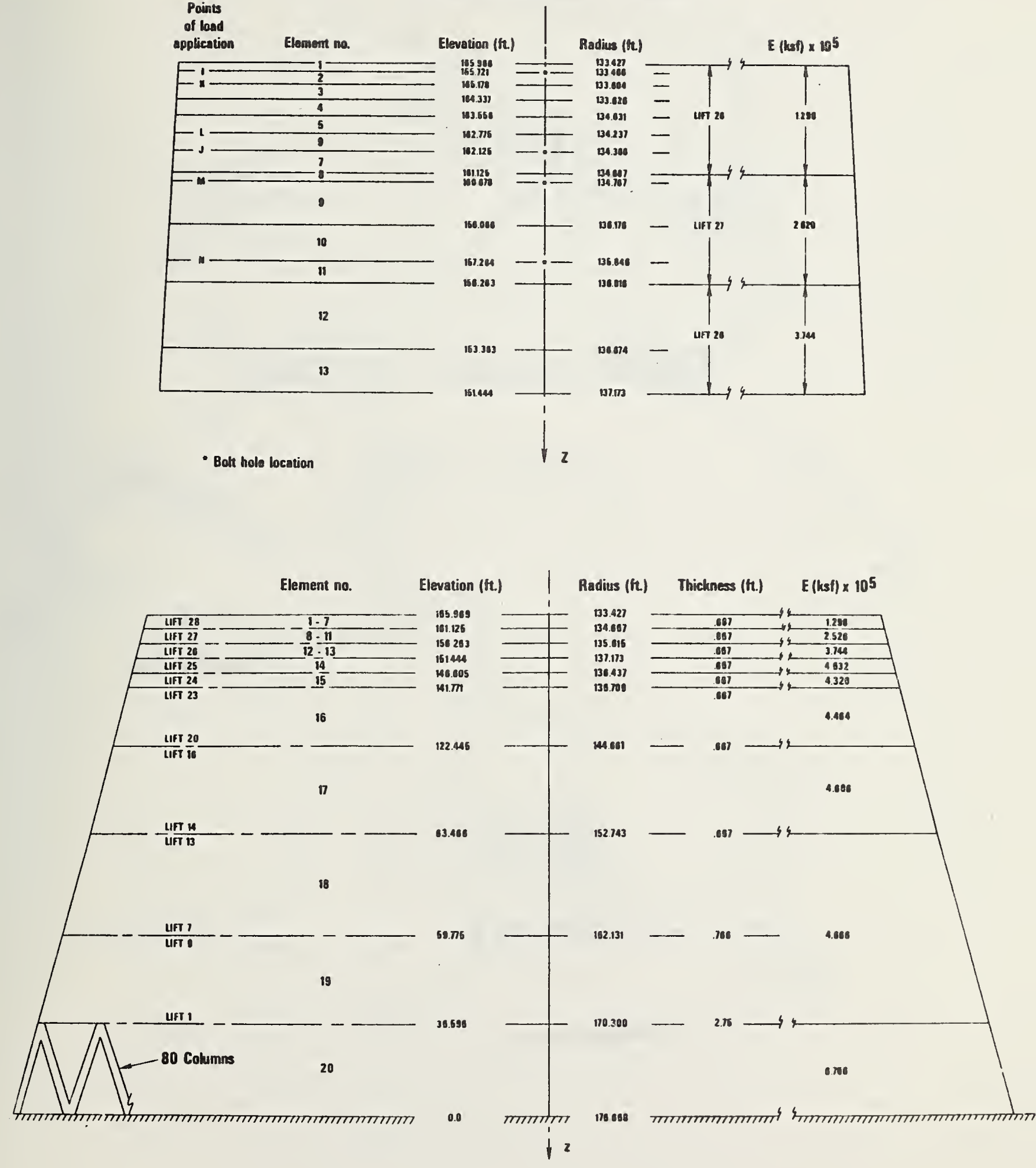

Figure 6.16 Cooling Tower Finite Element Model 


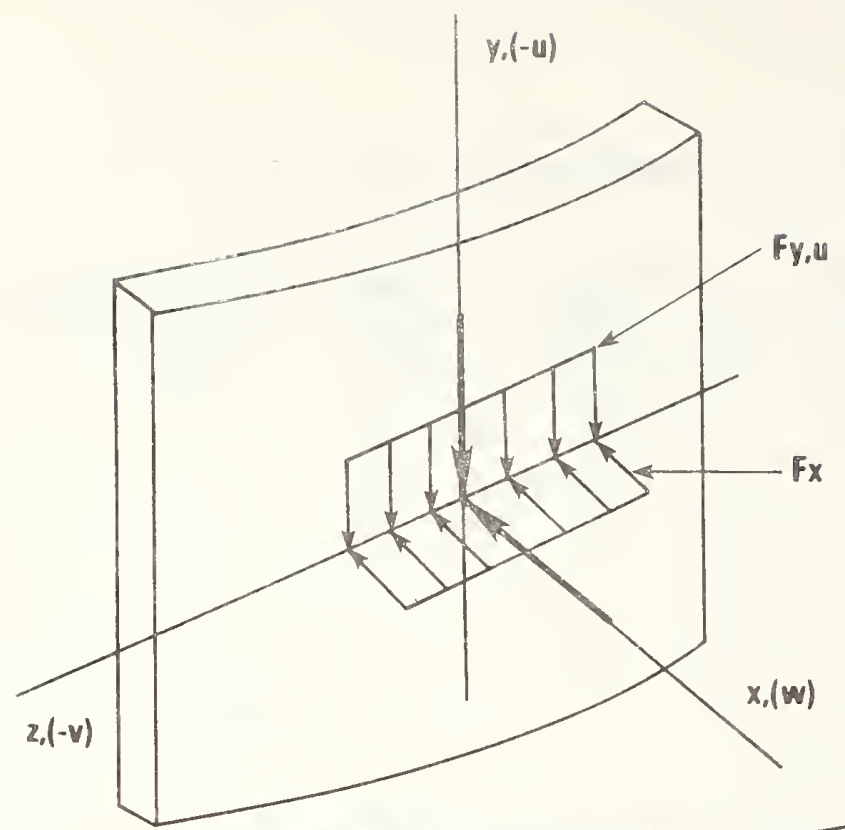

SHORE III UNE LOAOS

A. Meridional and normal forces
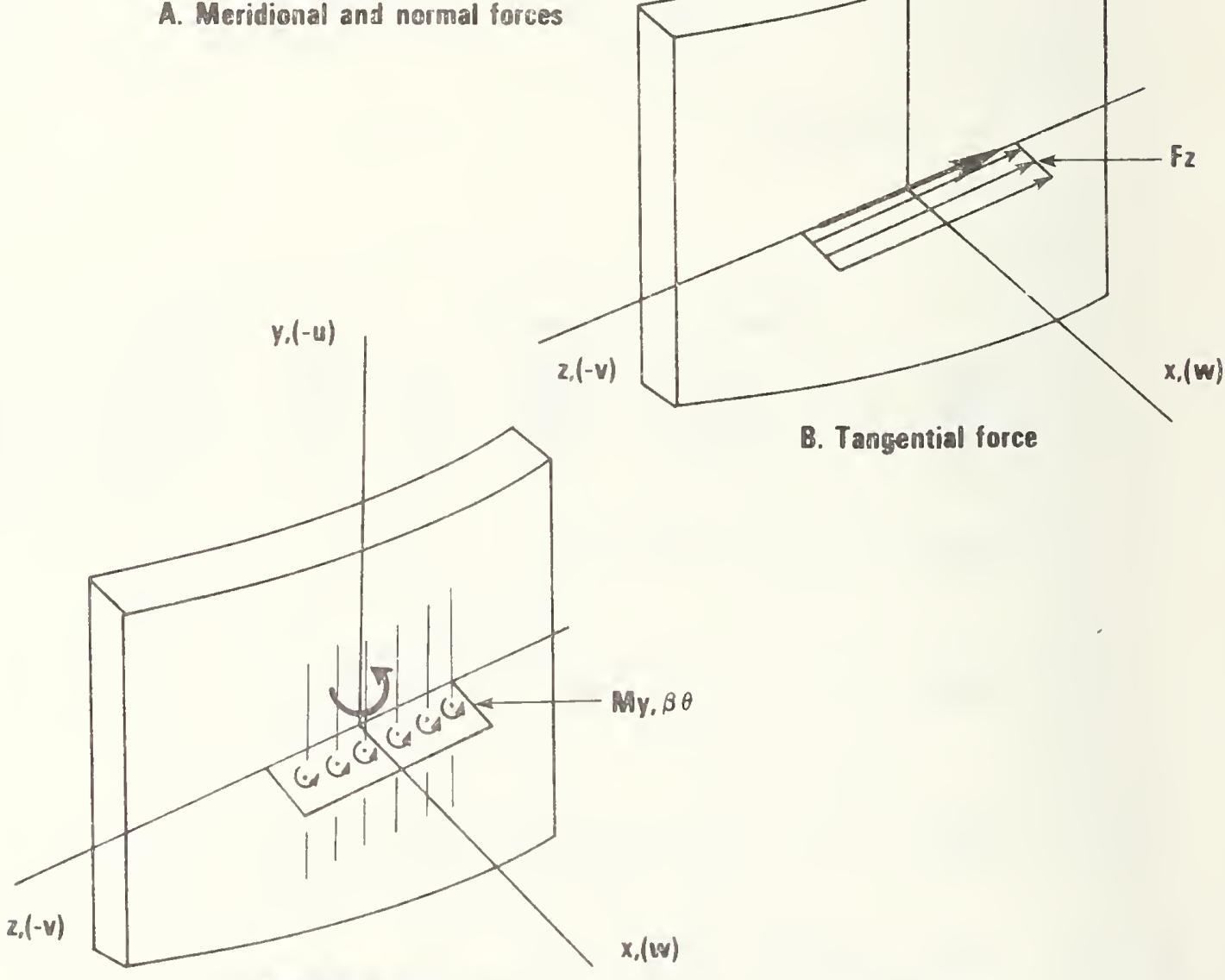

B. Tangential force

c. Meridional moment 


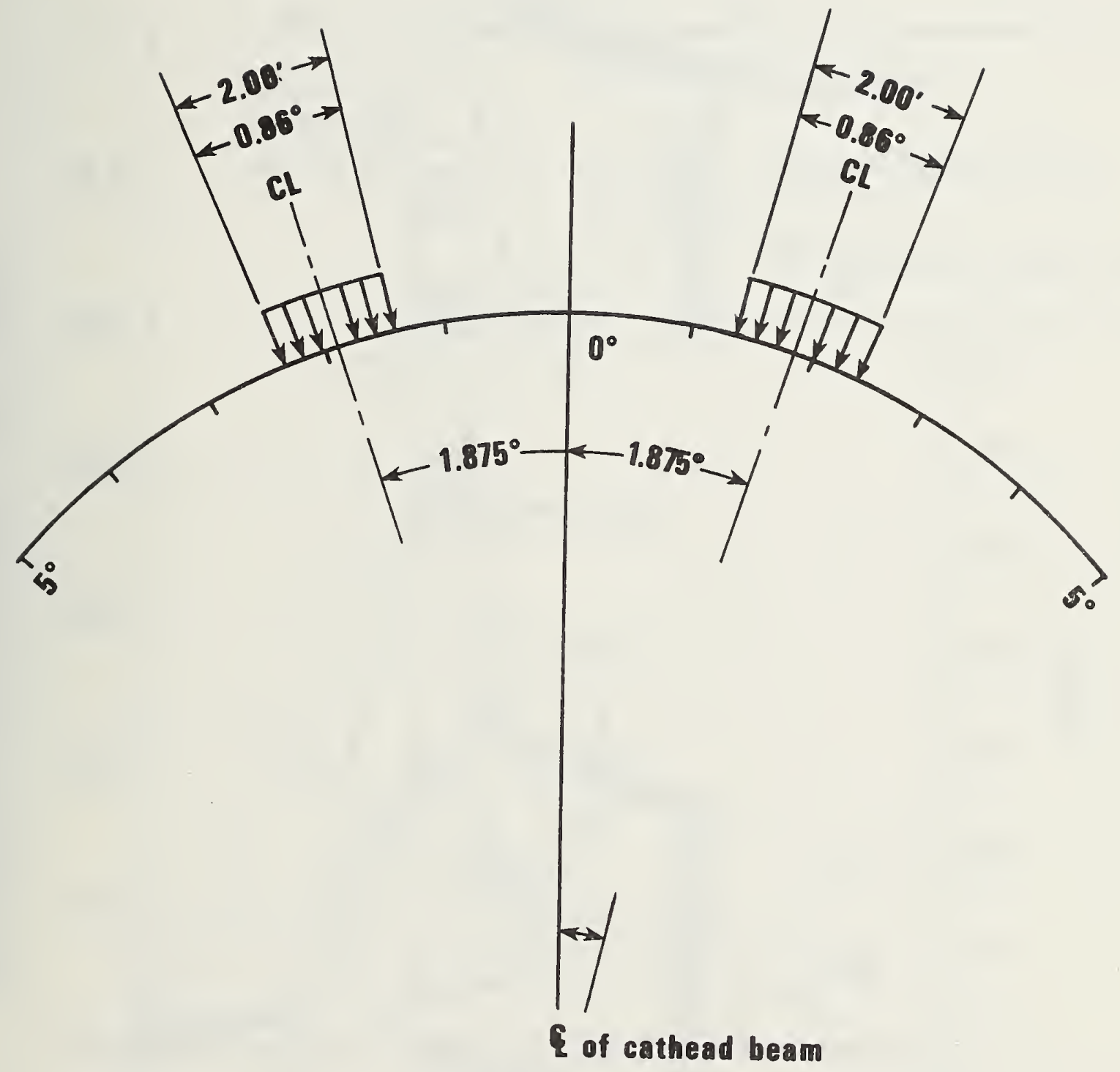

Higure 6.18 Normal Force $\left(F_{\mathrm{X}}\right)$ at Cathead for Load Case 4 


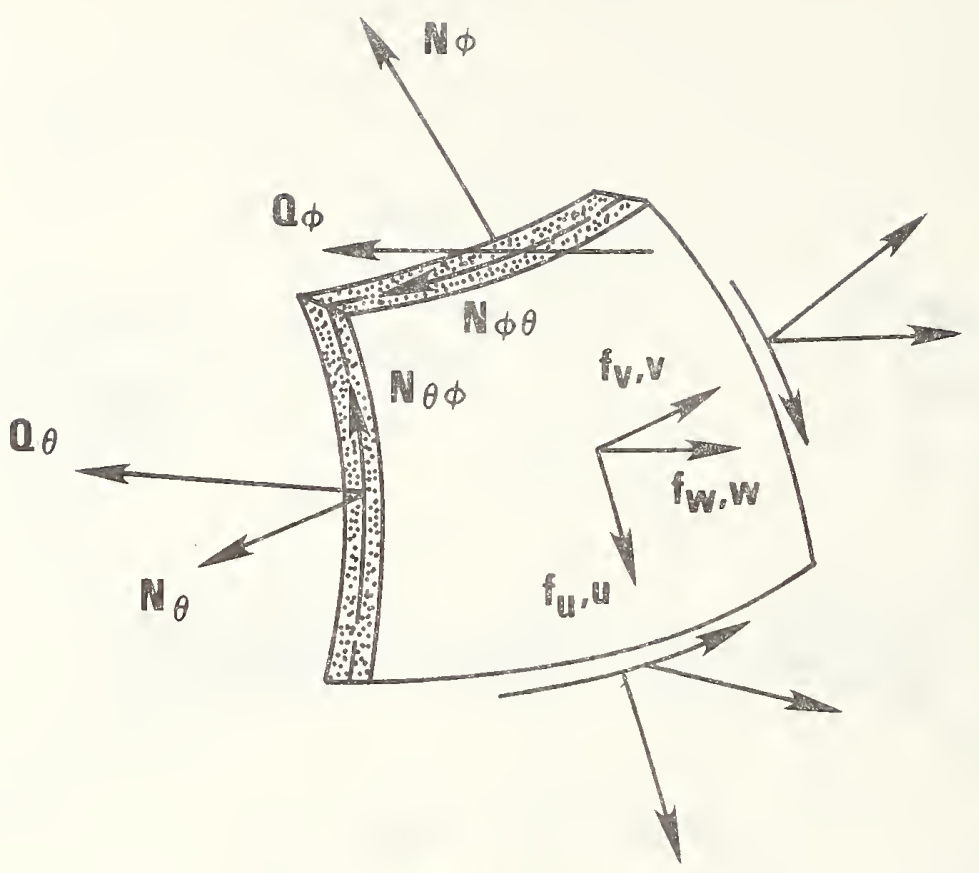

Stress resultants

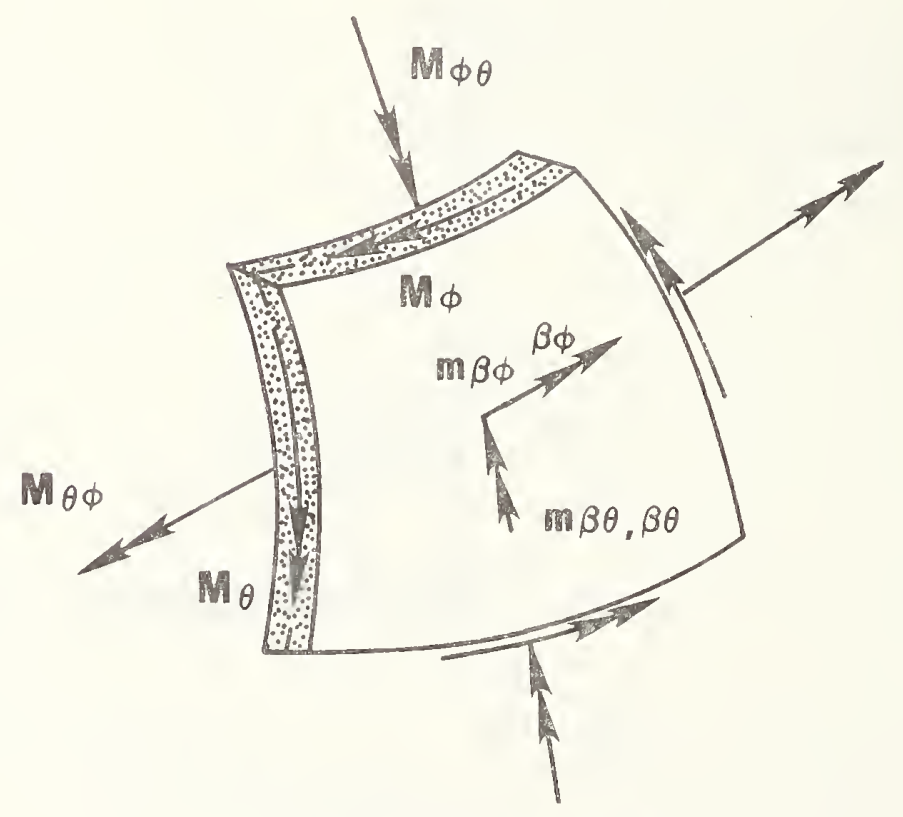

Stress-couple resultants

Figure 6.19 Sign Conventions 


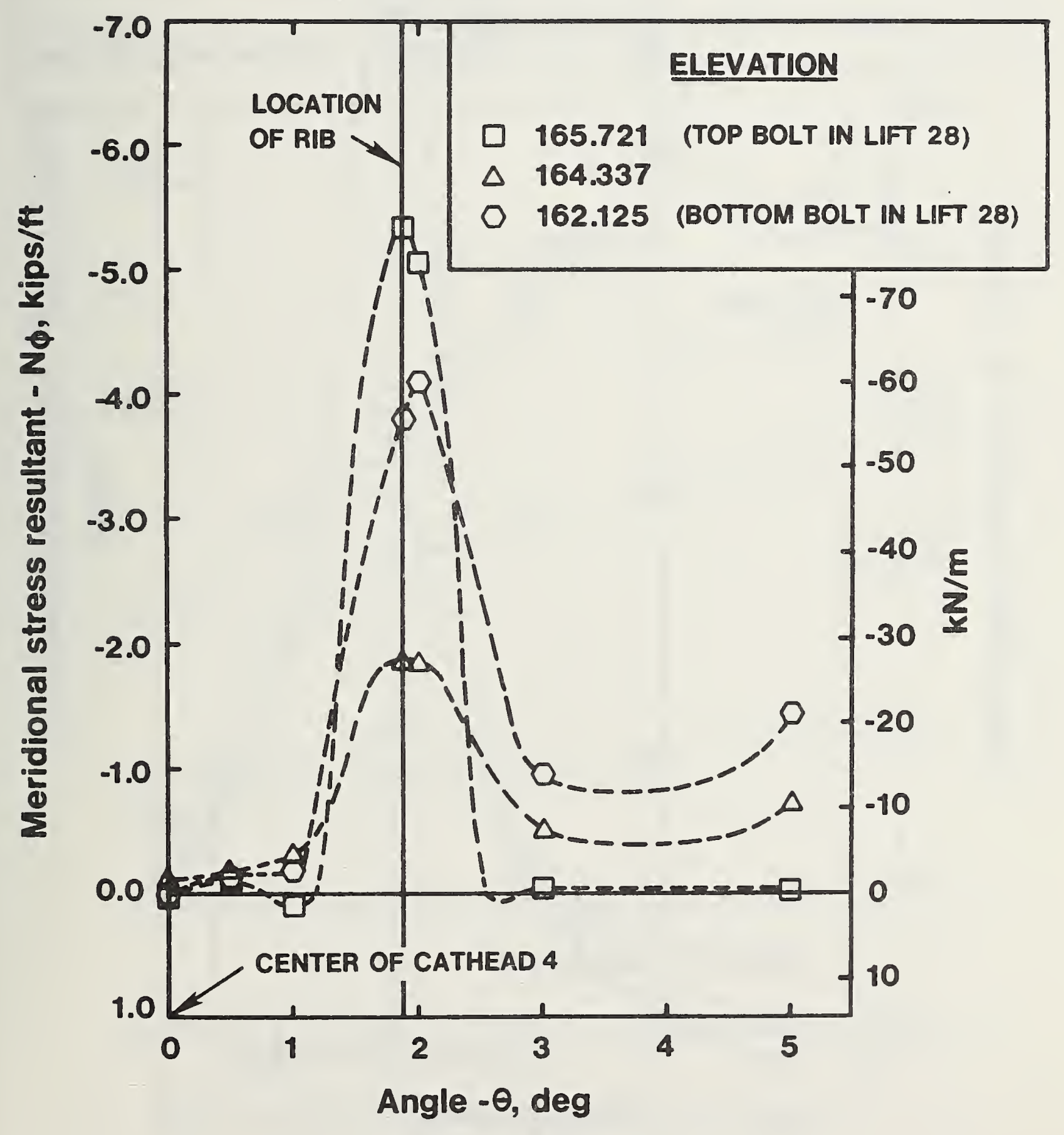

Figure 6.20 Meridional Stress Resultant at Cathead No. 4 


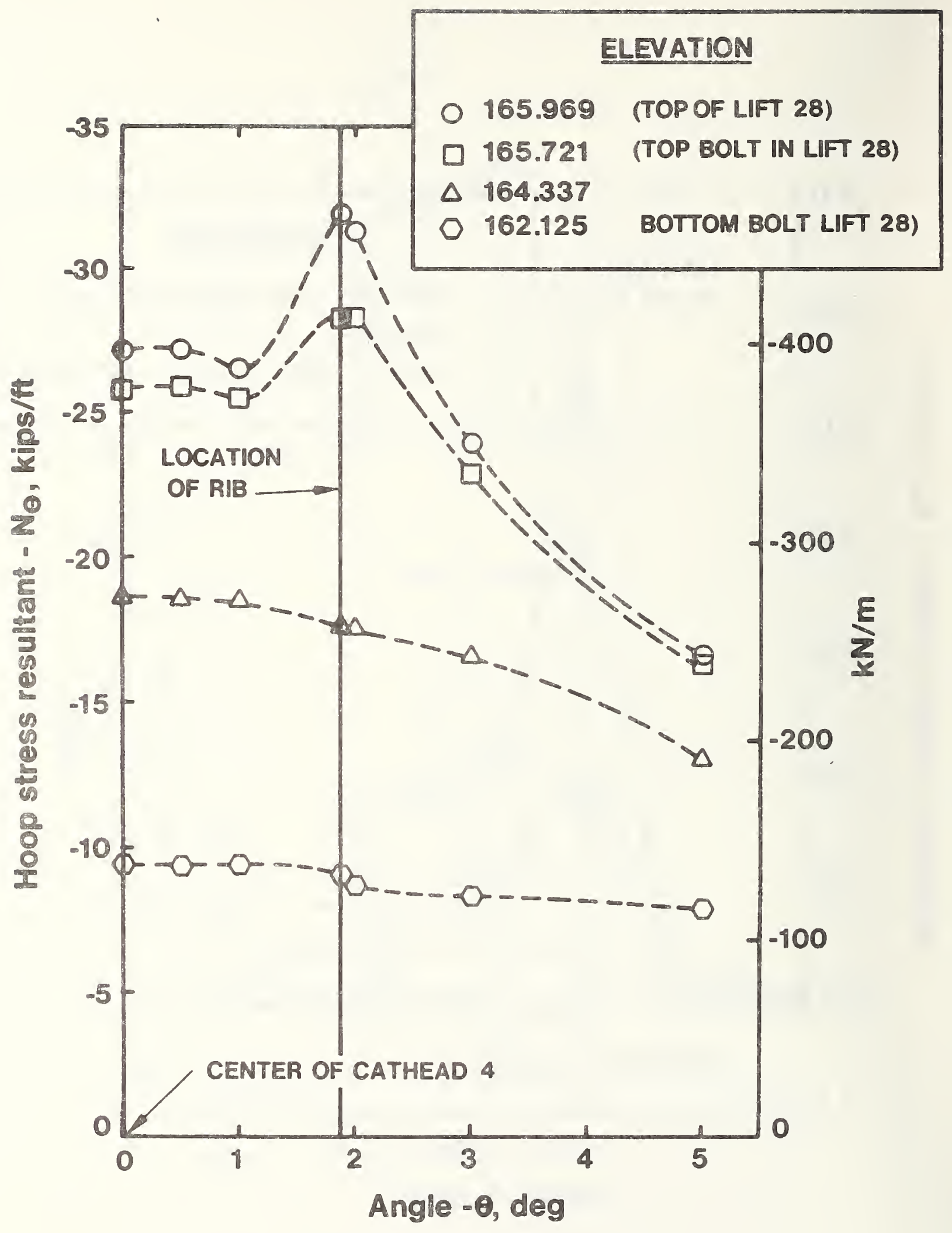

Figure 6.21 Hoop Stress Resultant at Cathead No. 4 


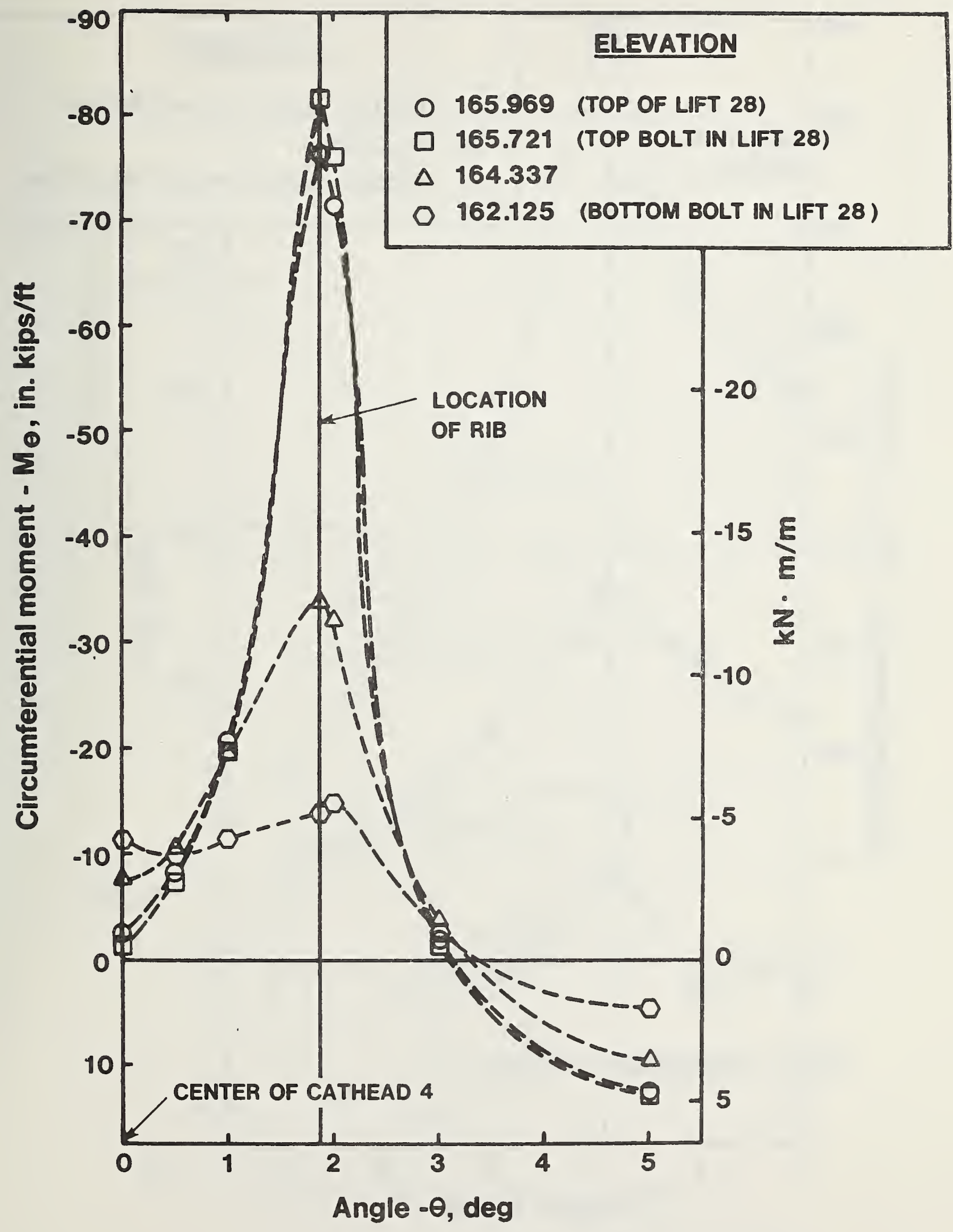

Figure 6.22 Circumferential Moment at Cathead No. 4 


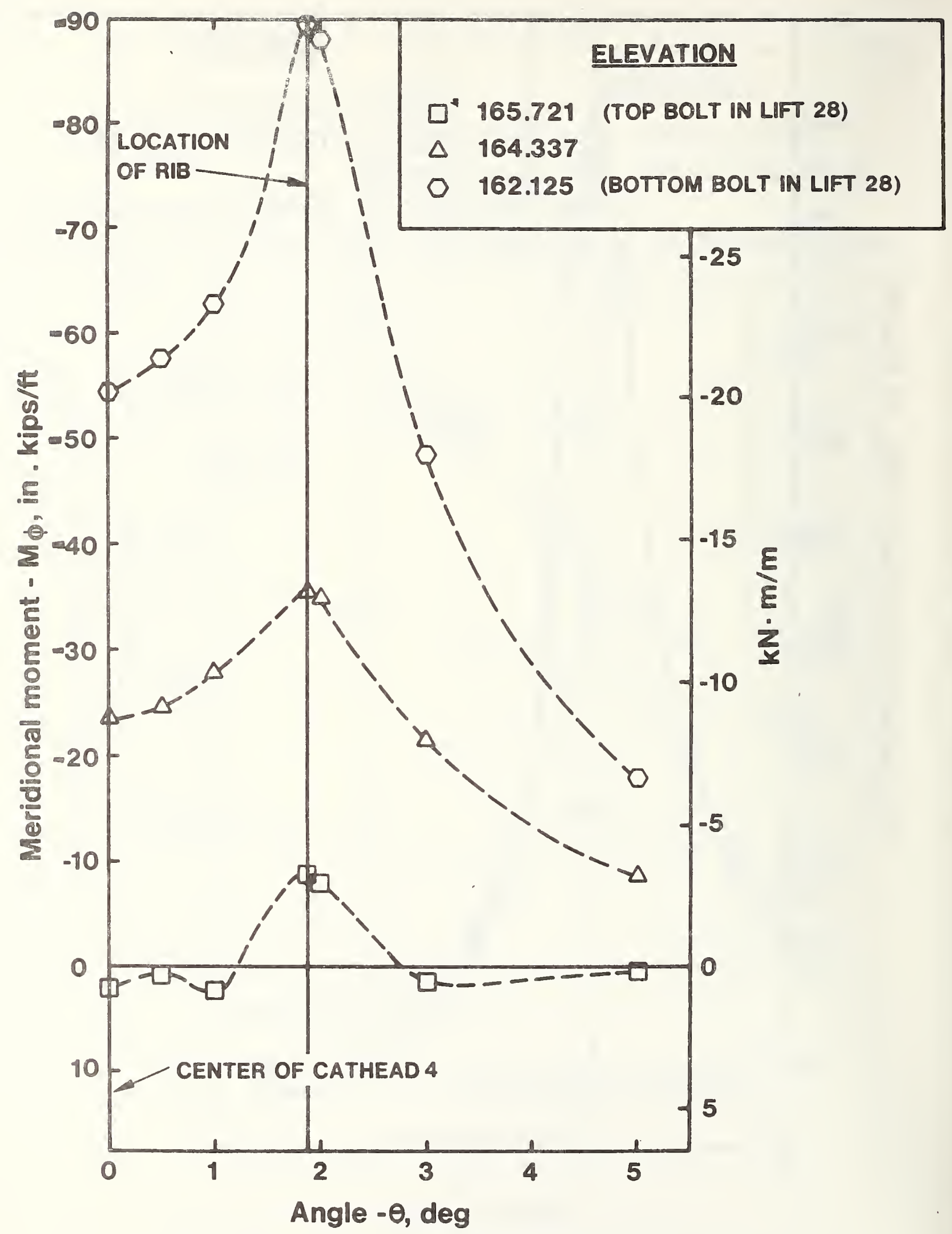

Figure 6.23 Meridional Moment at Cathead No. 4 


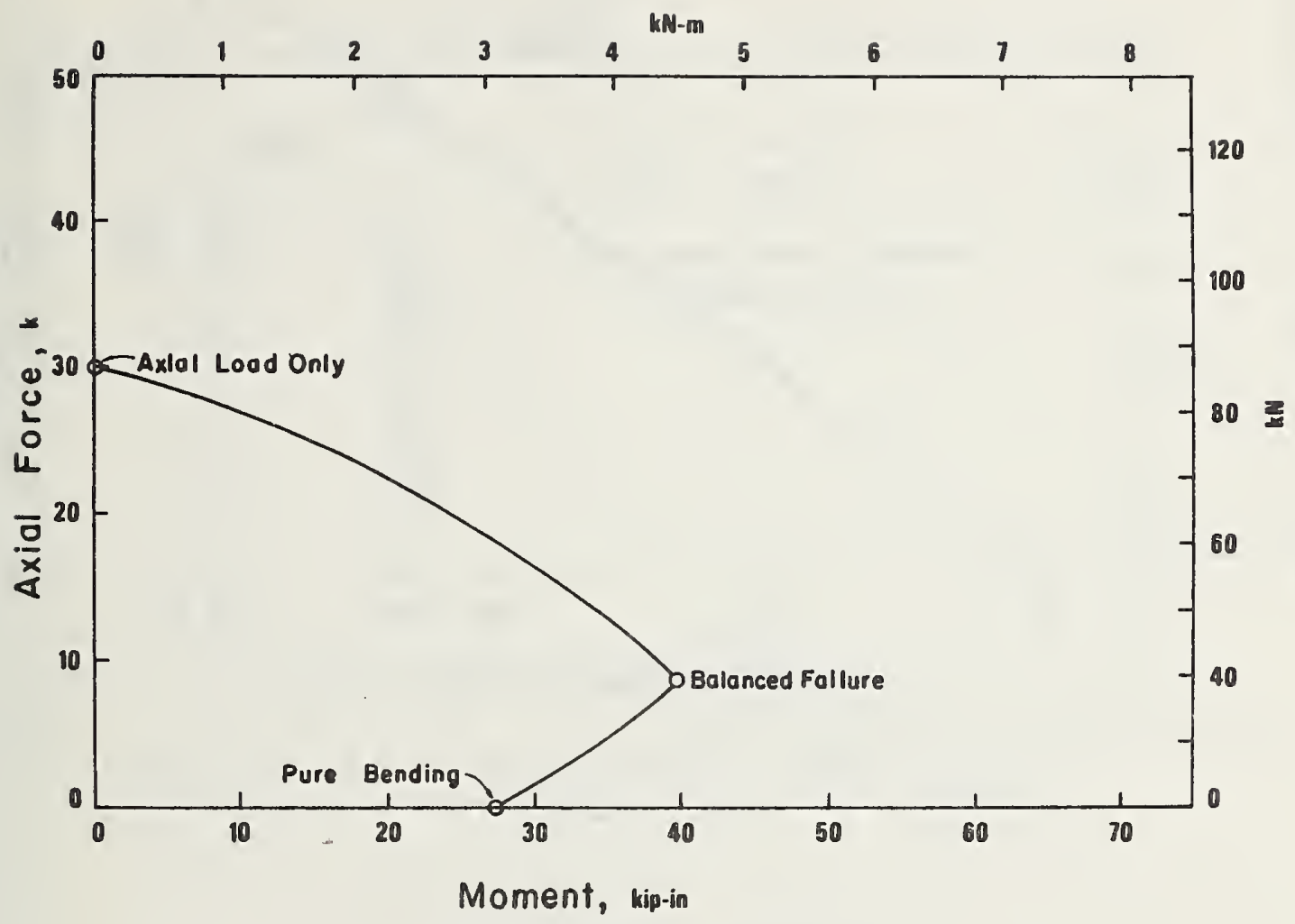

Figure 7.1 An Interaction Diagram under Combined Bending Moments and Axial Forces

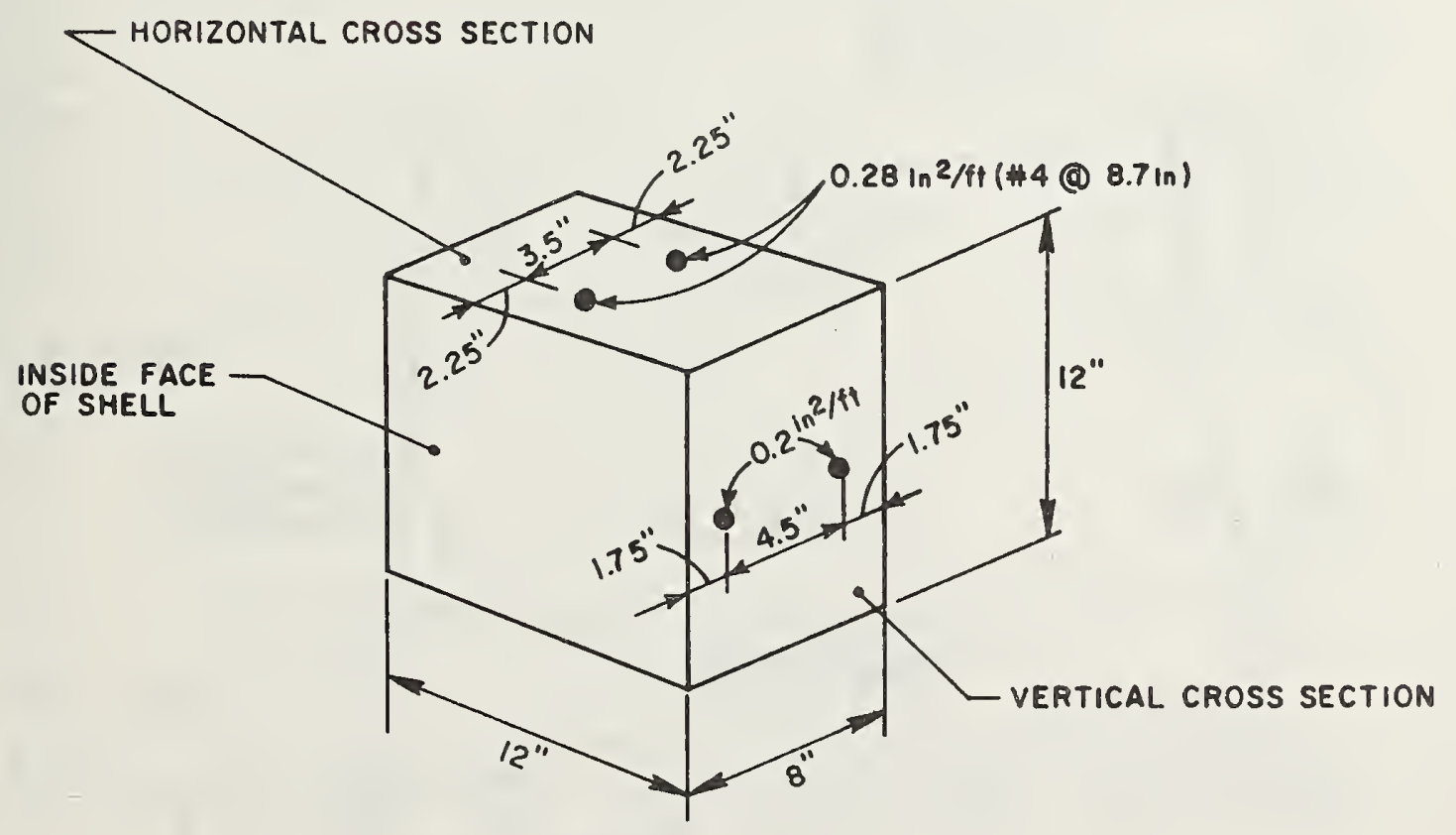

Figure 7.2 Physical Dimensions of Vertical and Horizontal Cross Sections of a Shell Element Used for Analysis 


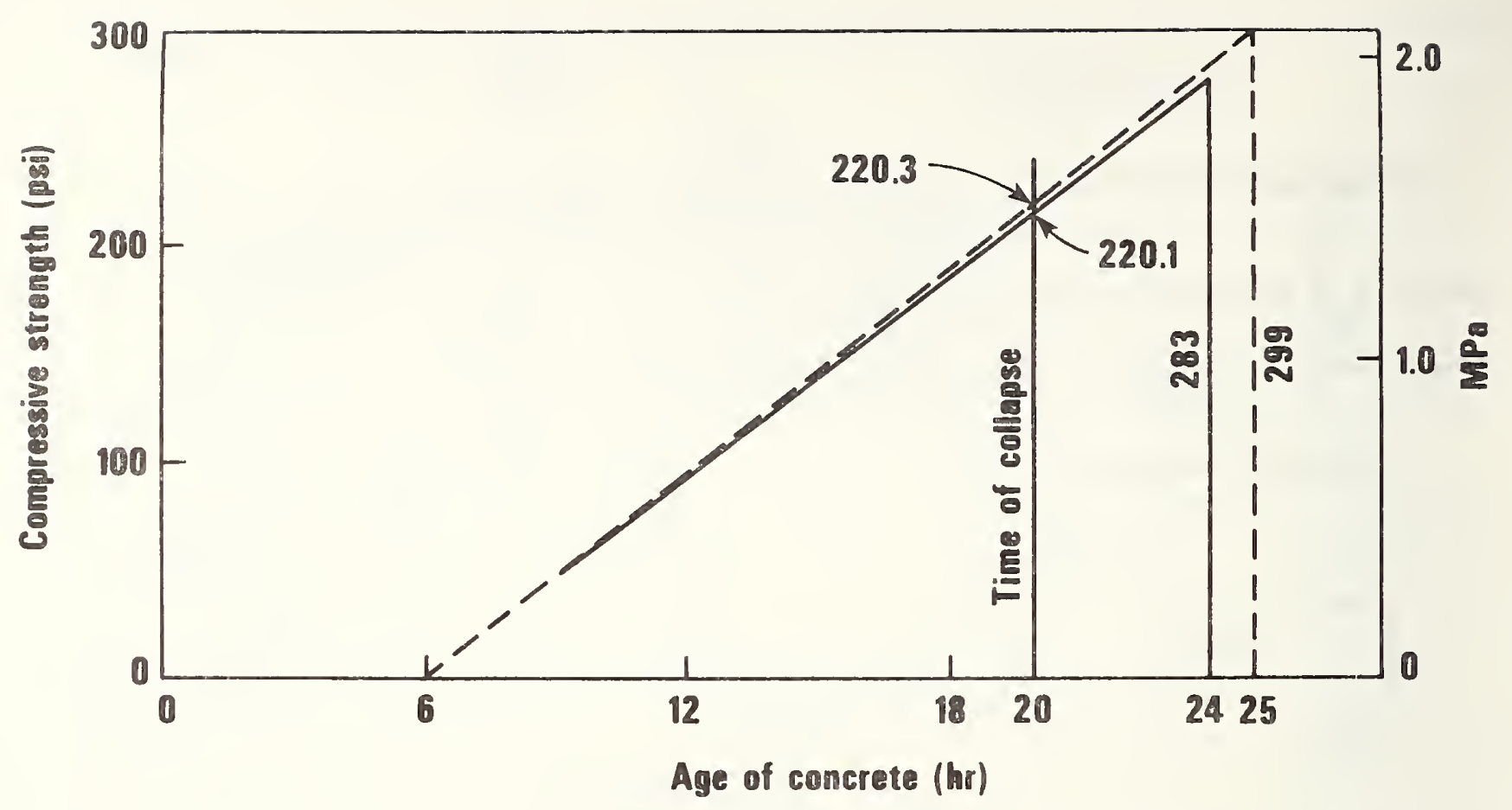

Figure 7.3 Procedure Used to Estimate Compressive Strength of Concrete at the Time of Failure

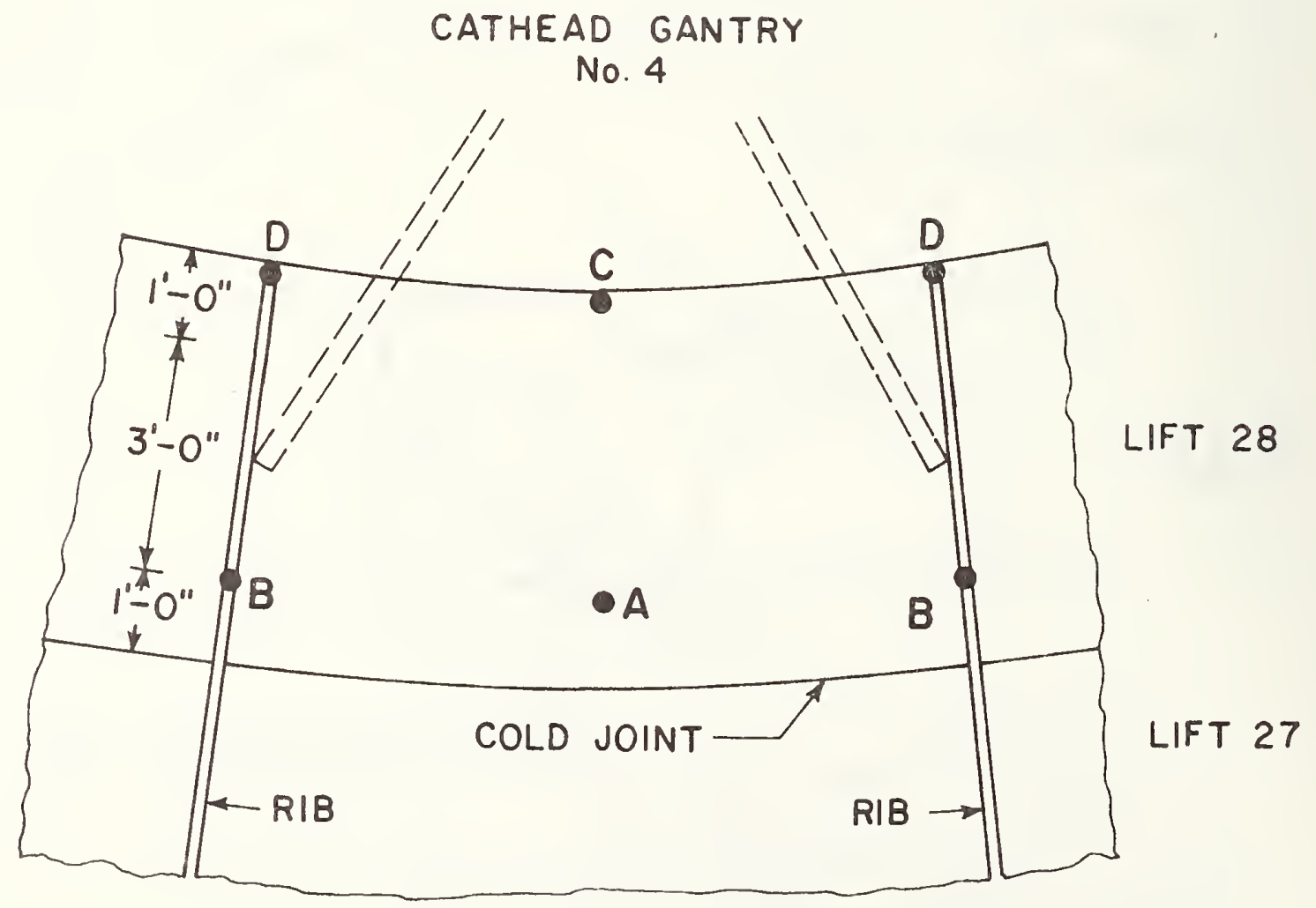

Figure 7.4 Locations of Maximum Hoop and Meridional Foices and Bending Moments in Lift 28 


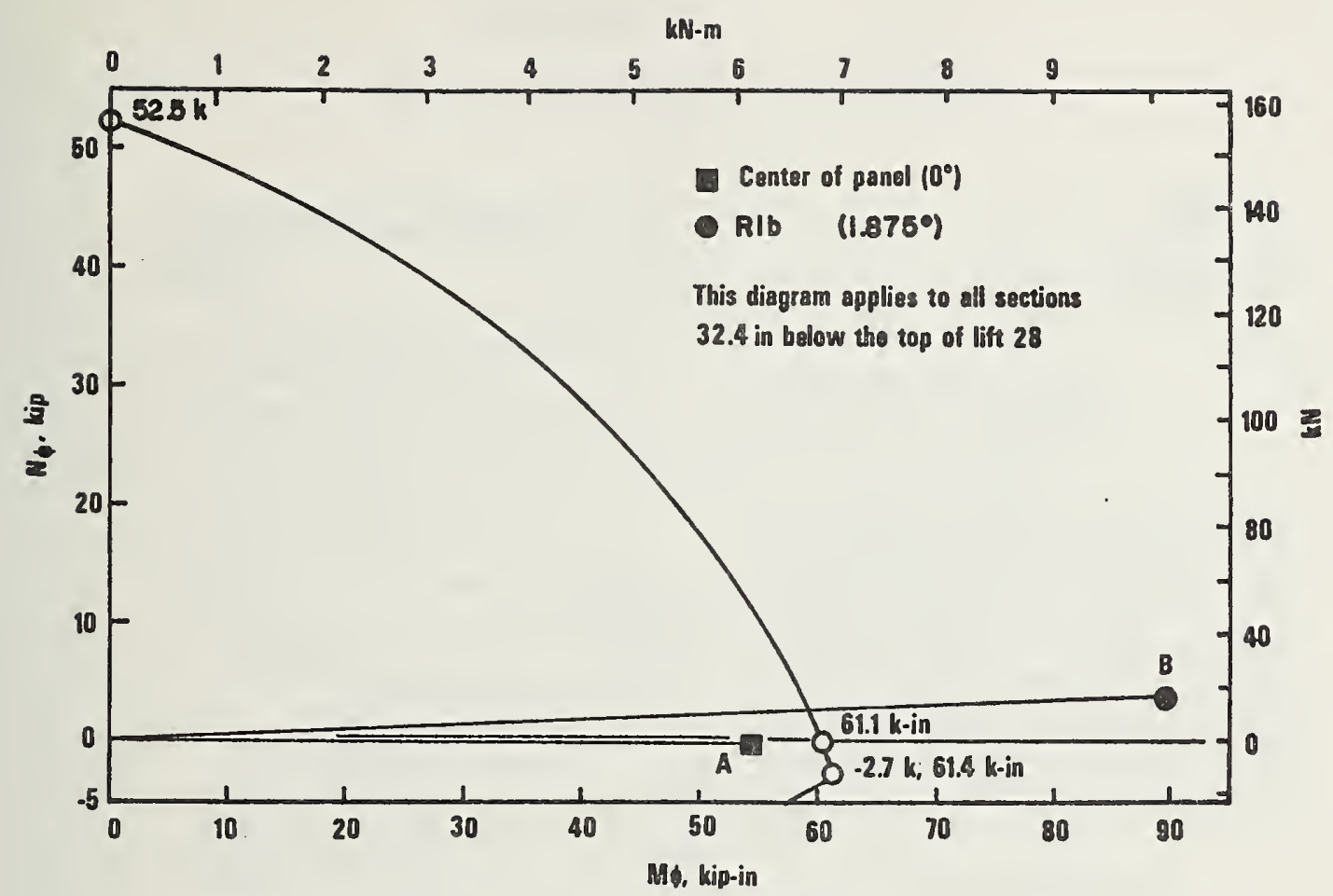

Figure 7.5 Combined Effect of Axial Force and Bending Moment at Locations $\mathrm{A}$ and $\mathrm{B}$

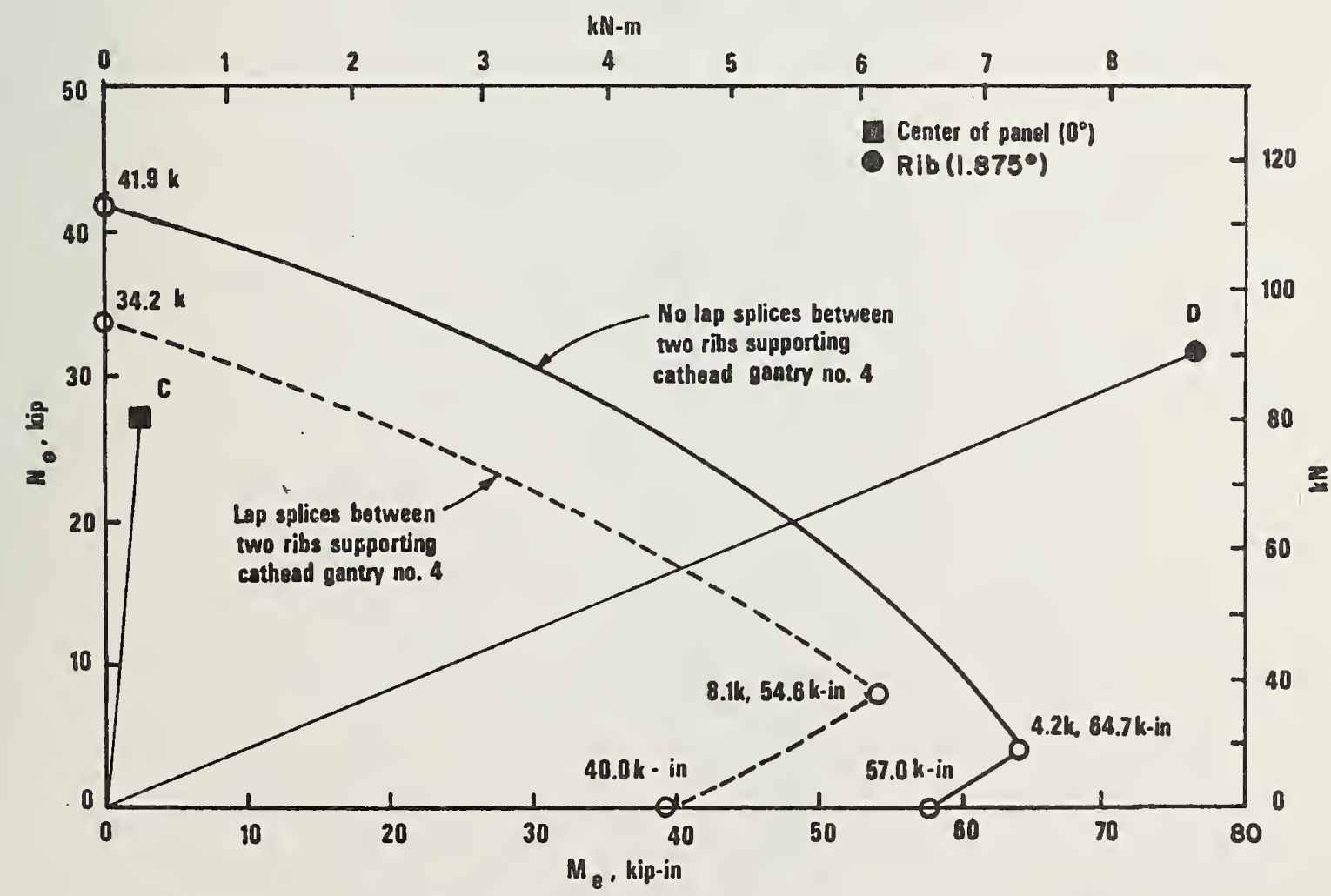

Figure 7.6 Combined Effect of Axial Force and Bending Moment at Locations $\mathrm{C}$ and $\mathrm{D}$ 
APPENDIX A

Patent of Wall Construction System 
[54] APPARATUS FOR CONSTRUCTING CONCRETE WALLS

[75] Inventor: Herman Scheller, Eaton, Colo.

[73] Assignee: Research-Cottrel, Inc., Bound Brook, N.J.

[21] Appl. No.: 681,723

[22] Filed: Apr. 29, 1976

[51] Int. Cl.2 …............ E04G 11/04; E04G 11/28

[52] U.S. Cl. $425 / 65 ; 249 / 20$;

$254 / 139$

[58] Field of Search [56] $249 / 20-22 ; 264 / 33-34 ; 254 / 139,142$ References Cited

\section{US. PATENT DOCUMENTS}

\begin{tabular}{|c|c|c|}
\hline & $11 / 1900$ & $254 / 139$ \\
\hline 957,521 & $s / 1910$ & ................................. 249/20 \\
\hline 3.472 .477 & $10 / 1969$ & Juhl ..................................... 249/20 \\
\hline $3,521,336$ & $7 / 1970$ & Rohlf ….............................. 425/63 \\
\hline $3,761,551$ & $9 / 1973$ & Ogata et al. ....................... 264/33 \\
\hline
\end{tabular}

$3,779,678 \quad 12 / 1973 \quad$ Scheller $425 / 05$

Primary Examiner-Francis S. Husar

Assistant Examiner-John McQuade

Attorney, Agent, or Firm-Harold L. Stowell

[57]

ABSTRACT

In an apparatus for constructing high-rising. poured concrete walls, pairs of spaced-apart, upright supports are preliminarily mounted on a foundation and then detachably attached to both sides of at least a partially. hardened level of concrete wall and at intervals along the length of the wall for repeated, upward, step-wise use as the wall is being formed; a plurality of carriages are mounted on adjacent supports along both sides of the wall for continuous upward movement as the wall is being cast, and adjustable concrete shaping assemblies are mounted on the carriages. Each assembly opposing a similar assembly to define a continuous mold into which new concrete is poured on top of previously poured concrete to form the wall.

3 Claims, 10 Drawing Figures

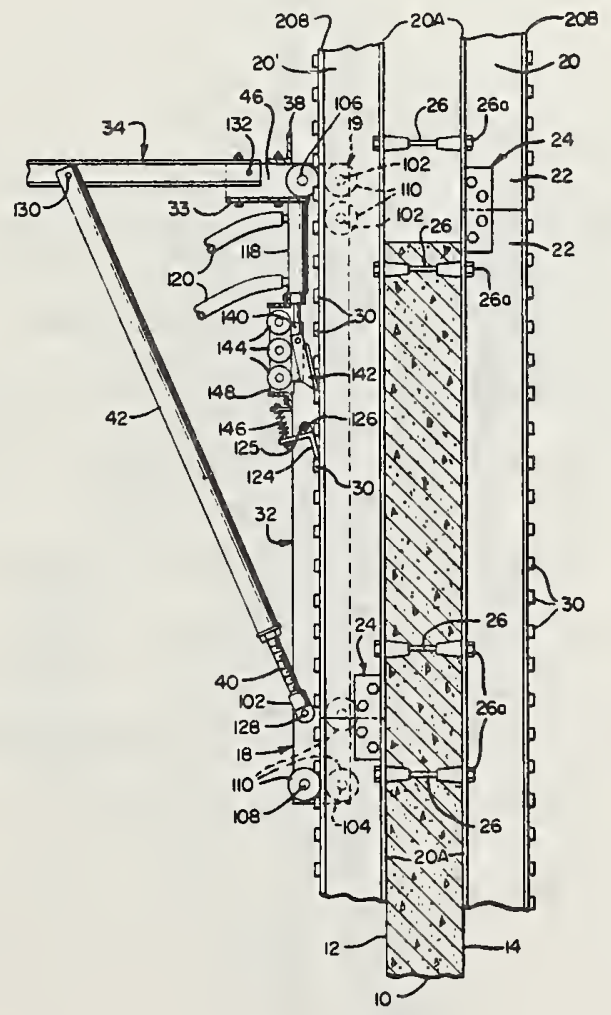


U.S. Patent Aug. 9, 1977 Sheet 1 of $6 \quad 4,040,774$

FIG. I.
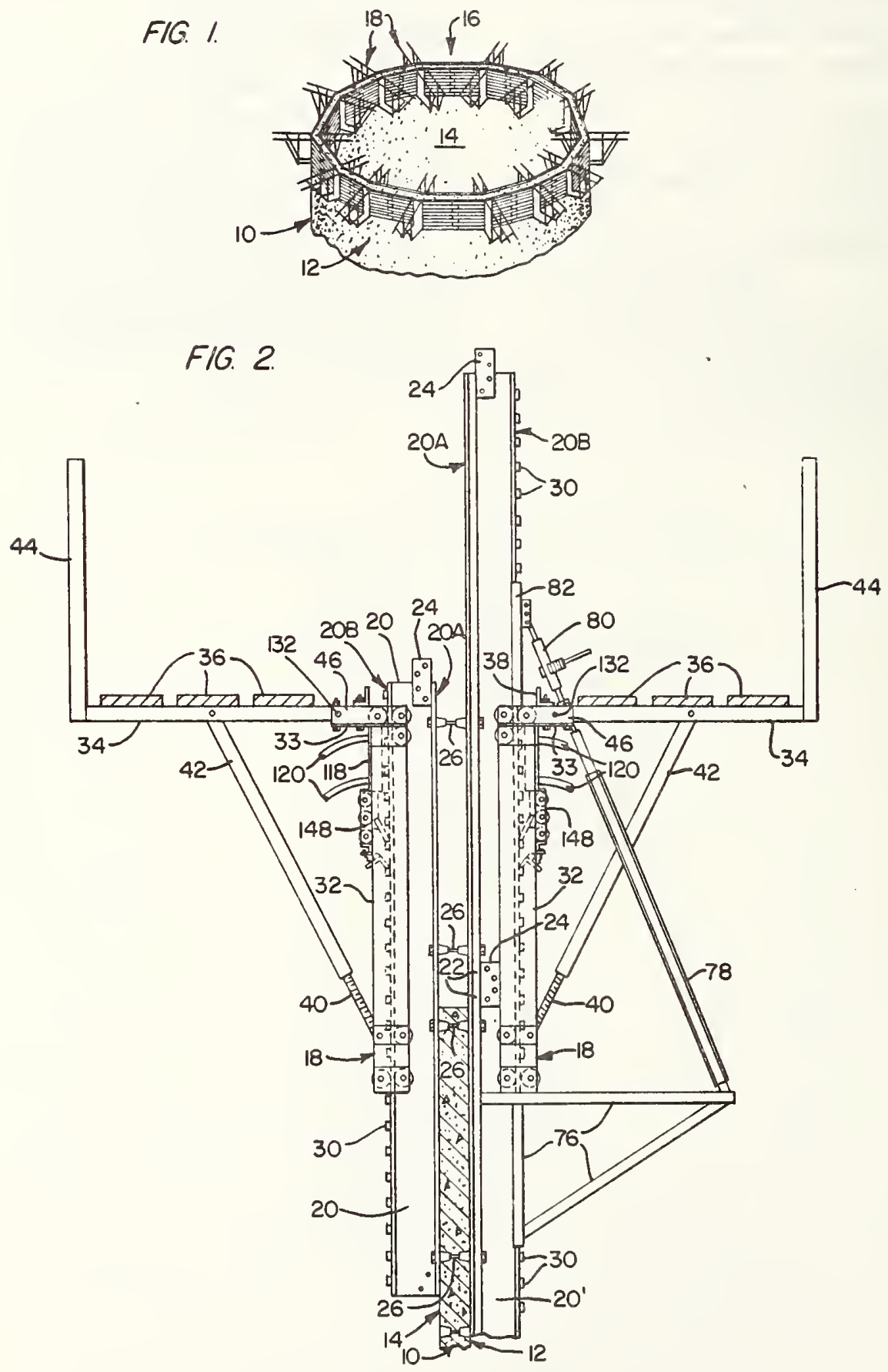
U.S. Patent Aug. 9, 1977 Sheet 2 of $6 \quad 4,040,774$

FIG. 3.
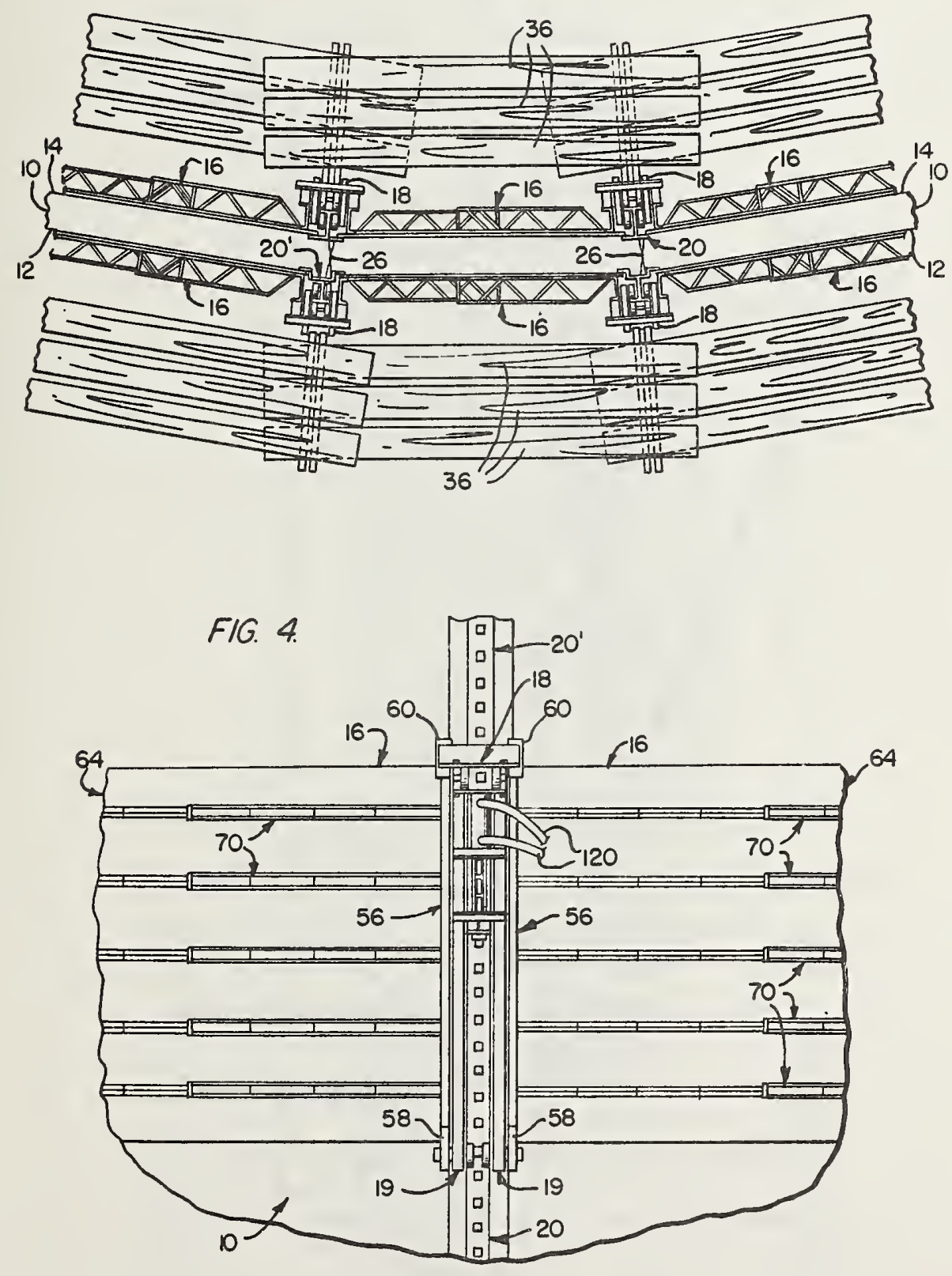
F/G. 5

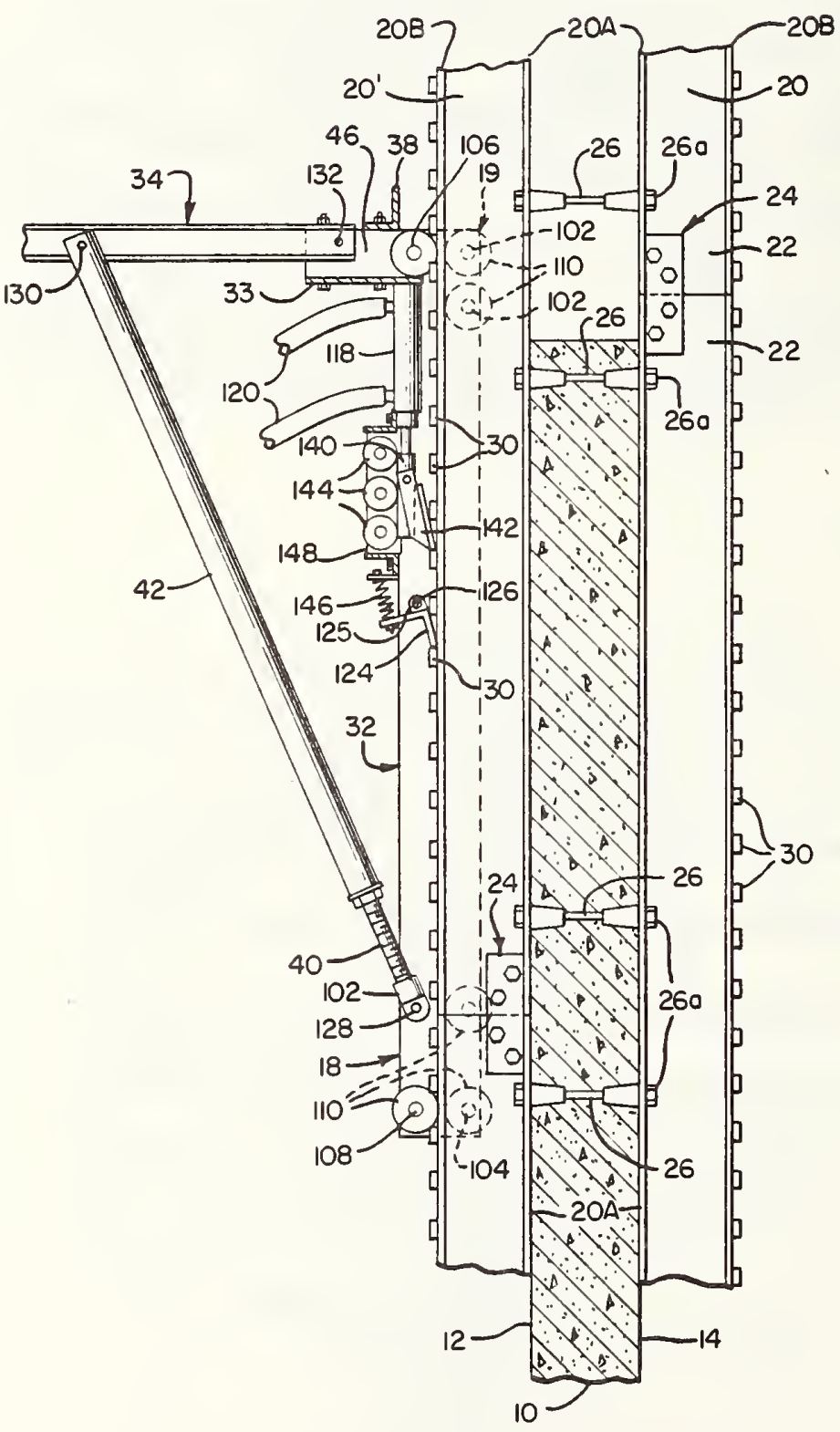


U.S. Patent Aug. 9, $1977 \quad$ Sheet 4 of $6 \quad 4,040,774$

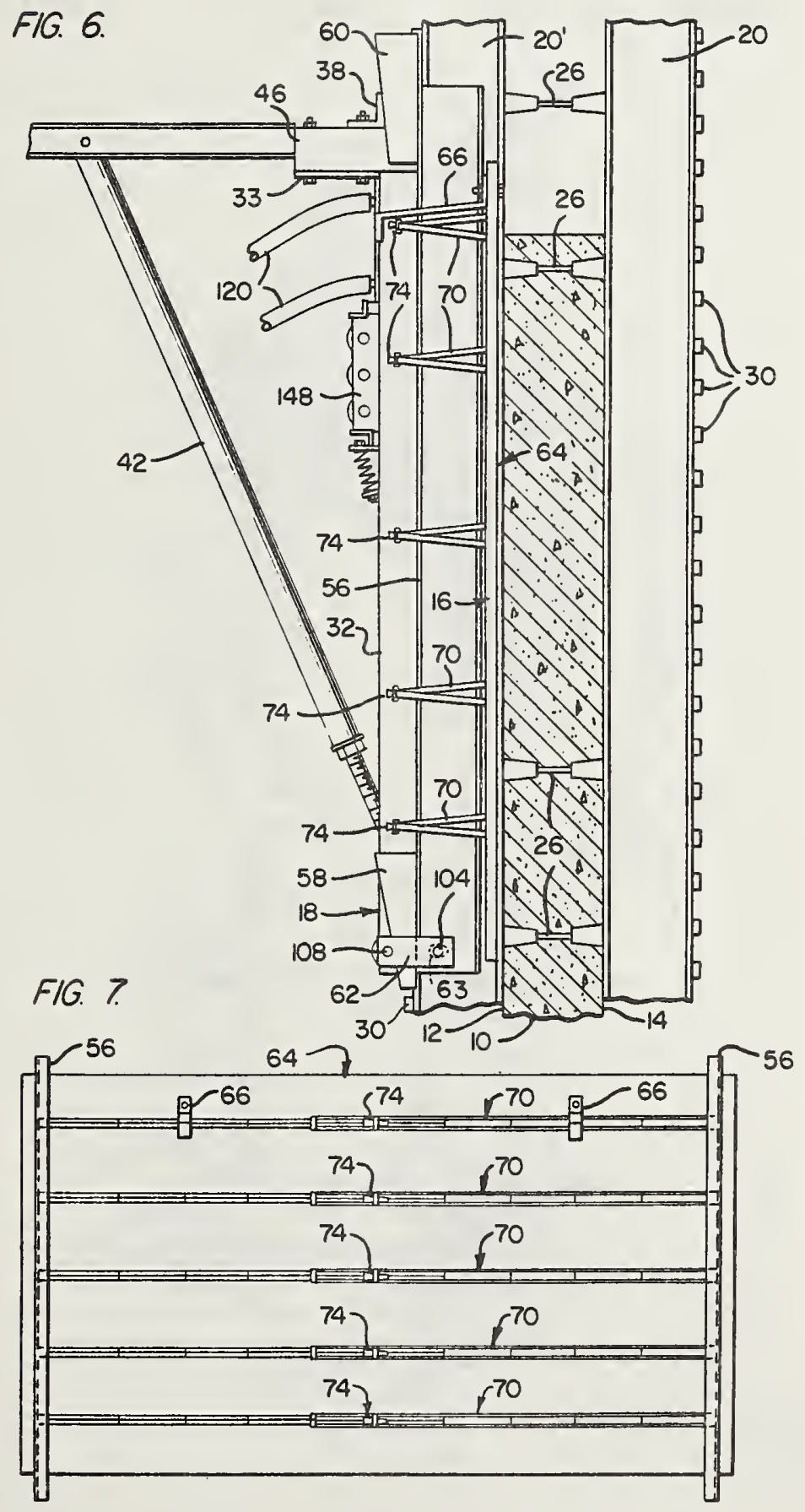




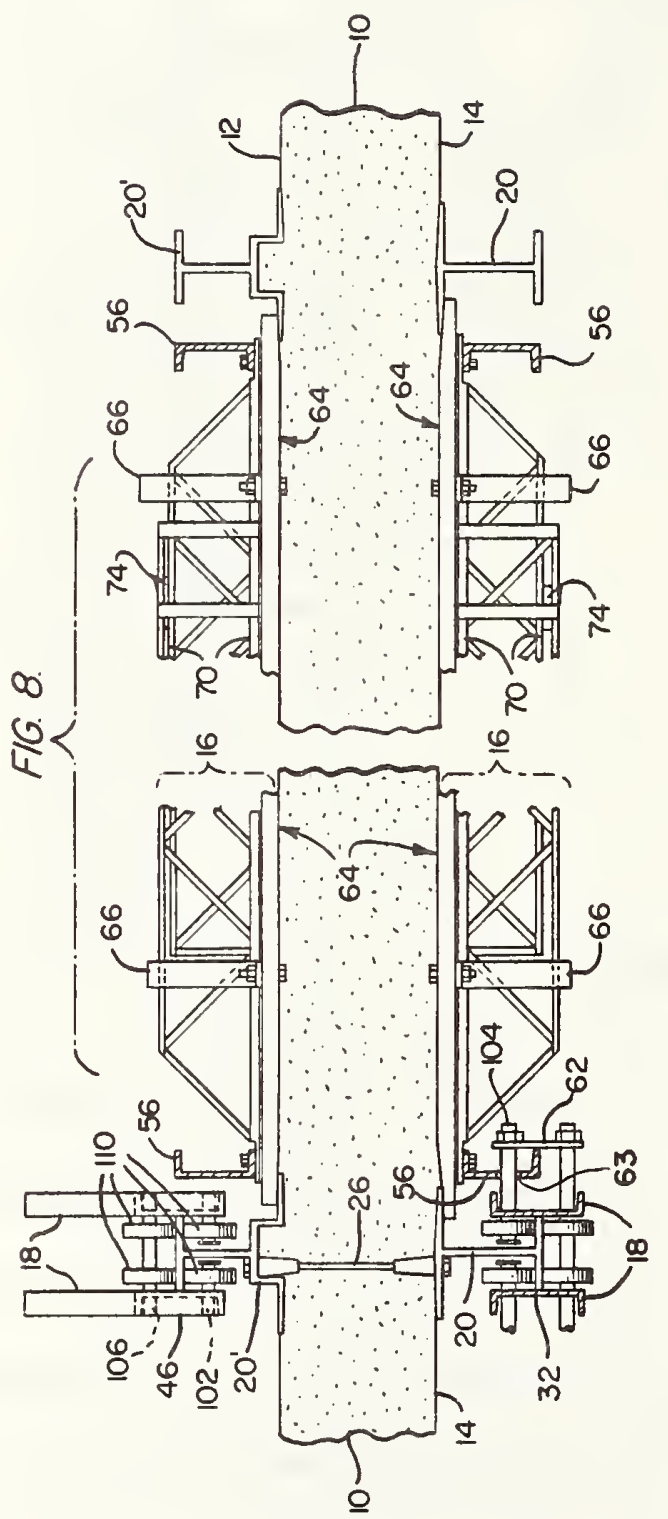


U.S. Patent Aug. 9, 1977 Sheet 6 of $6 \quad 4,040,774$
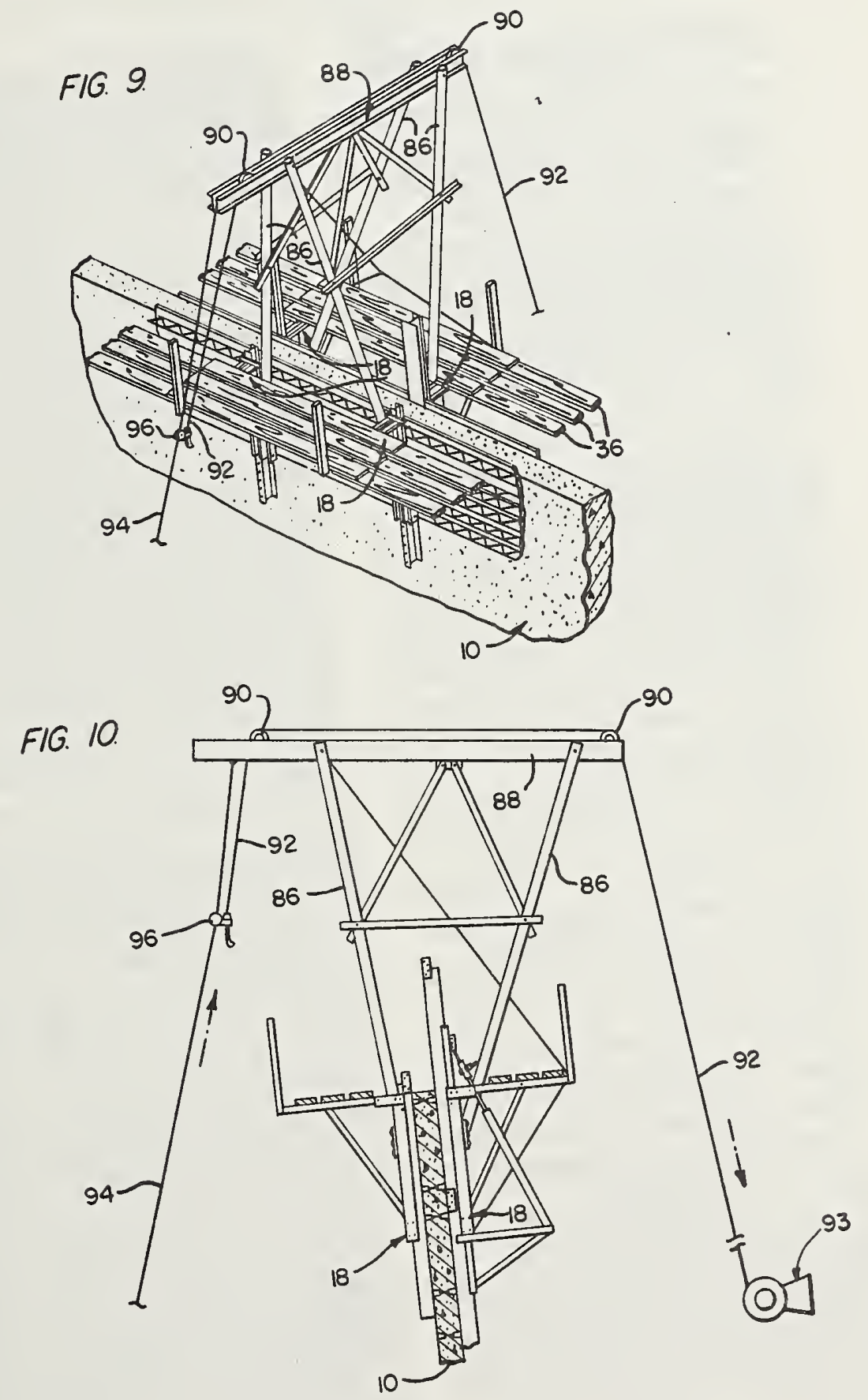


\section{APPARATUS FOR CONSTRUCTING CONCRETE WALLS \\ CROSS-REFERENCE TO RELATED SUBJECT MATTER}

Related subject matter is disclosed and claimed in my U.S. Pat. No. 3,779,678 granted Dec. 18, 1973.

\section{BACKGROUND OF THE INVENTION}

Modern concrete wall casting techniques frequently utilize pairs of spaced-apart, shaping forms held in position by various types of movable supports. the concrete being poured between te forms and on top of the section of wall poured earlier and partially set. After the last poured concrete has at least partially set, the forms are removed and relocated above the former position and then the procedure is repeated until the wall is completed.

\section{SUMMARY OF THE INVENTION}

This invention provides a new and improved apparatus for efficient casting of shaped concrete walls and, in the exemplary embodiment, includes a plurality of pairs of spaced-apart, upright supports extending from the foundation initially and then attached to opposing sides of the wall being formed along the entire length of the wall, sections of each support being detachable at the bottom of the support and from the wall at intervals and re-attached at the upper end of the support to form a continuously advancing support as the wall is formed.

\section{BRIEF DESCRIPTION OF THE DRAWINGS}

FIG. 1 is a perspective, stylized view of the base portion of a cooling tower veil being formed by the casting apparatus of this invention;

FIG. 2 is a vertical section of the apparatus showing the preferred form of supports and carriage:

FIG. 3 is a top view of the apparatus shown in FIG. 2;

FIG. 4 is an enlarged, fragmentary side elevation of a form or shaping assembly;

FIG. $\mathbf{5}$ is an enlarged, vertical section showing the carriage elevating and retaining mechanism;

FIG. 6 is an enlarged, vertical section showing the intermediate form in relation to the carriage;

FIG. 7 is a rear elevation of the sheet portion of the form assembly;

FIG. 8 is a fragmentary horizontal sectional view of the form assembly and related apparatus;

FIG. 9 is a perspective view of the hoisting apparatus; and

FIG. 10 is a side elevation of the hoisting apparatus.

\section{DESCRIPTION OF THE PREFERRED EMBODIMENT}

The preferred embodiment of the apparatus is set forth herein, for illustrative purposes, in connection with the construction of a concrete veil or outside wall of a nature draft cooling tower, which frequently rises 450 feet above the ground and has a diameter of 350 feet at ground level. In such construction, the round concrete wall decreases in diameter as it rises until narrow section or throat is reached, and then increases in diameter toward the top to form the hyperbolic shape. As illustrated in FIG. 1, the tower veil or wall 10 has an outer surface 12 and an inner surface 14, and a series of carriages 18 located entirely around the top of the wall.
During the initial construction of a cooling tower and after the ground foundation has been laid, pairs of opposed, spaced-apart, generally vertical supports or $\mathbf{H}$. beams, designated 20 for the inside 14 and $20^{\prime}$ for the 5 outside 12, are anchored on the foundation. Each sup. port 20 and 20', not shown in FIG. 1 burt located at each carriage 18, is 20-30 feet long and is composed of several sections 22 of extruded aluminum, generally H.shaped beams, jointed at their ends by bolted plates 1024 as shown in FIGS. 2 and 5. The beams of each pair are separeated from each other by a distance while will generally be the thickness of the wall 10 being formed, which at the base of a tower is about 30 inches. The beams are spaced apart, as desired, as best shown in FIG. 5, by a plurality of horizontal spacers or internally threaded inserts 26 attached to the beam flanges $20 \mathrm{~A}$ by bolts $26 a$ before concrete is poured between the beams. Each pair of beams are separated by about 10 feet from similar pairs around the wall so that the beams are lo.

20 cated at spaced intervals completely along both the inner and outer wall surfaces 12, 14. As the concrete is poured between the beams and the wall increases in height, a lower section of each beam is detached from the side of the wall 10 by removing bolts $26 a$ from the spacers 26 , leaving the spacers in the wall. Then the section is attached to the top of the same beam. As the concrete cures, the lower sections of each support held tightly against the wall surfaces easily support the carriages 18 and other structures mounted on them. The beam sections 22 may be lifted into new position by a simple block and tackle or other lifting means mounted on the carriages 18 . The beams $20-20^{\prime}$ are also provided with spaced apart lugs 30 (FIG. 2) permanently affixed to the outer flange $20 \mathrm{~B}$ of each beam for a purpose later described.

A plurality of carriages 18, shown in FIGS. 1, 2, 3, 4, 5 and 6 , are separately mounted for vertical movemen on beams 20-20' and adjacent carriages support there between concrete form assemblies 16 which shape the 40 surfaces of the wall being formed. Additionally, as shown on FIG. 2, the carriages provide a working platform for men and equipment which extends entirely around the wall being formed.

Each carriage 18, reference being made to FIGS. 2, 4, 5 and 6, includes a pair of similar frames 19 composed of several common structural beams welded and bolted together to form a strong, unitary structure. In detail and as shown in FIG. 2, each frame includes a vertical channel 32 , which is welded to a horizontal tubing $\mathbf{4 6}$, 50 which in turn is bolted with bolt 132 , to channel 34 , which is welded to channel 44 . Two adjacent frames 19 , one being constructed opposite hand, are jointed together to form each carriage 18 mounted on a beam 20 by bolted connector plates 33 (FIG. 5 ), angle 38 , roller s5 frame 148, and machine bolts 108, 126, 128, 130 and 132 , which also serve as axles to other components. A pipe 42 and a thread rod assembly $\mathbf{4 0}$ are bolted between adjacent frames 19 , and serve as an adjustable support to channel 34 . Wheels 110 are attached to channel 32 and tube 46 of each frame by axles 102,104,106 and 108 , and ride against opposing sides of the two outer flanges $20 \mathrm{~B}$ of the beam holding the carriage against the beam

A hydraulic jack 118 (FIG. 5) is attached to plate 33 and roller frame 148 in each carriage by bolts and 5 mounts and exerts upward thrust against the carriage when hydraulic pressure is supplied through flexible hose 120 . A reciprocating bar 140 is attached to the ram of the hydraulic jack 118, which in turn has a pivoted 
pawl 142 which is spring louded (spring not shown) to insure positive engagement between pawl 142 and lug 30 on beam $20-20^{\circ}$

Further, wheels 144 are mounted on roller frame 148 which extends between adjacent beams 32 , and are in rolling contact with reciprocating bar 140 to resist lateral forces on bar 140 and prevent disengagement between pawl 142 and lugs 30 . In addition, a followe pawl 124 welded to a short pipe 125 , which in turn is mounted for rotation on a shaft 126 extending between 10 beams 32, engages lugs 30 and is held in engagement by spring 146.

Normally, the carriages progress in an upward direction by extension of pawl 142 until tooth 124 engages a higher lug, 30 followed by withdrawal of pawl 142 for relocation against a higher lug 30 , and repeating. How. ever, if necessary, a carriage can be lowered by extend. ing hydraulic jack 118 so that the load carried by follower pawl 124 is now transferred to extendable pawl 142 and engaged cleat 30 . When the load is thus transferred, pawl 124 can be pivoted so that by slowly retracting the jack will allow the carriage to settle and follower pawl 124 to engage in the next lower cleat 30 .

A working scaffold is formed by planks 36 resting on beams 34 of adjacent carriages and an outer rail 44 between which ropes or planks may be placed.

Concrete shaping form assemblies 16, generally shown in FIGS. 4, 6 and 7 span the distance between adjacent carriages 18 on both sides of the wall being formed and form and sides of the mold into which fresh 30 concrete is poured. Each form assembly 16 includes a forming sheet 64 , two end stiffback channels 56 , to which lateral, telescoping steel trusses 70 are bolted, with incorporated wedges 74 , that strengthen the trusses 70 when in the proper position. Forming sheet 3 64 may be $3 / 43$ plywood for example, or any ridgic material that can be easily cut, or added to, to provide a smooth casting surface, telescoping trusses $\mathbf{7 0}$ provide lateral support for sheet 64 , throughout their effective length, once the incorporated wedges 74 are wedged firmly.

The stiffback channels $\mathbf{5 6}$ are structural channels that are vertically supported at the bottom by axle 104 which extend beyond beam 32, thru slotted holes 63 (FIGS. 6 and 8) to a retainer plate 62. Further, axle 108 also extends beyond beam 32 to the retainer plate 62 . The form panel 64 is held firmly against the extruded llange $20 \mathrm{~A}$ of bearns $20-20^{\prime}$. This is accomplished by wedging the opposite side of the stiffoack channel 56 (FIG.6) with a steel wedge 58 against the extended axle 50 108.

Similarly the top of channel 56 forces form panel 64 tightly against the extruded flange $20 \mathrm{~A}$ of beams $20-20^{\prime}$, with a hardwood wedge 60 , driven between its opposing side and angle 38. With reference the FIGS. 6 and 7, the forming sheet 64 is held vertically by a bracket 66 which merely serves to keep the sheet 64 from falling out when the entire form assembly is unwedged as re. quired while "jacking".

As in the case of cooling tower construction, as the tower moves upward in height the diameter decreases to the throat or neck of the tower, requiring the carriages 18 to become closer together. With reference made to FlG. 8 it can be seen that as the carriages 18 move upward and wedges 74 of the steel trusses 70 being loosened, they are forced together, or can open freely as required. FIG. 8 also illustrates that while the form assembly 16 has its wedges loosened, the form panel 64 is only supported from falling by bracket 66 and can easily be pulled out be sliding it upward from

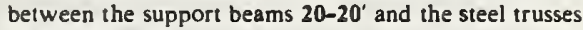
70 for cutting.

The nature of the extruded aluminum beams 22 that make up the support beams 20-20' permits that they can be repeatedly bent or flexed approximately 3 inches over each length without permanent damage.

Using this characteristic, (FIG. 2) a frame 76 , com. prising iwo opposite hand weldments are attached to either half 19 of the carriage 18 on one side of the wall 10. The frame 76 encases the outer flange $20 \mathrm{~B}$ of a portion of beams $20-20^{\prime}$ which is adjacent to firm concrete. Similarly a frame $\mathbf{8 2}$ is mounted on the top of either half 19 of the carriage 18 which encases the outer flange $20 \mathrm{~B}$ of beams $20-20^{\prime}$ above the form enclosure. An arm 78 is bolted to the lower frame 76 , and in turn a stream-bolt ratchet $\mathbf{8 0}$ connects to the top frame $\mathbf{8 2}$. By extending or contracting the steam-bolt ratchet 80 , lateral pressure is applied sufficient to bend the suppori beam 20 and properly align the wall 10 being cast.

The vertical strength afforded by such a forming system is also used to best advantage by eliminating excessively high mobile cranes or tower cranes required in high rise construction, as used in previous forming systems. Gantries are erected at selected points around the top of the tower as illustrated in FIGS. 9 and 10. Each gantry is comprised of a beam $\mathbf{8 8 ,}$ which is bolted to four pipe legs 86 , which in turn are attached to four separate carriages 18 . On the upper side of beam 88 , two sheaves 90 are attached. A commercial hoisting engine 93 on the ground is used with these gantries so that the load line 92, originating from the hoisting engine on one side of wall 10, is supported over the wall on sheaves 90 so that materials can be hoisted on the opposite side of wall 10 as the arrows indicated in FIG. 10. Also, a stationary static line 94 , which extends from beam 88 to a strategic point or concrete hopper on the ground, is used as a guide for the load line 92 , which is attached to a small block 96 so that its sheave wheel rolls on static line 94 . The static line 94 serves to make the ground loading point (not shown) central, which expedites concrete handling from a concrete truck or hopper, as well as keeping the workmen from working beneath the scaffolding along the perimeter of the tower.

The two variations in the form surface, or flanges $20 \mathrm{~A}$ of jack beams $\mathbf{2 0}$ and $20^{\circ}$, are shown as in cooling tower construction, the outer wall surface 12 is generally o ridged and the inner wall surface 14 is generally smooth. The plurality of vertical ribs thus formed on the outside surface 12 of the completed tower serve to induce air turbulance, thus enhancing heat transfer.

In casting the initial courses of the wall, an ordinary general crane is used to raise the plastic concrete from the ground to the working scaffold where it is distrib. uted by wheeled carts to the forms around the periphery of the structure. It will be appreciated that several cranes may be used simultaneously so that such a large structure can be cast at a reasonable rate. When the structure height exceeds reach of the cranes, a number of gantries are attached to selected carriages.spaced around the wall. These gantries now provide the means to transport plastic concrete and other materials to the work area. The concrete is raised in buckets (approximately cu. yd. capacity) by cables running over the gantries and returning to hoisting engines on the ground. Thus, the necessity for using a large tower 
crane is avoided and the work can progress much more quickly and safely than with such a crane.

I claim:

1. Apparatus for forming a concrete wall comprising

a. a plurality of generally vertical supports spaced s apart along both sides of the wall being formed, each support being located opposite to another support on the other side of the wall and detachably connected to said opposing support by a plurality of spacers some of which are contained in the wall 10 previously formed, each support consisting of separate segments detachably joined together at their ends, and the lower portion of each support being held contiguous the surface of the wall previously formed by said spacers while the upper portion is extends above the portion of the wall previously formed.

b. a carriage mounted on each support with means for advancing the carriage upwardly along the supports as the wall is formed

c. a plurality of concrete casting assemblies located along and on both sides of the wall being formed adjacent its top, each assembly supported at its ends by two carriages on adjacent supports and each assembly having a generally vertical casting surface extending between the adjacent supports so that the assemblies and the supports together define a continuous mold extending on top of the wall into which concrete is poured, whereby as the concrete hardens the carriages and assemblies are moved upwardly on the supports to form a new level of

\section{6}

wall and, at intervals, support segments are detached from the bottom of each support and attached to the top to provide a continuous track for the carriages,

d. each casting surface comprises the inner surfaces of generally horizontal, plywood sheets which combine to form a continuous casting surface,

e. each casting assembly comprising a plurality of generally horizontal braces positioned contiguous the outer surface of the plywood sheets to support the sheets while the concrete is setting against the inner surface of said sheets, and

f. each casting assembly comprising at leası a pair of slotted beams movably carried by adjacent carriages, said plurality of horizontal braces mounted between said slotted beams which are adapted to be wedged against said adjacent carriages, so that by wedging the slotted beams against the carriages the inner surface of the sheets are drawn into contact against the adjacent supports thereby providing said continuous mold.

2. The apparatus defined in claim 1 further including hoisting means attached to said carriages, a ground 5 supported hoisting engine, and a hoisting cable connecting said hoisting engine and said hoisting means.

3. The apparatus defined in claim 2 further including a stationary cable connecting the hoisting means to a central loading point below on which the hoisting cable is guided. 
APPENDIX B

Computer Programs for Shell Analysis 
Appendix $B$

Computer Programs for Shell Analysis

\section{B.1 Introduction}

Failure of the cooling tower shell under the imposed construction loads at the location of cathead gantry no. 4 was believed to be a plausible cause for the initiation of the total collapse of lift 28 . Thus, an analysis of the shell structure as it existed at the time of the collapse was made using the construction loads. The complexity of the loading conditions as well as the variation in shell thickness and material properties required that the finite element method be employed as the means of analysis. A survey of finite element programs available for the analysis of this type of shell structure with the constraints mentioned previously indicated that SHORE-III[6.2] satisfied these requirements and has been used previously [B.1, B.2] to analyze this type of structure.

As a means of verifying the results obtained in the SHORE-III analysis, a second finite element program, SAP IV [6.3], was selected. SAP IV is a general finite element program which provides an alternate method for load input and an alternate shell model from those used in the SHORE-III analysis.

This appendix will present a discussion of the pertinent features of the two finite element programs used in the analysis of the shell and a comparison of the results obtained from each analysis, for selected loading conditions. 
B.2 Discussion of SHORE-III and SAP IV

SHORE-III (SHORE) is a finite element program for the linear elastic static and dynamic analysis of arbitrarily loaded axisymmetric plates and she1ls. SAP IV (SAP) on the other hand is a general finite element structural analysis program for the linear elastic analysis of three dimensional structural systems. Although both programs are capable of performing either a static or dynamic analysis, this discussion will be limited to the static analysis since all construction loads used in the analysis were treated as being static. Furthermore, since SAP has a rather large element library (truss, beam, plane stress or strain, three-dimensional solid, pipe, etc.) only the plate/shell element which was used in the SAP analysis will be discussed.

The capacity of SAP is primarily dependent upon the total number of nodal points needed to model the shell while SHORE is restricted to a model comprised of no more than fifty (50) elements. This element restriction for SHORE is not serious for this analysis since the stress distributions at the lower elevations of the shell do not have a significant effect on the results obtained for lift 28 . Thus, the number of elements used to model the lower portion of the shell can be reduced. The shell model is developed for SHORE by discretizing the meridian curve of the shell with a series of curved rotational ring elements. SAP requires a discretization along the meridian and around the circumference of the shell in order to develop its model. Thus, the SHORE model is composed of a series of continuous ring elements along the meridian of the shell while the SAP model is a three-dimensional assemblage of flat plates. 
Only a brief description of the elements used in the SHORE and SAP analysis will be presented. References which present the details on the formulation of the individual elements are given in the description. The curved rotational ring element [B.3] used in SHORE has an element stiffness matrix which is derived from displacement fields that may vary from linear to sixth order and includes the exact geometry of the shell as well as the effect of transverse shear deformation. The extra coefficients in the higher order displacement fields are eliminated by kinematic condensation at the element level. Sixth order displacement fields were used throughout in this analysis. The element used in the SAP analysis is a quadrilateral of arbitrary geometry formed from four compatible triangles. A constant strain triangle [B.4] and a linear curvature compatible triangle with nine (9) degrees of freedom [B.5] are used to represent the membrane and bending behavior, respectively, of the SAP element. A central node is located at the average of the coordinates of the four corner nodes and has six degrees of freedom which are also eliminated by condensation at the element level.

Each element in both SHORE and SAP have constant material properties (moduli of elasticity) although the properties may vary as required from element to element in the respective models. The thickness of a particular element in SAP must be constant, but may change as required throughout the SAP she11 model. The thickness of the SHORE element can vary linearly along the meridian as dictated by the shell geometry .

Various loads including thermal effects may be used as input for both the SHORE and SAP analysis with distributed loads (gravity, 
pressure, etc.) and thermal loads being treated as consistent equivalent nodal loads in both analyses. However, a major difference exists in the manner in which other loads are input for analysis. SAP requires that all external loads including moments applied to the she11 structure be input as concentrated loads at nodal points while for the SHORE analysis all loads are expanded in Fourier harmonics with respect to an element nodal point and the final result is obtained by superimposing the results of each harmonic.

Finally, both finite element programs solve the resulting set of linear simultaneous equations for the structural model by a modification of the Gaussian elimination scheme which takes advantage of the symmetric narrow banded nature of the global matrices used.

\section{B.3 Comparison of Results}

Several of the most significant differences between the two finite element models are considered and comparisons of results are made. The differences include the effect of element discretization, boundary conditions, the method of applying the loads, the precision of calculations and the type of elements used.

One of the biggest differences between the two analyses lies in the initial scheme for discretizing the shell. While SHORE uses continuous ring elements as shown in figure B.1, SAP requires that the rings be broken into numerous elements. The radial grid adopted is shown in figure B.2. The changes in radial increment were chosen to reduce the number of nodes required for the model in hopes of making the program manageable on the computer while preserving resolution at cathead gantry no. 4 and providing loading points at the other catheads. As it was, 
the SAP analysis required more than eight hours of computer time. The effect of having varying radial increments was to introduce some variations in the solution which could be attributed directly to the variations in the size of the elements. This can be best illustrated by considering the gravity loads which should be identical at any angle. Figures B.3 and $B .4$ illustrate the radial variation of hoop stress, $N_{\theta}$, and the meridional stress, $N_{\phi}$, respectively, $1.5 \mathrm{ft}(.457 \mathrm{~m})$ below thé top of lift 28 . The radial variations in the stresses as predicted by SAP are due to the changes in size of adjacent elements and to the poor aspect ratio of the larger elements. The smallest elements at cathead no. 4 (elements 126 and 127$)$ are $2.18 \mathrm{ft}(0.66 \mathrm{~m})$ long by approximately $0.6 \mathrm{ft}$ $(0.18 \mathrm{~m})$ high for an aspect ratio of 3.63 while the largest elements near the top (elements 112 and 120) have an aspect ratio of approximately 58. As can be seen in figure B.3 and B.4 element size change has more of an effect on $N_{\phi}$ (fig. B.3) than the aspect ratio, while the aspect ratio has more of an influence on $\mathrm{N}_{\theta}(\mathrm{fig} \cdot \mathrm{B.4})$. However, figure B.3 and B.4 do illustrate that the stress distribution becomes more uniform near cathead no. 4 where the mesh is finer and the aspect ratio of the elements is more favorable to obtaining a good solution. In the SHORF analysis, the radial stress distribution is dependent only upon the equations used to develop the ring elements. The SHORE and SAP analyses for the gravity load showed good agreement between $N_{\phi}$ and $N_{\theta}$ along the meridian at cathead no. 4. The largest difference was less than 5 percent.

Different boundary conditions are used in the two models. The SHORE model uses an open type element developed specifically to represent the columns at the base of the shell. The effect on the model is 
to smear the stiffness of the columns into a ring. In the SAP model the shell at the top of the ring beam tying the columns together was fixed by prescribing zero displacements. This was done to reduce the number of nodes in the SAP mode1. Consequently, the stress distributions within the bottom ring of the shell are quite different for the two models. However, in element 17 of the SHORE model (see fig. B.1) and the corresponding elements in the SAP model, the stress distributions are similar. The same results are presented in reference $B .1$ where the effect of different boundary conditions on a hyperboloidal shell were studied. Consequently, the effects of the boundary conditions at the base seem to be far enough away from the area of interest, the top two lifts, so that none of the differences in results are due to the differences between boundary conditions used in the two models.

The method of applying the loads seems to have a great impact upon the results. SHORE requires that the loads be applied as line loads acting over some finite length. The length is chosen to allow a reasonably rapid convergence of the fourier series used to generate the load. SAP requires that the loads be point loads applied at nodes. For this problem where the loads are essentially applied to the shell by bolts, the point load approach is more realistic. The effect of using the distributed line loads is to cause the stress distribution to be more uniform near the point of application and the maximum stress predicted should be lower than the real stress experienced by the shell.

The loading function used in the SHORE analysis is developed by first distributing the concentrated loads about the centerline of the jumpform beam. The loads are distributed over 0.358 degrees (10 in 
or $254 \mathrm{~mm}$ at lift 28) for the scaffold loads (load cases 2 and 3) and 0.859 degrees (24 in or $610 \mathrm{~mm}$ at 1ift 28) for the cathead gantry and hoist loads (load cases 4 and 5). The 10 in (254 mm) distribution width is the surface contact length between the shell and jumpform beam. This distributed load is then expanded in a Fourier Series which applies the load at the required points around the circumference of the tower for that particular construction load. The larger distribution angle used in load cases 4 and 5 was chosen because it reduces the number of Fourier series harmonics required to adequately define the loads. Ideally, a 0.358 degree distribution angle should have been used for all cases. However, when the distribution angle was reduced from 0.859 to 0.358 degrees, the number of harmonics required to produce a load function with an acceptable shape increased from 56 to 150 and computer time and costs almost tripled. A sample analysis was conducted using both the 0.358 and 0.859 degree distribution angles and the maximum stresses differed by only a few percent. The stress distributions were also essentially the same. Consequently, it would appear that the compromise between distribution angle and computer analysis time is justified. Figure B.5 illustrates this distributed line loading for the normal, meridion and tangential forces $F_{x}, F_{y}$, and $F_{z}$, respectively and for the meridion moment $\mathrm{M}_{\mathrm{y}}$, applied to the shell by the jumpform beams. The bold vectors represent the points loads used in the SAP analysis.

The development of a convergent Fourier series with only a few harmonics was found to be a difficult task for load cases 4 and 5 which are. applied only at cathead 4. This is because as the number of application 
points decreases (two points or ribs for cases 4 and 5), the number of harmonics required for a convergent series increases rapidly. In addition, the required computer time to analyze a load case using SHORE is related to the number of harmonics. An investigation of the stress distributions that occurred axound the circumference of the shell in load case 4 where the six cathead gantry loads are applied, for both the SHORE and SAP analysis, indicated that the internal shell forces decayed rapidly to a small value at approximately $20^{\circ}$ from the cathead as shown in figures $B .6$ and B.7. Thus, it was concluded that since the catheads are $60^{\circ}$ apart, the loads applied at a cathead have little influence on the internal forces at the catheads on either side. Consequently, in order to reduce the number of harmonics necessary to obtain convergence, the loads for load cases 4 and 5 were applied, in the SHORE analysis, at all six cathead locations instead of just at cathead no. 4. Figure B.8 illustrates the loading function for a normal force applied to the shell by the jumpform beams at a cathead. This load would then be repeated at all six cathead locations in load case 4 to produce a symmetric loading condition.

The loading functions were developed for each construction load (cases 2 through 5) and a separate analysis was made for each case, including the gravity load which was internally generated by both programs. Since both SHORE and SAP are linear elastic finite element programs, the principle of superposition applies and the results for each load case may be combined algebraically to find the resultant stresses for any combination of the construction loads. 
Comparison between values of membrane stress, $\mathrm{N}_{\theta}$, and bending moment, $M_{\theta}$, obtained for solutions to load case 4 using SHORE and SAP are Illustrated in figures B.6 and B.7. The comparisons are illustrated for selected elevations in lift 28 and are typical of results from other load cases. It is interesting to note that although the loads are distributed over an are length in the SHORE analysis, the stress magnitudes predicted compare well with those obtained using SAP. However, because loads are applied at points in the SAP analysis, the stresses would be expected to be larger than those obtained using the SHORE analysis. Several features of the SAP model and solution process may contribute to the apparent inconsistency. A major feature is that SAP calculates stresses at the center of the element which essentially represent the average stress in the whole element. Since even the smallest elements are over two feet wide and the stress distribution is sharp the peak stress may be missed by a significant amount. A second feature involves the precision of the calculations. SHORE carries out all calculations in double precision on a 32-bit word machine while the version of SAP used carries out single precision calculations on a 36-bit word machine. Consequently, roundoff errors may have occurred in the SAP solution process, especially since there were over 6400 equations to be solved and the band width of the stiffness matrix was 612 . Another reason the SAP program calculates smaller stresses may be the poor aspect ratio of the elements and the relative size of adjacent elements. Finally, there are differences in the types of elements used in the two models. SAP uses a plate/shell element which provides only for membrane stresses and bending moments. SHORE on the other hand uses a shell element which accounts for transverse shear and thus provides for a better estimate of bending moments since the elements are relatively thick $(0.667$ 
$\mathrm{ft}, 0.2 \mathrm{~m}$ ) in lift 28 . This appears to be corroborated by the fact that the comparison between membrane stresses in figure B. 6 is better than the comparison between bending moments in figure B.7.

\section{B. 4 Conclusion}

Despite the differences in the values of the stresses there are several encouraging points which arise from the comparison of the two solutions. Both models gave stress distributions of similar shape for corresponding stress components. Also, the fact that such different models could lead to the prediction of stresses and moments for which the peak values agreed within a few percent for membrane stresses is encouraging, especially since insufficient time was available to refine the SAP model. Consequently, the SAP model is considered to be a first cut at verification of the SHORE results, while the SHORE program is designed specifically for the solution of problems involving shells of revolution.

Based primarily on the difference between the SHORE closed ring element, which included transverse shear deformation, and the SAP plate/she11 approximation which does not, it is believed that the stress resultant and moments obtained in the SHORE analysis are a better approximation of the stress levels experienced by the shell in lift 28 for the specified construction loads. The actual stress levels may be higher since the distributed loads used by SHORE to represent the loads applied to the shell at the jumpform beam bolts tend to smear the loads over a larger surface area of the shell than actually occurs and the shell model is not sufficiently able to model the stress distributions that occur at the bolt locations.

Both the SAP and SHORE models give stress distribution that agree reasonably well for the type of loads applied in each analysis. Thus, the areas of high stresses in lift 28 could be predicted from the results of either model. 
B. 5 REFERENCES

[B.1] Sen, S.K. and Gould, P.L., "Hyperboloidal Shells on Discrete Supports," Journal of Structural Division, American Society of Civil Engineers, New York, NY, March 1973.

[B.2] Sen, S.K. and Gould, P.L., "Free Vibration of Shells of Revolution Using F.E.M.," Journal of Engineering Mechanics Division, American Society of Civil Engineers, New York, NY, April 1974.

[B.3] Brombolich, L.J. and Gould, P.L., "A High-precision Curved Shell Finite Element," AIAA/ASME 12th Structures, Structural Dynamics and Materials Conference, American Institute of Aeronautics and and Astronautics, American Society of Mechanical Engineers, Anaheim, CA, April 1971.

[B.4] Felippa, C.A., "Refined Finite Element Analysis of Linear and Non-linear Two-dimensional Structures," SESM Report 66-2, Department of Civil Engr., Univ. of Calif., Berkeley, 1966.

[B.5] Clough, R. W. and Felippa, C. A., "A Refined Quadrilateral Element for Analysis of Plate Bending," Proceedings 2nd Conference on Matrix Methods in Structural Mechanics, Wright-Patterson Air Force Base, Ohio, 1968. 


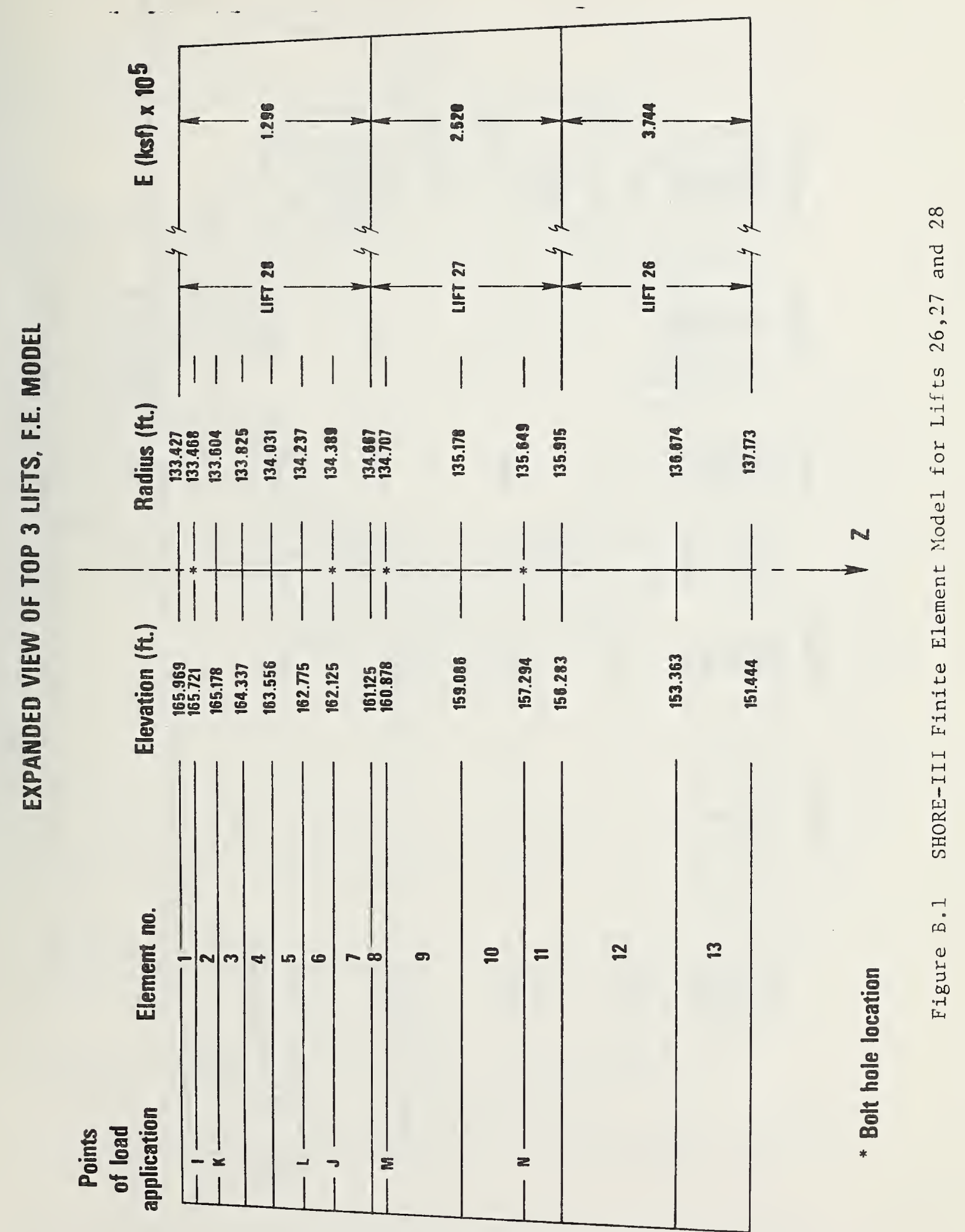




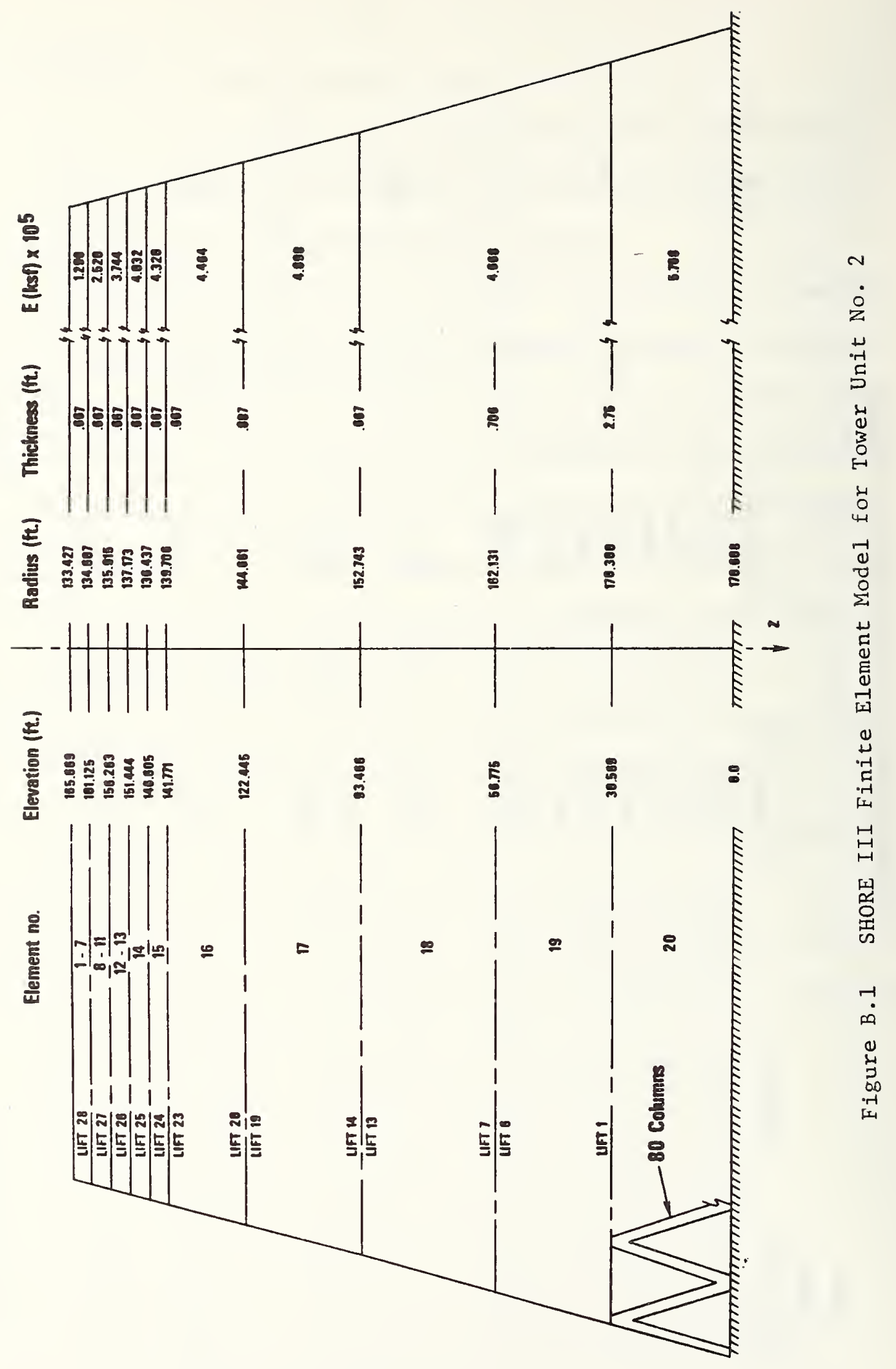




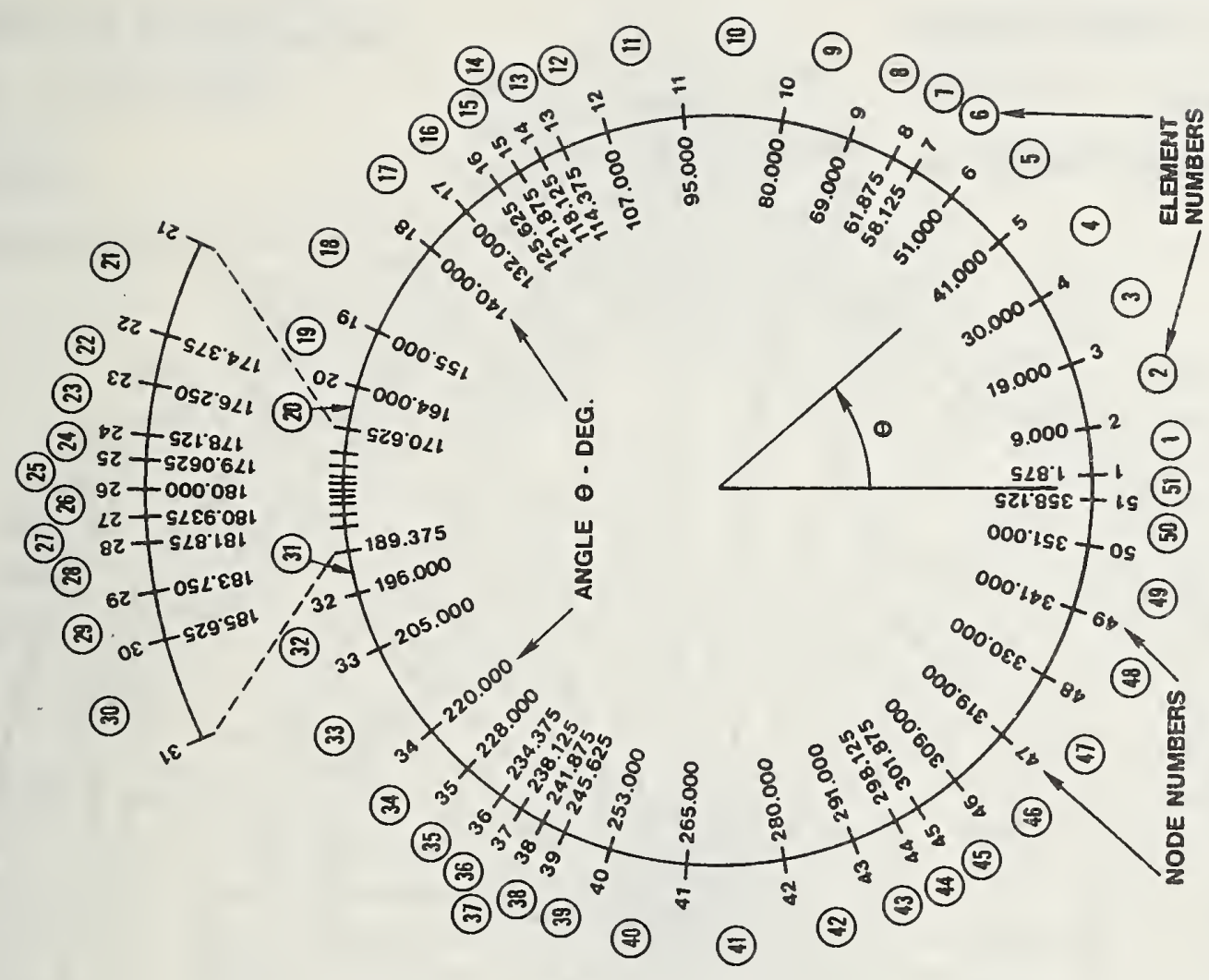

2

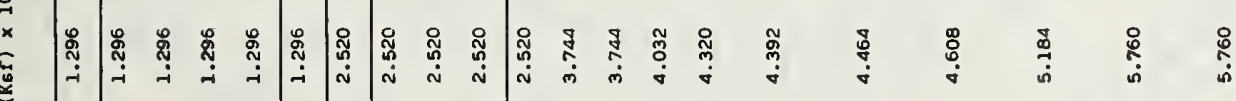

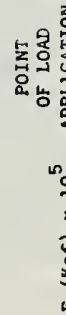

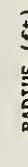

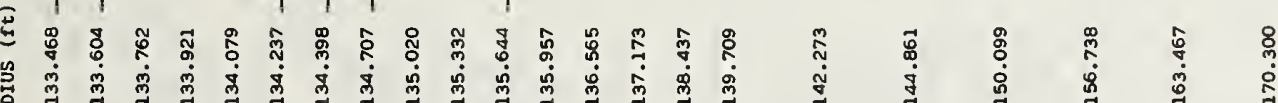

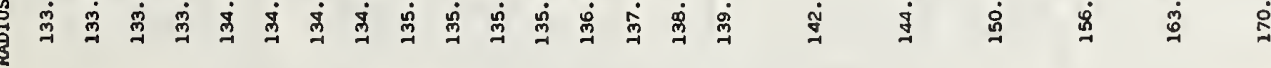

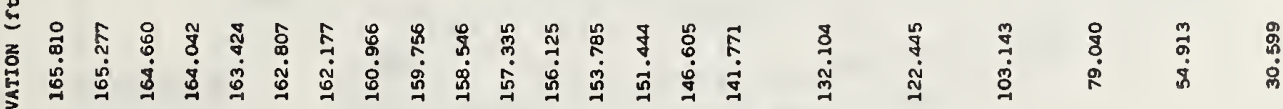

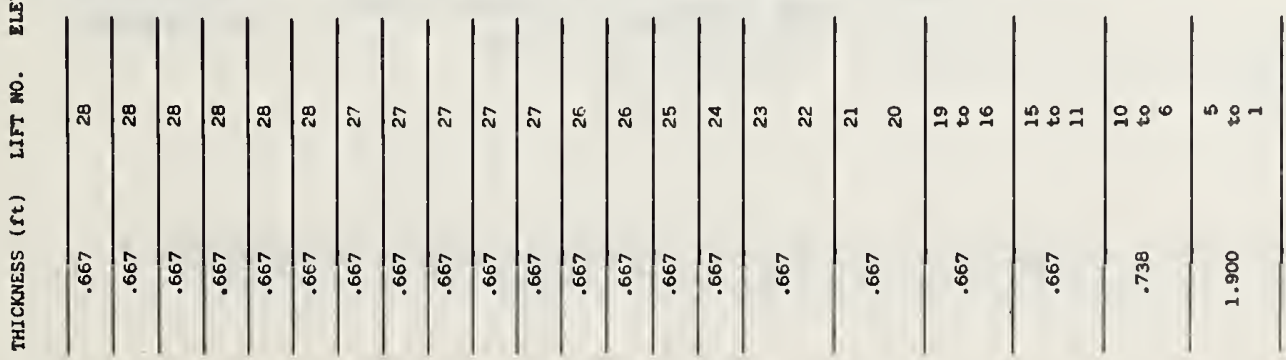

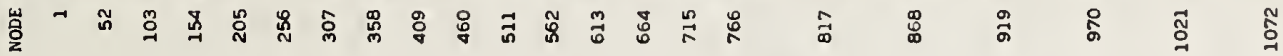




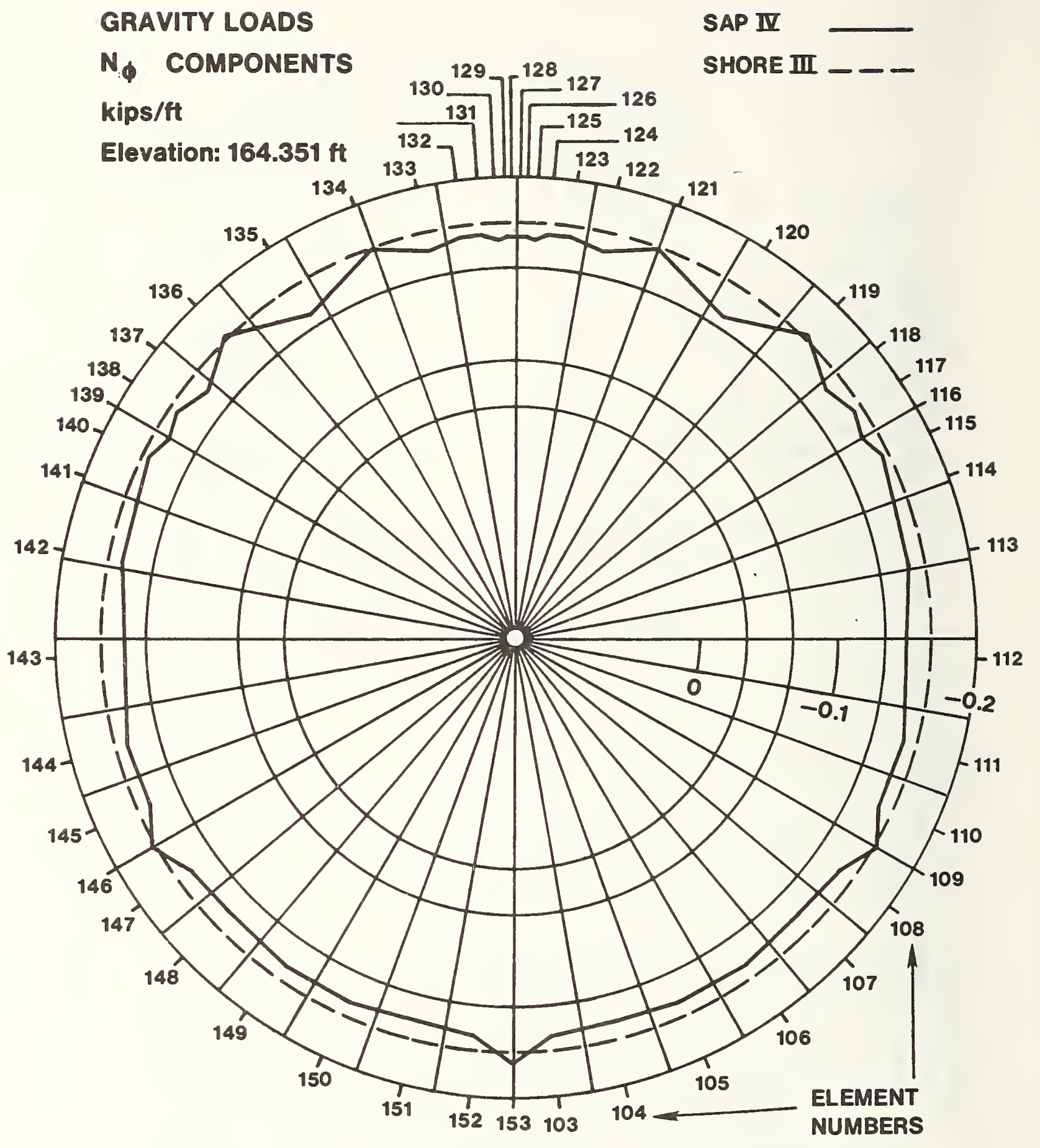

Figure B.3 Comparison of $\mathrm{N}_{\phi}$ from Gravity Load, Load Case 1 


\section{GRAVITY LOADS}

$\mathbf{N}_{\odot}$ COMPONENT

\section{SAP N}

SHORE III _-

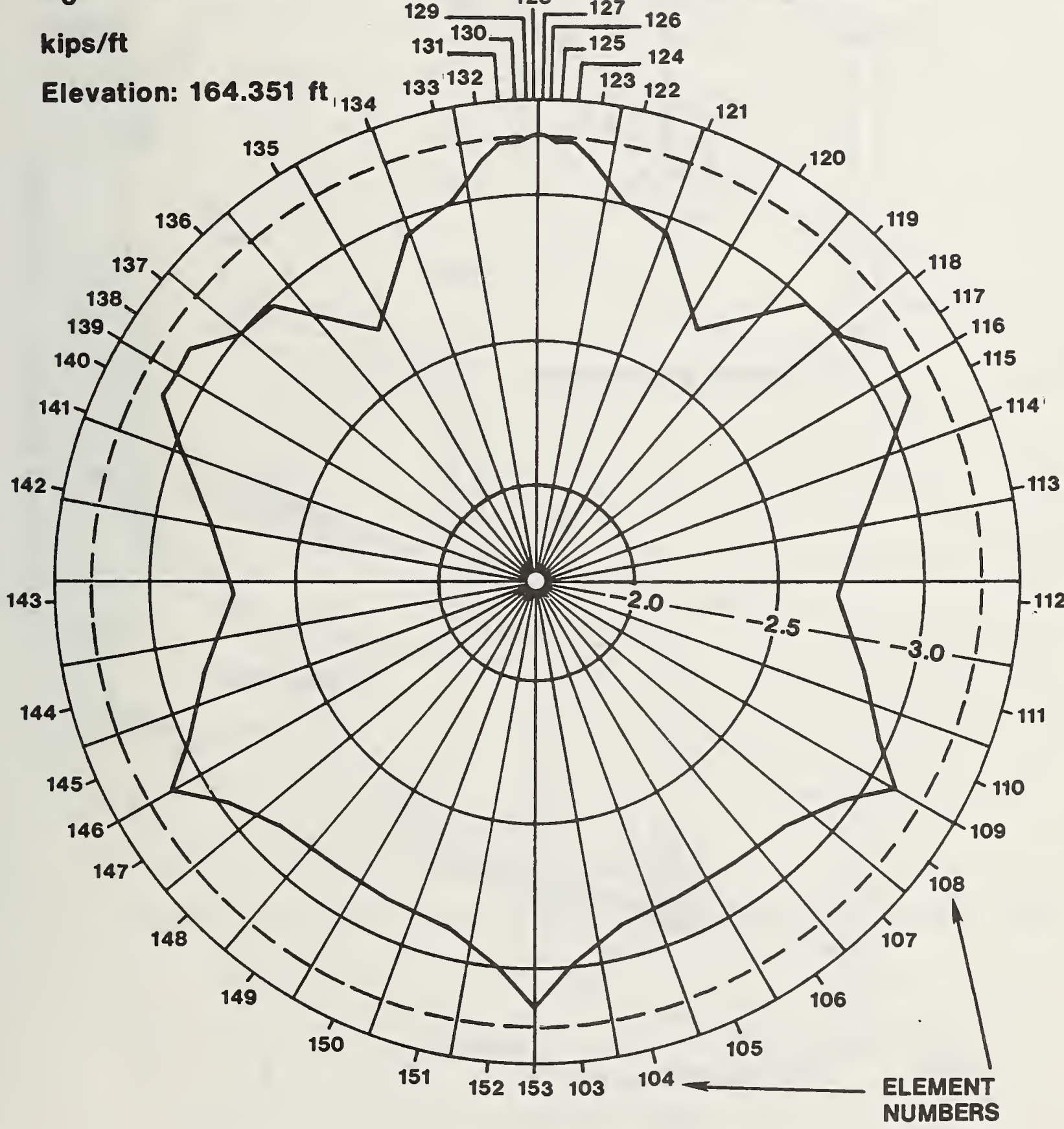

Figure B.4 Comparison of $\mathrm{N}_{\theta}$ from Gravity Load 

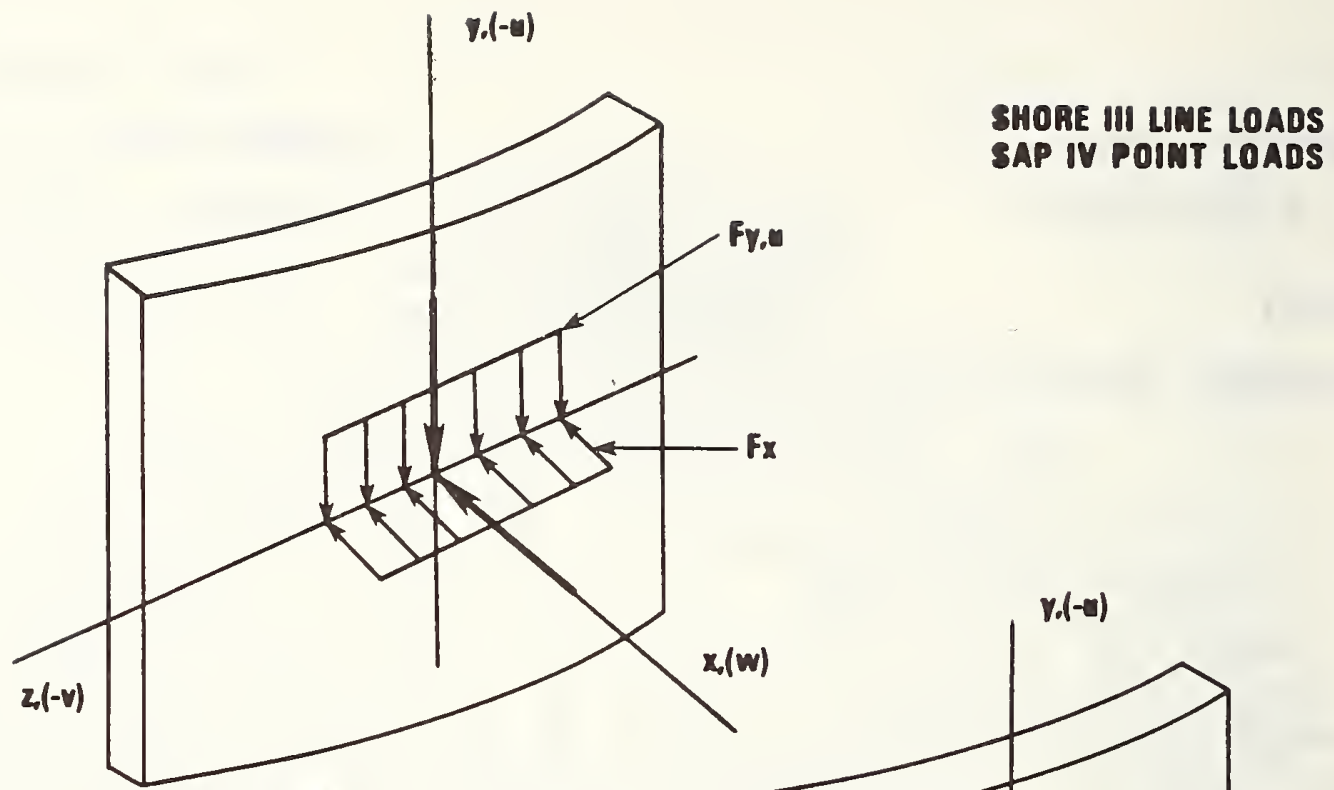

A. Meridional and normal feres

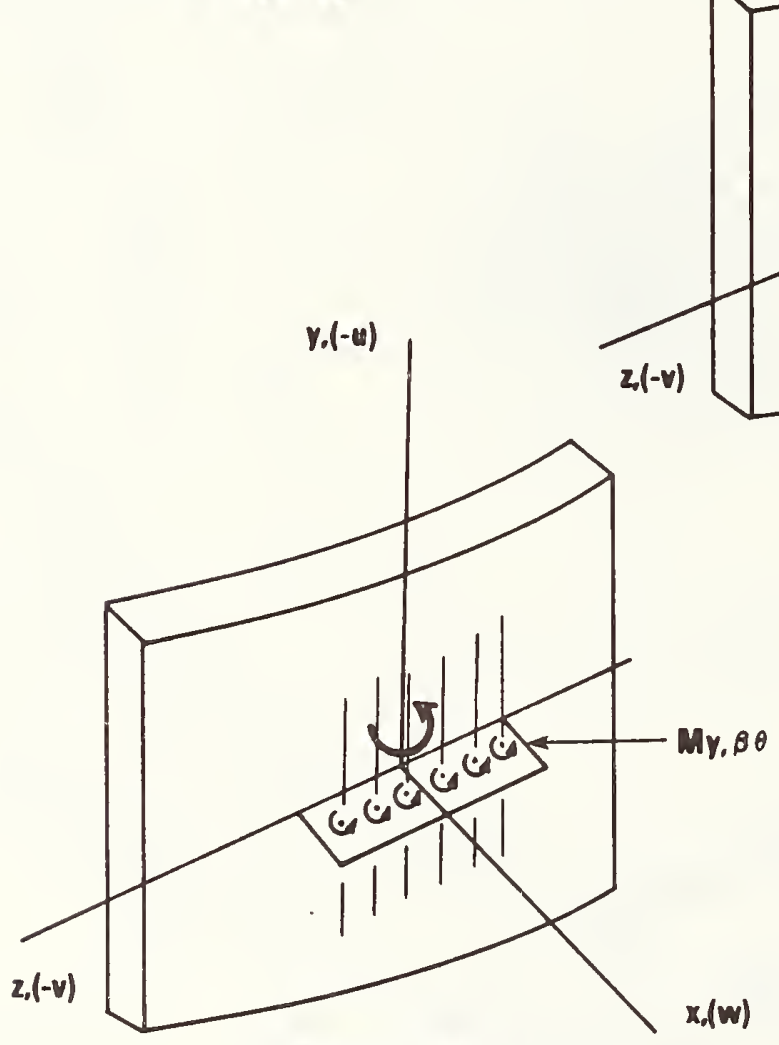

C. Meridional moment

B. Tangential force

SAP IV POINT LOADS 


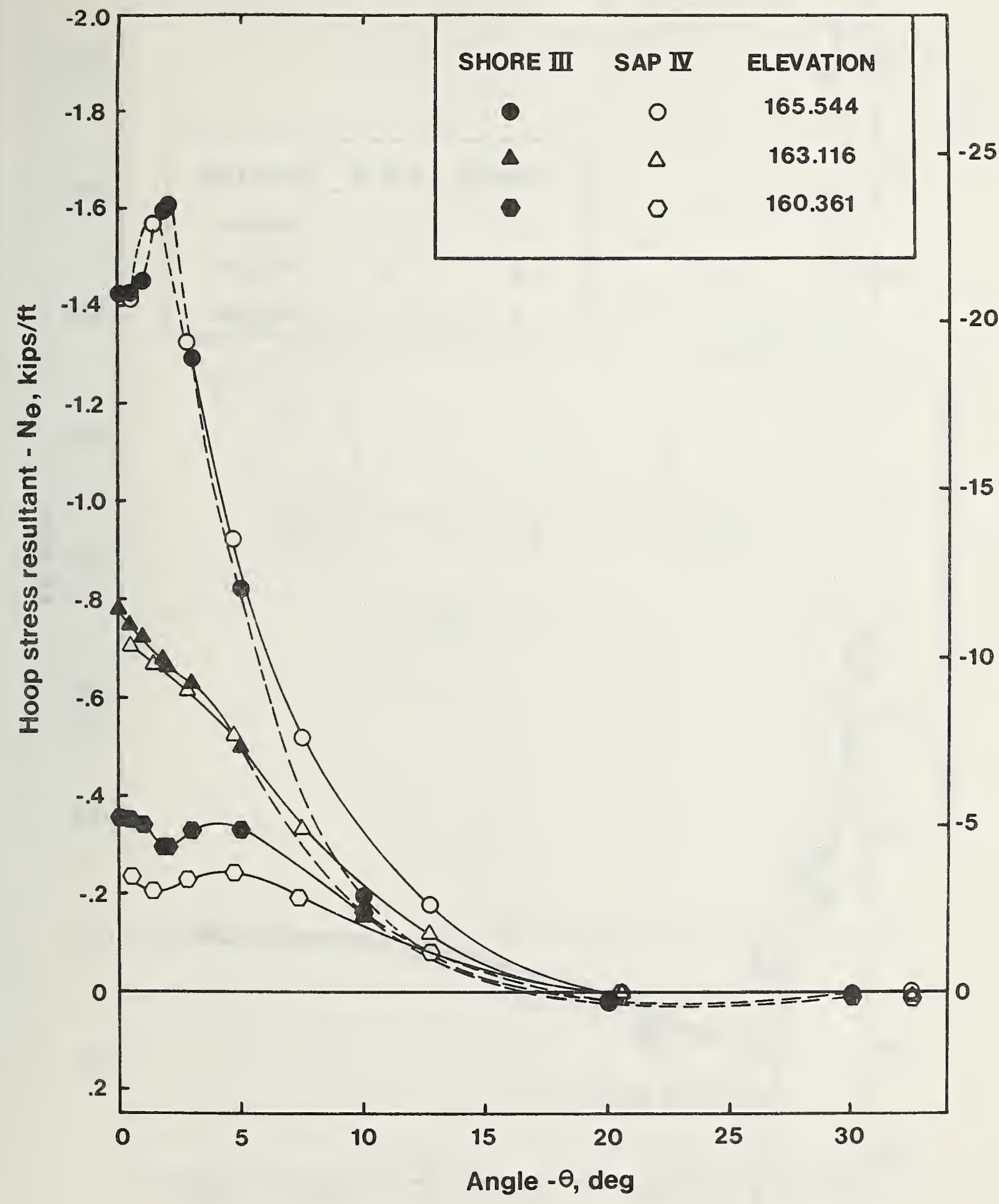

Figure B.6 Comparison of Hoop Stress Resultant for load Case 4 


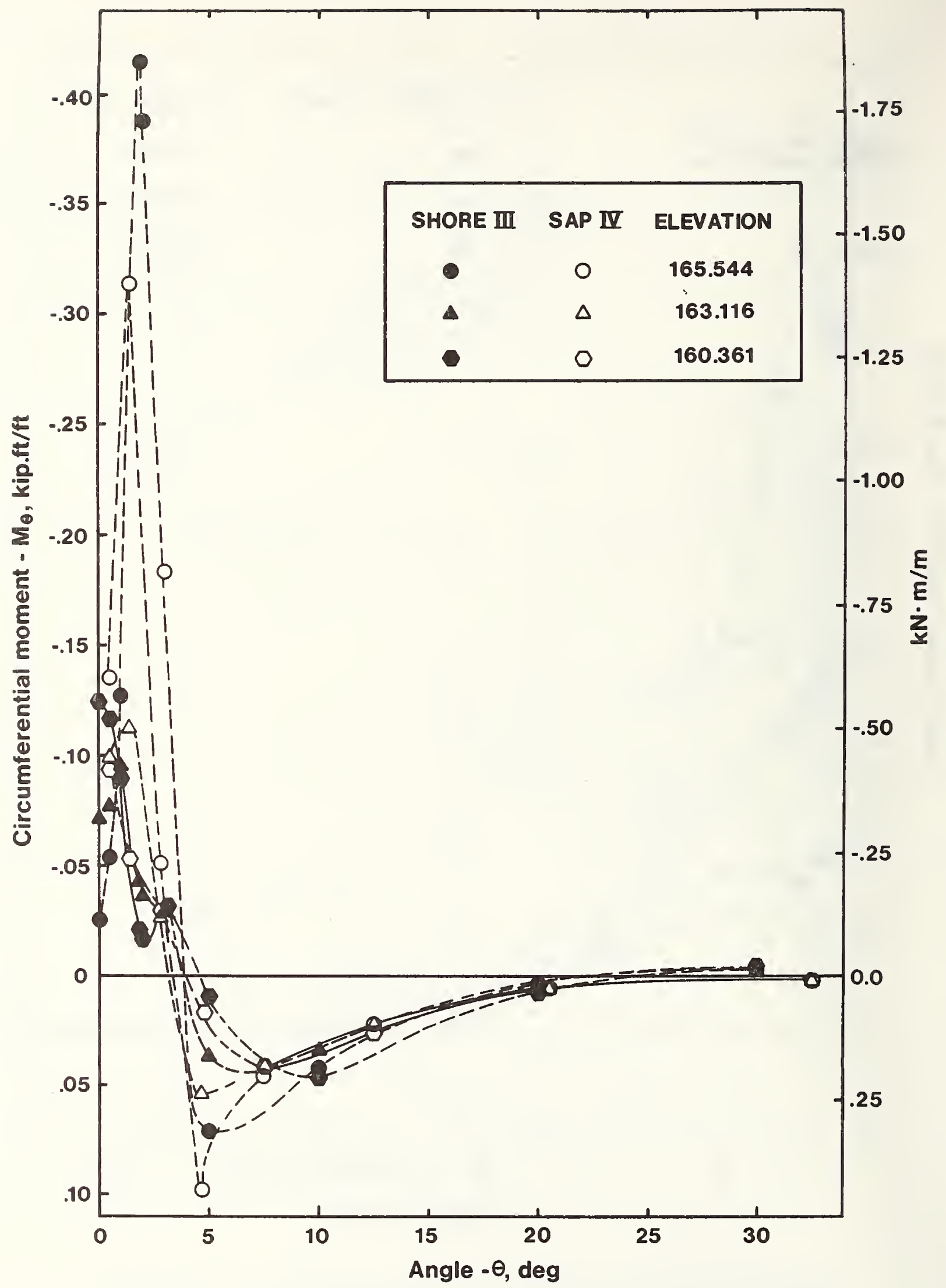

Figure B.7 Comparison of Circumferential Momemt for Load Case 4 


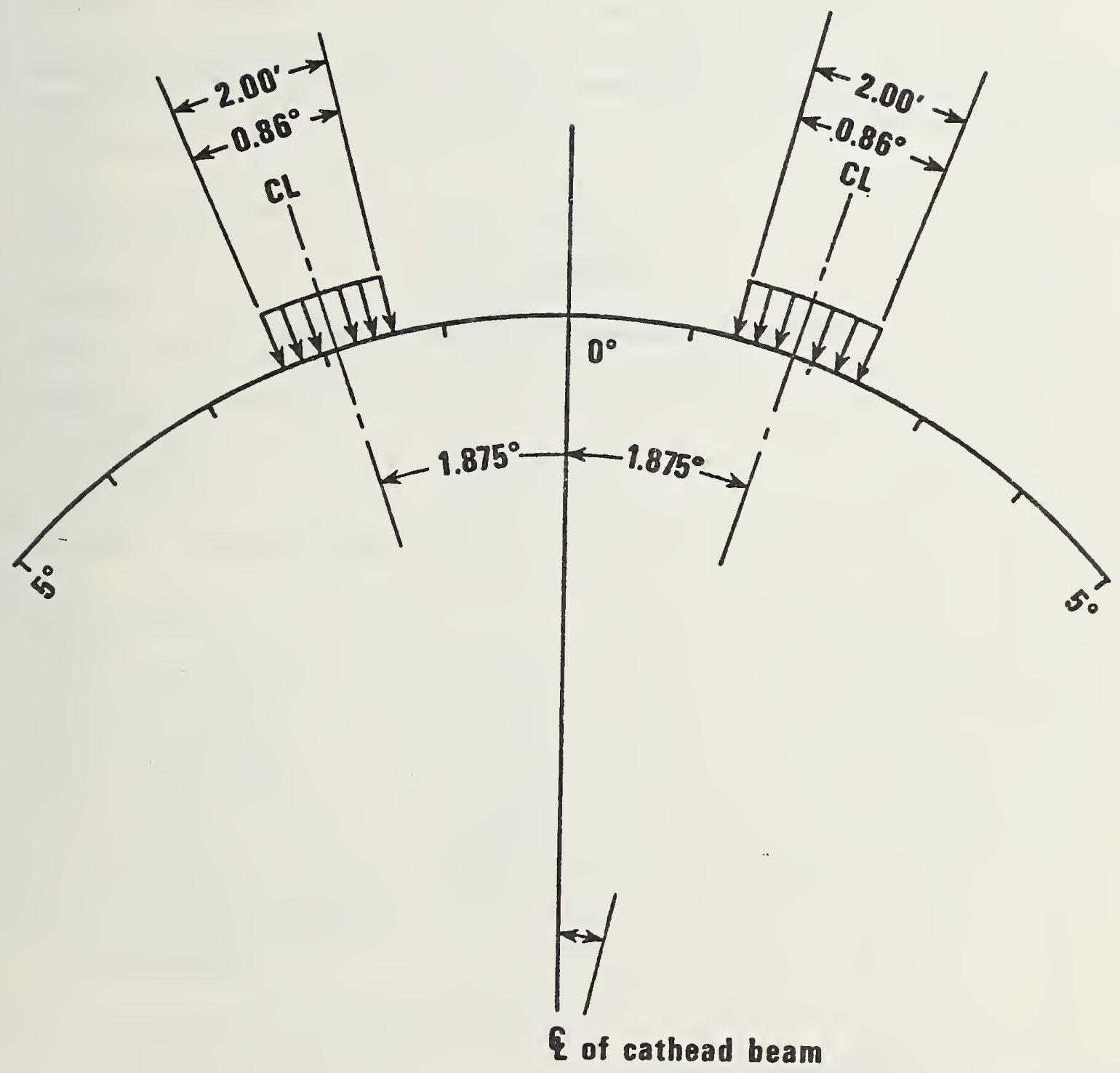

Figure B.8 Loading Function for Normal Force, Load Case 4 


\section{APPENDIX C}

Results of Chemical Analysis of Cemet 


\section{LAW ENGINEERING TESTING COMPANY}

MATEKIALS TESIING. ENCINELKS

SOIL AND FOUNDAIIUN INVESTICAIIIUNS

412 Plasters Avo.. N. E. - P. O. Box 13815. Sta. K

ATLANTA, GEORGIA 30324

REPORT OB_CEMENT ANALYSIS

C.ant: LETCO MC LEAN

Bulnet: NBS SAMPLE $\# 45$

LETCO JOB NO. M- 110
Ocies: Atlanta, Georgia

Date: August 9, 1978

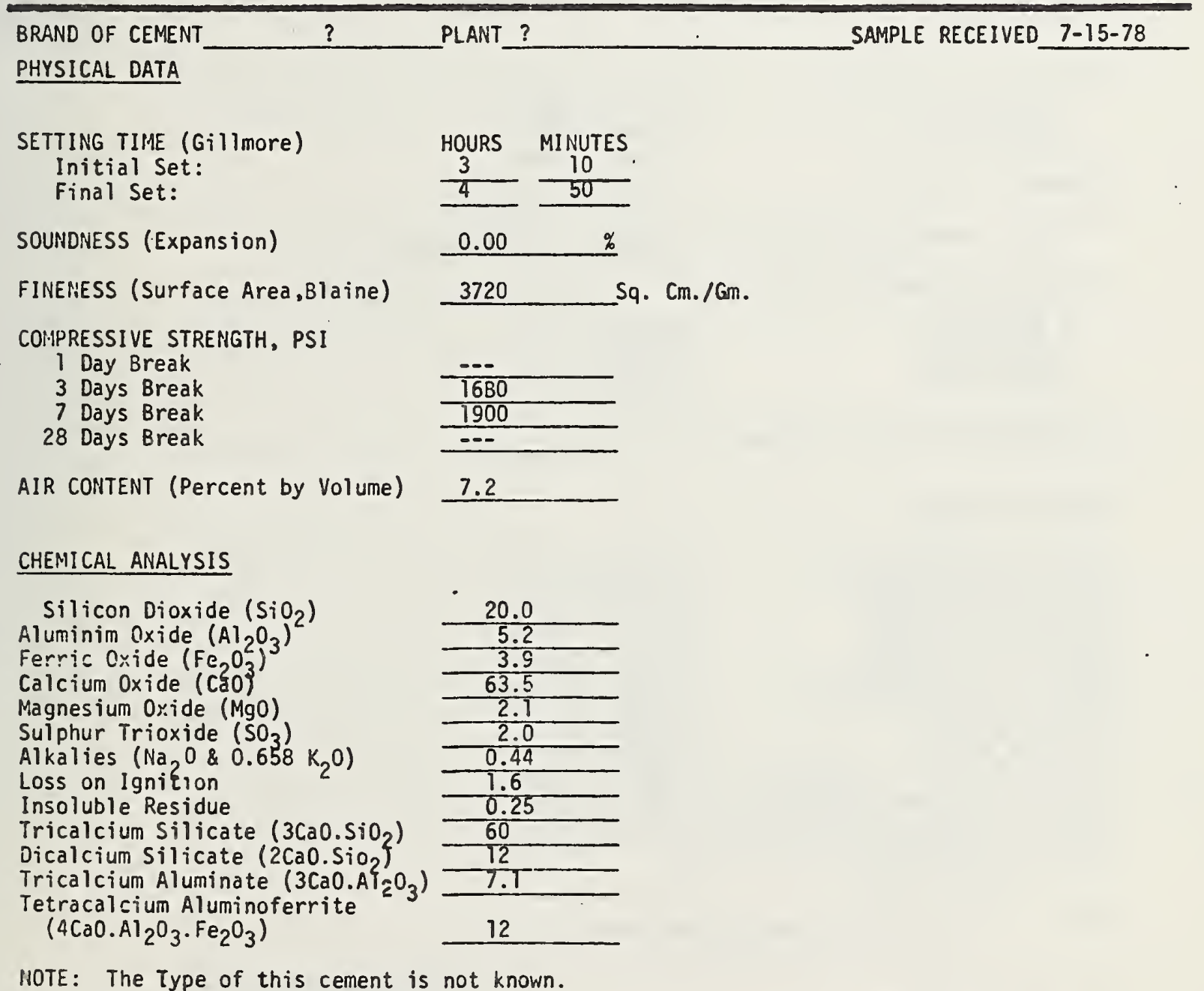

cc: H.S. Lew Washington, D.C.

Respectfully submilled,

LAW ENGINEERING TESTING CO.

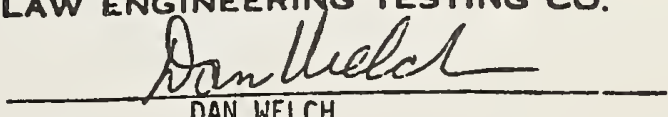




\section{LAW ENGINEERING TESTING COMPANY}

AIATEKIALS II:SIING ENCIINAIKS

SOIL. AND FOUNDAIIUN INUESTICIAIIINST

412 Plesters Ave., N. E. - P. O. Box 13815. Sla K

ATLANTA. GEORGIA 30324

REPORT OF_ CEMENT ANALYSIS

atat: LETCO MC LEAN

Esolect:NBS SAMPLE \#29

LETCO JOB NO. M- 110
ODes: Atlanta, Georgia

Date: August 9, 1978

Lab. No. 21531-A

\begin{tabular}{|c|c|c|}
\hline BRAND OF CEMENT? & \multicolumn{2}{|c|}{ PLANT ? } \\
\hline PHYSICAL DATA & & \\
\hline $\begin{array}{l}\text { SETTING TIME (Gillmore) } \\
\text { Initial Set: } \\
\text { Final Set: }\end{array}$ & $\begin{array}{l}\text { HOURS } \\
\frac{2}{4} \\
\end{array}$ & $\begin{array}{l}\text { MINUTES } \\
\frac{49}{45} \\
\end{array}$ \\
\hline SOUNDNESS (Expansion) & 0.00 & $\ddot{6}$ \\
\hline FINENESS (Surface Area, Blaine) & 3710 & Sq. Cm. $/ \mathrm{Gm}$. \\
\hline $\begin{array}{l}\text { COMPRESSIVE STRENGTH, PSI } \\
7 \text { Day Break } \\
3 \text { Days Break } \\
7 \text { Days Break } \\
28 \text { Days Break }\end{array}$ & $\frac{\overline{--}}{2140}$ & \\
\hline IIR CONTENT (Percent by Volume) & 7.4 & \\
\hline
\end{tabular}

CHEMICAL ANALYSIS

Silicon Dioxide $\left(\mathrm{SiO}_{2}\right)$

Aluminim Oxide $\left(\mathrm{Al}_{2} \mathrm{O}_{3}\right)$

Ferric Oxide $\left(\mathrm{Fe}_{2} \mathrm{O}_{3}\right)$

Calcium Oxide ( $\mathrm{CaO}$ )

Magnesium Oxide ( $\mathrm{MgO})$

Sulphur Trioxide $\left(\mathrm{SO}_{3}\right)$

Alkalies $\left(\mathrm{Na}_{2} \mathrm{O} \& 0.658 \quad \mathrm{~K}_{2} \mathrm{O}\right)$

Loss on Ignition

Insoluble Residue

Tricalcium Silicate ( $3 \mathrm{CaO} . \mathrm{SiO}_{2}$ )

Dicalcium Silicate $\left(2 \mathrm{CaO} . \mathrm{SiO}_{2}\right)$

Tricalcium Aluminate $\left(3 \mathrm{CaO} . \mathrm{AT}_{2} \mathrm{O}_{3}\right)$

Tetracalcium Aluminoferrite

$\left(4 \mathrm{CaO} \cdot \mathrm{Al}_{2} \mathrm{O}_{3} \cdot \mathrm{Fe}_{2} \mathrm{O}_{3}\right)$

NOTE: The Type of this cement is not known.

CC: H. S. Lew

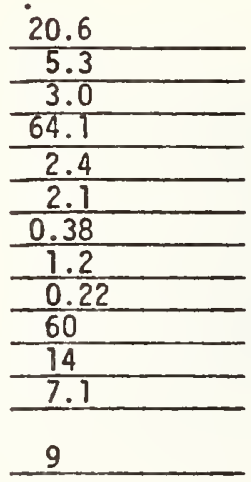

Reopecifully oubmilled.

LAW ENGINEERING TESTING CO.

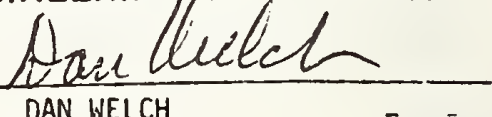


APPENDIX D

Results of Analysis of Concrete 
Project: Slow Setting Concrete wall Section

Project No.: CT-0477

Date: November 7, 1978

Customer: National Bureau of Standards (Washington, D.C.)

\section{Objective}

Determine if Pozzolith $200-\mathrm{N}$, a water-reducing admixture, was present in concrete placed in a wall section of a thin wall structure at a concentration sufficient to account for an unusually slow setting behavior.

\section{Conclusion}

The concrete in question contained a water-reducing admixture, similar in composition to Pozzolith $200-\mathrm{N}$, at a level not exceeding that normally recommended by the admixture manufacturer ( 3 to $5 \mathrm{fl}$. 02./100 Ibs. of cement).

\section{Sample Identification and Background Information}

A piece of hardened concrete, weighing about 11 lbs., and three small bottles of various liguid substances, identified as Pozzolith 200-N, Starch Hydrozylate, and Amine Derivatives Mixture, respectively, were received from Dr. H. S. Lew, Structures and Materials Division, Center for Building Technology, on $9 / 5 / 78$.

\section{Methods of Test}

The concrete sample was subjected to chemical analyses to determine the presence and addition level of a water-reducing admixture (ASTM C-494, Type $A$ ). The liquid sample identified as Pozzolith 200-N was characterized to obtain its chemical composition and certain physical properties. The two remaining liquid samples, identified as Starch Hydrozylate and Amine Derivatives Mixture, were subjected to infrared analysis to oetermine the principal ingredients present.

\section{Results and Discussion}

The liguid sample identified as Pozzolith 200-N consisted principaliy of a mixture of corn syrup (Starch Hydrozylate) and

triethanolamine (Amine Derivatives Mixture). The latter comprised 11 of of the admixture formulation as received. Chloride ion $\left(\mathrm{Cl}^{-}\right)$in the amount of 0.248 also was detected. A comparison of this sample with one analyzed previously by us in Oetober 1975 suggested they were guite similar.

Chemical analysis revealed the concrete sample most likely contained no more than a normal dose of a water-reducing admixture similar in composition to Pozzolith 200-N (ASTM C-494, Type A). In this case, a normal dose is an addition rate of 3 to 5 fluid ounces per 100 lbs. of cement, as recommended by the admixture manufacturer (Master Builders).

A more precise determination of admixture concentration is not possible at this time, unless a calibration curve was to be prepared employing actual job materials at the levels specified in the mix design.

\section{$\therefore$ Michaci heyer \\ L. M. Meyer, Manager}

Technical Services Section

Ig

CT-0477

Copy to -

J. J. Shideler
Chemical Aralyses by:

J. R. Polky

Research Chenoist

A. A. Alonzo Q Q a Associate Research Chemist D. I. Glochowsiky $\mathrm{deg}$ Assistant Research Chemist 


\section{TITLE AND SUBTITLE}

2. Gov't Accession. No.

3. Recipient's Accession No.

5. Publication Date

Investigation of Construction Fallure of Reinforced Concrete Cooling Tower at Willow Island, West Virginia

6. Performing Organization Code

\section{7. $\Lambda$ UTHOR(S)}

H.S. Lew, S.G. Fattal, J.R. Shaver, T.A. Reinhold, B.J. Hunt 9. PERFORMING ORGANIZATION NAME AND ADDRESS

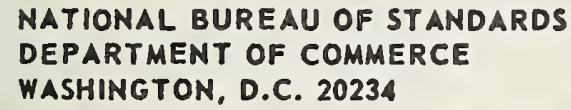

8. Performing Organ. Report No.

10. Project/Task/Work Unit No.

11. Contract/Grant No.

13. Type of Report \& Period Covered Fian1

14. Sponsoring Agency Code U.S. Department of Labor Washington, D.C. 20001

16. ABSTRACT (A 200-word or less factual summary of most significant information. If document includes a significant bibliography or literature survey, mention it here.)

The coolapse of the natural-draft hyperbolic concrete cooling tower unit no. 2 at the Pleasants Power Station at Willow Island, West Virginia has been investigated. This investigation included onsite inspections, laboratory tests of construction assembly components and concrete specimens, and analytical studies.

Based on the results of these field, laboratory and analytical investigations, it was concluded that the most probable cause of the collapse was due to the imposition of construction loads on the she11 before the concrete of lift 28 had gained adequate strength to support these loads. The analysis of the she11 indicates that the collapse initiated at the part of the shell in lift 28 where cathead no. 4 was located. It further showed that calculated stress resultants at several points in that part equaled or exceeded the strength of the shell in compression, bending and shear. The failure of these points in that part of the she11 would have propagated to cause the collpase of the entire lift 28 .

17. KEY WORDS (six to twelve entries; alphabetical order; capitalize only the first letter of the first key word unless a proper name; separated by semicolons)

Collapse; concrete; concrete strength; construction; cooling tower; failure; hyperbolic she11; shell.

8. AVAILABILITY

$\llbracket$ For Official Distribution. Do Not Release to NTIS

[ Order From Sup. of Doc., U.S. Government Printing Office Washington, D.C. 20402, SD Cat. No.C13

Order From National Technical Information Service (NTIS) Springfield, Virginia 22151

\begin{tabular}{|l|l|}
\hline $\begin{array}{l}\text { 19. SECURITY CLASS } \\
\text { (THIS REPURT) }\end{array}$ & 21. NO. OF PAGES \\
UNCL ASSIFIED & \\
\hline $\begin{array}{l}\text { 20. SECURITY CLASS } \\
\text { (THIS PAGE) } \\
\text { UNCLASSIFIED }\end{array}$ & 22. Price \\
\hline
\end{tabular}


$\begin{array}{r}6 \leq 341 \\ \hdashline 15\end{array}$ 





